\title{
Informal fund transfer systems
}

Citation for published version (APA):

Han, C. R. (2020). Informal fund transfer systems: mechanisms, survival, and adaptation. [Doctoral Thesis, Maastricht University]. Maastricht University. https://doi.org/10.26481/dis.20201207ch

Document status and date:

Published: 01/01/2020

DOI:

10.26481/dis.20201207ch

Document Version:

Publisher's PDF, also known as Version of record

\section{Please check the document version of this publication:}

- A submitted manuscript is the version of the article upon submission and before peer-review. There can be important differences between the submitted version and the official published version of record.

People interested in the research are advised to contact the author for the final version of the publication, or visit the DOI to the publisher's website.

- The final author version and the galley proof are versions of the publication after peer review.

- The final published version features the final layout of the paper including the volume, issue and page numbers.

Link to publication

\footnotetext{
General rights rights.

- You may freely distribute the URL identifying the publication in the public portal. please follow below link for the End User Agreement:

www.umlib.nl/taverne-license

Take down policy

If you believe that this document breaches copyright please contact us at:

repository@maastrichtuniversity.nl

providing details and we will investigate your claim.
}

Copyright and moral rights for the publications made accessible in the public portal are retained by the authors and/or other copyright owners and it is a condition of accessing publications that users recognise and abide by the legal requirements associated with these

- Users may download and print one copy of any publication from the public portal for the purpose of private study or research.

- You may not further distribute the material or use it for any profit-making activity or commercial gain

If the publication is distributed under the terms of Article $25 \mathrm{fa}$ of the Dutch Copyright Act, indicated by the "Taverne" license above, 


\title{
Informal Fund Transfer Systems: Mechanisms, Survival, and Adaptation
}

\author{
Dissertation
}

to obtain the degree of Doctor at Maastricht University, on the authority of the Rector Magnificus Prof.dr. Rianne M. Letschert in accordance with the decision of the Board of Deans, to be defended in public on Monday, 7 December 2020 at 13.00 hours

$$
\text { by }
$$

\section{Chang Ryung HAN}

Approved

Prof. dr. Rianne M. Letschert, Rector Magnificus 


\section{Supervisor}

Prof. dr. J.M. Nelen

\section{Co-supervisor}

Dr. B. Leeuw, city of The Hague

\section{Assessment Committee}

Prof. dr. M.G. Faure (Chair)

Dr. C.A.R. Moreland

Prof. dr. J.M.M. Ritzen

Prof. dr. N. Passas (Northeastern University, USA)

Prof. dr. E.U. Savona (Università Cattolica del Sacro Cuore, Milan, Italy) 


\section{Acknowledgement}

I am about to finish this long journey. Of course, this journey is a stepping-stone to other journeys that I will embark on. I am grateful to many people for helping me reach this stage. First of all, I would like to express my deepest gratitude to Dr. Hans NELEN. Without his dedicated guidance, persistent encouragement, and thoughtprovoking suggestions, I would not have been able to arrive at this final product and would still be wandering aimlessly. I am also grateful to Dr. Bastiaan LEEUW for his trenchant comments and suggestions regarding this project. He has helped me enormously in developing and refining this dissertation. I would like to thank my wife, Hyun Ah CHO. When I stopped this long journey at one point, she persuaded me to resume the journey and encouraged me to finish it. I also want to express my gratitude to several professors, colleagues and friends in the United States, Belgium, and Korea. I entered the world of criminology and crime science thanks to Dr. Ric CURTIS and Dr. Joshua FREILICH at John Jay, and Dr. Ko-lin CHIN, Dr. Ronald CLARKE, Dr. Marcus FELSON, Dr. Michael MAXFIELD, and Dr. Bonita VEYSEY at Rutgers. Dr. Thomas CANTENS and Ms. Rachel MCGAURAN who worked with me in Belgium showed great interest in my research. Dr. Gohar PETROSSIAN and Dr. Min LIU, who studied criminology with me in the United States, have constantly encouraged me. My Korean colleagues were very patient with me and gave me the space to write this thesis. Last but not least, I appreciate Mireille KASTERMANS for proofreading the manuscript. Thanks to all. 
This page intentionally left blank 


\section{Table of Contents}

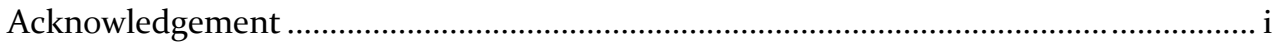

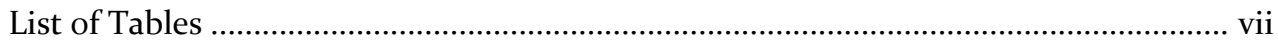

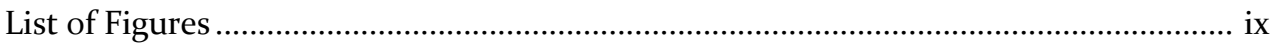

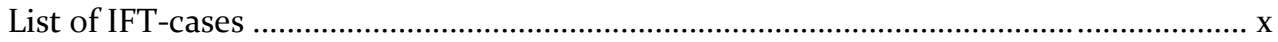

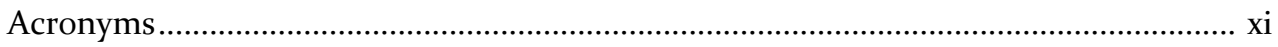

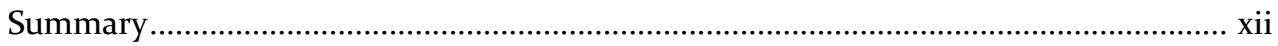

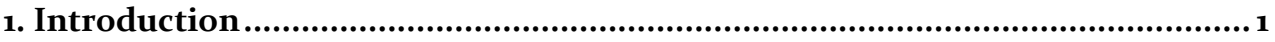

1.1 Background

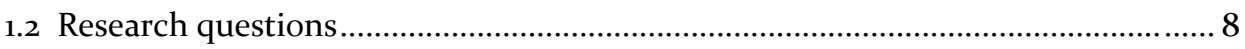

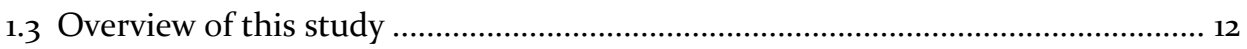

2. Concept, Features, and Legitimacy of IFT-systems ................................ 17

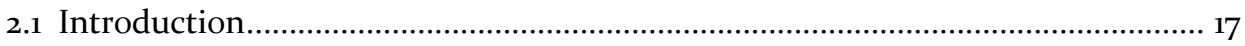

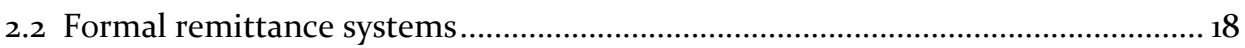

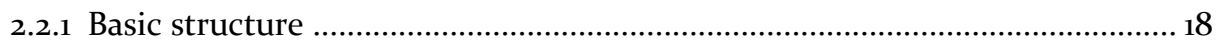

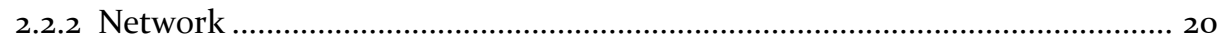

2.2.3 Advantages and disadvantages of formal remittance systems .......................22

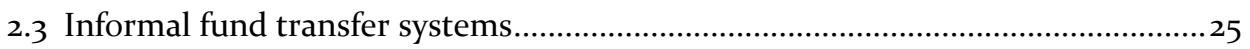

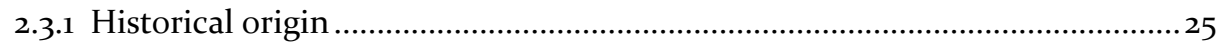

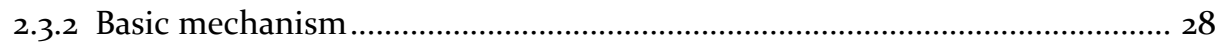

2.3.3 Settlement of outstanding debts between IFT-brokers ................................ 30

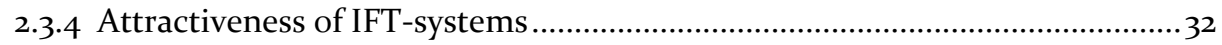

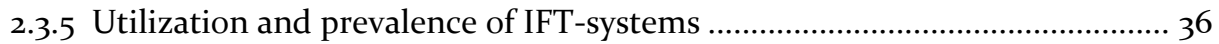

2.4 Assessment of legitimacy of remittance systems ................................................ 40

2.4.1 Views on conception of crime ................................................................... 40

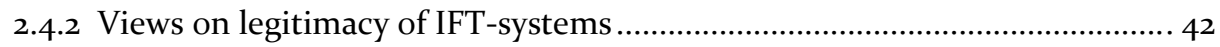

2.5 Perception, government approach, and law enforcement in relation to IFT-

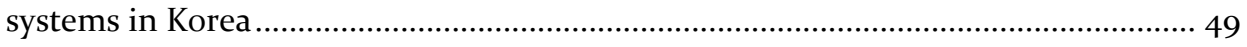

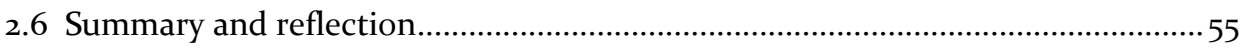

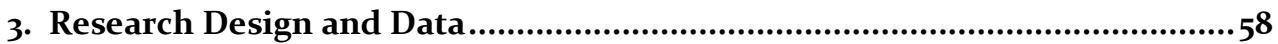




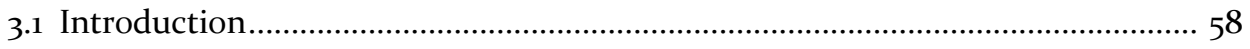

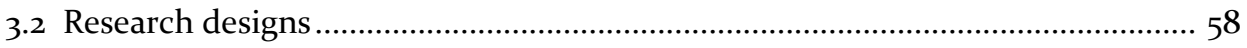

3.3 Research method and data for the global analysis of IFT-systems........................ 60

3.4 Research methods and data for the country-focused analysis of IFT-systems in

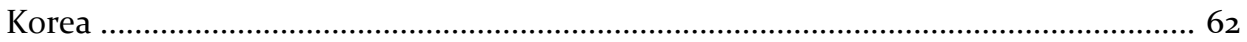

3.4.1 Reasons for selection of Korean cases................................................................ 64

3.4.2 Research instruments and data for the case study of IFT-systems.................66

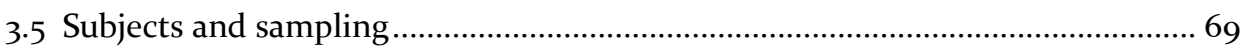

3.5.1 Overview of the subjects ................................................................................. 69

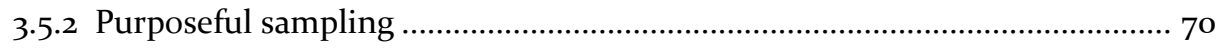

3.5.3 Data saturation and sample size .................................................................72

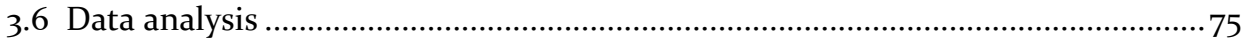

3.7 Summary and reflection ................................................................................... 79

4. Global Analysis of IFT-systems: Development of a Global IFT-risk Indicator81

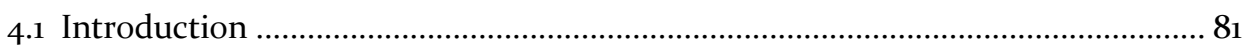

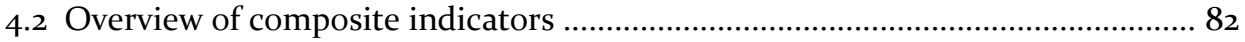

4.3 Construction process of composite indicators....................................................... 83

4.3.1 Identification of a theoretical framework and selection of variables.............. 84

4.3.2 Data treatment and normalization ............................................................... 85

4.3.3 Weighting and aggregation............................................................................. 86

4.4 Construction of a global IFT-risk indicator …………………………................ 87

4.4.1 Dimensions of IFT-risk and data employed ..................................................... 87

4.4.2 Preparation of an IFT-risk dataset …………………………………………..... 94

4.4.3 Putting together of a global IFT-risk indicator ……………………………...... 102

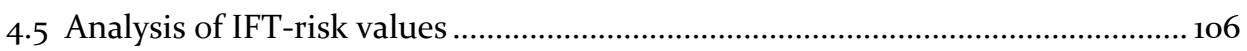

4.5.1 IFT-risk values by different weighting methods ................................................106

4.5.2 IFT-risk values by region and national income level ......................................108

4.5.3 Highest and lowest at-risk countries..............................................................112

4.5.4 Association between the overall IFT-risk level and the IFT-risk elements...117

4.6 Summary and reflection .................................................................................... 120 


\section{Country-focused Analysis of IFT-systems in Korea: A Perspective on Illegal}

Markets.

.123

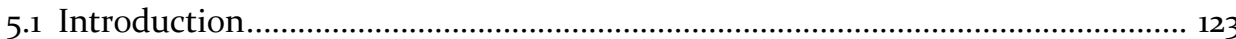

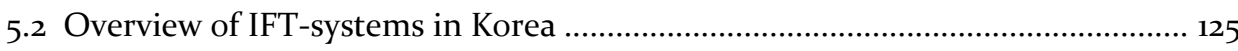

5.2.1 Actors involved in IFT-activities ................................................................ 127

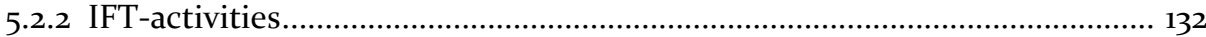

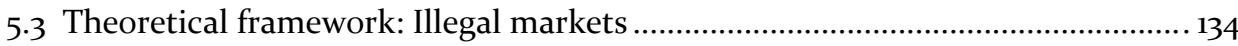

5.3.1 An overview of the theoretical frameworks for the local analysis ................. 134

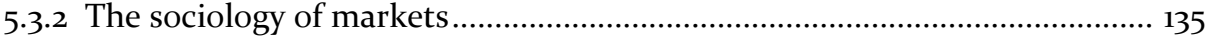

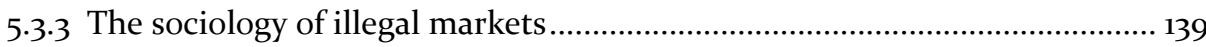

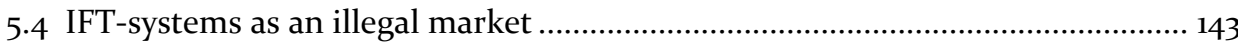

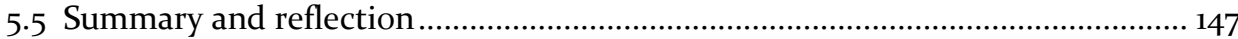

\section{Country-focused Analysis of IFT-systems in Korea: Social Exchanges and}

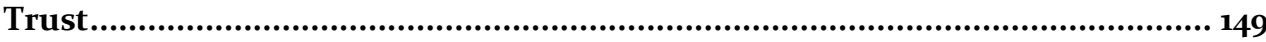

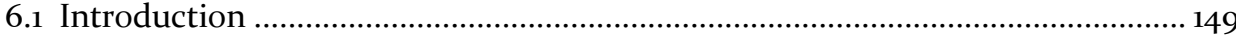

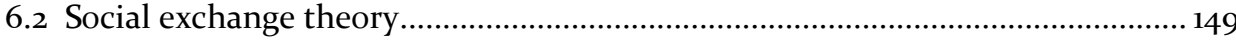

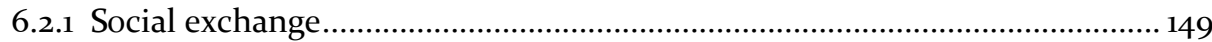

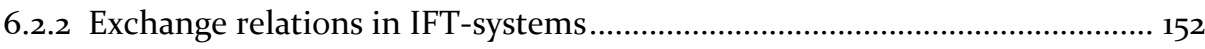

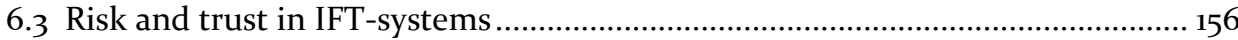

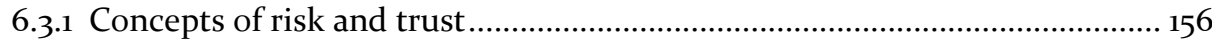

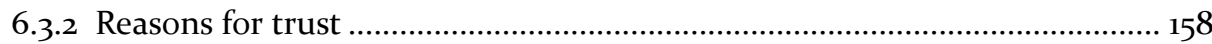

6.3.3 Responses to social uncertainty and risk ......................................................160

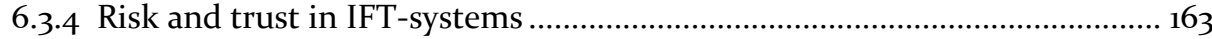

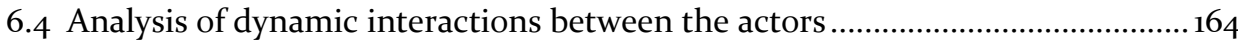

6.4.1 Coming up with the idea of setting up an IFT-business ................................166

6.4.2 Deciding on an IFT-business model ........................................................ 167

6.4.3 Obtaining at least one bank account ....................................................... 172

6.4.4 Establishing a business relationship with a counterpart IFT broker ............ 176

6.4.5 'Advertising' IFT-business and gathering IFT-users .................................... 179

6.4.6 Assessing the trustworthiness of prospective IFT-users and IFT-brokers... 183

6.4.7 Receiving funds from the senders ........................................................... 187

6.4.8 Sending remittance orders to the counterpart IFT broker ...........................191 
6.4.9 Paying the money to the recipients .............................................................199

6.4.10 Settling reciprocal debts made from IFT-transactions ............................... 202

6.4.11 Reviewing trustworthiness of the counterpart IFT broker...........................203

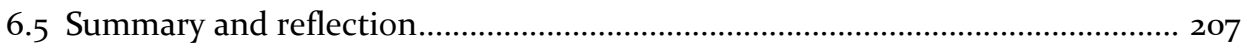

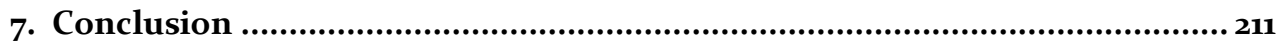

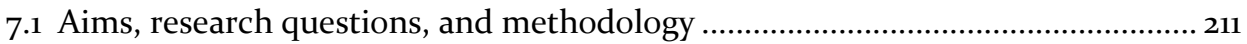

7.1.1 Rationale for the research and research questions.......................................211

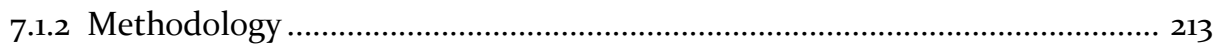

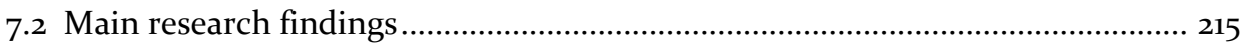

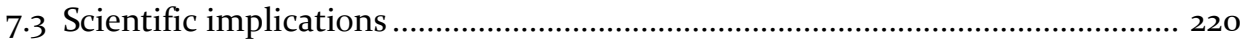

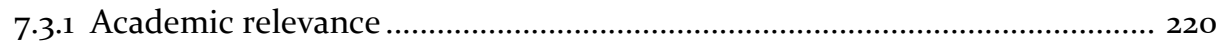

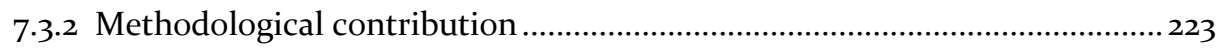

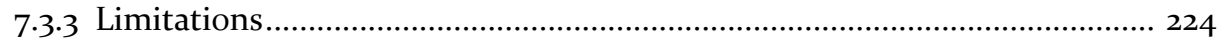

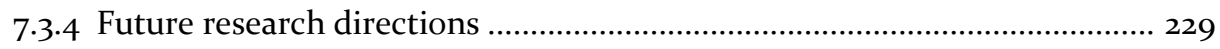

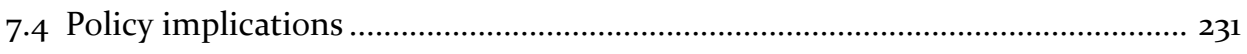

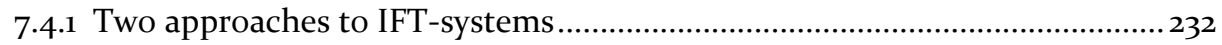

7.4.2 Considerations in developing anti-IFT-systems measures............................234

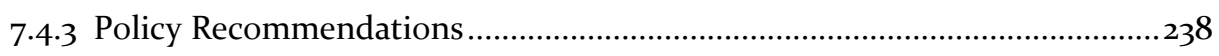

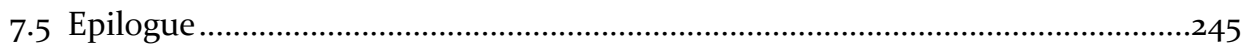

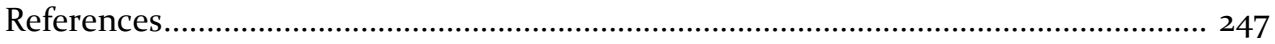

Appendix 1: IFT-risk elements and 121 countries' responses ..................................... 279

Appendix 2: Z-scores of 121 countries' responses on IFT-risk elements ....................... 285

Appendix 3: Ranks from IFT-risk element values .................................................... 289

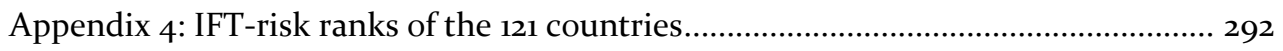

Appendix 5: Consent form for interviews .............................................................. 294

Appendix 6: Semi-structured questionnaire for the KCS’s customs investigators ...... 295

Appendix 7: Semi-structured questionnaire for the KoFIU's officials ..........................298

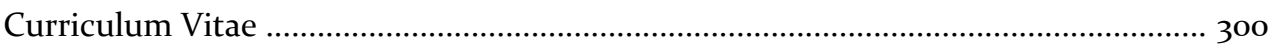




\section{List of Tables}

Table 2.1: Perceptions of remittance activities

Table 3.1: Research designs and data collection methods

Table 3.2: Analysis levels and types of data 60

Table 3.3: Number of subjects

Table 3.4: Research framework of this study 79

Table 4.1: Dimensions and measurements of IFT-risk 89

Table 4.2: Composition of the 121 selected countries 95

Table 4.3: Distribution of IFT-risk variables 98

Table 4.4: Centrality measure of IFT-risk variables

by region and national income level 101

Table 4.5: Component loadings of global IFT-risk index

from principal components analysis with varymax rotation with Kaiser normalization 105

Table 4.6: Countries with more than 30 rank difference

by the two different weighting methods

Table 4.7: Standard deviation values of IFT-risk elements 107

Table 4.8: 10 countries with the highest IFT-risk

Table 4.9: 10 countries with the least IFT-risk

Table 4.10: The differences of IFT-risks faced by the high-income countries in Europe and Centra Asia

Table 4.11: The differences of IFT-risks faced by the countries in South Asia and Sub-Saharan Africa 116

Table 4.12: The regression coefficients between the overall IFT-risk rank and the IFT-risk element ranks 118 
Table 5.1: Themes identified in the IFT-case reports and the interviews

Table 5.2: Nationalities of foreigners engaging in economic activities in Korea (in 2018)

Table 5.3: Nationalities of the main offenders in the IFT-case reports 129

Table 5.4: The trade proportions of Korea with its major trade partners 130

Table 5.5: Countries of residence of the main offenders in the IFT-case reports 131

Table 6.1: The bilateral remittances (million USD) between Korea and China 155

Table 6.2: Procedures of IFT-activities 165

Table 7.1: Countries with the highest and the lowest IFT-risk levels 216 


\section{List of Figures}

Figure 1.1: Transferring medical service payments via two IFT-brokers

Figure 2.1: Basic structure of remittance transferring

by formal financial institutions

Figure 2.2: Remittance transferring via a franchised network 21

Figure 2.3: Basic mechanism of an IFT transaction

Figure 2.4: Settlement of debts between IFT service providers 32

Figure 3.1: A conceptual diagram of thematic analysis 76

Figure 3.2: The theoretical frameworks for the analysis of IFT-systems 78

Figure 4.1: Comparison of GNIs per capita between the World Bank Members and the subjects (countries) of this study 96

Figure 4.2: Scree plot of eigenvalues after PCA of IFT-risk data 103

Figure 4.3: Overall IFT-risk values by region and national income level 109

Figure 4.4: IFT-risk element values by national income level 111

Figure 6.1: Solo IFT broker transmitting remittances 169

Figure 6.2: Three types of IFT-transactions 194 


\section{List of IFT-cases}

Case 1: A unilateral IFT-business

Case 2: IFT-systems used to bypass a restrictive foreign control policy 133

Case 3: A stereotyped IFT-business whereby two IFT-brokers work together 167

Case 4-5: Unconventional IFT-brokers 172

Case 6-7: Combination of an IFT-business and cross-border trade 181

Case 8-9: IFT-businesses covered by other legitimate businesses 182

Case 10: Source money transferred by IFT-systems 189

Case 11-12: Wire transferring via the third party's bank accounts 195

Case 13-14: Couriering of cash and exchanging of cash in currency exchange offices 198

Case 15: Symbiosis between IFT-business and gambling business 200 


\section{Acronyms}

AML

AML/CFT

BIS

FATF

FIU

FSRBs

GAO

GNI

IFT-brokers

IFT-cases

IFT-systems

IFT-users

IMF

KCS

KNPA

KoFIU

KRW

KYC

MOEF

MVTS

PCA

RSP

SAR

STR

USD

UAE

WEF
Anti-Money Laundering

Anti-Money Laundering and Combating Financing of Terrorism Bank for International Settlement

Financial Action Task Force

Financial Intelligence Unit

FATF-Style Regional Bodies

Government Accountability Office

Gross National Income

Informal Fund Transfer brokers

Informal Fund Transfer cases

Informal Fund Transfer systems

Informal Fund Transfer users

International Monetary Fund

Korea Customs Service

Korea National Police Agency

Korea Financial Intelligence Unit

Korean Won

Know Your Customer

Ministry of Economy and Finance

Money or Value Transfer Services

Principal Component Analysis

Remittance Service Provider

Suspicious Action Report

Suspicious Transaction Report

United States Dollar

United Arab Emirates

World Economic Forum 


\section{Summary}

Most people visit formal financial institutions or use online banking services when they should send funds across borders. However, some people use unauthorized remittance operators, or informal fund transfer systems (IFT-systems), to send remittances to foreign countries. IFT-systems may be an unknown phenomenon to the general public. They may not have a clear idea on how IFT-systems work and whether they are perceived as acceptable and legitimate in society. This study was conducted to examine why and how IFT-systems survive in a globally connected world and how they adapt to changing environments. Before addressing the question, this study first discussed about the legitimacy of IFT-systems in parallel with an illustration of the basic working mechanisms of them. That is because the legitimacy of IFT-systems is associated with the risks - external and internal risks - that IFT-systems face and cope with. While describing the working mechanism of IFT-systems, this study showed that IFT-systems adopt the same mechanisms as formal remittance systems. This study also examined how IFT-systems differ from formal remittance systems, explaining that IFTsystems have two aspects - a channel for cross-border fund transferring and a channel for money laundering. While examining the roles that IFT-systems play in a given society, this study contrasted two approaches: an economic approach and a criminological approach. The two approaches relate to different positions on the legitimacy of IFT-systems: While the economic approach tends to construe IFT-systems as legitimate albeit illegal, the criminological approach seems to view IFT-systems as illegal and unacceptable.

This study employed two research designs and two research methods, in relation to two research sub-questions. A cross-sectional design and data analysis was adopted for the global analysis of IFT-systems to answer the first sub-question: to what extent do IFT-systems (or are they likely to) thrive across countries despite adverse external environments? The global landscape of IFT-businesses - a collection of IFT-risks faced by each country - entails the question of which countries are more - or less susceptible to adverse environments, or external risks (e.g., an increased control of IFT- 
systems, fierce competition with formal remittance channels, and negative societal attitude towards the informality)? The global analysis of IFT-risks is based on several secondary (public domain) datasets from international entities, such as the World Bank and the FATF. These datasets deal with macro-level factors that are likely to be associated with IFT-activities, such as migration, financial inclusion, AML/CFT measures, and societal attitudes towards informality. The global analysis resulted in the development of a global IFT-risk indicator that gauges the level of IFT-risk faced by each country in the form of a composite indicator. A case study design and thematic analysis was used to address the second sub-question - how IFT-transactions are carried out despite the internal risks that IFT-users and IFT-brokers face (e.g., deception and betrayal) - by examining IFT-systems in Korea. The case study on IFT-systems in Korea focused on investigating the adaptation of IFT-systems to the internal risks. This was done by investigating the relationships between the actors involved in IFT-activities in light of trust and risk. The data analyzed for this case study include the IFT-case reports of the Korean customs administration and the interviews with Korean government officials who investigated or had knowledge of IFT-systems. In conducting research on the survival and adaptability of IFT-systems, this study is based on the view that IFT-systems in Korea are exposed to different environments from those in other developing countries. In other words, IFT-systems that survive in - and adapt to harsh external environments may have salient features that IFT-systems in favorable environments do not have or need.

This study conducted an analysis of IFT-risks from 121 selected countries to provide a panoramic view on the global landscape of IFT-systems. With macro-level factors that are likely to contribute to the survival of IFT-systems, this study a 'global IFT-risk indicator' to gauge the degree of survival (or prosperity) of IFT-systems across various countries. Most of the developed countries analyzed were rated as having low IFT-risk, mainly because of a high level of access to formal financial institutions and a high level of compliance with international AML/CFT standards. However, among the developed countries, some countries considered popular destinations for immigrants were rated as having a high level of IFT-risk. On the other hand, most of the developing 
countries were rated as being exposed to a high level of IFT-risk because of a large number of emigrants, poor formal financial systems, low compliance levels with international AML/CFT standards, and lenient attitudes towards illegality. The global IFT-risk indicator suggests that the level of IFT-risk is related to the level of economic development of each country.

For the country-focused analysis (the local analysis) of IFT-systems in Korea, three theoretical frameworks - the sociology of (illegal) markets, social exchange theory, and the perspective of trust and risk - were employed to examine the relationships and interactions between the actors in IFT-systems. This is because the focus of the local analysis is on interactions (e.g., trust, risk-taking, and transactions) between the actors in IFT-systems, rather than on the criminality of the actors or on criminogenic opportunities, and the three theoretical frameworks can be applied to IFTsystems that operate in environments where ethnic ties, social embeddedness, and informal social control are weak or restricted. Based on the theoretical frameworks, the local analysis of IFT-systems shed light on the internal dynamics of IFT-systems. This study presented a temporal sequence of IFT-activities consisting of 11 procedures, inspired by Derek Cornish's crime script analysis, and analyzed them, in terms of trust and risk. While the main findings from the local analysis confirmed those of previous studies on IFT-systems, this study produced several new findings on IFT-systems. IFTusers and IFT-brokers actively used online banking services in sending funds to the other party. This somewhat contrasts with the general assumption that IFT-systems are isolated from formal financial institutions, except with regard to the procedure for the settlement of outstanding debts between IFT-brokers. This study identified 'solo IFTbrokers', whose existence contradicts the conventional IFT-systems where separate IFTbrokers in sending and receiving countries work together to transfer funds. Through online banking services, solo IFT-brokers provided IFT-services in both sending and receiving countries without counterpart IFT-brokers. This study found that online banking services also benefit IFT-users. By using these services, remitters can easily send funds to IFT-brokers in remote places, leaving trails that work as a safeguard to protect them from IFT-brokers who fail to meet their obligations. Online banking 
systems therefore play an important role in reducing the vulnerability of both IFT-users and IFT-brokers facing social uncertainty. This study also identified some variant IFTtransactions, which differ from the traditional hawala-style IFT-transactions. They transfer funds across borders through the wire-transfers of formal financial institutions and the physical transfer of cash.

As for policy recommendations, while critically reviewing existing AML/CFT measures against IFT-systems, this study puts forward not only general considerations for measures against IFT-systems, but also practical measures that would make it possible to take advantage of the external and internal risks that threaten IFT-systems. They are based on the situational crime prevention and behaviorally-informed approaches. While the global IFT-risk indicator may enhance societal capacity to monitor IFT-risks across countries, these policy recommendations may provide the global AML/CFT community with more options in the fight against IFT-systems. 
This page intentionally left blank 


\section{Introduction}

\subsection{Background}

Korean plastic surgeon SHIN dexterously operated on Korean actors and actresses. As his reputation spread to China, a number of Chinese patients visited Korea in order to get surgery from him via Korean Chinese broker CHOI, who played a role in gathering patients in China and sending them to SHIN. CHOI sold plastic surgery packages to Chinese patients on behalf of SHIN in China. He therefore transferred the medical service payments, excluding brokerage fees, to SHIN via formal financial institutions in China and Korea. However, although his plastic surgery business prospered, it was not necessarily good news for SHIN, given that business growth often draws the attention of tax authorities and leads to an increased tax burden. In addition, it took several days to receive the payments from CHOI via formal financial institutions between the two countries. In order to evade taxes and receive the payments more quickly, SHIN and CHOI colluded: CHOI sent the payments to SHIN via Ms. HWANG, who was designated by SHIN. HWANG told CHOI about her business partner Ms. LIU in China concerning the cross-border fund transfers. CHOI handed over the payments to Ms. LIU. LIU informed HWANG of the amounts that she received from CHOI. HWANG then wired the corresponding amounts to SHIN. In other words, doctor SHIN and broker CHOI agreed that they would leave no formal records of foreign exchange transactions, making use of HWANG and LIU. During the course of an examination ${ }^{1}$ of several suspicious bank accounts associated with illegal traders, their two-year long transactions were detected by the customs administration in Korea. It turned out that they evaded taxes on sales amounting to 4 million USD².

\footnotetext{
1 Although the customs administration initially detected the IFT-activities in 2014, while examining several suspicious bank accounts related to importers, the case was transferred to the tax authority because it related to tax evasion.

2 This study uses USD in describing monetary transaction values for the convenience of communication, although the official currency in Korea is Korean Won (KRW). The KRW exchange rate to USD adopted in this study is 1,00o KRW to 1 USD despite fluctuations in the exchange rate.
} 
Figure 1.1: Transferring medical service payments via two IFT-brokers

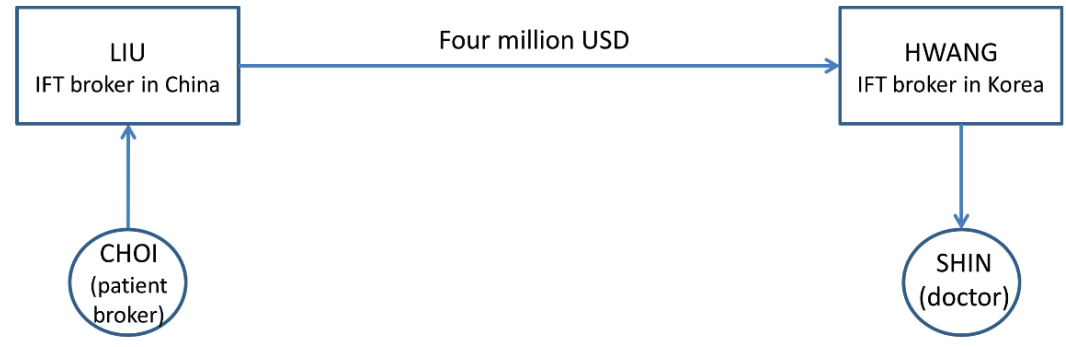

Source: The author

This is a simple case. Similar cases are commonplace in nearly every society. The way in which HWANG and LIU moved the payments across borders without engaging with formal financial institutions, and the way the two ladies engaged in tax evasion, are likely to intrigue people. Several scholars and professionals call the network between HWANG and LIU an informal fund transfer (IFT) system (El Qorchi et al., 2003; Hernandez-Coss, 2005b), and take note of the roles that they played in cross-border fund transfers because their activities have significant ramifications - not only regarding financial inclusion, but also in terms of the fight against money laundering. This is the subject that this study seeks to address.

As illustrated in the case above, IFT-systems are useful for hiding money flows from government oversight. They are susceptible to being abused for concealing illegally obtained funds. In other words, IFT-systems can be used to launder money. Money laundering is committed to disguise proceeds from a criminal activity, thereby concealing their illegal origins (Schott, 2006). Money laundering normally involves crimes committed for financial purposes, irrespective of what offenses are included in the scope of predicate offenses ${ }^{3}$. Petty criminals may not need a means to launder their

3 A money laundering predicate offense refers to the underlying criminal activity that generated proceeds, which when laundered, results in the offense of money laundering. The scope of predicate offenses has expanded. The United Nations Convention Against Illicit Traffic in Narcotic Drugs and Psychotropic Substances (as known as Vienna Convention) confines predicate offenses to drug trafficking offenses. 
economic gains from property crimes ${ }^{4}$, such as theft and burglary. Criminals with illegal businesses ${ }^{5}$ - or businesses including illegal aspects, however, seek an insulating devise to disconnect their criminal businesses from the resultant economic gains (Reuter and Truman, 2004). Money laundering techniques exploiting formal financial institutions, which are allegedly the most widely used, were tackled by national financial supervision authorities and law enforcement authorities and various international entities (Tsingou, 2010). Anti-money laundering measures and measures that help combat the financing of terrorism (AML/CFT) have been instituted in the formal banking sector, although their forms differ from country to country. This is because formal financial institutions care about their own reputations and are under government supervision, although they have expressed concerns regarding the compliance costs ${ }^{6}$ of AML/CFT measures (Gill and Taylor, 2004; Johnston and Carrington, 206; McIntosh, 2016; Sinha, 2014; Vitale, 2001). AML/CFT measures in the formal banking sector were enhanced in terms of reporting requirements and enforcement actions (Brown-Hruska, 2016; Mitsilegas and Vavoula, 2016). Those measures have made money laundering activities via formal financial institutions more difficult and costly. They are thus believed to result in the

The Financial Action Task Force (FATF) expands the scope of predicate offenses to 20 designated categories of offenses (Schott, 2006).

4 According to the U.S. Federal Bureau of Investigation's Uniform Crime Report program, property crime refers to offenses taking money or property but does not involve force or threat of force against the victims. Property crime includes burglary, larceny-theft, motor vehicle theft, and arson.

5 As money laundering meant laundering proceeds from illegal businesses, tax evasion did not fall under the category of predicate offenses for money laundering. However, in the wake of $9 / 11$ attacks, the view prevailed that irrespective of illegality of underlying businesses that generate proceeds, concealing the proceeds from an 'indictable offense' should be controlled in light of money laundering. Tax evasion thus became a predicate offense for money laundering (Oliver, 2002).

6 AML compliance cost can be broken down into: "KYC/Customer due diligence analysis, periodic compliance screening analysis, sanctions screening analysis, transaction monitoring analysis, training, customer education, compliance management, audit, technology (external and internal costs)" (LexisNexis Risk Solutions, 2016: 9). According to a survey study on AML compliance cost in Asia, "a majority of respondents $(55 \%)$ indicated that AML compliance has a negative impact on their firms' business productivity" (LexisNexis Risk Solutions, 2016: 3). Another survey study on AML compliance cost in Europe indicates that the annual AML compliance costs of the five European countries (i.e., Germany, France, Italy, the Netherlands, and Switzerland) are estimated to amount to 83.5 billion USD; which are roughly four times higher than those of six Asian countries (i.e., China, Hong Kong, Singapore, Malaysia, Indonesia, and Thailand) (LexisNexis Risk Solutions, 2017). 
displacement of money laundering activities to other channels ${ }^{7}$ outside government control, such as IFT-systems (FATF, 2003b; 2010; Unger and Den Hertog, 2012; Vlcek, 2017).

IFT-systems may sound unfamiliar to the general public, and even to some law enforcement professionals. This phenomenon, however, is based on a relatively simple mechanism, where unauthorized entities - other than formal financial institutions transfer funds across borders by making use of their own pools of funds. This phenomenon was occasionally reported on by the media, and could be observed in most societies. One of the most important events that triggered media attention for IFTsystems were the 9/11 attacks. Allegedly, Al-Qaeda funded these terrorist attacks via hawala banking - an (arguably original) expression for IFT-systems used in the Middle

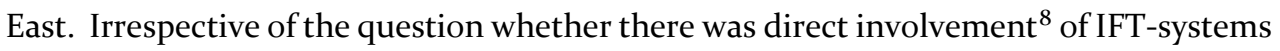
in the 9/11 attacks, it is true that Al-Qaeda frequently made use of IFT-systems. AlQaeda, which was supplied with funds from its financial facilitators ${ }^{9}$ and donors, used hawala to move its funds to Afghanistan to support the training and activities of its operatives before the 9/11 attacks. This is because Afghanistan's banking system was rudimentary and global scrutiny over the formal financial system was enhanced after the August 1998 East Africa bombings ${ }^{10}$. The hawala network that Bin Laden used to transfer funds operated in Pakistan, in Dubai, and throughout the Middle East (Roth et al., 2004).

7 Although the non-banking sector has been subject to AML-measures, the control over it is less strict and less effective than that over the formal banking sector yet. The main focus of AML-measures is still on the formal banking sector (Vlcek, 2017).

8 Despite the allegation of direct involvement of hawala in the 9/11 attacks, according to Van de Bunt (2008a), there is little evidence of the misuse of hawala directly associated with the $9 / 11$ attacks to date.

9 Financial facilitators with respect to terrorism financing play a role in soliciting funds from donors and transferring them to terrorist organizations in a way of drawing little attention of regulatory or law enforcement authorities (Roth et al., 2004).

10 Osama bin Laden's Al-Qaeda bombed two American embassies in Nairobi, Kenya and Dar-es-Salaam, Tanzania. The bombings killed 224 people and injured thousands. Although Al-Qaeda had engaged in a number of terrorist attacks prior to the bombings, it had not attacked the U.S. citizens directly (McKinley, 1998). 
Another relatively well-known IFT-system scandal involved an Indian businessman named Naresh JAIN (Greenwood, 2009). Allegedly, he was able to provide his customers with funds in any country of their choice, as his business network developed over 20 years - covered five continents. His list of customers included not only British gangsters, but also Albanian and Italian heroin dealers, as well as narcotics cartels in America, the UAE, and Pakistan, and Al-Qaeda suspects. He was believed to control a worldwide money laundering system that - at its height - was capable of moving 2.2 billion USD a year. As much of the money he allegedly moved was through an informal trust-based money transfer system, he was called the hawala king. He was tracked by the law enforcement authorities of several countries, such as Italy, Spain, the Netherlands, the UAE, the UK, and the US, and ended up being arrested in India (Laville, 2009; Nelson, 2009).

Different types of IFT-activities can also exist. If a Somali taxi driver in London wants to transfer part of his earnings to his brother, a farmer in his home country, he has the option of going to a Somali-owned shop in London and handing over a large sum of cash to the shop owner. Then, within a few hours, his brother will receive a text message stating that his money is ready for collection. The remittance transferring service that the taxi driver uses is an unregistered remittance service - an IFT-system - and the shop owner is an IFT-broker (Economist, 2015). As such, IFT-systems may be used primarily by expatriate workers. An unanticipated group of customers relies on IFT-systems to transfer funds as well, including international and domestic NGOs, donor organizations, and development aid agencies ${ }^{11}$ that operate in fragile states, such as Afghanistan and Syria (Maimbo, 2003; Thompson, 2015). Humanitarian agencies have difficulties in providing cash-based relief to refugees residing in fragile states, where the banking system is in a state of near or complete collapse. Their only way of

\footnotetext{
11 Technically speaking, IFT-users are also perpetrators who violate rules and regulations prohibiting IFTactivities. Law enforcement authorities usually less attend to IFT-users, if they are construed to have little criminal intent. However, if IFT-users are organized crime group members or terrorists, this is a different story.
} 
transferring funds to conflict areas outside of government control, is the informal network of 'money men' or hawaladars (Thompson, 2015).

Despite various designations (Passas, 1999) for this phenomenon, there is an agreement on the existence of cross-border remittance channels outside government supervision. This study, which adopts the term suggested by the International Monetary Fund (IMF) and the World Bank ${ }^{12}$, refers to such illegal cross-border remittance channels as 'IFT-systems' (El Qorchi et al., 2003; World Bank, 2006). Compared to the interest that other domains have expressed in IFT-systems, these systems have barely received interest from scholars and professionals in criminology and criminal justice. That might be because IFT-systems play the relatively simple role of transferring criminal proceeds, rather than directly contributing to the act of committing a crime. In the wake of the 9/11 attacks, however, IFT-systems received increasing attention from criminologists. Law enforcement engaged in the prevention of cross-border crimes and terrorism focused on disrupting and preventing financial support for them (Economist, 2001; GAO, 2003; McCusker, 2005; Passas, 1999; Soudijn, 2015; Van de Bunt, 2008a). Research on crime facilitators also increased (Levi et al., 2005; Middleton and Levi, 2015; Nelen and Lankhorst, 2008; Soudijn, 2014).

A number of studies on IFT-systems were conducted from various perspectives. The origins and historical roles ${ }^{13}$ of IFT-systems were examined from an anthropological point of view. Economists analyzed the roles of IFT-systems with respect to the migration and economic development of developing countries. Criminologists have investigated the exploitation of IFT-systems by organized crime groups. The global

12 Illegal cross-border remittance channels are called in various names, such as hawala, underground banking, alternative remittance system, and informal value transfer system (Passas, 1999). This study is reluctant to reiterate the intense discussion as to which term is better because such discussion is beyond the scope of this study. The term IFT-system seems to relatively well reflect the phenomenon to capture and draws little concern from scholars and professionals.

13 In the ancient times, the role of IFT-systems was more concentrated on settlement of trade payments rather than transferring remittances. This is discussed in detail in Chapter 3. 
AML/CFT community's endeavor to tackle IFT-systems was also discussed from various points of view (IMF, 2005). The Financial Action Task Force (FATF) - an intergovernmental body that aims to combat money laundering and the financing of terrorism - developed global standards to tackle money laundering and the financing of terrorism, including the abuse of IFT-systems. Based on the FATF Recommendations, some countries concentrated on cracking down on IFT-systems, and others placed emphasis on coaxing IFT-systems into government registration. These investigations unveiled the basic mechanisms ${ }^{14}$ of IFT-systems (Ballard, 2005; El Qorchi et al., 2003), their strengths and weaknesses, as well as the relationships between the actors involved in IFT-activities (Passas and Maimbo, 2008). Yet, although the number of studies on IFT-systems increased, and their research scopes expanded to include various dimensions, previous studies rarely addressed IFT-systems with 'theoretical underpinning'. Most of them remained focused on uncovering the working mechanisms of IFT-systems in a descriptive fashion. Although relevant factors for IFTsystems were sometimes sifted out, the relationships among them were rarely examined to develop or look for theoretical frameworks for IFT-systems. Findings from previous studies on IFT-systems were layered with limited structure. There was little effort to discern and organize findings according to the economic and social environments faced by IFT-systems. Disarrayed ideas about IFT-systems thus rarely promoted the development of systematic knowledge regarding this phenomenon (Hambrick, 2007; Shapira, 2011). Many questions about IFT-systems remain unanswered. For instance, it is unclear why and how IFT-systems can still operate and flourish in some countries, despite efforts to disrupt and regulate them. Formal financial institutions should have long since replaced IFT-systems in the cross-border remittance market, as nearly all formal financial institutions worldwide are connected to one another. More systematic efforts are thus needed to identify and examine the factors that make IFT-systems

14 IFT-systems used to be perceived as a mysterious method to transfer funds because it does not involve banks (FATF, 2013a; Passas, 1999). Many studies on IFT-systems disclosed that the working mechanism of IFT-systems is basically the same as that of banks. The basic mechanism of IFT-systems is discussed in detail in Chapter 3. 
attractive and allow them to outcompete formal financial institutions, but also those factors that neutralize the weaknesses of IFT-systems.

\subsection{Research questions}

This study intends to fill this research gap and address a fundamental question concerning IFT-systems: why and how IFT-systems, a primitive financial service system, can still be operational today (i.e., survival) and adapt to unfavorable environments (i.e., adaptation). There are various types of adverse environments: the rapidly evolving social and economic environments in which IFT-systems operate; the dramatic increase in global concern about IFT-systems (Johnston, 2005), and the exponential strengthening and expansion of networks among formal financial institutions (Minoiu and Reyes, 2013). Given these adverse environments, IFT-systems are assumed to have been replaced by formal remittance systems or at least to be at risk. One would expect that there is little room ${ }^{15}$ for IFT-systems to operate and thrive. Nevertheless, if an individual (or an entity) continues to provide cross-border remittance services without a proper license and registration, and remitters can locate the business (albeit with some efforts) in a country, then it is referred to as 'survival' of IFT-systems in a country. As there are no formal entry and exit procedures for IFT-businesses, it is challenging to determine the extinction or survival of IFT-systems. It is important to locate IFTbusinesses and identify whether environments are conducive to or adverse to IFTsystems with respect to the likelihood of locating IFT-systems. Despite these adverse environments, IFT-systems exist in most countries and even flourish in some regions (Todoroki et al., 2014). They have seemingly adopted measures to cope with adverse

15 According to Hernandez-Coss's study (2005) on the U.S.-Mexico remittance corridor, the improvement of access to formal remittance channels dramatically changed the remittance corridor between the two countries. Whereas in the late 1990s, IFT-systems were prevalent in the corridor, since the early 2ooos, the formal remittance channels have dominated the corridor. A survey study conducted by the World Bank on remittance markets (Todoroki et al., 2014: 91) also suggests that "as the formal remittance market becomes more competitive, partly as a result of better regulatory policies implemented by countries, there would be fewer incentives among migrant workers to use informal transfer systems for sending and receiving remittances". 
environments. The process to avoid or overcome adverse environments and to take advantage of friendly environments is referred to as 'adaptation' of IFT-systems. The survival of IFT-systems and their adaptation to adverse environments merit an investigation.

The adverse environments that threaten the survival of IFT-systems are basically derived from the illegitimacy ${ }^{16}$ of IFT-systems. The illegitimacy of IFT-systems results not only in external risks but also in internal risks. External and internal risks refer to threats that remitters (i.e., IFT-users) and informal remittance service providers (i.e., IFT-brokers) worry about and seeks to cope with in engaging in IFT-activities. Specifically, external risks facing IFT-systems refer to threats that come from outside IFT-systems, such as the increased control of IFT-systems, unfavorable societal attitude towards the informal economy, and fierce competition with formal remittance channels. Internal risks refer to threats inherent in IFT-systems, or the likelihood that IFT-users and IFT-brokers are deceived or betrayed by the other party or counterparts. Whereas the internal risks are faced by both IFT-users and IFT-brokers, some of the external risks somewhat differently affect IFT-users and IFT-brokers. For instance, the heightened competition between IFT-systems and formal remittance channels works as an opportunity or benefit for IFT-users. Of course, IFT-systems operating in (favorable) environments that have little regard for their illegality — or are regarded as legitimate - may thrive without concerns about the external and internal risks. In order to survive such adverse environments or conditions, IFT-systems adopt various adaptation strategies: to cope with external risks, they may operate in a covert manner or restrict the scope of their business to social niches (such as ethnic enclaves), and to cope with internal risks, they may employ various social and technological mechanisms. In other words, as IFT-systems are not only confronted with external risks, but also face the

16 Legality and legitimacy (or illegality and illegitimacy) are sometimes interchangeably used. However, as discussed in Chapter 2, this study distinguished between legality and legitimacy (or illegality and illegitimacy) given that regulations on the books are not necessarily enforced as written. For instance, although IFT-systems are illegal in most countries, in some developing countries, they are not cracked down, are ignored, or even admitted. This is a matter of legitimacy, not legality. 
internal risks derived from their illegitimacy, their survival depends on how they adapt to these adverse external and internal conditions.

In order to address the two main elements of the overarching question - the survival and adaptation of IFT-systems, this study focuses on examining how IFTsystems respond to the two types of threats: external and internal risks. IFT-systems' responses to external risks are represented in the form of the global landscape of IFTbusinesses - the distribution of IFT-risks across countries, which is seemingly affected by various external conditions. IFT-risk refers to the likelihood that IFT-systems survive and prosper in a certain country. As most countries may somehow seek to control IFTsystems, IFT-risks imply the threats that IFT-systems pose to each country. The responses of IFT-systems to internal risks are examined with respect to the internal dynamics of IFT-systems. In order to demonstrate how IFT-systems respond to the two types of threats, this study seeks to address the survival and adaptation of IFT-systems metaphorically with a 'camera' that can take panoramic, medium, and close-up shots. The panoramic shot from a far-away vantage point can capture how IFT-risks are distributed across countries. By zooming in on IFT-systems, the medium shot provides an overview of IFT-systems as a remittance channel competing with formal financial institutions, before zooming in on IFT-systems. By zooming in further on IFT-systems, the close-up captures delicate interactions among actors within IFT-systems. The three pictures of the survival and adaptation of IFT-systems at the 'two levels' is related to dividing the overarching question into two sub-questions: how much - or to what extent - IFT-systems (are likely to) thrive ${ }^{17}$ across the world despite the 'external risks', and how IFT-transactions are carried out despite the 'internal risks' involved in them.

\footnotetext{
17 As for the measurement of how much IFT-systems thrive across countries, one extreme situation of the prosperity of IFT-systems is near extinction of IFT-systems whereas its other extreme situation is near supplantation of formal financial institutions by IFT-systems. The extent of prosperity of IFT-systems demonstrates IFT-systems' survival or viability. In terms of operationalization, the prosperity of IFTsystems is transposed into IFT-risks faced by each country, thereby composing the global IFT-risk indicator in Chapter 4.
} 
When it comes to the global landscape of IFT-businesses, it is challenging to measure the extent to which IFT-systems thrive, especially because they are illegal in most countries ${ }^{18}$. However, it is possible to gauge the global landscape of IFT-risk the distribution of the external risks (elements) for IFT-businesses - by assessing the variance in likelihood that IFT-systems flourish across countries. Each country has different environments for cross-border fund transfers. A cross-sectional comparison of countries, which looks at factors that are likely to contribute to the survival and adaptability of IFT-systems, can help map a nuanced landscape of IFT-risk faced by each country. The global landscape of IFT-risk can thus discern and demonstrate which countries are more (or most) susceptible to the risk of IFT-activities, and need more assistance from the AML/CFT community. This study will therefore address the first research sub-question, drawing on the global landscape of IFT-risk.

The second sub-question that this study will address is related not only to internal risks embedded in IFT-transactions, which threaten the establishment of an IFT-transaction and the survival of an IFT-system, but also to their adaptation to internal risks. In other words, this study seeks to examine why the actors involved in IFT-activities (appear to) trust each other and continue to engage in IFT-activities, even though their contracts related to IFT-services are not enforced and protected by legal systems. This study will also examine the two following phenomena: IFT-activities that operate outside the legal protection systems are inherently vulnerable to mistrust between actors with no recourse to legal means to coordinate their conflicts; and, IFTsystems are presumed to last only temporarily when the actors involved in IFT-activities are strangers. The second sub-question will thus look at how actors operating in IFTsystems cope with the internal risks that threaten the establishment and continuity of IFT-systems, including the mistrust between them and the risks of being deceived or betrayed by the other party. The trust between the actors in IFT-systems and the risk

18 According to a survey study conduced by the World Bank (Todoroki et al., 2014), unauthorized remittance services are prohibited in all of the surveyed remittance-sending countries and in most remittance-receiving countries (except for Guatemala, Indonesia, and Surinam). 
that they must bear and cope with when placing trust in actors involved in IFTtransactions are not separate - but rather intertwined - issues. The coping mechanisms that they adopt to respond to such internal risks may include not only actions to gain the trust of the other party, but also the precautionary measures that they take against predictable harm to themselves. These coping mechanisms may represent areas of interest for scholars and policy makers. The second sub-question may thus be useful in devising measures against IFT-systems.

In sum, the overarching research question of this study is why and how IFTsystems continue to survive to date, despite the adverse external and internal risks. The differences between the two sub-questions are related to the risks that IFT-systems face and the scope of the investigations into IFT-systems. The first sub-question constitutes how IFT-systems continue to prosper across countries, and how they cope with adverse external risks. In answering this question, this study seeks to capture the nuanced IFTrisk landscape by examining the influence of macro-level factors that are likely to contribute to the 'survival and prosperity (or shrinkage)' of IFT-activities across countries. In addressing the second sub-question, this study focuses on the factors that allow IFT-systems to adapt to - and survive despite - the internal risks involved in IFT-activities by investigating interactions between the actors in IFT-systems.

\subsection{Overview of this study}

IFT-systems may be an unknown phenomenon to the general public. They may not have a clear idea on how IFT-systems work and whether they are perceived as acceptable and legitimate in society. A discussion about the legality or legitimacy of IFT-systems is thus made in parallel with an illustration of the basic working mechanisms of IFT-systems. The section about the legitimacy of illegal remittance activities (in Chapter 2) will begin with an examination of formal remittance systems. Most people are familiar with formal remittance systems, mainly in the form of crossborder remittance services of banks. Surprisingly, IFT-systems adopt the same mechanisms as formal remittance systems. Chapter 2 will focus on how IFT-systems 
differ from formal remittance systems, explaining that IFT-activities involve two aspects: a channel for cross-border fund transfers and a channel for money laundering. The advantages of IFT-systems may stem from the shortcomings of formal remittance systems. While examining the roles that IFT-systems play in a given society, this study contrasts two approaches ${ }^{19}$ : an economic approach ${ }^{20}$ and a criminological approach. An economic approach to IFT-systems focuses on the advantages of IFT-systems that benefit those who have difficulty in accessing formal financial institutions, whereas a criminological approach looks into the absence of government control over remittance activities, which is attractive for those who seek a remittance channel for illegal activities. The two approaches relate to different positions on the legitimacy ${ }^{21}$ of IFTsystems: while the economic approach tends to construe IFT-systems as legitimate albeit illegal, the criminological approach seems to view IFT-systems as illegal and unacceptable. This study thus seeks to examine the legitimacy of IFT-systems whether IFT-activities are not only unlawful, but also unjustified - drawing on

19 According to Todoroki and her colleagues (2014: xxiv), "significant progress has been made over the last decade in reconciling these perspectives, and in highlighting the needed synergies between these two approaches, notably from a policy and risk standpoint. However, important challenges remain with respect to how best to make the remittance market work on the ground and how to strike the right balance and risk-based approach to AML/CFT supervision and regulation, with a view to spurring remittance flows while ensuring their integrity".

20 Economists tend to touch upon IFT-systems concomitantly while examining the relationships between migrants' remittances and economic development of their home countries. From their point of view, IFT-systems is deemed a (auxiliary) way that expat workers send funds to their home countries where domestic capital for economic development is scant. Economists attend to the bright side of IFTsystems, of which expat workers make use to send remittances fast and inexpensively rather than the dark side of them, of which criminals take advantage to launder their criminal proceeds.

21 According to Fallon (2005), there are three types of legitimacy - legal, sociological, and moral. Legal legitimacy depends on legal norms. Lawful means legitimate. When legitimacy is measured in sociological terms, it is regarded as justified or appropriate. Sociological legitimacy is a variable, not constant. High legitimacy with some groups may lack sociological legitimacy among others. When legitimacy is used in a moral sense, the term is a function of moral justifiability or respect-worthiness. Although the three types of legitimacy are sometimes interconnected, it would be useful to distinguish them. This study used the term legitimacy in order to connote social acceptability separable from legality. Thus, legitimacy and illegitimacy are not synonyms of legality and illegality in this study. 
discussions of crime conception, whereby several elements contributing to the criminalization of certain deviant activities will be explored.

The section 'research design and data' (in Chapter 3) will discuss two research designs and two research methods employed in this study, in relation to the two research sub-questions. A cross-sectional design and data analysis was performed for the global analysis of IFT-systems to answer the first sub-question: to what extent do IFT-systems (or are they likely to) thrive across countries despite adverse external environments? The global landscape of IFT-businesses - a collection of IFT-risks faced by each country - entails the question of which countries are more - or less susceptible to the risks associated with being involved in IFT-activities? The global analysis of IFT-systems is based on several secondary (public domain) datasets collected by international entities, such as the World Bank and the FATF. These datasets deal with macro-level factors that are likely to be associated with IFT-activities, such as migration, financial inclusion, AML/CFT measures, and societal attitudes towards informality. The global analysis results in the development of a global IFT-risk indicator that gauges the level of IFT-risk faced by each country in the form of a composite indicator $^{22}$. A case study design and thematic analysis was performed to address the second sub-question - how IFT-transactions are carried out despite the internal risks involved - by examining IFT-systems in Korea. The case study on IFT-systems in Korea aims to investigate the adaptation of IFT-systems to the internal risks to which they are exposed. This will be done by investigating the relationships of trust between the actors involved in IFT-activities. The data analyzed for this case study include IFT-case reports produced by the Korea Customs Service (KCS) and transcripts of interviews with Korean government officials who investigated or had knowledge of IFT-systems. In conducting research on the survival and adaptability of IFT-systems, this study is based on the view that data from Korea seem to have different advantages from those from developing

22 A composite indicator is defined as a single index compiled from individual indicators on the basis of an underlying model of the multi-dimensional concept to be measured (OECD and JRC, 20o8). The detailed procedures to construct a composite indicator is unfolded in Chapter 4 . 
countries where IFT-systems are common, given the different external conditions in Korea for IFT-systems from those in other developing countries. For instance, IFTsystems that survive in - and adapt to - harsh external environments may have salient features that IFT-systems in favorable environments do not have or need. A thematic analysis technique was used to extract information on the working mechanisms of IFTsystems and the relationships between the actors involved in IFT-activities from the IFT-case reports and the interview data.

This study first conducted an analysis of IFT-risks from 121 selected countries (in Chapter 4) to provide a panoramic view on the global landscape of IFT-systems. With macro-level factors that are likely to contribute to the survival of IFT-systems, the global analysis of IFT-systems has led to the development of a 'global IFT-risk indicator' - a composite indicator that gauges IFT-risks across 121 selected countries. As an analytical tool, a composite indicator has rarely been used in the field of criminology and criminal justice $^{23}$. In putting together the composite indicator, weighting and aggregating the variables involve value judgments. The global IFT-risk indicator is anticipated to play a meaningful role in gauging the degree of survival (or prosperity) of IFT-systems across various countries.

For the country-focused analysis (hereafter referred to as 'the local analysis') of IFT-systems in Korea, three theoretical frameworks applicable to the relationships and interactions between the actors in IFT-systems will be discussed in Chapters 5 and 6 . Most studies on IFT-systems focus on disclosing the working mechanisms of IFTsystems in a descriptive fashion. There are only a few studies that connect them to theoretical perspectives. As IFT-systems involve multiple actors to complete even a

23 Only one composite indicator regarding criminal justice is noticed - Rule of Law Index. World Justice Project (WJP) launched the rule of law index in 2008, measuring each jurisdiction's rule of law performance across eight factors: constraints on government powers, absence of corruption, open government, fundamental rights, order and security, regulatory enforcement, civil justice, and criminal justice. As of October 2016, this index covers 113 countries (WJP, 2018). 
single transaction ${ }^{24}$, several concepts that deal with the engagement of multiple actors (e.g., co-offending, networks, and markets) can be considered for theoretical analysis. However, this study begins its analysis with the concept of 'market' and investigates IFT-systems from a sociological perspective by looking at (illegal) markets, social exchange theory, and the perspective of trust and risk. This is because the main focus of this study is on interactions (e.g., trust, risk-taking, and transactions) between the actors in IFT-systems, rather than on the criminality of the actors or on criminogenic opportunities.

On the basis of the theoretical frameworks in Chapters 5 and 6, the local analysis of IFT-systems sheds light on the internal dynamics of IFT-systems. For the local analysis, a thematic analysis technique is employed to analyze the IFT-case reports and the data from interviews with Korean government officials. By making use of the thematic analysis technique, this study identifies the internal working mechanisms of IFT-systems within the datasets, and analyzes the findings drawing on the three theoretical frameworks. This study also reorganizes the findings in a temporal order, inspired by a crime script approach, in the hope that scholars or law enforcement authorities will gain more insight into the decision-making and commissioning processes of IFT-activities.

The conclusion of this study includes not only a summary of the main findings, but also scientific implications including the limitations of this study and policy recommendations. As for policy recommendations, while critically reviewing existing AML/CFT measures against IFT-systems, this study puts forward not only general considerations for measures against IFT-systems, but also practical measures that would make it possible to take advantage of the external and internal risks that threaten IFTsystems.

\footnotetext{
24 As IFT-systems have the same mechanism as formal financial institutions in transferring funds across borders, normally four actors are involved in an IFT-transaction: sender, IFT-broker in a sending country, IFT-broker in a receiving country, and receiver. Detailed information about their roles were explicated in Chapter 3.
} 


\section{Concept, Features, and Legitimacy of IFT-systems}

\subsection{Introduction}

The term IFT-systems cannot exist without formal remittance systems: the concept of 'informal' fund transfer systems only came into being with the emergence of formal remittance systems, despite the fact that IFT-systems far predate formal remittance systems. The question of how IFT-systems are involved in money laundering requires an understanding of how IFT-systems work as a remittance channel. The basic working mechanism of IFT-systems is akin to that of formal remittance systems (El Qorchi et al., 2003). Nevertheless, only a few studies on IFT-systems examine formal remittance systems in parallel with IFT-systems. IFT-systems were considered a somewhat mysterious remittance channel, particularly because of their historical origin. This chapter therefore outlines formal remittance systems, thereby comparing them with IFT-systems. Although IFT-systems may have come into existence first, formal remittance systems tend to work as a reference system to IFT-systems, given that formal remittance systems are more prevalent in most countries and more accessible to the general public. A comparison between the two remittance systems is expected to contribute to a better understanding of the underlying mechanism of IFT-systems.

Despite its similarities with formal remittance systems in terms of its working mechanisms, the legal status of IFT-systems distinguishes them from formal remittance systems. Because of its dual function - channels for fund transferring and money laundering, there are somewhat conflicting views on the status of IFT-systems: illegal yet legitimate, or illegal and illegitimate. This study therefore first conducts the conceptual delineation of IFT-systems, drawing on various perspectives that would benefit the assessment of the status of IFT-systems. In section 2.5, based on the conceptual delineation of IFT-systems, this study determines the legitimacy of IFTsystems in Korea, taking into account the perception of relevant law enforcement officials of IFT-systems. 


\subsection{Formal remittance systems}

Irrespective of the association with IFT-systems, there are a number of studies on formal remittance systems. Most of them examine the relationship between migration, remittances ${ }^{25}$, and economic development (Kapur, 2005; Ratha, 2005; World Bank, 2006). However, only limited literature (BIS and World Bank, 2007) sheds light on the mechanisms of formal remittance systems. According to the literature on remittance transfers, remittance transfers generally refer to cross-border person-toperson payments of relatively low value (World Bank, 2006). However, there is little consensus on what constitutes remittance. The available definitions of remittance focus on 'person-to-person' payments, rather than business-to-business payments, or payments for goods or services. In practice, as the most important remittance flows constitute the recurring payments of migrants, the definitions of a remittance transfer used in studies usually only cover cross-border person-to-person transfers ${ }^{26}$.

\subsubsection{Basic structure}

Remittance transfers are made in many ways. However, they have key participants in common: the sender, the receiver, the capturing remittance service provider (RSP) in the sending country, and the disbursing RSP in the receiving country. Many banks and deposit takers, such as credit unions, function as the RSP. The basic structure of formal remittance systems is similar to that of IFT-systems.

\footnotetext{
25 Remittances are a critical source of external financing for many developing countries, and probably the most stable source of primary or additional income for many households in those countries. Despite the 2008-2009 global financial crisis, remittances continued to show resilience and growth. Remittances fell by only 5.5 percent in 2009, while foreign direct investment flows declined by 40 percent and private debt and portfolio equity flows reduced by 46 percent (World Bank, 2011).

26 From the perspective of those providing payment services (e.g., banks or money transmitters), remittances are often indistinguishable from low-value payments between businesses or from payments for business purposes between persons (BIS and World Bank, 2007; IMF, 2009).
} 
The remittance transfer process consists of four procedures: capturing, messaging, settlement, and disbursing. The capturing procedure refers to a step where the sender requests the capturing agent for remittance, with funds and information necessary to send the funds to the receiver. Payment can be made through various methods acceptable to both parties (e.g., by cash, by debiting or crediting a bank account, or by using prepaid funds). In order to comply with AML/CFT regulations ${ }^{27}$, the capturing agent checks the identification of the sender, although it is not an essential element for sending the funds to the receiver. Messaging and settlement procedures take place between the capturing and the disbursing agents. Messaging arrangements are undertaken by the capturing agent to send information about the remittance to the disbursing agent. The information between the capturing and the disbursing agents usually flows independently of the funds. However, if there is limited communication between the capturing and the disbursing RSPs, the information travels together with the funds (BIS and World Bank, 2007).

Figure 2.1: Basic structure of remittance transferring by formal financial institutions

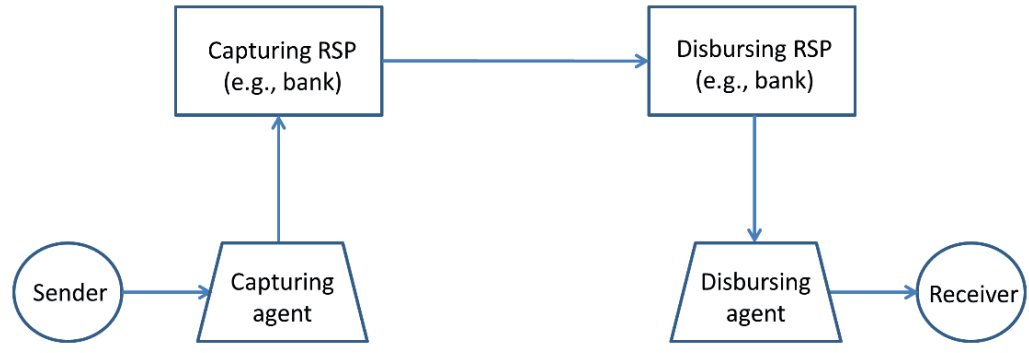

Source: the author

Settlement arrangements move the funds from the capturing agent to the disbursing agent. A remittance transfer involves a chain of settlements: a series of separate payments between the capturing agent and the capturing RSP, between the capturing RSP and the disbursing RSP, as well as between the disbursing RSP and the

27 FATF Recommendation 10 and 11 stipulate regulations regarding customer due diligence and recordkeeping (FATF, 2015). 
disbursing agent. Each payment between them is made by means of a credit transfer. In most cases, the payments from the agents to the RSPs, and between the RSPs, are not made individually or in real time, because each remittance amount is small. Instead, the funds from multiple remittances are kept for a certain period of time and transferred in a single transaction. Batching of separate funds is possible, as the information for individual remittance transfers can travel independently of the funds. When it concerns a two-way flow of funds between the agent and the RSP, and between the RSPs, the twoway payments are offset against each other and only the smaller net amounts are transferred (BIS and World Bank, 2007). A disbursing procedure is referred to as a step where the disbursing agent identifies the recipient with the information transferred from the sender, and transfers the funds to the recipient in cash, or by crediting his bank account. The disbursing agent can request the recipient to prove their identity and their entitlement to the funds transferred (BIS and World Bank, 2007).

\subsubsection{Network}

Remittance services can be classified into four types, according to how a network between the capturing agent and the disbursing agent is created and works: unilateral, franchised, negotiated, and open services (BIS and World Bank, 2007). A unilateral service refers to a proprietary service provided by a single RSP, without involving other entities as capturing or disbursing agents in sending or receiving countries. Thus, remittance transfers in a unilateral service ${ }^{28}$ are regarded as cross-border - but 'internal' - transactions within the single RSP. Examples of unilateral services are remittance services provided by global banks with branches in many countries, or other banks with branches in countries where migrants are concentrated (e.g., BNP Paribas branches in France, Belgium, and large countries in the Middle East and Africa; HSBC branches in the U.S., the U.K., Hong Kong, and China; and Citibank branches in the U.S.

\footnotetext{
28 A unilateral remittance service may appear to be irrelevant to IFT-systems in terms of its working mechanism. However, some IFT-brokers in Korea have established unilateral remittance networks although their network sizes are tiny, making use of the online banking systems of formal financial institutions. This is discussed in Chapter 6.
} 
and India). A franchised service is also a proprietary service provided by a central RSP, but with other entities under its umbrella. In a franchised service, the central RSP (franchisor) provides the infrastructure for remittance services. It invites other entities (franchisees) to take on the role of capturing or disbursing agents - in sending or receiving countries - to provide its customers with remittance services. Global money transfer operators (e.g., Western Union or MoneyGram) can be classified as this type of remittance service.

Figure 2.2: Remittance transferring via a franchised network

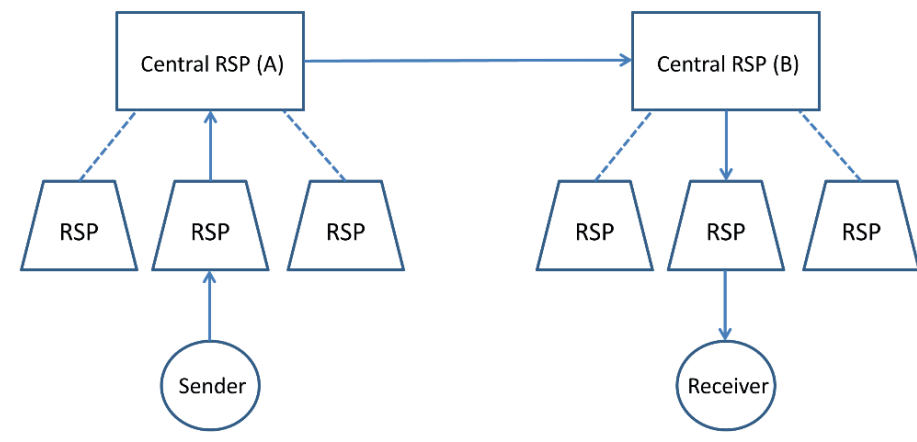

Source: the author

A negotiated service is provided by an RSP in alliance with a limited number of other independent RSPs or agents in other countries. Examples of negotiated services are bilateral arrangements between banks, between credit unions, and between postal services (one in sending and one in receiving countries). The negotiated partner RSP or agent does not need to be the only one in the sending country or in the receiving country. An RSP in the sending country can have multiple disbursing RSPs or agents in the receiving country and vice versa. Each capturing and disbursing RSP can join multiple remittance corridors with different partner RSPs. In an open service, an RSP can send the funds to any other RSP or agent in the world, leveraging the international banking network consisting of national payment systems ${ }^{29}$, which can be accessed mostly

29 A national payment system refers to a country's entire matrix of institutional arrangements and infrastructures that facilitates the transfer of money value between two parties. Thus, money is 
through a correspondent bank ${ }^{30}$ in another country. Open services are the most common network type for remittance services provided by banks (BIS and World Bank, 2007).

Among the four types of formal remittance networks, IFT-systems are analogous to the negotiated service network, given that independent IFT-brokers in sending and receiving countries are in alliance with each other, and that they are not subject to the other party's network. These characteristics are examined below.

\subsubsection{Advantages and disadvantages of formal remittance systems}

Several scholars assess formal remittance systems according to the following five criteria $^{31}$ : service coverage, speed, cost, accessibility, and risk (BIS and World Bank, 2007; Gadanecz and Tissot, 2016). Exploration of the advantages and disadvantages between different types of formal remittance systems provides clues regarding the attractiveness of IFT-systems. This is because remittance customers view the various remittance

transferred between buyers and sellers in commercial and financial transactions through the national payment system (BIS, 2006). In most countries, national payment systems are monitored and managed by their central banks; only banks can have direct access to national payment systems. Non-bank RSPs can indirectly access the system as customers of banks. As national payment systems process the funds and payment instructions manually and are expensive, the systems work well for the large-value transfers and may be less suitable for retail payments such as remittances (BIS and World Bank, 2007).

30 Correspondent banking is defined as "agreements and contractual relationships between banks to provide payment services for each other." Thus, "one bank (correspondent) holds deposits owned by other banks (respondents) and provides payment and other services to other respondent banks" (BIS, 2015: 6).

31 The assessment of the remittance markets normally takes into account the competitiveness and risk of them (BIS and World Bank, 2007). In a survey on financial inclusion conducted by the International Finance Corporation, a sister organization of the World Bank, the concept of financial inclusion is measured with several dimensions, such as availability of financial services, access to financial services, demand for financial services, effective use of financial services, financial literacy, and quality of infrastructure (Gadanecz and Tissot, 2016). Given that the competitiveness of the remittance markets can be interpreted in terms of financial inclusion, in this study the remittance markets are assessed by risk and several elements of financial inclusion. 
systems as available choices in one big remittance market, rather than several separate remittance markets.

Remittance service coverage is determined by the numbers of receiving countries and disbursing RSPs in the countries that a capturing RSP can access. Technically, remittances using an open service can be transferred between similar institutions anywhere in the world (BIS, 2015). In contrast, a unilateral service is likely to have the most limited service coverage. The service coverage of franchised and negotiated services depends on the number of participating RSPs and agents in the remittance service networks. The banking network of developing countries may not be extensive, especially in rural areas, which can be problematic in terms of physical access for many recipients. The remittance network coverage can influence the speed and cost of remittance services (BIS and World Bank, 2007).

The overall remittance speed depends on the speeds of messaging and settlement, which are influenced by the relationships between the agents and the RSPs, and between the RSPs (BIS and World Bank, 2007). Remittance transfers through a unilateral, franchised or negotiated service are usually faster than those through an open service. That is because in a unilateral, franchised or negotiated service, the capturing agent and RSP have direct access to the disbursing RSP and agent, whereas communications between different systems with different message formats in an open service may be an obstacle to overcome. In addition, in an open service where the capturing RSP needs to go through intermediary banks to transfer the funds to the disbursing RSP, some intermediary banks hold onto the funds for a certain period of time. This allows the intermediary bank to earn interest on the funds, thus slowing down the remittance transfers. Due to the limited relationship between the agent and the RSP, and between the RSPs, an open service - where information about remittances is transferred together with the funds to the disbursing agent - is slower than other types of services where the information can be sent separately from the funds. Unilateral and franchised services can afford to provide liquidity to the receiver, even before settlement is complete. These services can transfer remittances to the recipient 
faster than other types of services that do not pay the recipient until settlement is complete (BIS and World Bank, 2007).

The remittance service price charged to remittance service users normally consists of an exchange rate and a remittance fee. The capturing RSP charges the sender an exchange rate, including a margin, which is higher than the current interbank or wholesale market rate. In determining the margin level, the RSP often takes into account the uncertainty that it faces. Thus, an open service may charge more for the remittance service than unilateral, franchised, or negotiated services. When it comes to accessibility, formal financial institutions may be reluctant to open branches in rural areas, where it is unlikely that they will be profitable. Formal remittance systems may therefore be inaccessible to low-income migrants with a high demand for remittance services. In foreign countries, migrants may experience difficulties not only in understanding remittance services provided in local languages, but also in providing proper identification and proving their creditworthiness required to use certain services. Thus, these constraints may limit the number of services that marginalized remittance customers can access, even if certain remittance markets are competitive (BIS and World Bank, 2007; El Qorchi et al., 2003).

Remittance services involve several risks or challenges that RSPs are faced with. The most common risk involved in remittance services is losing funds while they are in transit. This risk can become a reality if one of the RSPs goes bankrupt or commits fraud against remitters. Which RSP or agent is responsible for compensating the lost funds depends on the type of remittance network. In a unilateral or franchised service, as long as the problem is not caused by the bankruptcy of the RSP, the RSP is likely to have the disbursing agent reimburse the recipient - irrespective of where the problem takes place. In a negotiated or open service, it is important to determine where and why the problem occurred. The responsibility of providing compensation for the lost funds may shift from the capturing RSP to the disbursing one. RSPs and their agents are also concerned about the possibility of being exploited for money laundering and for financing terrorist activities. Thus, in many countries, RSPs and their agents are 
required to be licensed or registered. They are also obligated to verify the identities of the sender and the receiver, to record individual transactions, and to report suspicious or large transactions to the relevant authorities. In some countries with exchange controls, RSPs and their agents are restricted in dealing with foreign currencies. Some countries supervise RSPs and their agents in terms of financial prudence.

A number of studies contended that, since formal remittance services are expensive and inaccessible to some (marginalized) prospective remittance service users, IFT-systems have become an alternative channel to remittance service users (Beck and Martínez Pería, 2011; Freund and Spatafora, 20o8; Martinez et al., 2015; Passas and Maimbo, 2008). According to them, IFT-systems fill the gap in formal remittance systems in some areas, and complement or compete with them in other areas. However, some studies on remittance services (Todoroki et al., 2014) have suggested the promotion of 'competition' in the formal remittance market, in order to reduce the price of remittance services and to make them more accessible ${ }^{32}$. They have made recommendations to reduce regulatory barriers to entering the remittance market as much as possible (World Bank, 2006). However, lowering regulatory barriers may improve the availability of formal remittance services to their prospective customers only 'in theory'. In practice, only a few remittance services may be accessible to them, as the expansion of formal remittance systems is closely linked to their profit. This situation leaves a door open for IFT-systems.

\subsection{Informal fund transfer systems}

\subsubsection{Historical origin}

32 The level of access to formal remittance systems is (negatively) associated with the demand for IFTservices. Expansion of the coverage of formal remittance systems and improvement of their service quality can result in a decrease in the demand for IFT-services. Thus, various ideas to make formal remittance systems more accessible are considered to reduce space for IFT-systems (Mohapatra and Ratha, 2011; Orozco, 2004; Ratha and Riedberg, 2005). 
IFT-systems emerged in ancient times, when formal enforcement of internal transactions by rulers or governments did not exist. They continued to operate throughout the medieval eras and are still in use today (Scaeffer, 2008). IFT-systems are referred to in various ways: underground banking, a shadow channel for remittance, alternative remittance systems, and hawala (El Qorchi et al., 2003; Passas, 1999; Maimbo and Passas, 2005; Thompson, 2008; Van de Bunt, 2008a). The most well-known designation is hawala. The media have been using this term, following the suspected role of IFT-systems in the 9/11 attacks as a channel for financing of terrorism. Even after this suspicion was resolved by discovering that Al-Qaeda had actually made use of formal financial institutions to fund the terrorist attacks (Van de Bunt, 2008a), many scholarly and professional studies habitually used the term hawala in illustrating crossborder remittance transfers via unauthorized financial entities, and in analyzing the likelihood of its connection to transnational organized crime and terrorism. Its origin had rarely been examined until Thompson's study $(2007,2008)$ disentangled the link between hawala and Islam.

Hawala is an Arabic term that means 'transfer' in an etymological sense, but is understood in legal Arabic commentaries as the 'exchange of debt', given its historical context involving long distance trade. According to Schramm and Taube's study (2003), which is based on classical Islamic sources, the term hawala appeared on the hadith, the collection of the Prophet Mohammed's sayings. The authors therefore argue that the practice of delegation of debt existed (perhaps in the $7^{\text {th }}$ century A.D.) well before its codification in Islamic law. They argue that hawala as a financial term originally referred to "the payment of a debt through the transfer of a claim" (Thompson, 2008: 95). For instance, if $A$ is in debt to $B$ but has a claim against $C, A$ can settle their debt by transferring their claim against $C$ to the benefit of $B$. In this transaction, no physical transfer of money takes place, only the delegation of a debt (Thompson, 2008). However, this mechanism of the original hawala transactions is different from that of the modern hawala transactions, whereby money (actually value) is transferred from one place to another through service providers called hawaladars, while avoiding the inconvenience and risk incurred from physically transporting money (Schaeffer, 20o8). 
According to Islamic legal and religious texts, this modern hawala transaction mechanism is more analogous to a financial instrument called suftaja, which operated by employing two methods: the first method consisted of the customer borrowing money from a money dealer, with a promise to pay them in another town when the written note was presented there; the second method consisted of the customer paying money, with a promise from a money dealer that the money would be recovered in another town once the note was presented. The second method is similar to the function of hundi - a letter of credit, or promissory note, used among ancient Indian merchants to document debt while engaging in long-distant trade (Martin, 2009). With respect to the relationship between hawala and suftaja, Grasshoff 33 demonstrates that hawala is a legal concept of delegation of debt, whereas suftaja refers to a bill of exchange as one of the commercial instruments applicable to hawala (Thompson, 2008).

There is a misperception that Islam suppresses commerce, given that Islam prohibits interest. However, it departs from the ancient Arabian standards of mercantile behavior. The Prophet Mohammed used to be a merchant and was supportive of competitive commerce, as long as it did not harm the poor (Thompson, 2008). Islam afforded flexibility into the Islamic system of commerce by inventing devices, such as credit partnerships, to circumvent the prohibition of interest. As Islam invigorated business life and promoted an exchange of goods, the conversion to Islam was attractive to cities that sought to foster trade with other cities. Islam made socioeconomic cooperation and the integration of cities with different cultural backgrounds possible, as it had an unprecedented potential to lift previous cultural and logistical barriers to trade. Pilgrimages to holy places in Arabia, on which a myriad of pilgrims converged each year, provided a great opportunity for merchants to exchange information and to market local products along the route. Along the way, Arabic commercial instruments, such as the transfer of debt, were used between merchants

33 Richard Grasshoff is a German scholar in the late 19 century that studied the origin of trade. Thompson (2008) carefully examined Grasshoff's study conducted in 1899. 
from different regions, and Islam institutionalized trust-based trade among spatially dislocated traders who had no recourse to formal enforcement systems. Arabic commercial instruments and practices were therefore not confined to the Arabic world; in fact, were widespread among non-Muslim merchant communities ${ }^{34}$ through the ancient and medieval periods (Thompson, 2008; Lascaux, 2015).

\subsubsection{Basic 35 mechanism}

IFT-transactions refer to cross-border fund transfers made by an entity that is not permitted or authorized to do so. IFT-activities do not just involve transferring funds across borders, but also other activities required for IFT-transactions, such as investigation and inquiry among IFT-users and IFT-brokers, and advertising of IFTbusinesses. The basic mechanism of IFT-transactions is similar to that of formal remittances by formal financial institutions (Schaeffer, 2008). Like formal remittances, four players are involved in IFT-transactions: the sender, the IFT-broker (or IFT service provider) in the sending country, the IFT-broker in the receiving country, and the recipient. IFT-users (or the customers of IFT-systems) usually do not differ from those of formal financial institutions for remittance, although IFT-systems may be deemed more approachable to the marginalized remittance customers and more susceptible to misuse for criminal purposes than formal financial institutions ${ }^{36}$. Studies (Passas, 2006a;

34 IFT-systems were found not only in the Arabic and Indian world but also in China. In ancient China, a similar fund transfer system named fei-ch'ien ("flying money") or pien-huan ("credit exchange") existed. Thompson (2008) surmises that the Chinese fund transfer system may be created by the influenced of hundi of India while Indian and Chinese merchants traded with each other.

35 Even though IFT-systems are illegal in most countries, they are also businesses. The ways that they work differ from country to country and from IFT-broker to IFT-broker. There must be a plethora of variations in running IFT-businesses. An in-depth discussion of variants of IFT-systems across countries is beyond the scope of this study. This section focused on the main skeleton of IFT-systems relevant to the themes of this study. Passas's studies (1999, 2003, 2005a, 2005b, 2005c, 2006a, 2006b) provide detailed information about a variety of IFT-systems.

36 Even though most sensational money laundering cases involved formal financial institutions, IFTsystems might be deemed more susceptible to money laundering than formal financial institutions, given that IFT-systems are under the radar of government regulators unlike formal financial institutions. Some 
Passas and Maimbo, 2008) that emphasize the remittance transferring role of IFTsystems argue that most remitters are expatriate workers. Remitters are usually part of the same ethnic group as IFT-brokers. However, some studies (Van de Bunt, 2008a) demonstrated that shared ethnicity does not necessarily work as a major binding factor between IFT-users and IFT-brokers.

Figure 2.3: Basic mechanism of an IFT transaction

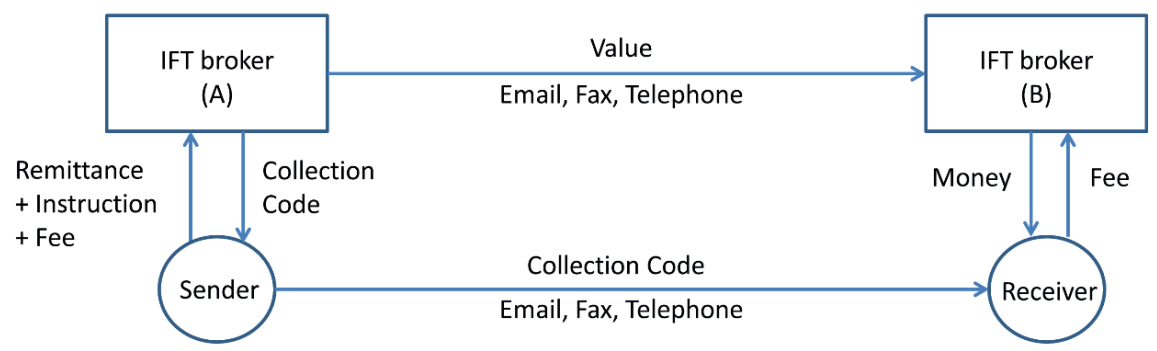

Source: Han and Ireland (2013)

The differences between IFT-systems and formal financial institutions are mainly linked to IFT-brokers who carry out cross-border payment transactions without being subject to government control. The provision of IFT-services is legally banned in most countries, even in Islamic countries, such as Pakistan and Iran (Hernandez-Coss, 2005a; Todoroki et al., 2014). IFT-brokers in one location accept various monetary instruments, such as cash, checks, or other valuable goods (e.g., diamond or gold), and pay corresponding amounts in cash or other types of monetary instruments in another location. Many IFT-brokers also run legitimate businesses (e.g., travel agencies, restaurants, or delicatessens) together, thereby not only taking advantage of their legitimate business networks but also hiding their IFT-businesses behind them. Some large IFT-brokers deal with large amounts of remittances collected by their agents or independent local petty IFT-brokers (Passas, 2005b). As IFT-brokers operate outside of

of the reasons that formal financial institutions were involved in massive money laundering scandals may be attributed to their capacity to deal with large amounts of funds, mingle criminal proceeds with large amounts of legitimate funds, and transfer criminal proceeds through thick and wide networks. 
government control, they do not need to comply with legal obligations, such as checking the identification of customers, keeping records of transactions, and reporting unusual transactions, unlike formal financial institutions (Passas and Maimbo, 2008; Soudijn, 2015; Van de Bunt, 2008a). Thus, a conventional belief existed that IFT-transactions do not involve paper trails that can be traced back to the sender and receiver. However, according to empirical studies on IFT-systems, although IFT-brokers do not have an obligation to keep records of their transactions, it turns out that they often keep some form of record of their transactions for their own purposes (Passas, 20o6a; Van de Bunt, 2008a).

For transferring funds across borders, IFT-brokers in sending countries communicate with counterpart IFT-brokers in receiving countries, who must pay out funds to the receiver designated by the sender. The communication between the two IFT-brokers takes place by means of various methods (Passas, 1999), including telephone, email, and smartphone messaging apps. IFT-brokers in sending countries charge a certain fee for remittances. There are few definitive rules or common practices regarding the fee. According to previous studies (El Qorchi et al., 2003; Van de Bunt, 2008a), the fee is usually in proportion to the remittance amount. However, some IFTbrokers do not charge remittance fees and instead take profits from informal exchange rates (Passas, 2005b).

When it comes to the illegality of IFT-systems, IFT-brokers and IFT-users may be fully aware of the nature of their business and services (Passas and Maimbo, 2008). IFT-activities are exposed to internal risks, such as deception, fraud, or betrayal between the actors involved in IFT-activities. Trust between IFT-users and IFT-brokers, and between IFT-brokers, is therefore the most critical element in IFT-activities. The risks involved in IFT-activities and trust among the actors will be examined in Chapter 6 .

\subsubsection{Settlement of outstanding debts between IFT-brokers}


Similar to formal remittance transfers between formal financial institutions, IFTtransactions rarely involve the physical transfer of funds between IFT-brokers, and are characterized as exchanging credits and debts. IFT-brokers in sending and receiving countries do not settle their debts and credits every time (Schaeffer, 2008). IFT-brokers in receiving countries tend to pay out to the recipient without receiving funds from IFTbrokers in sending countries. For instance, after an IFT transaction is completed, an IFT broker (A) in a sending country has a liability to an IFT broker (B) in a receiving country, and the IFT broker (B) has a claim against the IFT broker (A) (El Qorchi et al., 2003). Thus, IFT-transactions always involve settlement issues. There are several ways to settle outstanding debts in IFT-systems: simple reverse IFT-transactions, financial settlement, physical transfers of cash, trade in goods or services, and international asset transactions (El Qorchi et al., 2003; Passas and Maimbo, 2008).

The most obvious form of debt settlement between IFT-brokers is the simple reverse IFT-transaction, which is used by formal financial institutions as well. This method is based on the notion that the two roles of IFT-brokers in remittance transferring are switched. For instance, IFT broker (A) who requests IFT broker (B) to pay out to a recipient today, may need to pay out another recipient several days later at IFT broker (B)'s request. In other words, remittance transfer transactions between the IFT-brokers are assumed to take place on a continuous basis. Consequently, they become indebted to each other. If the amount one party owes to the other is the same, the debts can be simply cancelled out and there is no need for a physical transfer of funds between them. However, in practice, the likelihood of account balancing through reverse IFT-transactions is low, given that aggregate remittance flows between countries (e.g., developed vs. developing countries) are highly asymmetric (Maimbo and Ratha, 2005). After cancelling out remittance transactions over a certain period of time (e.g., monthly or quarterly), an IFT broker who still owes the other IFT broker, is required to transfer funds to the IFT broker who is still entitled to funds. 
Figure 2.4: Settlement of debts between IFT service providers

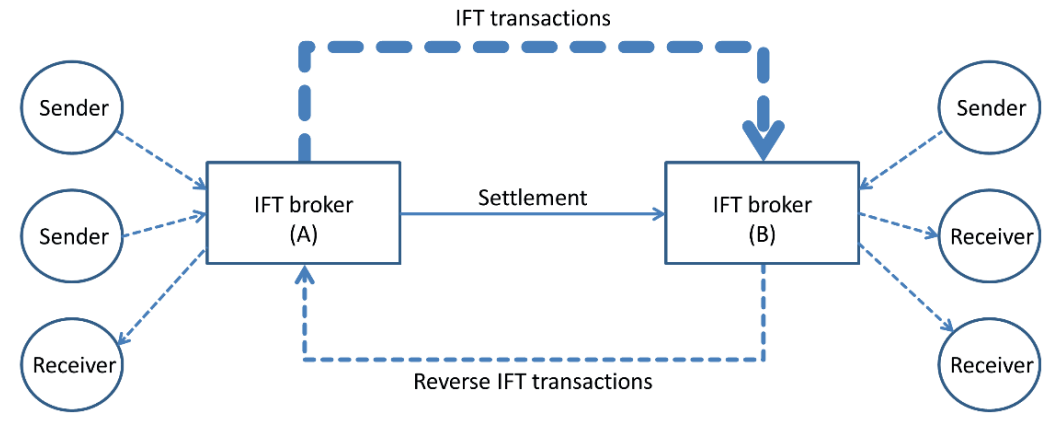

Source: the author

The transfer of funds for debt settlement between the two parties can be made by means of formal remittance systems as well (Schaeffer, 20o8; Van de Bunt, 2008a). After cancelling out their credits and debts through reverse IFT-transactions, IFTbrokers who are indebted to counterpart IFT-brokers can simply wire the outstanding debts through formal financial institutions. Several studies (El Qorchi et al., 2003; Hernandez-Coss, 2005a; Passas and Maimbo, 2008) have critically addressed the conventional notion that IFT-systems have little connection to formal financial institutions. These studies also argued that the barrier between formal and informal channels is not solid, and that the two channels somewhat merge. The outstanding debts can also be cleared by trading goods. IFT-brokers who are indebted to other IFTbrokers import goods at overvalued prices, or export goods at undervalued prices, in order to pay off their debts incurred through IFT-transactions. The outstanding liabilities can be also liquidated by way of IFT-brokers with liabilities purchasing services (e.g., travel, education, or medical services) or assets (e.g., stocks, bonds, or real estate) on behalf of IFT-brokers with claims. Although it may be a primitive method, cash couriers who transport bulk cash legally or illegally are mobilized to pay off the outstanding debts (El Qorchi et al., 2003; Schaeffer, 2008; Van de Bunt, 2008a).

\subsubsection{Attractiveness of IFT-systems}


The competitive advantages of IFT-systems over formal remittance channels draw remitters and satisfy their demands. Many studies on IFT-systems consider the fast, efficient, and low-threshold services of IFT-systems to be advantages for their customers over formal financial institutions 37 (Maimbo and Passas, 2005; El Qorchi et al., 2003; Hernandez-Coss, 2005b; Van de Bunt, 2008b). These advantages are mainly attributed to the absence of government control. IFT-systems outside of government supervision are quite flexible in providing their services. In particular, IFT-systems are competitive in terms of dealing with the small amounts of remittances (e.g., less than 200 USD) that IFT-users usually send (Maimbo et al., 2003; Passas, 2003). When transferring small remittance amounts, formal financial institutions typically charge flat fees of 10 to 15 USD per transfer (equivalent to 10 to 20 percent of a remittance of 200 USD). This is more expensive than via IFT-systems that charge 2 to 5 percent of the total remittance amount (El Qorchi et al., 2003; Freud and Spatafora, 2008; Houssein, 2005). A study (Passas, 2005 $\mathrm{C}^{38}$ ) suggests that some IFT-systems may charge higher fees than formal financial institutions when remittances are suspected to be involved in criminal activities. When it comes to the speed of transferring funds, IFT-systems can send remittances within 24 hours. Formal financial institutions, on the other hand, take about a week to transfer funds between major international cities. For instance, if the destination is a major international city, it takes 6 to 12 hours on average; if the recipient lives in a rural area of a developing country, IFT-brokers can complete their remittance transfer within 24 hours (Schaeffer, 2008). Some IFT-systems deliver remittances to the recipient' doorstep (Passas, 2006a). The inexpensive and swift service of IFT-systems is

37 The advantages of IFT-systems over formal remittance systems are consistent with the findings from studies on the informal economy: filling the void left by the formal economy, the informal economy provides opportunities, jobs, and often more efficient products/services than the formal economy generate alone (Webb et al., 2012).

38 According to Passas's study (2015c: 85) that analyzed the U.S. and U.K court cases regarding IFTsystems, "substantial differences in the commission or fees charged to ordinary clients as compared with select other customers who are charged a higher rate. The higher rate may reflect the understanding of a hawaladar that the money or transaction is not entirely legal. Due to the higher risk the hawaladar runs by facilitating such deals, the premium charged is expected to be higher. When hawala services are much more expensive than the alternatives, they should raise suspicions of illegality." 
— to some extent - associated with the small remittance amounts that IFT-brokers manage. Several studies (Maimbo, 2003; Thompson, 2006; Van de Bunt, 2008a), however, demonstrate that some IFT-brokers can transfer large sums of funds at short notice.

Some studies (Maimbo and Passas, 2005; El Qorchi et al., 2003) argue that some remitters choose IFT-systems, even though they can make use of formal financial institutions. This is mainly because IFT-systems are familiar to them. Technical jargon and complex procedures featured in formal financial institutions seem to deter remitters with language barriers. Several studies (Gibson et al., 2012; Zhan et al., 2009) on the relationship between immigrants 39 and financial inclusion demonstrate that financial literacy among immigrants and expatriate workers is low. However, IFTsystems are flexible in adapting their services to the demands and cultures of the areas in which they operate. Some IFT-systems cater to specific ethnic groups on the basis of personal networks. Some remitters use IFT-systems simply because their friends, relatives or compatriots operate IFT-systems (Maimbo and Passas, 2005). Some ethnic groups with little trust in formal institutions, including the banking sector, prefer IFTsystems to formal financial institutions for their remittance transfers (Osili and Paulson, 2008). IFT-systems have the advantage of accessibility over formal financial institutions in certain regions. Formal financial institutions have wider coverage than IFT-systems, specifically in sending countries. In fragile states, or in the rural areas of developing countries, few reliable formal financial institutions exist that can deal with cross-border payments (Passas, 2006a). IFT-systems do not need the infrastructure required for formal financial institutions. They therefore operate not only in unprofitable areas

39 Among various advantages of IFT-systems, it is challenging to distinguish advantages attractive to only immigrants from those for other customers of IFT-services. If immigrants in (remittance) sending countries are in legal status, technically they can make use of formal remittance systems; however, they are likely to opt for IFT-systems due to IFT-systems' remittance service quality, such as fast, inexpensive, and more accessible service. Illegal immigrants cannot help but rely on IFT-systems because of their immigration status; they enjoy IFT-systems' anonymous and secret services. 
where formal financial institutions are reluctant to open their branches ${ }^{40}$, but also in situations of political or economic crisis, such as civil wars, conflicts, or economic sanctions or blockages (Mambo and Passas, 2005).

The absence of government control has additional features: anonymity and secrecy. In transferring remittances via IFT-systems, senders are not requested to fill out remittance application forms. IFT-brokers do not need to check their customers' identities, to record transactions, and to make efforts to discover unusual transactions. Illegal migrants with no proper identification experience difficulties in accessing formal institutions for remittance transfers. However, as IFT-brokers do not require remitters to identify themselves, illegal migrants can send remittances to their home countries without worrying about being detected and deported by law enforcement authorities. The anonymity of IFT-systems is an attractive characteristic for prospective remitters who want to send funds without governments scrutiny, because IFT-systems leave few audit trails for law enforcement authorities (El Qorchi et al., 2003). Organized crime groups ${ }^{4^{1}}$ may make use of IFT-systems in order to elude investigations of law enforcement authorities into connections between their criminal activities and the proceeds that result from those activities. Businesses that intend to evade taxes also take advantage of the anonymity of IFT-systems, as it allows them to hide payment transactions related to their businesses, even though their proceeds do not originate from criminal activities (Maimbo and Passas, 2005). Because of their status outside of government control, IFT-systems also can provide services that formal financial institutions cannot. For instance, IFT-systems help remitters avoid governments control with regard to foreign exchange rates. In countries with fixed or managed

40 From the perspective of formal financial institutions, transferring of remittances is a minor function among the list of financial functions that they carry out at a local branch. They do not need to open local branches at unprofitable areas simply because there are some business demands for remittance transfers. 41 Despite the high probability that IFT-systems are abused for organized crimes, there are few empirical studies on the link between organized crimes and IFT-systems except for Van de Bunt and Soudijn's studies (Van de Bunt, 2008a; Soudijn, 2015). 
exchange rates, IFT-systems typically offer more favorable exchange rates than those offered by formal financial institutions (El Qorchi et al., 2003; Schaeffer, 2008).

Despite these advantages, IFT-systems have one major shortcoming: IFT-systems cannot provide a formal dispute resolution mechanism. Thus, before entering into and until completing - IFT-transactions, the actors involved rely heavily on mutual trust between IFT-users and IFT-brokers, and between IFT-brokers (Van de Bunt, 2008b). The trust and risk involved in IFT-activities are an important element in this study, because while trust between the actors involved makes IFT-transactions possible, the internal risks of deception and betrayal between them threaten the survival of IFTsystems, or at least render them fragile. Theoretical frameworks for IFT-activities, and trust and risk in IFT-systems, will be examined in Chapters 5 and 6.

\subsubsection{Utilization and prevalence of IFT-systems}

Despite various discussions about the use of IFT-systems, the main reasons for using IFT-systems are the transfer of remittances and money laundering (Todoroki et al., 2014). Some studies (Van de Bunt, 2008a; Thompson, 2008) have argued that IFTsystems are used either legitimately or illegitimately. They elaborate on this view by stating that a formal remittance via IFT-systems is referred to as the transfer of lawfully obtained funds via an unregistered fund transfer service entity, without any intent to support criminal purposes (e.g., tax evasion). However, there is no 'lawful' use of IFTsystems. The 'legality' of remittance activities is mainly determined by whether a remittance service provider is authorized. The FATF defines remittance transfers by unauthorized entities as illegal, and recommends that members take measures to ensure that money or value transfer services (MVTSs) are licensed or registered ${ }^{42}$. If an IFT-system registers with a government as a MVTS in accordance with relevant rules or regulations, the registered (or licensed) IFT-system will therefore no longer be an

42 MVTS was stipulated in Special Recommendation XI of the old FATF 49 Recommendations adopted in 2003 and it is now in Recommendation 14 of the new FATF 40 Recommendation adopted in 2012. 
'informal' fund transfer system. A study43 (Maimbo, 2004) raises a question about the illegality of an IFT-system where an 'unregistered' remittance operator in a sending (receiving) country works with either a 'registered' remittance operator in a receiving (sending) country or informal remittance fund operator in a receiving (sending) country that does not explicitly prohibit unauthorized remittance services. It is an issue of the requirements on foreign counterparts (FATF, 2013a). The illegality of IFT-systems is assessed in each jurisdiction. There is no question of the illegality of remittance transactions by unauthorized operators. Whether authorized remittance operators in sending countries are required to send funds to only registered or licensed remittance transmitters in receiving countries vary from country to country. According to the FATF's survey (2013a), most countries surveyed do not have such requirements.

The increased focus on IFT-systems stemmed largely from the likelihood of their involvement in money laundering and the financing of terrorist activities. This is due to their nature of informality, whereby anyone, including criminals, terrorists, and corrupt politicians, can move and launder their funds under the radar of state regulation (Thompson, 2008). There was a belief that IFT-brokers did not take the risk of accepting criminal clients, for fear of their businesses being detected and shut down by law enforcement authorities, but also because of limited financial capacity to transfer large amounts of criminal proceeds. However, more recent studies (Soudijn, 2015; Van de Bunt, 2008a) have demonstrated that IFT-systems are abused 44 to support various criminal activities, irrespective of the awareness of IFT-brokers regarding the origins of the funds to be transferred. In addition, some IFT-brokers do have the ability to handle large amounts of funds at short notice. Similar to formal financial institutions, IFTsystems can contribute to the placement and layering of funds in the money laundering

43 Maimbo (2014: 5) claimed that "the legal approach may not even be practical as informal transfers involves cross-border transactions between two jurisdictions and while it may not be illegal in one country, it may be so in the other country and this would be a bar on regulation".

44 Many scholars distinguish 'abuse' of IFT-systems from 'use' of them according to whether they serve criminal activities (Guiora and Field, 2007; Passas, 2005a). 
process ${ }^{45}$. IFT-systems can separate criminal proceeds from criminal activities, combine criminal proceeds with ordinary remittances, and transfer them overseas without physical transfers of money. This makes it difficult to link criminal proceeds to the associated activities. The susceptibility of IFT-systems to money laundering and the financing of terrorist activities - i.e., the likelihood of IFT-systems being used for these purposes - lies in the anonymity derived from the absence of government supervision. Unlike laundering criminal proceeds, funds to support terrorist activities are not necessarily sourced from criminal activities. Thus, terrorist financing focuses on concealing the identity of senders, rather than on separating funds from their origins (El Qorchi et al., 2003).

IFT-systems serve other types of illegal activities, such as evasion of taxes ${ }^{46}$ and avoidance of foreign exchange controls. Traders make payments via IFT-systems in order to evade customs duties, excises, and income taxes. Tax evasion via IFT-systems is generally coupled with misinvoicing. Importers request counterpart foreign exporters to under-invoice goods and submit undervalued declarations to customs (Passas and Maimbo, 2008). The differences between the actual prices and the invoiced ones are transferred from the importers to the foreign exporters via IFT-systems 47 (El Qorchi et al., 2003). IFT-systems can be used as a channel to circumvent controls on foreign exchanges, which tend to be imposed by the governments of countries facing a shortage of foreign exchange reserve. Businesses that need foreign exchanges (e.g., USD or euro) to import foreign goods, or to purchase foreign services, can make payments to IFTbrokers in sending countries. They make these payments in local currencies, instead of

45 Money laundering is conceptually comprised of the three stages: placement, layering, and integration (Reuter and Truman, 2004).

46 There used to be a view that as tax evasion differs from conventional criminal activities, it is not a predicate offence for money laundering (Busuioc, 2007). The FATF expanded the scope of money laundering predicate offences by including tax crimes in 2012. This study discusses the supporting role of IFT-systems for tax evasion separately from that for conventional money laundering, given that proceeds from tax evasion are somewhat different from those from conventional criminal activities.

47 A more detailed description of the modus operandi for tax evasion is provided in Chapter 6. 
purchasing foreign exchanges from formal financial institutions. IFT-brokers in receiving countries then pay out to exporters or sellers in foreign currencies (El Qorchi et al., 2003). Van de Bunt's study (2008b) uncovered that some IFT-brokers not only coordinate the transfer of funds across borders, but also become involved in settling illegal transactions, such as drug smuggling or human trafficking, by providing escrow or notary services.

Estimating the amount of funds transferred via IFT-systems is challenging, as IFT-transactions are illegal and cannot be formally recorded and reliably captured (El Qorchi et al., 2003; Schaeffer, 2008). Alternative attempts have been made to quantify the prevalence of IFT-transactions, even though such rough estimates are only indicative of the number of remittances via IFT-systems. El Qorchi and his colleagues at the IMF developed a simulated model to estimate the size and scope of global IFTtransactions. This was done on the basis of data on formal remittance transfers, and on parallel exchange rates in the illegal markets of 15 countries (El Qorchi et al., 2003). The model estimated that 10 to 35 billion USD was transferred via IFT-systems per annum between 1981 and 2000, and that IFT-transactions decreased 48 following the liberalization of financial systems (El Qorchi et al., 2003; Schaeffer, 2008). Studies on IFT-systems in Pakistan, the Philippines, Sudan, and Egypt suggest that the prevalence of IFT-transactions in these countries could be double or triple the amount of officially recorded remittances (Schaeffer, 2008). According to a study that estimates the prevalence of IFT-transactions in Saudi Arabia alone (Shehu, 2003), foreign workers are believed to transmit 150 billion USD through IFT-brokers per annum. These estimates

48 Most countries have strict regulations that govern their financial markets. Thus, it is challenging to establish a new financial business in the financial market (Komai and Richardson, 2011; World Bank and IMF, 2005). As cross-border remittance services involve foreign exchanges, financial supervision authorities tend to apply stricter regulations on the businesses. Thus, formal financial institutions that provide cross-border remittance services are limited. IFT-systems may have taken advantage of it. If financial supervision authorities liberalize the requirements for cross-border remittance services and allow new formal financial institutions that provide cross-border remittance services, the cross-border remittance market size on which IFT-systems can encroach dwindles and the number of IFT-systems in turn decreases. 
of the number of remittances via IFT-systems appear to be inconsistent. This does not mean that the estimates are not valuable, but it does suggest that there is still a long way to go in understanding and tackling IFT-systems. As these estimates are based on simplified assumptions regarding the remittance market, they should be interpreted with caution.

\subsection{Assessment of legitimacy of remittance systems}

Although IFT-systems are illegal in most countries, many scholars are reluctant to call IFT-systems 'illegal' fund transfer systems. Some countries are trying hard to tackle IFT-systems, others simply ignore their existence or impact. Taking joint action against IFT-systems is a bigger challenge than expected. This symbolizes the unstable or ambiguous conceptual delineation of IFT-systems. How IFT-systems are regarded in terms of legitimacy - whether they are perceived as a crime or a punishable offence, aside from their mere illegality — is an essential question to be answered in clarifying the conceptual delineation of IFT-systems and developing policies concerning IFTsystems. In other words, whether perceiving IFT-activities as a criminal offence is a matter of assessing the legitimacy of IFT-systems. Various views on conception of crime would benefit the assessment of the legitimacy of IFT-systems in comparison with other types of cross-border moves of funds.

\subsubsection{Views on conception of crime}

Regardless of whether remittance sources are legal or not, the legitimacy of remittance transfers is first determined by the nature of a channel that processes remittances - i.e., whether it is authorized. However, some scholars do not believe that the fact that IFT-systems are classified as illegal necessarily means that IFT-systems are (considered to be) illegitimate. They were reluctant to characterize the remittance transfers of expatriate workers via unauthorized remittance systems as 'criminal'. This is because they construed that remittance transfer services are not inherently illegal, and their illegality is not incurred from criminal activities (Cross and Pena, 2006). Thus, 
there is confusion about the legitimacy of remittance transfer activities. It is therefore not clear whether or not remittance transferring services provided by unauthorized entities should constitute a criminal offence.

There is little agreement among criminologists about what constitutes a crime. Although many legal scholars and criminologists have discussed why - and how - a certain social activity is criminalized, deciding on what constitutes a crime is not as obvious as it seems. What some might consider deviance or shrewd business, may be considered a criminal act by others. Since the eighteenth century, crime has been legally defined as 'acts prohibited by criminal law to punish' (Lanier and Henry, 2010). Criminal law specified the acts or omissions that constitute a crime. Many criminologists traditionally relied on such a legal definition in their studies, believing that the debate about the definition of a crime is settled in favor of a legal definition (Lynch et al., 2015). However, some criminologists have argued that since the legal definition is too narrow to take into account harms 49 that are addressed by administrative law, the definition should be extended to include all offenses that are socially injurious (Lanier and Henry, 2010). They also argue that because what is legally considered a crime varies from country to country, and changes over time. In addition, all definitions are value laden and biased to some degree (Lacey and Zedner, 2012). Thus, whether someone is harmed is not an established answer to the question of what constitutes a crime. Nor does the law answer the question of what constitutes a crime. The question of relativity in defining crime relates to the way crime is defined, and who defines the types of behavior that are labeled as crime. From a jurisprudential perspective, crime is created by societies that enact laws. Social reaction theorists, who focus on the actual process of labeling certain actions as crime, argue that societies define deviance, or crime, by

49 In criminal law, harm is normally defined in a narrow sense - the violation of a legally protected interest (Kleinig, 1978). Harm is considered a dimension to determine seriousness of crime, referring to "the injury done or risked by the act" (Von Hirsch and Jareborg, 1991: 2). There is a view that criminable harm is "not to be determined solely by reference to the impairment of the welfare interests of assignable individuals, but also by having regard to the social consequences of acts" (Kleinig, 1978: 36). Some critical criminologists attend to social harm, claiming that conventional concept of crime include many petty events but exclude many serious harm (Hillyard and Tombs, 2007). 
proclaiming (either formally or informally) that certain human behaviors are 'bad' and 'punishable' (Grattet, 2011; Henry, 2009; Vold et al., 2002). According to Becker (1963: 9), deviance is defined as "not a quality of the act the person commits, but rather a consequence of the application by others of rules and sanctions to the offender."

The process of defining crime involves two perspectives, depending on whose interests are at play in the process: consensus and conflict perspectives. Consensus perspective deems that since a society shares a collective morality, acts that shock the common conscience and produce intense moral outrage in people, are defined as a criminal act. Supporters of this position claim that there is a consensus among most people about what acts are unacceptable and should be labeled a criminal act. However, conflict perspective is based on the notion that rather than being similar, people are different and struggle over their differences. The conflict over different interests leads to differing conceptions of crime. The official definitions of crime are determined by the group in power, and are used to protect its interests and consolidate its power. Powerless groups are generally the victims of oppressive laws (Milovanovic and Henry, 2001). Thus, crime is defined as behavior of those who threaten the interests of the powerful. The crimes of street offenders are considered serious, whereas those from white-collar offenders are considered less serious, even though the financial loss that results from white-collar crime is much greater than the financial loss associated with street crime (Vold et al., 2002).

\subsubsection{Views on legitimacy of IFT-systems}

The two perspectives related to the process of defining crime engender several integrated approaches to the conception of crime.

Felson (2006) provides a useful dual lens scope - legality and acceptance which produces four blends: legal and acceptable, legal but disliked, illegal but tolerated, and illegal and despised. When his perspective on the conception of crime is applied to remittance activities, which include not only the transfer of the remittances of 
expatriate workers and criminal proceeds via IFT-systems, but also the transfer of capital flight via formal channels (Arezki et al, 2013; Johannesen and Pirttila, 2016), it can provide a view as to how different types of remittance activities are likely to be construed by society. According to his framework, remittance transfers via formal financial institutions are obviously legal and acceptable. The transfer of expatriate workers' remittances via IFT-systems can be deemed illegal, but tolerable in some countries. This view is confirmed by the fact that many scholars are reluctant to criminalize IFT-transactions, and given that IFT-systems operate in an overt manner in some countries (Passas and Maimbo, 2008).

Table 2.1: Perceptions of remittance activities

\begin{tabular}{c|l}
\hline \multicolumn{1}{c|}{ Type } & \multicolumn{1}{c}{ Example } \\
\hline Legal and acceptable & Formal remittances \\
\hline Legal but disliked & Capital flight via formal remittance channels in least developed countries \\
\hline Illegal but tolerable & Expat workers' remittance transfers via IFT-systems \\
\hline Illegal but despised & Transfers of criminal proceeds via IFT-systems \\
\hline
\end{tabular}

Source: Felson, 2006; Han et al., 2015

Another perspective applicable to the nuanced aspects of IFT-systems is to make a distinction between legality and legitimacy, thereby acknowledging that there exist illegal yet legitimate economic activities. According to scholars supporting this perspective (Castells and Portes, 1989; Godfrey, 2011; Webb et al., 2009), a society is comprised of groups with different norms, values, and beliefs, thereby having different opinions about what is socially acceptable. When one group's norms, values, and beliefs become the basis of laws and regulations in a society, other groups with different norms, values, and beliefs may disagree about what is socially acceptable with respect to salient issues (Scott, 1995). Because of these differences, a gap often exists between what some groups understand to be legal - as specified by laws and regulations - and what they 
consider to be legitimate $5^{0}$ - as specified by norms, values, and beliefs. The gap between what is legal in a given society and what some groups consider to be legitimate in that same society, is a basis for an informal economy ${ }^{51}$ to emerge. Portes and Haller (2005) characterize the informal economy as a constructed response by civil society to unwanted interference by the state.

Webb and his colleagues (2009) address the informal economy in a more systematic manner. They divide the overall economic system into three categories: formal economies, renegade economies, and informal economies. This division is made according to the way in which both formal and informal ${ }^{22}$ institutions assess economic opportunities or activities in terms of social acceptability. According to these scholars, informal economies exist where the assessments of formal and informal institutions about economic opportunities or activities do not match. Formal and renegade economies, on the other hand, are based on congruent assessments of those institutions. In other words, the formal economy comprises 'the set of legal and legitimate' economic opportunities or activities that both formal and informal institutions deem socially acceptable. The renegade economy is made up of 'illegal and illegitimate' economic opportunities or activities that both institutions deem socially unacceptable (e.g., drug cartels). The informal economy refers to the set of illegal economic opportunities or activities that fail to comply with the established institutional rules, or are denied their protection, yet are not 'antisocial in intent', thereby remaining acceptable or legitimate

50 Legitimacy refers to "a generalized perception or assumption that the actions of an entity are desirable, proper, or appropriate within some socially constructed system of norms, values, beliefs, and definitions" (Suchman, 1995: 574).

51 Economic anthropologist Keith Hart, coined the term informal economy in 1990 after observing popular entrepreneurial activities in Africa which were at odds with wisdom received from the western discourse on economic development (Portes and Haller, 2005).

52 According to North (1990: 97), institutions are "the humanly devised constrains that structure political economic and social interaction" and consist of formal and informal institutions. Formal institutions refer to laws, regulations, and their supporting apparatuses (e.g., enforcement agencies and regulatory bodies). Informal institutions refer to norms, values, and beliefs that define socially acceptable behavior (Webb et al., 2009). 
to many individuals within society (Feige, 1990; Webb et al., 2012). Some businesses engage in the informal economy because certain factors keep them from participating in the formal economy. Others who are allowed to enter the formal economy choose to participate in the informal economy. Among them, some businesses proactively try to take advantage of institutional incongruence and weak enforcement of the laws and regulations of formal institutions in order to exploit opportunities in the informal economy (Ashforth and Mael, 1989; Polletta and Jasper, 2001; Webb et al., 2009).

The perspective of the distinction between legality and legitimacy appears to be simple, but it has significant implications for understanding the survival and prosperity of IFT-systems in the current world. There is little doubt that IFT-systems are illegal. However, according to scholars who support the concept of the informal economy, IFTsystems may be socially acceptable unless they engage in money laundering and the financing of terrorism (Feige, 1990; Fernandez-Kelly, 2006). They argued that most unregistered remittance services primarily accommodate non-criminal businesses, such as transferring the remittances of expatriate workers to their home countries. However, there is a counterargument that it is nearly impossible for IFT-brokers to stick to 'clean' remittances, and to separate criminal proceeds from the funds that they take before transferring them to partner IFT-brokers. Nearly all governments also have policies to bring IFT-systems into the legal domain by registering IFT-brokers as MVTSs. However, many IFT-brokers ${ }^{53}$ seem to refuse to comply with such policies (FATF, 2013a). This is not only because it is challenging for most small IFT-brokers to meet the requirements to become legal MVTSs, but also because they are reluctant to become subjected to governments supervision. Many IFT-brokers, in particular those who operate in ethnic enclaves, therefore opt to remain unregistered, even if this exposes them to the risk of government suppression, because they can take advantage of the limited understanding and lax attitude of governments towards IFT-systems, and weak enforcement of laws

53 The extent to which IFT-systems' responses to the formalization of the remittance markets vary from country to country (Todoroki et al., 2014). When the U.A.E government introduced the registration regime to formalize its remittance market in 2002, 124 IFT-brokers registered with in the U.A.E. government (Al-Hamiz, 2005). 
and regulations ${ }^{54}$ (FATF, 2013a). IFT-systems have survived by taking advantage of the incongruent views - of governments and some groups of people - regarding the roles and ramifications of IFT-systems. However, given that there is no way to monitor whether IFT-systems engage in money laundering activities, construing IFT-systems as socially acceptable may be a lenient (or indiscriminate) approach to IFT-systems.

The perspectives on the conception of crime can also benefit the conceptual delineation of IFT-systems, as they can shed light on IFT-systems, using different dimensions for the conception of crime. Hagan (1985), with his notion of crime and deviance as 'a continuous variable', addressed the definition of crime from three dimensions: agreement about the norm, evaluation of social harm, and severity of societal response. The first dimension in defining crime, the degree of consensus or agreement about the wrongfulness of an act, can range from confusion and apathy, through levels of disagreement to conditions of general agreement. The second dimension is the relative seriousness of an act based on the harm it causes. Hagan's third dimension is the severity of society's response in law, which ranges from social avoidance or an official warning, through fines and imprisonment to the death penalty. For instance, while some acts, such as gambling, drug use, and prostitution, are victimless crimes or consensual crimes that do not harm anyone other than the participants in such crimes (Veneziano and Veneziano, 1993), hijacking a plane and crashing it into a building involves serious harm. Hagan (1985) assessed crimes with his pyramid of crime that integrates these three dimensions, in order to explain societal responses to different types of crimes. However, it provides a limited explanation for

54 Weak enforcement of formal institutions is a precursor of the emergence and development of the informal economy. Enforcement entails substantial costs as the number and complexity of laws and regulations increase. To enforce laws and regulations effectively, the costs may possibly exceed value expected by formal institutions (Webb et al., 2009). Businesses thus exploit opportunities in the informal economy by taking advantage of the imperfect enforcement of laws and regulations. For instance, a significant portion of enforcement tends to concentrate on prominent businesses' activities. Targeted enforcement increases awareness of violations and is viewed as an effective method of setting an example for other businesses that do not comply with formal institutions. However, targeted enforcement also leaves small businesses' illegal activities undeterred (Webb et al., 2009). 
less visible crime (Lanier and Henry, 2010). When Hagan's pyramid of crime is used to assess remittance activities, it hardly explains the societal responses to most illegal remittance activities, which are rarely exposed to the general public.

Henry and Lanier (1998) improved Hagan's pyramid of crime by adding three additional dimensions: the visibility of harm, the degree of victimization, and the likelihood of societal responses. They looked at the phenomena in which many people are victimized without being aware of their victimization for a long period of time (e.g., environmental crimes and corporate crimes). Lanier and Henry (2010) also underscored the importance of the number of victims - or the degree of harm - in the conception of crime. They argued that the likelihood that a convicted offender is punished with a serious penalty should be taken into account when determining the conception of crime. This is because the crimes of the powerless are more likely to be punished with severe sentences (e.g., bank robbers who are sentenced to 7 to 8 years' imprisonment) than are those of the powerful (e.g., those sentenced to 2 to 4 years' imprisonment for savings and loan scandals) (Lanier and Henry, 2010). The authors called their model 'crime prism', given that their six dimensions in the conception of crime can be represented in six lines of a prism. The crime prism is created by putting together two pyramids of crime. The upper pyramid represents the highly visible crimes that are typically committed by the powerless. The lower inverted pyramid represents less visible crimes, which include a variety of crimes of the powerful, such as offenses by political elites, corporations, and organizations (Lanier and Henry, 2010).

When deviant acts are obvious, highly visible, and extremely harmful, societal responses to these types of crimes are immediate and serious; punishments are severe. These acts normally constitute violent crimes, traditionally called mala in se, such as homicide and rape. Although a relatively small number of people are harmed by such acts, societal responses are severe and involve little controversy. Some deviant acts, such as public drunkenness and urinating in public, are relatively harmless and involve a lack of consensus about their criminal status. They rarely lead to a formal law enforcement response. The lower part of the crime prism encompasses mala prohibita 
crimes, which are created by legislative action. As mala prohibita crimes depend on social, ecological, and temporal contexts, these acts (e.g., prostitution or the use of marijuana) may be criminal in one society, but not criminal in another. Societal responses to such acts tend to be mild. Some crimes (e.g., toxic discharge into rivers) at the lower part of the crime prism hurt many people over an extended period of time in an indirect and hidden manner. The impact of these crimes is diffused and challenging to identify. Law enforcement authorities are rarely sufficiently equipped to tackle them. In sum, the crime prism presents a conceptual framework for analyzing crimes from different angles. The advantage of the crime prism is that it can shed light on less visible crimes, such as white-collar crime, and to draw attention to the fact that the conceptions of crimes are context-embedded (Lanier and Henry, 2010).

Henry and Lanier's crime prism therefore provides a useful explanation as to why the illegitimacy of IFT-systems is often questioned, even though IFT-systems are prohibited in many countries. IFT-activities are normally carried out in a covert manner, although some IFT-systems overtly advertise their activities in some countries. As discussed earlier, the harm of IFT-systems to ordinary people is limited; they rarely inflict direct damage on victims. The majority of people who have little difficulty accessing formal financial institutions for remittance transfers are not interested in financial inclusion for expatriate workers. The interests of formal financial institutions may be adversely affected by IFT-systems. However, given that contemporary IFTsystems prosper in developing countries - where formal financial institutions struggle to reach every nook and cranny, the damage to formal financial institutions from IFTsystems may be limited and negligible (Freund and Spatafora, 2005; Hernández-Coss, 2005). Societal measures against IFT-systems are therefore usually mild and focused on administrative sanctions rather than criminal punishments ${ }^{55}$. However, if IFT-systems

55 The U.S. Criminal Code (18. U.S. §1960) stipulates that "whoever conducts, controls, manages, supervises, directs, or owns all or part of a business, knowing the business is an illegal money transmitting business shall be fined in accordance with this title or imprisoned not more than 5 years or both." In the Netherlands, De Nederlandsche Bank N.V. (DNB) is authorized to impose (max. 4 million euro) and to issue a cease and desist order to stop IFT-activities (FATF, 2016). In Korea, the Foreign Exchange 
deal with criminal proceeds and are used to finance terrorism, this is a different story. The involvement of IFT-systems in laundering criminal proceeds and financing terrorism can only be intercepted through the sources of funds and through the intentions of the remitters. Formal financial institutions in most countries must comply with AML/CFT rules and regulations, and are subject to rigorous examinations by their governments. IFT-systems are not subject to government supervision, and are therefore susceptible to exploitation by criminal syndicates for money laundering and terrorist financing purposes. The worst-case scenario is that the prosperity of unsupervised IFTsystems hinders the development of formal financial institutions, or disrupts the financial sector and makes crime proliferate. In other words, the impact of IFT-systems to society may not be direct, immediate, and visible, but they inflict harm on society in an indirect, slow and hidden manner. The evidence for this is that until the $9 / 11$ attacks, little attention had been paid to IFT-systems. In short, given that they operate outside of government supervision, there are few reasons for IFT-brokers to refrain from engaging in money laundering and the financing of terrorism. In addition, since the main feature of IFT-systems is cross-border enterprising, their negative effects are not limited to a specific society, but always involve multiple countries. Thus, despite their limited visibility and less obvious harm to society, their impact should not be overlooked. The global AML/CFT community has assessed IFT-systems as illegal and illegitimate, and characterizes IFT-transactions as criminal, thereby seeking to develop AML/CFT measures to control IFT-systems. IFT-activities should therefore be placed in the lower part of Henry and Lanier's crime prism.

\subsection{Perception, government approach, and law enforcement in relation to IFT- systems in Korea}

Transactions Act stipulates that while an IFT broker can be sentenced up to 3-year imprisonment or 300,00o USD fine, an IFT user can be sentenced up to 100,00o USD administrative fine. In practice, most IFT-brokers detected are imposed fines rather than imprisonment. 
Following the discussion of how IFT-systems can be understood in the general criminological sense, this study examines how IFT-systems are assessed in Korea, as the conception of crime is context-embedded (Lanier and Henry, 2010). This is mainly because the perception of IFT-systems in Korea underpins the legitimacy assessment of IFT-systems in Korea, and benefits the local analysis in Chapters 5 and 6 which focuses on the interactions between the actors in IFT-systems in Korea. The legality of IFTsystems is normally examined through the analysis of legal texts regarding IFT-systems and law enforcement instruments related to IFT-systems. This study assesses the legitimacy of IFT-systems in Korea not only by analyzing the rules and regulations governing IFT-systems, but also examining the attitude of Korean law enforcement officials towards IFT-systems ${ }^{56}$.

The analysis of legal texts related to IFT-systems demonstrates that IFT-systems are illegal in Korea, as monetary transactions with foreign countries can only be carried out by actors authorized by the central government, in accordance with the Foreign Exchange Transactions Act ${ }^{57}$. To become an authorized actor who is entitled to carry out foreign exchange transactions, it is required to: have a certain amount of seed capital

56 The legitimacy of IFT-systems can be measured with various actors' attitudes towards IFT-systems, such as formal financial institutions, IFT-brokers, IFT-users, law enforcement authorities, and even the general public. Whereas the attitudes of IFT-brokers and IFT-users may be most lenient, formal financial institutions as competitors of IFT-systems may be most strict. Researchers normally seek to gauge societal attitudes towards certain types of crimes via the general public's perception of them, based on the assumption that the general public is a potential victim of them. However, as mentioned earlier, in countries with a high level of access to formal financial institutions, most lay persons have nothing to do with IFT-systems. Most of them may not have proper knowledge of IFT-systems and may be indifferent to IFT-activities. As informed and capable agent of the general public, law enforcement officers can play a role in capturing societal attitude towards IFT-activities.

57 The Foreign Exchange Transactions Act stipulates that an actor who intends to run a foreign exchange business shall possess sufficient capital, facilities, and experts and register with Minister of Economy and Finance (MoEF) except for financial institutions that MoEF allows not to do so, considering the business contents (Article 8 (1)); foreign exchange businesses shall be run only by financial institutions, and their foreign exchange businesses shall be confined to those directly associated with their financial businesses (Article 8 (2)); and despite Article 8 (1) and Article 8 (2), an actor other than an financial institution who seeks to run a foreign exchange business (called a money exchanger) shall possess capital, facilities, and experts that Presidential Directive requires and shall register with MoEF (Article 8 (3)). 
( 2 million USD); be equipped with computerized systems connected to the central bank of Korea; and employ a minimum number of foreign exchange experts (two employees with more than two years of experience in foreign exchange transactions ${ }^{8}$ ). Thus, authorized actors who meet such requirements for foreign exchange transaction businesses in Korea are only formal financial institutions. The foreign exchange transactions of unauthorized actors - IFT-transactions - are illegal, and actors involved in IFT-transactions are subject to punishment59.

In gauging the attitudes of Korean law enforcement officials towards IFT-systems, this study focuses on KCS investigators, given the likelihood that they have encountered and investigated IFT-systems and their expertise in IFT-systems. Law enforcement authorities $^{60}$ in charge of intercepting IFT-systems and IFT-transactions in Korea are

58 The Enforcement Decree of the Foreign Exchange Transactions Act stipulates that an actor who intends to run a foreign exchange business shall fulfill following requirements: (i) the proper amount of capital and financial structure meeting the financial solvency guidelines set by the Financial Services Commission, (ii) computerized system dealing with foreign exchange transactions, (iii) connection of the computerized system to the Bank of Korea, and (iv) two employees with more than two years of experience in foreign exchange transactions (Article 13(1)).

59 The Foreign Exchange Transactions Act stipulates that as for an actor who is illegally registered with MoEF, violating Article 8 (1) and Article 8 (3), MoEF can revoke its registration or suspend its foreign exchange businesses for 6 months (Article 12 (1)); an actor who is not registered with or is illegally registered with MoEF, violating Article 8 (1) and Article 8 (3), can be sentenced up to 3-year imprisonment or 300,00o USD fine (Article 27-2).

6o Law enforcement authorities tasked with the fight against IFT-systems may differ from country to country. In some countries, the police alone tackle IFT-systems. In other countries, non-police authorities, such as customs or financial supervisory authority, join the fight. In law enforcement, statutory ambits and actual enforcement can be decoupled. It is necessary to discern the statutory ambits and actual enforcement activities of law enforcement authorities tasked with tackling IFT-systems. 
the Korea National Police Agency (KNPA) ${ }^{61}$ and the $\mathrm{KCS}^{62}$. The Bank of Korea - the central bank of Korea - and the Korea Financial Intelligence Unit (KoFIU) play an important but supportive role in the fight against IFT-systems. The Bank of Korea collects all information regarding foreign exchange transactions and relays it to the law enforcement authorities either directly or via the KoFIU. The KoFIU - like all other FIUs in the world - collects not only suspicious transaction reports ${ }^{63}$, but also currency transaction reports from formal financial institutions, and forwards them to the law enforcement authorities. As for the two law enforcement authorities, it is not known how much police manpower the KNPA deploys to combat IFT-activities. The KCS does not have a specialized unit to tackle IFT-systems either. According to the KCS officials interviewed, the KCS use approximately $10 \%$ (i.e., 500 officers) of its total manpower for criminal investigations. $18 \%$ (i.e., 90) of its investigators are tasked with investigating money laundering, including IFT-systems. There are no official data on the contributions of the police agency and the customs administration to the fight against IFT-systems. According to the interviewed KoFIU officials ${ }^{64}$, the KCS is responsible for

61 There is a difference in statutory ambit between the two law enforcement authorities in the fight against IFT-systems. The national police's ambit for the fight against IFT-systems includes not only transferring funds for investment and trade payments, but also simple remittances. The investigation of the customs administration is confined to IFT-systems related to cross-border trade. That is because customs are tasked with dealing with cross-border trade transactions. However, it has been known that there are few specialist IFT-brokers who only deal with funds related to cross-border trade. Most of IFTbrokers do not mind why IFT-users transfer funds across borders and do not seek to discern the sources of funds to transfer. Thus, most IFT-brokers are somehow involved in transferring funds for cross-border trade.

62 The customs administration is tasked with the examination and investigation of IFT-systems by the Foreign Exchange Transactions Act. The national police agency does not need specific delegation of authority for investigation of IFT-systems as the national police agency is a 'general' criminal investigation authority according to Criminal Procedure Act.

63 Suspicious transaction reports are often called suspicious activity reports in some countries (e.g., the UK and the US).

64 The KoFIU is at a vantage point to monitor law enforcement authorities' investigative performance against money laundering. This study asked the KoFIU officials about each law enforcement agency's performance in the fight against IFT-systems. The detailed interview structure including semi-structured questionnaires was discussed later. 
50 to 60 percent of investigations into IFT-systems in Korea ${ }^{65}$, although there have been some differences in this ratio over the years. Since IFT-transactions are in fact crossborder financial transactions, the customs administration, which oversees financial transactions related to cross-border trade, outperforms the police, which normally focuses on dealing with local crimes.

Gaining insight into the Korean government's approach towards IFT-systems cannot be achieved solely through an analysis of the regulations in the books, including the governmental instrumentality tasked with tackling IFT-systems. Policy is often decoupled from practice (Tilcsik, 2010). Drawing on Henry and Lanier's crime prism, this study examined the government's perception of IFT-systems by interviewing customs investigators and KoFIU officials (Appendices 6 and 7; the detailed method will be unfolded in Chapter 3). The aim was to gauge the perceived legitimacy of IFTsystems in Korea and to examine the Korean government's response to IFT-systems. The legitimacy of IFT-systems involves several stakeholders, including IFT-brokers, formal financial institutions, traders, expatriate workers, financial regulatory authorities, law enforcement authorities, and the general public. Expatriate workers and traders may be adherents of IFT-systems, whereas formal financial institutions have clear objections to IFT-systems. The general public may not be interested in IFTsystems, as most people in Korea experience few difficulties in accessing formal financial institutions. In addition, IFT-systems do not harm their interests. Government

65 Despite the KCS's great contribution to investigations of IFT-systems, there seems to be a view that this study may involve selection bias as IFT-cases investigated by the customs administration may be different from those by the police and this study did not include the police's investigations of IFT-systems. In order to resolve the concern about selection bias with respect to IFT-systems, it is important to prove that IFT-brokers handle a wide spectrum of funds and transfer a large amount of funds at once. IFTbrokers who can manage (large amounts of) trade payments normally deal with (small amounts of) remittances as well. According to a KoFIU police official interviewed, the police agency's main interest with respect to AML is not in IFT-systems unless they are involved in major crimes, such as organized crimes or drug trafficking. He told that IFT-systems that the police investigated were barely associated with organized crimes or drug trafficking and most of them dealt with expat workers' remittances to their home countries. Thus, the IFT-case reports from the police rather may miss important features of IFTbrokers who are normally subject to the customs administration. 
authorities, which reflect social values and public opinion (Burstein, 2003; Croley, 2008; Fernández-Gutiérrez and Van de Walle, 2019), may be better informed and less biased towards a particular interest regarding concerns about IFT-systems. Government officials do not necessarily adhere to regulations on the books and the status quo (Manning et al., 2000; Passas, 2005b; Shinar, 2013). Thus, among other factors, the perception of IFT-systems by authorized officials may work as a useful way of assessing the legitimacy of IFT-systems.

The legitimacy of IFT-systems can initially be assessed on the basis of the perceptions of the social harm inflicted by IFT-systems, including the degree of victimization, according to Henry and Lanier's crime prism. Most of the interviewed investigators stated that as IFT-systems are susceptible to illegal activities, such as money laundering, it is reasonable to treat them as illegal. Some officers observed that the illegality of IFT-systems may relate to the risk that IFT-systems undermine the integrity of formal financial institutions. Some questions were also asked regarding the level of punishment for - and decriminalization of - IFT-systems. In the question regarding the dimension of severity of societal responses, none of the interviewed investigators argued that the punishment level should be lowered. The majority of officers responded that the current level of punishment ${ }^{66}$ for IFT-systems and IFTtransactions is adequate, and should remain as it is. When asking a question about the dimension of (social) agreement on norms in the crime prism was asked, none of the investigators agreed on the idea that IFT-systems should be decriminalized immediately. This reason for this is that, according to them, the harm that these systems inflict on society is not negligible. However, about half of the interviewees predicted that decriminalization of IFT-systems may be possible in the future, if proper monitoring systems on IFT-systems are put into place. The other half of the officers disapproved of the future decriminalization of IFT-systems. As for the scope of investigations of IFT-

66 According to the KoFIU officials and the KCS investigators interviewed, IFT-brokers are normally sentenced to criminal fines, not administrative fines. Even though it is rare, IFT-brokers who deal with a large amount of remittances (e.g., 10 billion USD) are sentenced to imprisonment. 
systems, which relates to the dimension of the likelihood of specific societal responses in the crime prism, two-thirds of the investigators argued that as IFT-systems per se are illegal, the actors involved should be investigated and prosecuted regardless of their involvement in predicate crimes. Examples of such crimes include drug trafficking and tax evasion. One third of the investigators expressed the view that IFT-systems should be investigated only when they are involved in predicate crimes. In short, according to Henry and Lanier's crime prism, the extent of the social harm or victimization caused by IFT-systems in Korea is not considered negligible, even though the social harm caused by IFT-systems may not be clearly visible. There seems to be little objection to maintaining the criminalization of IFT-systems. Overall, the severity and likelihood of societal responses to IFT-systems can also be perceived as adequate. Therefore, given the views of the investigators on IFT-systems, these systems appear to be treated as illegal and illegitimate by Korean law enforcement and customs authorities. Studies on IFT-systems in Korea (Lee, 2017; Shah, 2018) shows that ethnic minority workers in Korea also perceive that IFT-systems are illegal and unacceptable in Korea, even though they opt for hundi over formal remittance channels to send funds to their home countries.

\subsection{Summary and reflection}

This chapter addressed the two main issues that have been somewhat neglected in previous studies on IFT-systems: the relationships between formal remittance systems and IFT-systems, and the conceptual delineation of IFT-systems. These two issues are a prerequisite for an in-depth understanding of the working mechanisms of IFT-systems, and for the global and local analyses of IFT-systems.

The comparison between formal remittance systems and IFT-systems arose from the idea that formal financial institutions may have little - if any - connection to IFTsystems. However, IFT-systems should be examined in parallel with formal remittance systems given their historical background, roles, and their users. The basic mechanism of IFT-systems is analogous to that of formal remittance systems. In the remittance 
market, IFT-systems are in competition with formal remittance systems. Many remitters make decisions on how to transfer their funds, for instance, by comparing the services of formal remittance systems with IFT-systems. The comparison between the two remittance channels has provided a foundation for the analysis of IFT-systems within the remittance market. This approach is linked with a theoretical framework focused on illegal markets in Chapter 5 .

IFT-systems involve two distinctive perspectives in terms of their conceptual delineation. While adopting the FATF Recommendations, most countries treat unregistered (or unlicensed) IFT-systems as 'illegal'. Many economists share the view that IFT-systems dealing with expatriate workers' remittances, albeit unregistered, are 'legitimate' (El Qorchi, 2002; Hernandez-Coss and Bun, 2007; Malit et al., 2017). They are therefore reluctant to call IFT-systems 'illegal' fund transfer systems. Their view is based on the notion that legality and legitimacy should be distinguished from each other. According to this view, some IFT-systems that only remit expatriate workers' remittances may be deemed legitimate, whereas IFT-systems that participate in money laundering and terrorist financing should be defined as illegitimate. However, it may be challenging to distinguish IFT-systems that deal with criminal proceeds from those that are protected against such activities without first investigating them. Therefore, caution should be exercised in labeling IFT-systems as legitimate or illegitimate, without disclosing the sources of funds and without considering other social and economic factors, such as access to formal remittance systems. Generally speaking, in urban areas of developed countries with high level of access to formal remittance systems, IFT-systems may be viewed as illegal and illegitimate, whereas in rural areas or fragile countries with limited access to formal remittance systems, IFT-systems may be viewed as illegal yet legitimate (Passas and Maimbo, 2008). Nevertheless, the conflicting views on IFT-systems - and the unstable and ambiguous conceptual delineation of IFT-systems - seemed to confuse policymakers about the nature of IFTsystems - and hamper the development of effective measures against IFT-systems. 
In order to assess the legitimacy and clarify the conceptual delineation of IFTsystems, several perspectives have been explored in this study. Among them, drawing on Henry and Lanier's crime prism, this study has assessed the legitimacy of IFT-systems in Korea. In assessing its legitimacy, this study has taken into account customs investigators' perceptions of IFT-systems. According to them, the victimization incurred from IFT-systems in Korea is not clearly visible; however, the extent of the resulting social harm is not negligible. The idea of decriminalization of IFT-systems did not appeal to them. They expressed the opinion that the level of punishment for IFTsystems is adequate. By examining the Korean government's rules regarding IFTsystems and the attitude of law enforcement officers towards them, this study has demonstrated that IFT-systems in Korea are illegal, but are also considered illegitimate. The discussion on the legitimacy and conceptualization of the phenomenon in this chapter has provided a basis for empirical research into the survival and adaptation of IFT-systems. In the next chapter, the methodology of this empirical research will be clarified. 


\section{Research Design and Data}

\subsection{Introduction}

As discussed in Chapter 1, this study aimed to examine the survival and adaptation of IFT-systems in a globally connected world, where formal financial institutions operate in extensive and thick networks for cross-border fund transfers (Manyika et al., 2016). Within the context of this overarching objective, this study has specifically sought to answer the two research sub-questions; the first being how much - or to what extent - IFT-systems (are likely to) thrive across the world despite the 'external risks', and the second, how IFT-transactions are carried out despite the 'internal risks' associated with them. The first sub-question regarding the global landscape of IFT-risk, which represents the susceptibility of each country to IFT-systems, required descriptive research. The second sub-question regarding the adaptation of IFT-systems to the internal risks, which deals with the relationship between the survival of IFT-systems and coping mechanisms among the actors against risks associated with trust, has been addressed through explanatory research.

\subsection{Research designs}

There are several types of research designs ${ }^{67}$. Taking into account not only the research questions, but also the availability of data ${ }^{68}$, this study adopted two separate designs: a cross-sectional design for the first sub-question and a case study design for the second sub-question. A cross-sectional design refers to the collection of data at a

\footnotetext{
67 Creswell (2009) presents three types of research designs (i.e., quantitative, qualitative, and mixed methods). De Vaus (2001) contends that there are four types of research designs (i.e., experiment, case study, longitudinal design, and cross-sectional design) and a particular research design is not necessarily associated with a certain approach or research method. For instance, case studies do not need to be automatically associated with participant observation, or cross-sectional designs are not necessarily linked to survey methods. This study has adopted De Vaus's classification of research design types.

68 Data availability is discussed in detail with respect to data collection.
} 
fixed point in time and is often used for population-based surveys or exploratory and descriptive studies (Maxfield and Babbie, 2004). A cross-sectional design is thus suitable for capturing and describing the patterns of IFT-risks between countries. Case studies $^{69}$ have the merit of being able to investigate "a contemporary phenomenon within its real-life context, especially when the boundaries between phenomenon and context are not clearly evident" (Yin, 2003: 13). A case study design can thus facilitate the analysis of: the internal mechanisms of IFT-systems; the relationships between the existence and viability of IFT-systems; and the coping mechanisms of the actors involved in IFT-activities, while facing uncertainties about the fulfillment of IFTcontracts.

Table 3.1: Research designs and data collection methods

\begin{tabular}{llll}
\hline \multicolumn{1}{c}{ Question } & $\begin{array}{l}\text { Research } \\
\text { type }\end{array}$ & $\begin{array}{l}\text { Research } \\
\text { design }\end{array}$ & Data collection \\
\hline Landscape of IFT-risks across countries & Descriptive & $\begin{array}{l}\text { Cross- } \\
\text { sectional } \\
\text { design }\end{array}$ & $\begin{array}{l}\text { Secondary } \\
\text { datasets }\end{array}$ \\
\hline $\begin{array}{l}\text { Relationships between survival of IFT- } \\
\text { systems and coping mechanism of the } \\
\text { actors }\end{array}$ & Explanatory & $\begin{array}{l}\text { Case study } \\
\text { design }\end{array}$ & $\begin{array}{l}\text { Secondary } \\
\text { dataset; } \\
\text { interviews }\end{array}$ \\
\hline
\end{tabular}

Source: the author

The types of data used for this study are different for the research questions and designs. The different types of data used - quantitative data for the first sub-question and qualitative data for the second sub-question - relate to each other in a contextual sense. Moreover, their findings complement each other, as they all related to the

69 In recent years, the case study method has fallen out of favor as an analytical tool because it does not seem to have a solid research design and data collection protocol (Eisenhardt and Graebner, 2007). A case study method has, however, the virtue of flexibility in dealing with activities or situations that researchers cannot manipulate or control because of unexpected changes in external conditions and unacceptable attrition rates. The case study method can reduce worries about internal validity by employing a triangulation method in data collection and directly examining alternative explanations in data analysis (Yin 2003). 
illegality of IFT-systems and their survival. However, the data cannot be integrated as they are used for different research questions and designs, and are different in nature (Table 3.1 and Table 3.2).

Table 3.2: Analysis levels and types of data

\begin{tabular}{|c|c|c|c|}
\hline Data source & Types of data & $\begin{array}{l}\text { Scope of } \\
\text { analysis }\end{array}$ & $\begin{array}{l}\text { Level of } \\
\text { analysis }\end{array}$ \\
\hline $\begin{array}{l}\text { - Migration and remittance dataset and Financial } \\
\text { inclusion dataset from the World Bank } \\
\text { - Financial access survey dataset from the IMF } \\
\text { - Mutual evaluation reports of compliance with } \\
\text { FAFT Recommendations from the FATF and the } \\
\text { FSRBs } \\
\text { - Executive opinion survey dataset from the WEF }\end{array}$ & Quantitative & 121 countries & Global \\
\hline $\begin{array}{l}\text { - IFT-case reports of the KCS } \\
\text { - Interviews with relevant government officials }\end{array}$ & Qualitative & Korea & Local \\
\hline
\end{tabular}

Source: the author

\subsection{Research method and data for the global analysis of IFT-systems}

In order to answer the first sub-question through the cross-sectional design, the global analysis of IFT-systems relies heavily on the secondary quantitative data collected by international entities. The global analysis of IFT-systems seeks to assess the level of risk faced by each country with respect to the prosperity of IFT-systems. This analysis aims to construct a global IFT-risk indicator, which reflects the level of risk at which IFT-systems thrive within each country. The data used to gauge IFT-risk should include relevant factors for the survival and prosperity of IFT-systems in a country. However, collecting such data is challenging, especially for a number of countries where there is no support from international entities. Data collection tools to record IFT-activities across the world have not yet been developed. Secondary data are thus a feasible option for assessing IFT-risks and developing a global IFT-risk indicator (Vartanian, 2011).

The datasets analyzed in this study are: the 'migration and remittances 2016' and 'financial inclusion 2015' reports from the World Bank, the 'financial access survey' from 
the IMF, mutual evaluation reports of each country's compliance with the FATF Recommendations from the FATF and FATF-Style Regional Bodies (FSRBs) ${ }^{70}$, and the 'executive opinion survey' from the World Economic Forum (WEF). The selection of these five datasets related to four factors likely to be associated with the viability and prosperity of IFT-systems. According to economic studies on IFT-systems, the majority of IFT-users are expatriate workers (Maimbo, 2003; El Qorchi et al., 2003). Their primary motive for using IFT-systems is the inability to access formal financial institutions. This study has therefore employed the datasets related to migration and financial inclusion or accessibility: the 'migration and remittances 2016' and 'financial inclusion 2015' reports from the World Bank and the 'financial access survey ${ }^{71}$ ' from the IMF. Another motive for using IFT-systems is the laundering of criminal proceeds and the financing of terrorism; the viability and prosperity of these systems are threatened by AML/CFT measures. This study has thus chosen the dataset that contains information on the performance of each country's AML/CFT system: the mutual evaluation dataset from the FATF and the FSRBs. The viability and prosperity of IFTsystems are influenced not only by economic and policy factors, but also by psychological factors, such as tolerance of informal economies - the extent to which informal economies are allowed in a society. The dataset with information about societal attitudes towards informality - the 'executive opinion survey ${ }^{72}$ ' from the WEF - was selected.

70 As of September 2018, the FATF is comprised of 35 member countries and two regional organizations (i.e., European Commission and Gulf Co-operation Council). The FATF conducts mutual evaluations of the 35 member countries. Mutual evaluations of non-member countries are conducted by nine FATFStyle Regional Bodies which cover nearly all countries of the world.

71 The two financial inclusion datasets - financial inclusion of the World Bank and financial access survey of the IMF - deal with similar variables. Given that the financial access survey is a supply-side dataset to measure and monitor financial inclusion, the financial access survey dataset includes somewhat better variables regarding use of ATMs than the financial inclusion dataset. Both of the two datasets are thus used for this study.

72 The executive opinion survey aims at capturing business leaders' opinions on a broad range of competitiveness topics for which statistics are unreliable, outdated, or nonexistent for many countries (Schwab and Sala-i-Martín, 2013). 
These datasets are easily combined, as the units of analysis of the five datasets consist of the various countries. The combined dataset is used to gauge each country's IFT-risk in a way that estimates IFT-risk based on the level of migration, access to formal financial institutions, AML/CFT measures, and societal attitudes towards informality. For instance, it may be assumed that a country faces a high level of IFT-risk if it has a certain number of migrants, who could be potential customers of IFT-systems. Other factors could include low access to formal financial institutions, which works as a motive for the use of IFT-systems, weak AML/CFT measures, and a lenient attitude towards informality. The number of countries ${ }^{73}$ subject to the global analysis amounts to 121. A more detailed clarification of the process of developing and applying a global IFT-risk indicator is provided in Chapter 4.

\subsection{Research methods and data for the country-focused analysis of IFT-systems in Korea}

In this study, the term 'local' is used to contrast with the term 'global' of the global analysis. Local analysis does not necessarily mean municipal or community-level analysis. The local analysis in this study focuses on IFT-systems in the 'single country' analysis vis-à-vis the global analysis, comparing IFT-risks in the 121 selected countries. The subjects of the local analysis are therefore IFT-systems detected in Korea. In addressing the second sub-question, drawing on the case study design, the local analysis of IFT-systems also faced challenges with regard to data collection ${ }^{74}$. In many countries, IFT-systems are not a lawful remittance transfer system. Reliable data on IFT-systems are therefore rather limited, despite the fact that many studies on this subject have been conducted at a national or regional level (Maimbo, 2003; Maimbo et al., 2005; Pieke et al., 2007; Soudijn, 2015; Van de Bunt, 2008a). Previous empirical studies (Maimbo et al.,

73 Hong Kong, China is regarded as a country for the convenience of analysis.

74 Data collection techniques frequently used in qualitative research are: individual semi-structured interviews, focus groups, documentary reviews, and participant observation (Palinkas et al., 2015). 
2005; Kosse and Vermeulen, 2014) on migrants' remittances tend to address the subject with little separation between formal remittance systems and IFT-systems. In addition, only a few studies (Rahman and Yeoh, 2008; Maimbo, 2003; Van de Bunt, 2008b) examine IFT-systems by analyzing the actors involved in IFT-activities; nevertheless, details regarding the internal dynamics of IFT-systems are rarely known. This study therefore aims to shed light on IFT-systems in relation to formal remittance systems, and to analyze them by looking into the internal dynamics between the different actors.

In discussing the relationships between the actors involved in IFT-activities, capturing their own perceptions or experiences would be ideal in terms of data validity. However, similar to other hidden and elusive populations engaged in illegal activities 75 (Watters and Biernacki, 1989), IFT-brokers and IFT-users were difficult to recruit for research purposes in Korea, where IFT-systems are illegal and operate in a covert manner. Therefore, it was decided in this study to make use of the case reports of law enforcement authorities that were drawn up following the investigation of IFT-systems. Especially given that law enforcement officials are just as knowledgeable ${ }^{76}$ as IFTbrokers - and more knowledgeable than IFT-users — on the topic of IFT-systems. IFT-

75 The extents to which informal activities are concealed are not necessarily consistent across them. The levels of concealment depend on many variables, such as the characteristics of each government's regulations and the effectiveness of its enforcement. In settings where the informal economy is widespread, it may be possible to obtain relatively reliable estimates of them because lax enforcement of regulations and widespread of informal activities make informal business owners and workers less worry about participating in research on the informal economy. However, when a government's regulation is extensive and highly effective, informal activities tend to be highly concealed and embedded in tighter social networks. Thus, no matter how well organized a record-keeping apparatus is, it is likely to miss a significant amount of an informal activity (Portes and Haller, 2005).

76 As for the level of knowledge among law enforcement officials regarding a certain type of crime, in this case IFT-activities, the premise of it is that law enforcement officials only know what they encounter. However, two aspects are involved in the premise. First, as law enforcement officials are no part of the network of IFT-brokers, they less know of the norms, values and dynamics within the circles of IFTbrokers. On the other hand, law enforcement officials who dealt with many IFT-cases are aware of various aspects of IFT-systems about which some IFT-brokers may not know. As this study focuses on various interaction mechanisms within IFT-systems rather than the delicate cultures embedded between IFTbrokers, the second aspect of the knowledge of law enforcement officials applies to this study more. 
case reports not only include information about IFT-businesses detected, but also about the relationships between IFT-brokers and IFT-users. It must be noted, however, that this information was provided by IFT-brokers while being interrogated by — and being interpreted from the perspective of - law enforcement authorities. The limitations 77 of the data produced by law enforcement authorities are discussed by several scholars (Agran et al., 1990; Loftin and McDowall, 2010; Soudijn, 2015). A critical view $7^{8}$ on the secondary analysis of qualitative data also exists, as qualitative data are normally analyzed according to the context in which the data were originally produced (Blommaert, 20o1; Mauthner et al., 1998). Nevertheless, case reports from law enforcement authorities have the merit of uncovering criminal phenomena. Law enforcement authorities can easily obtain criminal information (e.g., the number of customers and transactions and the amount of criminal proceeds) to which scholastic interviews with criminals or victims would only provide limited access (Cheng and Philips, 2014; Hinds et al., 1997; Soudijn, 2015).

\subsubsection{Reasons for selection of Korean cases}

The local analysis is conducted on IFT-systems investigated in Korea. This is not only due to the fact that some IFT-case reports of the Korean government were made available for this study. Korea is ideally suited for research into IFT-systems. Unlike well-known fragile or less developed countries ridden with IFT-systems, Korea has a

77 A major limitation of crime data from law enforcement authorities is that they deal with only crime events recorded by or reported to the authorities (Maltz, 1999). The limitations of law enforcement authorities' data are normally lessened by adopting the voices of criminals or victims. However, this study has inevitably adopted law enforcement authorities' data because acquisition of primary data from criminals or victims was not feasible for this study. Thus, caution is needed in interpreting the findings from this study.

78 The reason that this critical view is introduced is to emphasize that the findings of this study should be interpreted with caution. This critical view per se does not stem conducting the secondary analysis of qualitative analysis. There are a number of studies that quantify qualitative data (Basit, 2003). 
well-developed formal banking network across the country 79 , and the Korean government's AML/CFT system is considered to be in compliance with the FATF Recommendations (FATF, 2009b). To give away one of the findings of the global analysis of IFT-risks in advance: the level of IFT-risk faced by Korea is also fairly low. The results are further elaborated in Chapter 4. In Korea, (stereotypical) organized crime groups $^{80}$, who may abuse IFT-systems to launder their criminal proceeds, are not as active as those in Western and other Asian countries (IHS Markit, 2018; Ponsaerts et al., 2008). Nevertheless, in Korea, a significant number of IFT-systems are investigated every year. In other words, while IFT-systems in developing countries are a popular research topic, IFT-systems in emerging and developed countries are rarely reported ${ }{ }^{81}$. Perhaps this is due to the perception that IFT-systems in emerging and developed countries are not as prevalent as in developing countries. Moreover, the harm of IFTsystems may not be as serious, even if some of them may engage in laundering criminal proceeds (Passas, 2006b). Thus, Korea's unfriendly environment for IFT-systems high level of access to formal remittance systems and relatively low tolerance of IFTsystems (considered illegal and illegitimate) - would ironically prove useful in assessing the survival and adaptation of IFT-systems. IFT-systems that continue to operate in such an unfriendly environment may have salient features that cannot be found in fragile countries, including those that help IFT-systems withstand standard AML/CFT measures. The local analysis of IFT-systems in Korea may also play a role in

79 In 2013, Korea was ranked 6th, 16th, and 2nd among 138 countries on financial development index, financial institutional index, and financial markets index respectively, which are formulated and maintained by the IMF (Svirydzenka, 2016).

8o As briefly mentioned in Chapter 5, the concept of organized crime is elusive. Unlike the stereotypical image of organized crime groups, gambling syndicates or fraud syndicates technically fall under the category of organized crime groups as well. In order to avoid confusion about the concept of organized crime groups, the term organized crime groups used in this study normally include gang-style, stereotypical organized crime groups unless specifically mentioned.

81 Despite several sensational episodes introduced in the media, only a few studies were conducted on IFT-systems in developed countries, such as the United States and the Netherlands. This study (particularly Chapter 5) may be the first attempt to examine the IFT-risk faced by a non-developing country in a systematic manner. 
providing guidance in determining the features of IFT-systems in emerging and developing countries, given that there are few studies on IFT-systems in emerging and developing countries.

\subsubsection{Research instruments and data for the case study of IFT-systems}

The IFT-cases examined in the local analysis were obtained from the KCS. This study took advantage of the researcher's social network ${ }^{82}$, including relations with the KCS officials, to gain access to the KCS's IFT-case reports. Each IFT-case report acquired from the KCS includes information about at least one IFT broker and, if any, relevant co-offenders. The unit of analysis in the IFT-case reports is IFT-brokers. This is because the KCS mainly deals with IFT-brokers rather than IFT-users, although technically IFTusers can also be investigated ${ }^{83}$. This study also conducted interviews with customs investigators of the KCS and officials of the KoFIU, to improve the understanding of the IFT-case reports and complement them. The interviews are based on the notion that customs investigators who investigated IFT-systems could provide more (unwritten) information about IFT-activities than the IFT-case reports. KoFIU officials might also have valuable information about IFT-systems of which the KCS is not aware. In other words, case reports from law enforcement authorities normally include information necessary to bring cases to prosecutors and judges. The IFT-case reports thus contain information useful only for the prosecution of IFT-brokers for violations of the Foreign

82 The social network that this study used to collect data was, of course, not personal but professional. According to social network analysis scholars (Freeman, 2004; Wasserman and Faust, 1994), social network refers to structural relationships or ties between (or among) actors. The scope of social network is not confined to personal ties. Although the IFT-case reports were legally obtained in cooperation with the KCS officials, a social network approach was needed to contact proper officials.

83 As IFT-activities are prohibited by the Foreign Exchange Transactions Act, the use of IFT-systems should be punished as well. It may be challenging to disclose IFT-users' criminal intent in the investigations of IFT-activities. The investigations of IFT-systems are thus normally concentrated on IFTbrokers. Unless both actors are examined, information about the interactions between the two actors cannot help but be skewed to either of them. Nevertheless, the interactions between them are fairly included in the IFT-case reports. As their relationships in the case reports are not as vivid as expected, this study has employed the interviews to complement information from the case reports. 
Exchange Transactions Act, and for involvement in money laundering, tax evasion assistance, and other crimes. They do not include all the information about IFTactivities that customs investigators obtained in the course of investigations into - and interrogations of - the actors involved in IFT-activities. This study anticipated the fact that the interviews with the KCS investigators may reveal not only whether anti-IFTsystems policy and practice are decoupled, but also how IFT-brokers are associated with IFT-users. Furthermore, the interviews were expected to provide information about how - and possibly, why - IFT-brokers take advantage of formal financial institutions for the benefit of their IFT-businesses. The interviews with the KoFIU officials were expected to provide an indication as to whether IFT-systems are associated with organized crime in Korea. In sum, in order to compensate for the limitations related to the IFT-case reports, interviews were conducted with semi-structured questionnaires with the two groups of Korean government's officials: customs investigators who investigated IFT-cases and public officials at the KoFIU. The semi-structured interviews proved useful in collecting not only flexible answers to the prepared questions, but also in gathering reliable and comparable qualitative data. The number of interviewed officials will be discussed later with respect to sampling issues in qualitative research (Fylan, 2005).

The questionnaire for the KCS investigators consisted of 31 questions that can be categorized into four sections: general information about the interviewee, perception of harm incurred from IFT-systems, investigation methods, and the relationship between IFT-brokers and IFT-users. The questionnaire for the KoFIU officials comprised 15 questions. The interviews with the customs investigators focused on extracting information that was not included in the IFT-case reports, specifically with respect to the working mechanisms of IFT-systems and the relationship between the actors involved in IFT-activities. The interviews with the KoFIU officials sought to obtain information regarding IFT-systems investigated by law enforcement authorities other than the KCS. One of the sources of information regarding IFT-systems that sets the KoFIU apart from law enforcement authorities is access to suspicious transaction reports. The KoFIU receives these reports from formal financial institutions on 
suspicion of money laundering and the predicate offenses. The submitted suspicious transaction reports are normally analyzed ${ }^{8} 4$ together with other reference data at the KoFIU. The analyzed suspicious transaction reports are selectively ${ }^{85}$ distributed to the relevant law enforcement authorities, such as the police, the national tax authorities, and the customs administration. Thus, the KoFIU officials were expected to have information about the general trends regarding IFT-systems and IFT-transactions. The two questionnaires were developed on the basis of previous studies on IFT-systems and the IFT-case reports. Participation in the interviews was voluntary. The responses to the interview questions were kept confidential ${ }^{86}$ (Appendix 5). The interviewees in each group were asked identical questions in the same sequence. Data were collected between May 1 and September 7, 2017. Interviews were conducted in Korean. All interviews were recorded in writing because most interviewees opposed being taperecorded $^{87}$.

84 In order to examine suspicious transactions indicated in suspicious transaction reports, the KoFIU analysts take advantage of various reference data, such as not only suspects' personal information (e.g., criminal history, jobs, and family members) but also relevant business information (e.g., owned businesses' financial statements and foreign subsidiaries) and financial transactions (e.g., foreign exchange transactions, import-export declarations, and financial transactions regarding stocks, bonds, or real estate).

85 Not all suspicious transaction reports submitted to the KoFIU are distributed to law enforcement authorities. After some of the submitted suspicious transaction reports are analyzed with other reference data, only some of the analyzed suspicious transaction reports are sent to law enforcement authorities.

86 In order to protect the participants' human rights, this study made use of measures for confidentiality rather than those for anonymity. Anonymity refers to "a condition in which the researcher does not know the identity of the respondent" whereas confidentiality refers to "an implicit or explicit agreement that no traceable record of the participant's data will be disclosed (Ong and Weiss, 200o: 1694). This study was conducted on the privilege of accessing not only the IFT-case reports but also the KCS investigators and the KoFIU officials. The identities of the KCS investigators and the KoFIU officials were somehow known to the researcher of this study. Thus, it was not feasible to guarantee anonymity of them. When this study recruited the interviewees, they were given a consent form that informs of voluntary participation and confidentiality (Appendix 5).

87 When tape-recording of the interviews was attempted, the interviewees felt as if being interrogated rather than participating in the interviews. In order to recruit a decent number of the interviewees and protect their human rights, this study recorded the interviews in writing instead of tape-recording. 


\subsection{Subjects and sampling}

\subsubsection{Overview of the subjects}

This study makes use of three types of subjects: country-level jurisdictions (country), IFT-case reports (document), and interviewees (person). Their subject numbers are 121 (countries), 230 (case reports), and 40 (officials) respectively (Table 3.3). The subject of the global analysis should be viewed as a population of countries rather than as sample countries, because it covers nearly all Member States of the United Nations (UN) ${ }^{88}$, and a 'study population' or 'accessible population' is often different from a 'target population' or 'theoretical population' (Maxfield and Babbie, 2004). The sampling issues discussed here may not be relevant to the global analysis and are therefore limited to the local analysis in this study.

Table 3.3: Number of subjects

\begin{tabular}{l|l|l} 
Type of subjects & \multicolumn{1}{|c|}{$\begin{array}{c}\text { Accessible population } \\
\text { (or sampling frame) }\end{array}$} & \multicolumn{1}{c}{ Number of subjects (or samples) } \\
\hline Country & UN Member Countries & 121 countries \\
\hline IFT-case report & IFT-case reports of the KCS & $\begin{array}{l}\text { All IFT-case reports (230 cases } \\
\text { produced between '2011 and 2013' }\end{array}$ \\
\hline Interviewee & $\begin{array}{l}\text { Customs investigators of the KCS } \\
\text { Officials of the KoFIU }\end{array}$ & $\begin{array}{l}\text { 30 customs investigators of the KCS } \\
\text { 10 officials of the KoFIU }\end{array}$ \\
\hline
\end{tabular}

Source: the author

This study used a qualitative approach for the local analysis of IFT systems. IFTsystems and IFT-activities emerge in various forms in different local contexts. What is

88 According to the UN, the number of its Member States is 193 as of April 2018. Although there is a gap between the two groups of countries, there may be little problem in calling 121 countries a population. That is because the 193 Member States to the UN is a target population and the countries covered by this study (121) constitutes the study population.

89 The number of the IFT-case reports analyzed for this study seems to be bigger than the usual numbers of samples in qualitative research. 
important for the research on IFT-systems is to examine intricate local contexts in which IFT-activities occur, and delicate interactions between the actors involved in IFTactivities. As discussed earlier, this study collected two types of qualitative data: data from the IFT-case reports and data from the interviews. The aim of combining these two sets of data is to gain a better understanding of the local context where IFT-activities occur. The local analysis could not collect a large number of samples because the data on intricate local contexts and interactions between the actors are limited. Thus, the local analysis was not aimed at obtaining a generalizable broader understanding of IFTsystems with numerical descriptions; the aim was to gain an in-depth understanding of IFT-systems in Korea, albeit with limited numerical descriptions. Sampling for qualitative studies differs from that for quantitative studies, in particular in terms of the sampling aim, size, and procedures involved (Polit and Beck, 2010; Sandelowski, 2000). It is therefore necessary to explain the sampling method employed for the local analysis and to specify the number of samples gathered.

\subsubsection{Purposeful sampling}

Obtaining sufficient data is one of the foundations for credible research. Many scholars argue that determining sample sizes may differ according to research objectives and approaches (Baker and Edwards, 2012). Qualitative methods normally aim to achieving an in-depth understanding, whereas quantitative methods intend to obtain a broad understanding (Hollway and Jefferson, 2000). The two research approaches therefore have different standards for determining the sampling methods and sample sizes required to achieve their aims (Palinkas et al., 2015). Sampling is an ambiguous area in qualitative research (Marshall et al., 2013; Patton, 2002). Many qualitative studies do not clarify why a certain number of samples was selected, although they do disclose what sampling method was employed and how many participants were recruited. 
The local analysis adopted a purposeful sampling strategy ${ }^{90}$ to identify and select information-rich cases for the most effective use of limited resources. Researchers who employ a purposeful sampling method seek to identify and select individuals who are especially knowledgeable about - or experienced with - a phenomenon of interest (Boeije, 2002; Patton, 2002). Participants' availability and willingness to participate in a research project, and their ability to communicate their experiences and opinions in an articulate manner, are also factors for the employment of a purposeful sampling method (Johnson, 1990; Palinkas et al., 2015). The IFT-case reports produced by the 'KCS' between the years 2011 and 2013 were purposefully selected from the reports that the Korean government has been drawing up for decades. In other words, in selecting IFT-case reports, two selection criteria were used: organization and year. In this study, IFT-case reports produced by the KCS were selected, and, from the IFT-case reports of the KCS, the reports drawn up between 2011 and 2013 were selected. As discussed earlier, the customs administration is the most active authority in the fight against IFT-systems in Korea. The customs investigations of the IFT-cases undertaken in $2013^{91}$ were completed when the research plan for this study was formulated in 2015. The selection of the interviewees among the officials of the KCS and the KoFIU was also deliberate: prior to selecting the interview samples, this study obtained information as to which

90 There are several views on how to classify sampling strategies used in qualitative research (Coyne, 1997; Marshall, 1996; Patton, 2002). Nevertheless, there is no doubt that a purposeful sampling strategy is most commonly used for qualitative studies. A purposeful sampling strategy includes several techniques. Extreme or deviant cases are selected for the purpose of learning from unusual manifestations of phenomena of interest. The selection of cases with maximum variation is to document unique or diverse variations that have emerged in adapting to different conditions and to identify important common patterns that cut across variations. Homogeneous cases are selected to reduce variation, to facilitate group interviewing, and to simplify analysis (Palinkas et al., 2015; Patton, 2002).

91 When this study contacted a director of the KCS who was in charge of investigation of money laundering cases including IFT-systems to obtain IFT-case reports, the investigations and prosecutions of IFT-cases undertaken in 2013 were completed. Even though he allowed this study to access the IFT-case reports produced by the KCS, he did not want this study to access too many IFT-case reports given that it takes his own organizational resources (e.g., manpower) to retrieve and sort out IFT-case reports from the KCS enforcement database. Through a compromise between the need for sufficient IFT-cases for this study and the KCS's limited resources to support this study, this study was allowed to have access to only the 3-year IFT-case reports, those from 2011 to 2013. 
investigators of the KCS are most experienced in handling IFT-cases, and which KoFIU officials have knowledge of IFT-systems in their field.

\subsubsection{Data saturation and sample size}

In qualitative research, the issue of sample size is addressed through the concept of 'saturation'. Saturation refers to "the point at which the data collection process no longer offers any new or relevant data" (Dworkin, 2012: 1319). Saturation is influenced by many factors. These include the degree of homogeneity of the populations of interest, the selection criteria, the available budgets for conducting research, and the research timelines (Marshall et al., 2013). Despite conflicting views ${ }^{92}$ on saturation (Bowen, 2008; Sim et al., 2018), scholars agree on the need for a provisional decision on sample sizes at the outset of research (Robinson, 2014). Saturation plays an important role in providing numerical guidelines for sample sizes in qualitative studies. Many guidelines for sample sizes converge on 25 to 30 participants (Bernard, 20oo; Bertaux, 1981; Creswell, 1998; Kuzel, 1992; Marshall et al., 2013; Morse, 1995). The quality of research increases until the data are saturated. Once data saturation is reached, its (marginal) return diminishes. Gathering too much data can hinder researchers in the thorough and rich analysis of data, which is a characteristic of qualitative research.

92 There has been a view that data saturation is somewhat an elusive concept in qualitative research and provides little practical guidance for estimating sample size (Guest et al., 2006; Onwuegbuzie and Leech, 2007). That is because like quantitative researchers, qualitative researchers are normally requested to determine their sample sizes 'in advance'. It is challenging to specify the number of participants to recruit to complete a project at its inception. In addition, in order to know whether saturation is achieved, researchers are forced to conduct sampling, data collection, and data analysis at the same time, rather than to treat them as separate stages in a linear process. Nevertheless, many researchers contend that numerical guidelines for saturation are needed (Becker and Edwards, 2012; Guest et al., 2006). 
The number of samples collected in this study appears to meet the saturation guidelines recommended by several qualitative researchers. The number of IFT-case reports produced by the KCS between 2011 and 2013 is $230^{93}$, which is well above the recommended guidelines for saturation. In this study, all the IFT-case reports available for those three years were analyzed, although little additional information was collected after the analysis of the IFT-case reports for the first two years (i.e., 79 cases in 2011 and 116 cases in 2012). This means that the IFT-case reports of the two years were sufficient to identify the working mechanisms of IFT-systems and the interactions between the actors in IFT-activities. However, this study also analyzed the IFT-case reports of the third year, even after the point data saturation was reached. The reason for this is that the cost 94 of analyzing IFT-case reports did not increase in relation to the number of IFT-case reports. This is not the case when collecting data from interviews, were the costs closely related to the numbers of interviewees. For the local analysis, the number of analyzed IFT-case reports was sufficient; it could even be considered abundant. The concept of data saturation focuses on obtaining sufficient data and, on the other hand, on cautioning against endless data collection, given limited research resources. Thus, despite collecting and analyzing data beyond the point of saturation, it has not adversely affected this study.

93 The number of investigated IFT-cases is not a reliable indicator to measure the prevalence of IFTactivities in a year. Although 35 cases were investigated in 2013, following 116 cases in 2012, and 79 cases in 2011, IFT-activities were not necessarily most prevalent in 2012. Investigations of IFT-systems are mostly influenced by the KCS's investigation plan including high priority targets, rather than the prevalence of IFT-activities in the remittance market. Of course, the headquarters' interest in a certain type of crime is derived from an analysis of the prevalence of crimes. Nevertheless, the extent of investigations of IFT-systems is not necessarily correlated with the prevalence of IFT-activities.

94 This study paid little cost in collecting the IFT-case reports of the three years, as the KCS provided support for retrieving and sorting out the IFT-case reports. In terms of the research cost, there was little difference in analyzing between the IFT-case reports of the three years and those of the two years. 
As discussed earlier, the interviews during this study were conducted with two groups: 30 customs investigators ${ }^{95}$ of the KCS and 10 officials of the KoFIU ${ }^{96}$. All customs investigators who participated in the interviews were recruited from the KCS's financial investigation divisions tasked with the investigation of money laundering cases, including IFT-systems. At the time of the interviews, in September 2017, all interviewees were working in the role of customs officers. They therefore had experience in investigating IFT-systems. The 30 customs investigators account for approximately $30 \%$ of the customs investigators responsible for the KCS's financial investigations. The interviewed investigators can be divided into three sub-groups according to their ranks: 5 manager-level officials, 15 senior investigators, and 10 investigators 97 . As for the 10 interviewed KoFIU officials, their backgrounds were diverse: two prosecutors, two tax officials, two police officials, and four customs officials. The selection of the KoFIU officials was made in consultation with the KoFIU directors ${ }^{98}$. The officials at the KoFIU account for approximately $20 \%$ of the KoFIU officials tasked with the analysis of suspicious transaction reports and currency transaction reports. As most of them worked at management level, they oversaw all issues related to IFTsystems as part of their responsibilities. When it comes to the saturation of interview data, the number of interviewees is more than - or close to - the recommended guidelines for saturation, although the interviews are an additional data source to

95 The total number of customs officers at the KCS amounts to approximately 4,800 as of September 2016. Among them, approximately 500 officers are tasked with criminal investigations. Out of the 500 customs investigators, the number of customs investigators specialized in financial investigations of money laundering stands at approximately 90.

96 The total number of officials at the KoFIU is 8o. Among them, 52 officials are tasked with information analysis, whereas 28 officials deal with policies and programs concerning AML/CFT.

97 Among the interviewees, 15 officers worked at the KCS for more than 20 years; 10 officers' career in customs was between 10 and 20 years. The other five officers worked in customs for five years or more, but not 10 years yet. The investigators who investigated 10 IFT-cases or more amount to eight; four officers investigated five IFT-cases or more, but not 10 cases. The number of IFT-cases that each of the other 18 officers investigated is between one and five.

98 At the KoFIU, the police issues are relatively less than the other issues, such as tax and customs issues, and customs officials deal with most cross-border financial transactions issues. Considering the workload regarding IFT-systems at the KoFIU, decision on the number of the samples at the KoFIU was made. 
complement the IFT-case reports. During the interviews, most information about IFTsystems in Korea was gathered from the interviews with the first 15 investigators; new information was rarely gathered during the subsequent interviews. As most KoFIU officials responsible for the fight against IFT-systems were interviewed, the data collected from the KoFIU should also be considered saturated. Therefore, data saturation played an important role in deciding whether to collect more IFT-case reports and whether to recruit additional interviewees.

\subsection{Data analysis}

This study proceeds with the two different research designs (cross-sectional design and case study design) at two levels (global and local) in order to examine the survival and adaptation of IFT-systems in a globally connected world. Each analytical approach entails different data analysis techniques, depending on the characteristics of the data analyzed. The global analysis based on the cross-sectional design that examined the quantitative datasets made use of statistical data analysis. As the statistical data analysis is closely linked to the development of a global IFT-risk indicator, the details will be discussed in Chapter 4 .

The local analysis based on the case study design deals with two different types of qualitative data: the IFT-case reports and the interviews with the public officials. A structured analytical framework is required to process and analyze a relatively large amount of qualitative data of different types in a systematic manner. Given that the interview responses were converted into interview transcripts ${ }^{99}$, a thematic analysis technique was used in this study (Braun and Clarke, 2006; Vaismoradi et al., 2013). This widely used document analysis technique plays a role in extracting relevant and substantial information from textual data for a systematic analysis.

99 Bowen (2009) views transcripts from interviews as documents subject to thematic analysis. When data from interviews are analyzed into codes and themes, the subjects of thematic analysis are interview transcripts in which interviewees' oral statements are dictated. 
Thematic analysis often refers to an independent qualitative descriptive method for identifying, analyzing, and reporting patterns called 'themes' within textual data. A theme represents some level of patterned response or meaning that researchers identify in relation to research questions within data. Thematic analysis focuses on identifying themes and recognizing patterns within data through careful reading and re-reading of data (Figure 3.1). Thematic analysis ${ }^{100}$ is known to be useful in conducting exploratory work in a little-known area or topic (Fereday and Muir-Cochrane, 2006; Joffe and Yardley, 2004).

Figure 3.1: A conceptual diagram of thematic analysis

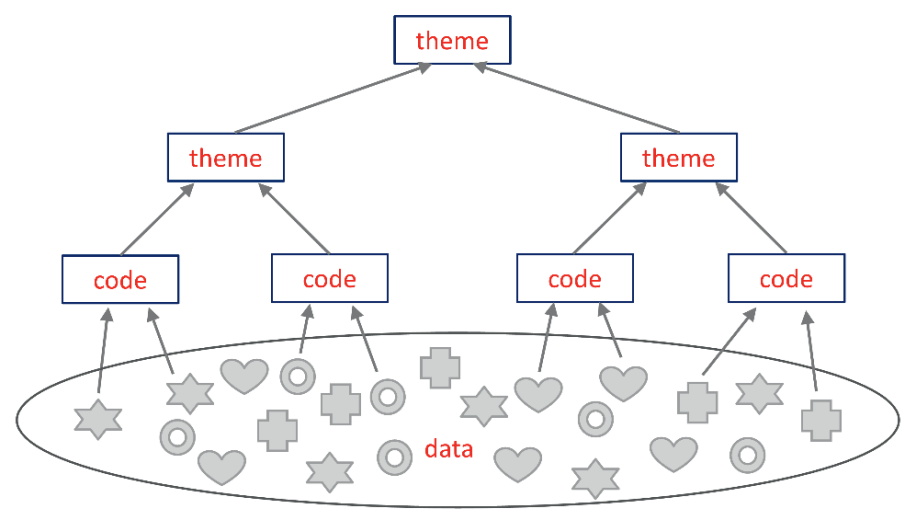

Source: the author

The local analysis was performed on the basis of a typical thematic analysis process. By reviewing the textual data and the findings from previous studies on IFTsystems, this study first identified preliminary themes regarding actors and activities in IFT-systems and the government's responses to IFT-systems, which are the main contributors to the dynamics within IFT-systems. This study then focused on the

100 As thematic analysis is called a process to identify themes in data, its analytical work begins when researchers set out on looking for and capturing patterns of meaning and issues of potential interest in data during data collection. As themes are derived from codes, the coding procedure, which takes chunks of text and labels them as falling into certain categories, plays a central role in thematic analysis (Joffe and Yardley, 2004). 
development of a code template or manual ${ }^{101}$ before conducting an in-depth analysis of the data. In developing the code template, this study took advantage not only of previous studies on IFT-systems and a preliminary scan of the IFT-case reports and interview transcripts, but also of theoretical frameworks borrowed from other areas. In particular, the theoretical frameworks benefitted the extraction of codes and themes from the textual data and previous study findings that relate to trust and risk involved in interactions between the actors, as well as to price, competition, and cooperation in the informal remittance market.

Theoretical frameworks, in fact, played a crucial role in this study, not just in collecting and analyzing data, but also in elaborating (sub) research questions and interpreting the outcomes. Despite a (mistaken) belief that theory has no place in a qualitative study, many qualitative scholars argue that it would be difficult to imagine a study without a theoretical or conceptual framework, given that theory is defined as an analytical and interpretive framework ${ }^{102}$ that helps researchers understand 'what is going on in the social setting being studied' (Anfara and Mertz, 2015; Flinders and Mills, 1993; Merriam, 1998). Some qualitative scholars (Kearney and Hyle, 2015; Mills and Bettis, 2015) also contend that theories from other fields can bring new insights into a phenomenon under study, and multiple perspectives contribute to deepening understanding of a problem. As elaborated in Chapters 5 and 6, this study used three theoretical frameworks: the sociology of (illegal) markets, social exchange theory, and the perspective of trust and risk. The aim was to shed light on IFT-systems as a remittance market and to zoom in on the dynamic interactions between the actors within IFT-systems (Figure 3.2). The three theories are more useful in examining the

101 As information elements that are likely to produce substantial findings in relation to previous studies on IFT-systems were extracted as codes, the code manual for the local analysis has played an important role for data management that organizes textual information (Boyatzis, 1998; Crabtree and Miller, 1999). 102 According to Sandelowski (1993) and Bradbury-Jones and her colleagues (2014: 136), "theory in qualitative research has numerous functions: it can provide rationalization or justification for the methodological approach used; it can offer a comparative context or an organizational framework for the interpretation and representation of data; or it can serve as a scheme for representing findings". 
dynamics between the actors of IFT-systems as a remittance channel, than conventional criminological theories, which focus on dealing with criminality and motivations of offenders (Lilly et al., 2018; Vold et al., 2002), and other criminological concepts, such as co-offending and organized crime groups (explained in Chapter 6). In particular, unlike many studies on IFT-systems that posit ethnic cohesiveness and informal social control in IFT-systems (Rahman and Yeoh, 2008; Hernandez-Coss, 2005b; Maimbo and Passas, 2005; Monsutti, 2004; Passas and Giannakopoulos, 2017), these three theories do not necessarily require ethnic ties, social embeddedness, and informal social control in addressing the dynamics between the actors of IFT-systems. They can be applied to IFT-systems that operate in more various contexts.

Figure 3.2: The theoretical frameworks for the analysis of IFT-systems

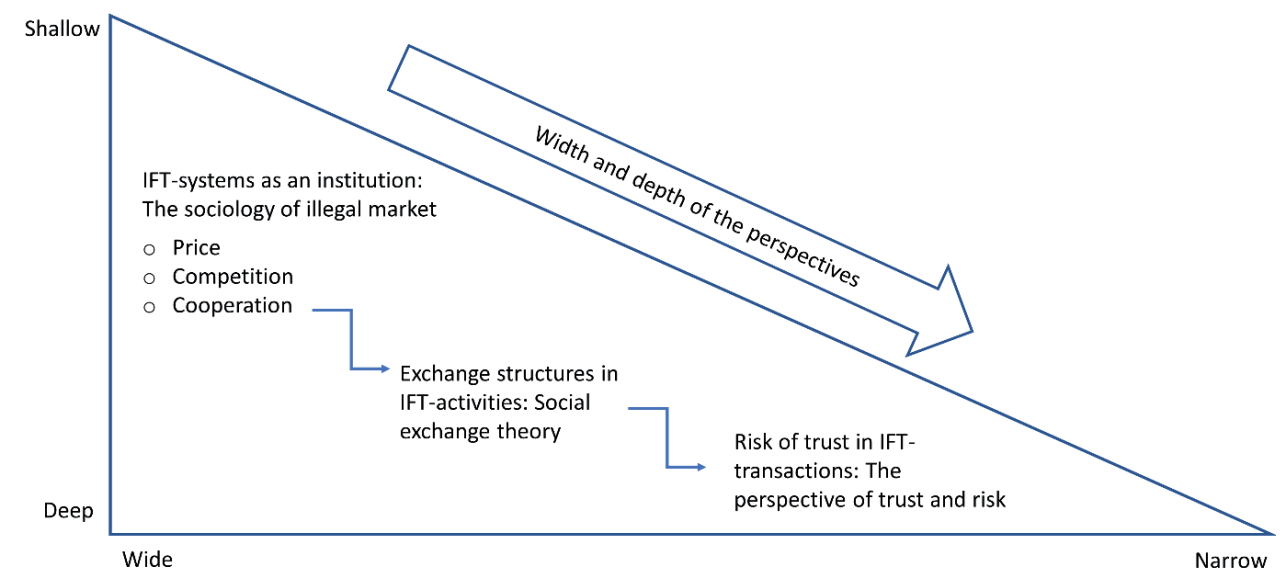

Source: the author

The themes and codes identified in the thematic analysis not only provided a basis for integrating the findings from the previous studies and the data collected for this study, but also served as a preliminary framework to understand how IFT-systems work. The identified themes and codes were arranged according to perspective levels in a temporal order to assess IFT-systems as a remittance market, and to illustrate the mechanisms of IFT-systems and the interactions between its actors. 
The findings from the thematic analysis will be unfolded in Chapter 5 and 6 according to the themes and codes without referring to specific case numbers. However, this study made distinction between the findings from the IFT-case reports and those from the interviews given that the main data source for the local analysis was the IFTcase reports and the interviews played a role in complementing the IFT-case reports. The findings in the local analysis are normally from the analysis of the IFT-case reports unless it is specifically indicated that certain findings are extracted from the interviews.

\subsection{Summary and reflection}

Following on from Chapter 2 - which provided background information on IFTsystems, this chapter provided a research framework for this study (Table 3.4) and detailed how this study was designed by examining the two research designs - crosssectional design and case study design - to address the two research questions.

Table 3.4: Research framework of this study

\begin{tabular}{|c|c|c|c|c|c|c|}
\hline $\begin{array}{c}\text { Overarching } \\
\text { question }\end{array}$ & Sub-question & Level & Design & Data & Analysis & Focus \\
\hline \multirow{3}{*}{$\begin{array}{l}\text { Survival and } \\
\text { adaptation } \\
\text { of IFT- } \\
\text { systems in a } \\
\text { globally } \\
\text { connected } \\
\text { world }\end{array}$} & $\begin{array}{l}\text { Survival (or } \\
\text { viability) of } \\
\text { IFT-systems in } \\
\text { response to the } \\
\text { external risks }\end{array}$ & Global & $\begin{array}{l}\text { Cross- } \\
\text { sectional } \\
\text { design }\end{array}$ & $\begin{array}{l}\text { Quantitative } \\
\text { : five datasets } \\
\text { from } \\
\text { international } \\
\text { entities }\end{array}$ & $\begin{array}{l}\text { Statistical } \\
\text { analysis }\end{array}$ & $\begin{array}{l}\text { Distribution } \\
\text { of IFT-risks } \\
\text { across } \\
\text { countries }\end{array}$ \\
\hline & \multirow{2}{*}{$\begin{array}{l}\text { Adaptation of } \\
\text { IFT-systems in } \\
\text { response to the } \\
\text { internal risks }\end{array}$} & \multirow[t]{2}{*}{ Local } & \multirow[t]{2}{*}{$\begin{array}{l}\text { Case } \\
\text { study } \\
\text { design }\end{array}$} & \multirow{2}{*}{$\begin{array}{l}\text { Qualitative } \\
\text { : IFT-case } \\
\text { reports and } \\
\text { interviews with } \\
\text { government } \\
\text { officials }\end{array}$} & \multirow[t]{2}{*}{$\begin{array}{l}\text { Thematic } \\
\text { analysis }\end{array}$} & $\begin{array}{l}\text { IFT-systems } \\
\text { as a market }\end{array}$ \\
\hline & & & & & & $\begin{array}{l}\text { Internal } \\
\text { dynamics } \\
\text { between } \\
\text { actors within } \\
\text { IFT-systems }\end{array}$ \\
\hline
\end{tabular}

Source: the author

This study addressed the survival and adaptation of IFT-systems with a 'camera' that can take panoramic, medium, and close-up shots, thereby providing three pictures of IFT-systems. For the panoramic shot of the global landscape of IFT-risk, which is 
depicted by a global IFT-risk indicator, this study used a cross-sectional design and analyzed the secondary datasets collected by several international entities with the statistical analysis technique. For the other two shots taken at the local level with respect to IFT-systems, this study employed a case study design and analyzed the qualitative data - the IFT-case reports and the interview data - with a thematic analysis technique. The thematic analysis technique was used to extract and arrange codes and themes from the textual data, in order to illustrate and examine how the actors involved in IFT-activities trust each other and how they cope with the internal risks of deception and betrayal between them. This was done by drawing on the three theoretical frameworks. In particular, the medium shot for the second picture focuses on IFT-systems' roles and relations in a remittance market, drawing on the sociology of (illegal) markets. The close-up shot for the third picture zooms in on IFT-systems to illustrate the internal dynamics between actors within IFT-systems, drawing on social exchange theory and the perspective of trust and risk. The different research designs and data used to take the three pictures in this study can be used to illustrate the survival and adaptation techniques of IFT-systems, which face external and internal risks from different angles. 


\section{Global Analysis of IFT-systems: Development of a Global IFT-risk Indicator}

\subsection{Introduction}

IFT-systems exist in nearly every economy, albeit in various forms. The extent of their activities may differ from country to country. There is little information about the prevalence and distribution of IFT-activities worldwide, despite the global concern over this subject. Such information would be essential for policy makers and scholars seeking to develop and evaluate measures against them. As discussed earlier, several studies attempted to gauge the amount of remittances transferred via IFT-systems with various methods. However, given that such efforts were at best limited to several countries, they do not meet the demands for a global picture of IFT-systems. This chapter does not seek to measure the prevalence of IFT-activities across the world, and to identify good predictors for IFT-activities. As IFT-activities are factually illegal activities that fall outside the scope of government monitoring, it is not feasible to capture their prevalence with the existing research instruments. This study will focus instead on assessing the IFT 'risk' of each country, as it is feasible to derive the likelihood that IFT-activities occur and prosper from factors related to IFT-systems and IFTactivities. In other words, this study seeks to map the IFT-risk of each country in the form of a composite indicator. This indicator is constructed by combining separate indicators theoretically associated with IFT-activities. As no composite indicator ${ }^{103}$ to capture IFT-risk appears to have been developed or discussed in the field of criminology and criminal justice, this chapter will first look at the concept of a composite indicator. It will then explain the process of constructing such an indicator. Last but not least, the results of the analysis based on the global IFT-risk indicator will be presented and discussed.

103 Yepes (2011) constructed an AML/CFT compliance index based on the FATF's mutual evaluation reports. It includes evaluation on preventive measures against the informal sector as one of seven components of the index. 


\subsection{Overview of composite indicators}

A composite indicator refers to a single index compiled from individual indicators, based on the underlying model of the multi-dimensional concept to be measured (OECD and JRC, 2008). Composite indicators are increasingly recognized as a useful tool for policy analysis and public communications ${ }^{104}$. International organizations, such as the UN and the World Bank, have developed aggregate development indicators, such as the Human Development Index, the Doing Business indicators, and the Worldwide Governance indicators (Arndt and Oman, 2006). Think tanks and non-governmental organizations, such as the Economist Intelligence Unit and Transparency International, have also produced composite indicators, such as the Quality of Life index and the Corruptions Perceptions Index (Foa and Tanner, 2012). A review of the rapid growth of composite indicators finds that attention to composite indicators is a recent phenomenon: more than 150 composite indicators are now in existence and more than 80\% of them have been developed since 1991 (Botero et al., 2011; Foa and Tanner, 2012). Their popularity seems to stem from their ability to summarize complex or multi-dimensional issues into a simple format, thereby making it possible for policymakers to obtain a tractable and representative sense of the phenomena of interest in a given country, and to make comparisons with other countries. As they provide single estimates, composite indicators allow for easy interpretation compared to the use of multiple separate indicators. In addition, the commitment to regular

\footnotetext{
104 There are various views on the roles of composite indicators. Composite indicators can thus work as a fact, a proxy, a diagnosis, a predictor, a target for reform, or a conceptual framework for societal action. The differing views have consensus on the need for the measurement of multi-dimensional concepts. However, they rarely reach consensus on appropriate ways to measure them (Botero et al., 2011). The controversy between supporters for composite indicators and dissenters may stem from distinct perspectives on composite indicators' analytical and pragmatic functions. The essence of nonaggregators' argument is in the subjective or somewhat arbitrary nature of composite indicators, whereas the focus of the aggregators' argument is on the practical use of composite indicators (Booysen, 2002; Saisana and Saltelli, 2011).
} 
updates of quantitative ratings facilitates communications with general audiences (Foa and Tanner, 2012; Saisana and Saltelli, 2011).

\subsection{Construction process of composite indicators}

Composite indicators are constructed through the integration of a number of underlying individual (sub)indicators or variables ${ }^{105}$. The construction process of composite indicators involves three levels of indicator groups: individual indicator sets, thematic indicators, and composite indicators. Individual indicator sets represent a list of separate indicators. This is a first step in gathering existing quantitative information. Thematic indicators are individual indicators that are grouped together around specific themes. Although they are linked, they are presented individually rather than synthesized in a composite indicator. A composite indicator is constructed by compiling thematic indicators into a synthetic composite measure. The construction process of a composite indicator consists of several steps: identification of a theoretical framework ${ }^{106}$, data selection or selection of variables, data treatment, weighting, aggregation, and testing for robustness (Freudenberg, 2003). This section provides a brief explanation of the general roadmap for constructing a composite indicator. The actual construction of a global IFT-risk indicator, based on the general construction process for a composite indicator, is unfolded in Section 4.4 .

105 Literature for composite indicators uses interchangeably the terms 'underlying (sub)indicators' and 'variables', which are combined into a composite indicator. It may be somewhat bothersome to distinguish underlying 'indicators' and a composite 'indicator' when they are used at the same time. Thus, this study uses the term 'variables' only in expressing components combined into a composite indicator. 106 This study has employed two sets of theoretical frameworks: one set for the global analysis unfolded in this chapter and the other set for the local analysis discussed in Chapter 5 and Chapter 6 . The theoretical framework for the global analysis has been derived from elements associated with IFT-risk, whereas the theoretical frameworks for the local analysis aim to examine interpersonal dynamics within IFT-systems. The theoretical framework to be used in this chapter accompanies the overview of construction of a composite indicator. 


\subsubsection{Identification of a theoretical framework and selection of variables}

A composite indicator aims to measure a complex or multi-dimensional concept by integrating individual variables that are linked around the concept to be measured. The quality of a composite indicator thus largely depends on the quality of the underlying individual variables. It is therefore crucial to gain a thorough understanding of the individual variables that comprise the concept and the relationships between them (Saltelli, 2007). Gaining an understanding of individual variables is made possible by a theoretical framework for the concept. A theoretical framework provides a basis for selecting the individual variables to be integrated into a composite indicator, combining them, and weighing them (Freudenberg, 2003).

The designers of composite indicators must decide which variables - and how many variables - to select ${ }^{107}$ when constructing a composite indicator, taking into account not only the selected theoretical framework, but also data availability ${ }^{108}$ (Freudenberg, 2003). The decision as to whether the designers should adopt a narrow or broad selection of variables, depends largely on the measurability of the latent variable that a composite indicator intends to capture. There is no definitive answer to the question of how many individual variables to include when constructing a composite indicator. In general, the more ambiguous the concept to be measured (e.g., governance), and the less data is available, the higher the likelihood that a large pool of

107 While the choice of variables should be guided by the theoretical framework, the data selection process can be somewhat subjective because there may be no single definitive set of variables (Saisana and Saltelli, 2011).

108 Strengths and limitations of composite indicators are strongly related to the quality of data employed for construction of them. Because of the expense and time required to develop internationally comparable indicators, composite indicators often employ data sources that are less desirable than expected. Composite indicators of country performance generally involve trade-offs between broader country coverage and lower quality data (Freudenberg, 2003). Given a scarcity of internationally comparable quantitative (hard) data, composite indicators often include qualitative (soft) data from surveys or policy reviews as well as proxy variables (Saltelli, 2007). 
variables will capture the phenomenon in question ${ }^{109}$ (Foa and Tanner, 2012). The interrelationships between selected variables are an important element in the construction of composite indicators (Saisana and Saltelli, 2011).

\subsubsection{Data treatment and normalization}

Although the designers of composite indicators select variables taking into account data availability, datasets are rarely ever complete. In many cases, data are only available for a limited number of countries, or only for certain data components. Like most statistical analyses, composite indicators are plagued by problems that occur as a result of missing values (Nardo et al., 2005). There are several methods for dealing with missing values. These can be categorized into two groups. The first and easiest is data deletion; omitting any country or variable for which substantial data are missing. This can prevent a number of methodological complications, such as identification of the reasons or patterns for missing values, and inference of the relation of missing values to the outcome of interest (Fitzmaurice et al., 2015; Little and Rubin, 2020). The second solution to the problem of missing data is to impute missing values (e.g., by using the mean substitution, nearest neighbor, or regression technique). The imputation technique may face the issue of legitimacy, where countries are rated on a given dimension of country performance, based on estimated data rather than actual data (Foa and Tanner, 2012; Freudenberg, 2003). In addition to the management of missing values, the data to be managed include outliers ${ }^{110}$, in order to keep them from becoming unintended benchmarks in the course of the normalization step. Outliers can have an impact on the correlation structure, and hence may introduce bias in the interpretation

109 The subject of the global analysis is IFT-risk, which is a complex and multi-dimensional concept, has few data to directly reflect itself, and is not likely to be measured with a handful of variables. How many variables are employed to construct a global IFT-risk indicator is discussed in the following section.

110 There are several methods to find outliers in data. Scatter (or box) plot and z-score are frequently used. The global analysis has examined the relationships between IFT-risk levels and regions (or national income levels) with scatter (or box) plots. Several outliers are identified in the box plots (Figure 8 and Figure 9). 
of the results. When constructing composite indicators, the impact of outliers ${ }^{111}$ can be measured by means of skewness and kurtosis (Saisana and Saltelli, 2011).

The individual variables underlying a composite indicator are often expressed in different measurement units. Before aggregation, different measurement units of each variable must be converted to the same unit to make the values of each variable comparable and combinable. In choosing a suitable method among several normalization methods, the designers of composite indicators must take into account data properties, as well as the objectives of composite indicators. The most popular normalization methods are ranking and standardization (i.e., z-scores).

\subsubsection{Weighting and aggregation}

In order to properly combine the information in the underlying variables, the designer of a composite indicator should decide on a suitable weighting method and an aggregation rule (Foa and Tanner, 2012). Weighting implies a 'subjective' evaluation, which is particularly sensitive when dealing with complex, interrelated, and multidimensional phenomena. Various weighting methods are developed, including statistical procedures (e.g., principal component analysis ${ }^{112}$ ). Ideally ${ }^{113}$, weights should

111 How to deal with outliers in the global analysis is discussed in the next section. The skewness and kurtosis test demonstrates that the values of each IFT-risk element are by and large normally distributed, and the influence of outliers seems to be negligible. Outliers that are legitimately included in data should be retained.

112 Principal component analysis (PCA) is developed as a dimension-reduction tool which can be used to reduce a large set of variables to a small set that albeit still contains most of the information in the large set. In other words, PCA transforms a large number of correlated variables into a small number of uncorrelated variables called principal components. Component loadings, which represent correction coefficients between the variables and the components, are used as weights in constructing a composite indicator (O'Rourke and Hatcher, 2013).

113 In practice, few composite indicators adopt weights derived from statistical procedures. There are several reasons for it: in part because it is difficult to explain to non-statisticians the procedures used to derive weights, in part because the weights themselves change as the data changes over time, but mainly 
reflect the importance of each variable for the overall composite indicator. Weights derived from statistical procedures technically represent the extent to which two or more correlated variables overlap. Alternatively, weighting may use participatory methods that reflect the views of various stakeholders, including experts and politicians. Whatever method is used for weighting, it is challenging to reach consensus on the use weights, and the weights employed are subject to criticism (Saisana and Saltelli, 2011).

There are several rules when combining weighted variables into a composite indicator. Individual variables could be summarized, multiplied, or aggregated using non-linear techniques ${ }^{114}$. Each technique is based on different assumptions and may produce different results (Saisana and Saltelli, 2011).

\subsection{Construction of a global IFT-risk indicator}

\subsubsection{Dimensions of IFT-risk and data employed}

The construct that this study aims to measure with a composite indicator is IFTrisk. In other words, this study has sought to measure how susceptible the countries of interest are to IFT-activities, and to present the extent of their IFT-risk in the form of a global IFT-risk indicator. IFT-risk is a multi-dimensional concept, as the prevalence of IFT-activities is influenced by various factors. According to previous studies on IFTsystems discussed in Chapter 2, IFT-activities are generally associated with the following four factors: migration, access to formal financial institutions, AML/CFT systems in place, and societal attitude towards the informal economy.

\footnotetext{
because the results using equal weights are not substantially different from those using weights derived from statistical procedures (Saisana and Saltelli, 2011).

114 Linear aggregation can be applied when the underlying variables are correlated and full compensability between them is allowed, whereas geometric aggregation (multiplication between variables, where weights appear as exponents) are appropriate when less compensability among them is envisaged (Saisana and Saltelli, 2011).
} 
Studies based on an economic perspective contend that major customers of IFTsystems are expatriate workers, who send part of their income to their relatives in their home countries. Thus, the more immigrants a (remittance sending) country has, the more IFT-risk the country faces; the more emigrants a (remittance receiving) country has, the more IFT-risk the country faces. However, if immigrants have easy access to formal financial institutions for cross-border remittances, this becomes a different story. The easier it is for immigrants to access formal financial institutions, the less the country is exposed to IFT-risk. While some immigrants encounter few obstacles in using formal financial institutions in sending countries, they still opt for IFT-systems. This is because their recipients may have limited access to formal financial institutions. For those who have limited access to formal financial institutions, IFT-systems are a substitute for formal remittance services. AML/CFT systems play a role in suppressing IFT-activities in both sending and receiving countries. In countries where comprehensive AML/CFT measures do not exist or do not function properly, IFT-systems are more likely to thrive than in countries where IFT-systems are strictly controlled by AML/CFT measures.

The extent of IFT-activities, or the degree of IFT-risk, may not be adequately explained with these economic and sociological factors alone. The numbers of migrants, (low) access to formal financial institutions and existing AML/CFT systems may provide important indications as to the likelihood that IFT-systems will thrive in sending and receiving countries. However, their mere association with IFT-systems may not be sufficient to explain the prosperity and decline of IFT-systems and IFT-activities. Even if the three elements converge, IFT-systems may not necessarily prosper. Alternative explanations may interfere with the relationship between the three factors and IFTactivities. In order for IFT-systems to thrive and expand, something needs to combine the three elements and connect them to IFT-systems. Societal attitudes towards the informal economy may be the missing link here; it reflects the degree of tolerance for informal arrangements in a society (e.g., a favorable (or unfavorable) attitude towards informality). The more migration takes place, and the more tolerant law enforcement authorities are towards IFT-activities, the higher the likelihood that IFT-systems will thrive and expand. In sum, a large number of migrants, low access to formal financial 
institutions, and a tolerant societal attitude towards informality may therefore encourage IFT-activities. The presence of strict AML/CFT systems and an intolerant attitude towards informality are likely to restrict IFT-activities. The number of migrants and access to formal financial institutions represent the demand side of IFT-services, whereas the AML/CFT systems in place constitute the supply side of IFT-services. Societal attitudes towards informality influences both sides. Operationalizations of each factor for IFT-systems are closely related to the measurements of relevant variables from the datasets employed for the construction of a global IFT-risk indicator. The operationalized factors are explained along with the datasets.

Table 4.1: Dimensions and measurements of IFT-risk

\begin{tabular}{l|l|l|l}
\hline \multicolumn{1}{c|}{ Dimension } & \multicolumn{1}{|c|}{ Measurement } & \multicolumn{1}{c}{ Dataset } & \multicolumn{1}{c}{ Source } \\
\hline Migration & $\begin{array}{l}\text { Cumulative stock of immigrants } \\
\text { (thousands); } \\
\text { Cumulative stock of emigrants } \\
\text { (thousands) }\end{array}$ & $\begin{array}{l}\text { Migration and } \\
\text { remittances factbook }\end{array}$ & World Bank \\
\hline $\begin{array}{l}\text { Access to } \\
\text { formal } \\
\text { financial } \\
\text { institutions }\end{array}$ & $\begin{array}{l}\text { Account at formal financial } \\
\text { institutions (\%); } \\
\text { Debit card (\%) }\end{array}$ & $\begin{array}{l}\text { The Little Data Book } \\
\text { on Financial Inclusion }\end{array}$ & World Bank \\
\cline { 2 - 5 } & ATMs per 10o,ooo adults & $\begin{array}{l}\text { Financial Access } \\
\text { Survey }\end{array}$ & IMF \\
\hline $\begin{array}{l}\text { AML/CFT } \\
\text { system }\end{array}$ & $\begin{array}{l}\text { Compliance score with 48 } \\
\text { recommendations; } \\
\text { Compliance score with special } \\
\text { Recommendation VI }\end{array}$ & $\begin{array}{l}\text { Mutual evaluation } \\
\text { reports }\end{array}$ & FATF \\
\hline $\begin{array}{l}\text { Societal } \\
\text { attitude } \\
\text { towards } \\
\text { Informality }\end{array}$ & $\begin{array}{l}\text { Protection of property rights; } \\
\text { Protection of intellectual } \\
\text { property; } \\
\text { Reliance of police services; } \\
\text { Strength of auditing and } \\
\text { reporting }\end{array}$ & $\begin{array}{l}\text { Executive opinion } \\
\text { survey }\end{array}$ & WEF \\
\hline
\end{tabular}

Source: the author

In this study, the following five datasets from four international entities (Table 4.1) were used to construct a global IFT-risk indicator and to assess IFT-risk across the world: migration data from the World Bank, financial inclusion data from the World Bank, financial access survey data from the IMF, mutual evaluation reports of the 
AML/CFT from the FATF, and executive opinion survey data from the WEF. First, this study extracted data on the cumulative numbers of emigrants and immigrants from the migration and remittance dataset of 2013 released by the World Bank in 2016 (World Bank, 2016). The use of this dataset was based, on the one hand, on the notion that the demand - or the market size - for IFT-services is strongly associated with the number of remittance senders and recipients ${ }^{115}$. And on the other hand, on the notion that expatriate workers and their relatives in home countries account for the majority of the customers of IFT-systems. The size of the demand for IFT-services in a country can therefore be gauged by summing up the cumulative numbers ${ }^{116}$ of emigrants (i.e., senders from foreign countries) and immigrants (i.e., senders in the country itself).

In this study, the 2014 financial inclusion dataset of the World Bank ${ }^{117}$ and the 2014 financial access survey dataset of the $\mathrm{IMF}^{118}$ were used to reflect the level of access to formal financial institutions in assessing IFT-risks across countries. This is because limited access to formal financial institutions implies a higher likelihood of using IFTsystems. The financial inclusion dataset from the World Bank and the financial access survey from the IMF include various factors concerning the use of financial services ${ }^{119}$

115 There are few datasets dealing with recipients of IFT-systems and few clues about the number of them. However, the cumulative number of emigrants can be used to gauge the market size for IFT-services in a certain receiving country.

116 As the market size is often gauged with the 'number' of target customers rather than the 'proportion' of target customers in the whole population (Evans, 1989), this study has sought to measure the market size for IFT-services in a country, with the stocks of emigrants and immigrants.

117 The World Bank launched the Global Findex database in 2011 and published in 2015 the first little data book containing the global financial development data collected in 2014. Even though as of February 2018, the 2015 version of the little data book is available, this study has employed the 2014 version in order to make a comparison with the migration dataset that the World Bank produced in 2013.

118 The IMF launched the financial access survey in 2009, which is a supply-side database to measure and monitor financial inclusion. Even though, as of February 2018, the 2017 financial access survey is available, this study has employed the 2014 version for the same reason that the World Bank's little book on financial inclusion 2014 was employed for the global analysis.

119 The two surveys all deal with financial inclusion. The World Bank's survey focuses on the demandside of financial inclusion, whereas the IMF's survey seeks to capture its supply-side. 
(Demirguc-Kunt and Klapper, 2012). The two datasets do not contain variables directly associated with 'cross-border' remittances. Thus, this study selected three ${ }^{120}$ proxy indicators, which estimate the extent of cross-border remittance transfers via formal financial institutions based on the assumption that access to formal financial institutions is positively associated with cross-border remittance transfers via formal financial institutions. These are: the percentage of possession of an account at a formal financial institution, the percentage of possession of a debit card, and the number of automated teller machines (ATMs) per 100,0oo adults ${ }^{121}$.

In this study, the mutual evaluation reports of the FATF and its eight regional partner organizations ${ }^{122}$ were analyzed to reflect the level of AML/CFT enforcement of each country when assessing its IFT-risk. This analysis is based on the assumption that IFT-activities may thrive to a lesser extent in countries where AML/CFT systems are

120 The financial inclusion dataset of the World Bank includes remittance-related variables percentages of use of accounts at formal financial institutions to send and to receive 'domestic' remittances. As they deal with domestic 'remittances', they may look more suitable than the three proxy variables in approximating cross-border remittances. However, according to a World Bank lead economist that the researcher of this study contacted via email, data for the two variables do not cover high income countries. Gallup interviewers used a telephone interview method to collect financial inclusion data for high income countries. They focused on major questions to collect as many data as possible before interviewees hang up. As the two variables for domestic remittances do not cover high income countries, they could not be used in this study.

121 Online banking services or mobile phones can give people in unbanked areas access to formal financial services because of a dramatic increase in the coverage of Internet infrastructure and mobile phones (Long, 2018). Nevertheless, as ATMs remain central to the banking industry (Proverbio et al., 2016), penetration of ATMs must be a major measurement for financial inclusion or banking sector outreach (Beck et al., 2005). The World Bank started to collect data regarding access to finance via mobile phones in 2014. However, as the variable includes many missing data, it could not be used for this study. 122 The FATF has eight associate members which work as its regional bodies despite their independence of the FATF. Those are: Asia/Pacific Group on Money Laundering (APG), Caribbean Financial Action Task Force (CFATF), Council of Europe Committee of Experts on the Evaluation of Anti-Money Laundering Measures and the Financing of Terrorism (MONEYVAL), Eurasian Group (EAG), Eastern and Southern African Anti-Money Laundering Group (ESAAMLG), Financial Action Task Force of Latin America (GAFILAT), Inter Governmental Action Group against Money Laundering in West Africa (GIABA), Middle East and North Africa Financial Action Task Force (MENAFATF), and Task Force on Money Laundering in Central Africa (GABAC). 
fully compliant with the FATF's 49 Recommendations ${ }^{123}$. Mutual evaluation reports include the assessment of the level of compliance of member countries' AML/CFT systems with the FATF's 49 Recommendations (FATF, 2004; 2009a). This study analyzed the third round of mutual evaluation reports, because the fourth round (initiated in October 2014) of mutual evaluations is still ongoing ${ }^{124}$. According to the methodology for the third round of mutual evaluations, the technical compliance of each member country's AML/CFT system with the FATF 49 Recommendations, was assessed according to a four-point ordinal scale: compliant, largely compliant, partial compliant, and non-compliant ${ }^{125}$ (FATF, 2013b). The mutual evaluation report of each jurisdiction's contains 49 assessment results corresponding to the 49 recommendations, but does not include the overall compliance level. This study presented separately the overall compliance level and a specific compliance level regarding IFT-systems - a recommendation applicable to money or value transfer services (MVTS). Furthermore, this study (arithmetically) averaged the 48 assessment results (except for the assessment regarding IFT-systems), with the aim of obtaining a single value that represents the level

123 This study has analyzed the third-round mutual evaluation reports based on the old methodology assessing compliance with the old 49 recommendations, not the new 40 recommendations.

124 Since the fourth round of mutual evaluations commenced in October 2014 (FATF, 2017), the FAFT has applied a new mutual evaluation methodology. One of the major differences between the old methodology for the third round of mutual evaluations and the new methodology for the fourth round is assessment of 'effectiveness' of AML/CFT measures in place: whereas the third round of mutual evaluations focus on assessing technical compliance of member countries' AML/CFT systems with the FATF's 49 Recommendations, the fourth round deals with effectiveness of AML/CFT measures in place as well as their technical compliance with the FATF's 40 Recommendations (FATF, 2003a; 2013b). Although the fourth round of mutual evaluations are more appropriate than the third round in assessing how AML/CFT systems actually work, this study could not employ the fourth round because the fourth round has been conducted only on 44 countries as of April 2018. Given that the third round of mutual evaluations took approximately 10 years to complete for more than 190 countries, it would be wise and realistic to analyze the third round of mutual evaluation reports rather than to wait for the fourth round to be completed in 6 years. The first fourth round of mutual evaluation report was published in October 2014.

125 The FATF and its associate organizations assess the compliance level of member countries with the FATF recommendations with a four-point ordinal scale. In the coding process, this study has assigned 4 to 'compliant', 3 to 'largely compliant', 2 to 'partially compliant', 1 to 'non-complaint', and o to 'not applicable'. 
of AML/CFT compliance for each country. The compliance level with regard to the recommendation for MVTS (Special Recommendation $\mathrm{VI}^{126}$ ) is combined separately for a global IFT-risk indicator.

In putting together a global IFT-risk indicator, this study also used data from the Executive Opinion Survey 2013 of the WEF, among several other publicly available domain datasets ${ }^{127}$ that deal with informality at a global level. The WEF's survey examines various aspects of competitiveness, such as institutions, quality of education systems, and the level of business sophistication, for which data sources are scarce or often nonexistent - in 148 countries, including most developed countries (Schwab and Sala-i-Martín, 2013). In this survey, business leaders in 139 countries were asked 20 questions regarding their opinions about institutions, based on the idea that the quality of a country's public and private institutions has a great impact on that country's competitiveness and growth. For the questionnaire, four variables were selected that are closely linked to societal attitudes towards informality: protection of property rights, protection of intellectual property, reliability of police services, and strength of auditing and reporting standards. This is because the four variables reify the degree of compliance with formality (or tolerance of informality). For instance, the protection of property rights — including intellectual property — is an essential element of the formal economy. Law enforcement authorities play a crucial role in protecting the property rights of individuals and businesses against crime and illegal activities. Furthermore,

126 Special Recommendation VI in the old 49 recommendations is equivalent to Recommendation 14 in the new 40 recommendations endorsed in 2012.

127 There may be only a few public domain datasets that deal with informality at a global level — the informal employment dataset of the International Labor Organization (ILO), the enterprise survey of the World Bank, and the executive opinion survey of the WEF. The ILO's informal employment dataset provides informal employment statistics which can be used as a proxy for attitude towards informality (ILO, 2013). However, as the dataset covers only 45 developing countries, it may not be qualified for being used in constructing a global IFT-risk indicator. The World Bank's enterprise survey also includes informality-related variables. Although this survey covers 139 countries, few high-income countries are included in the survey. Thus, this survey dataset does not fit a global IFT-risk indicator that seeks to compare IFT-risks of developing and developed countries. 
the auditing and reporting standards of businesses are a self-control mechanism that ensures that formal businesses do not engage in informal business practices. In other words, the aforementioned variables can measure the extent to which the formal economy is protected, by assessing the perception of business executives of institutions in certain countries. The inverse transformation of these measurements - the perception of the level of 'threat' to the formal economy - represents the attitude towards 'informality'. Since these variables relate to the control of the level of informality, they can reflect the expansion and shrinkage of the level of informality. If the interviewed business executives in a given country have a negative perception of the level of protection of property rights and intellectual property, the reliability of police services, and the strength of auditing and reporting standards, this could mean that the country has a favorable attitude towards informality. This could in turn lead to a further increase in the level of informality. Positive perceptions of these variables in a country suggest a reduced level of informality. The four variables in the opinion survey are measured according to a seven-point ordinal scale. As score 1 and score 7 indicate the most negative and the most positive perception respectively, the lower the scores of each variable, the friendlier the attitude towards informality in a given country. In this study, four variables were therefore used to estimate societal attitudes towards informality.

\subsubsection{Preparation of an IFT-risk dataset}

For the global analysis, this study developed a new dataset by combining the five datasets discussed earlier (the new dataset is included in Appendix 1) to assess the IFTrisk of each country, thereby constructing a global IFT-risk indicator. The unit of analysis in the global analysis is a country. The study population consists of countries that were subject to the examinations of the World Bank, the IMF, the FATF and its regional bodies, and the WEF. The subjects of the global analysis consist of 121 
countries $^{128}$. Before developing the combined dataset, the original five datasets had a different number of countries ${ }^{129}$ and each dataset included missing data. This study has adopted a case-by-case deletion approach in managing missing values in the combined dataset. This approach was chosen because the number of cases with missing values was not substantial and because the imputation method may have distorted the data on the level of IFT-risk faced by each country. In the end, the number of countries analyzed in this study was 121.

Table 4.2: Composition of the 121 selected countries

\begin{tabular}{|c|c|c|c|c|c|}
\hline & \multicolumn{4}{|c|}{ National income level } & \multirow{2}{*}{ Total (\%) } \\
\hline & High & Upper middle & Lower middle & Low & \\
\hline \multicolumn{6}{|l|}{ Region } \\
\hline Europe \& Central Asia & 28 & 11 & 5 & - & $44(36.4)$ \\
\hline Middle East \& North Africa & 5 & 4 & 2 & - & $11(9.1)$ \\
\hline Sub-Saharan Africa & - & 5 & 7 & 10 & $22(18.2)$ \\
\hline North America & 2 & - & - & - & $2(1.7)$ \\
\hline L. America \& the Caribbean & 3 & 12 & 5 & 1 & $21(17.4)$ \\
\hline East Asia \& the Pacific & 6 & 3 & 3 & 2 & $14(11.6)$ \\
\hline South Asia & - & - & 5 & 2 & $7(5.8)$ \\
\hline Total & $44(36.4)$ & $35(28.9)$ & $27(22.3)$ & $15(12.4)$ & 121 \\
\hline
\end{tabular}

Source: the author

This study divided the subjects according to regions and national income levels. The two variables were included in all the five datasets, and used as independent variables in the subsequent bivariate analysis (Table 4.2). From a geographical perspective, Europe and Central Asia account for the largest share (36.4\%) of the subjects, whereas the North American countries account for the smallest share (1.7\%). This does not mean that Europe and Central Asia are overrepresented and North

128 The 121 countries were not randomly selected samples but the study population per se. For the global analysis, this study has not attempted to obtain random errors and to infer the findings from the samples to the population (McCloskey and Ziliak, 1996; Ziliak and McCloskey, 2004).

129 Each dataset that this study has analyzed contains data from different numbers of countries. The number of countries for World Bank's Migration and Remittances Factbook 2016 was 214; that for World Bank's the Little Data Book on Financial Inclusion 2014 was 143; that for the IMF's Financial Access Survey 2015 was 174; that for the FATF's Mutual Evaluation Reports was 190; and that for the WEF's Executive Opinion Survey 2013 was 148. Thus, this study started to deal with missing values in 143 countries. 
America is underrepresented. Irrespective of the constitution of the subjects for this study, the number of European countries that are members of the United Nations or the World Bank is the largest, and that of North America is the smallest ${ }^{130}$. Taking into account the World Bank's country classification ${ }^{131}$, the 121 selected countries are also divided into four groups according to national income levels: high income, uppermiddle income, lower-middle income, and low-income groups. The high-income countries account for the largest part (36.4\%) of the subjects and the share of the lowincome countries for the smallest share $(12.4 \%)^{132}$.

130 The World Bank classifies its 217 members into 7 regional groups. A number of small economies have joined the World Bank as its members. Nevertheless, the subjects of the global analysis constitute a good coverage of countries of the world. Given the World Bank's 217 members, the subjects of the global analysis account for $75.9 \%$ of Europe and Central Asia region members, 52.4\% of Middle East and North Africa region members, $45.8 \%$ of Sub-Sahara Africa region members, $66.7 \%$ of North America region members, $50 \%$ of Latin America and Caribbean region members, 37.8\% of East Asia and Pacific region members, and $87.5 \%$ of South Asia region members.

131 The World Bank classifies approximately 200 economies into four income groups - low, lowermiddle, upper-middle, and high income, based on their GNI per capita expressed in U.S. dollars. The thresholds are adjusted for inflation every year. As of calendar year 2013, economies with 1,045 USD for GNI per capita or less are included in the low-income groups. Economies between 1,046 USD and 4,125 USD fall under the lower-middle income group. Economies between 4,126 USD and 12,745 USD are into the upper-middle income group. Economies with more than 12,745 USD are labeled as the high-income countries (Fantom and Serajuddin, 2016).

132 Comparison between the subjects of this study (121 countries) and the World Bank's members (191 countries) in terms of GNI per capita in 2013 has been made as below in order to find whether the subjects of this study are representative of the total number of countries of the world. The national income distribution of the subjects of this study (average $=16,868$ USD; standard deviation $=20,924$ ) is quite similar to that of the World Bank's members (average $=14,855$ USD; standard deviation $=21$, 011 ).

Figure 4.1: Comparison of GNIs per capita between the World Bank Members and the subjects (countries) of this study

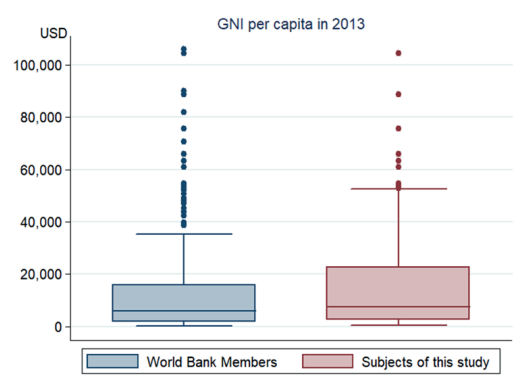


As a first step in the global analysis, this study conducted a univariate analysis of the eleven variables likely to underlie IFT-risk, prior to the normalization of each variable (Table 4.3). The global market size for IFT-services is estimated based on the numbers of emigrants and immigrants in 2013, namely 423.8 million. The average IFTservices market size of the 121 selected countries amounts to approximately 3.5 million, which is nearly equivalent to the total population of Bosnia and Herzegovina. The market size does not necessarily mean that all emigrants and immigrants are - or will become - customers of IFT-systems. Although citizens of a country can make use of IFT-systems, emigrants and immigrants are more likely to be involved in IFT-activities than (non-immigrant) citizens. As for access to formal financial institutions, in 2014, the median value of people with at least one account at a formal financial institution amounted to approximately 57\%, and the median value of people with a debit card amounted to $40 \%$. The number of ATMs per 100,000 adults stood at approximately 55.4 on average. Univariate statistics on the access to formal financial institutions provide little information regarding the patterns of IFT-activities; a bivariate analysis of these variables provides more sensible information. The averaged compliance level of the 121 selected countries with the FATF Recommendations is not as high as envisaged. The overall compliance level with the 48 recommendations (compliance with the MVTSrelated recommendation is excluded) was, on average, between largely compliant (score 3) and partially compliant (score 2 ) (Mean of overall compliance $=\mathbf{2 . 2 7}$ ). The average compliance level with the MVTS recommendation is slightly lower than the overall compliance level (Mean of MVTS compliance $=1.98$ ). In other words, the focus of AML/CFT systems seems to have been largely on formal financial systems, and IFTsystems may be more susceptible to money laundering and the financing of terrorism than formal financial systems. This study conducted the Skewness-Kurtosis test ${ }^{133}$ to examine whether the distributions of the eleven variables are symmetric, or whether

133 Sknewness-Kurtosis test is conducted to detect departures from normality of a variable of interest by measuring the direction and degree of its asymmetry and the tail weight of its distribution. The statistics of Skewness and Kurtosis between -2 and +2 are acceptable in proving that the distribution is normal (Gravetter and Wallnau, 2014). 
they are influenced by outliers. The outcome of the test proved that the eleven variables are normally distributed and that the influence of outliers is negligible.

Table 4.3: Distribution of IFT-risk variables

\begin{tabular}{|c|c|c|c|c|c|}
\hline & Mean & Median & SD & $\mathrm{MAD}^{134}$ & Skewness/Kurtosis \\
\hline $\begin{array}{l}\text { Market size of IFT-services } \\
\text { Stock of emigrants (thousands) } \\
\text { Stock of immigrants (thousands) }\end{array}$ & $\begin{array}{l}1,624.65 \\
1,878.13\end{array}$ & & $\begin{array}{l}2,378.16 \\
4,780.72\end{array}$ & & $\begin{array}{l}.00 / .00 \\
.00 / .00\end{array}$ \\
\hline $\begin{array}{l}\text { Access to formal financial } \\
\text { institutions } \\
\text { Account at formal financial } \\
\text { institutions (\%) } \\
\text { Debit card (\%) } \\
\text { ATMs per 10o,ooo adults }\end{array}$ & 55.21 & $\begin{array}{l}56.90 \\
39.70\end{array}$ & 48.11 & $\begin{array}{l}28.80 \\
25.20\end{array}$ & $\begin{array}{l}.72 / .00 \\
.15 / .00 \\
.00 / .00\end{array}$ \\
\hline $\begin{array}{l}\text { Compliance with the FATF } \\
\text { Recommendations } \\
\text { MVTS compliance (o-4) } \\
\text { Overall compliance (o-4) }\end{array}$ & $\begin{array}{l}1.98 \\
2.27\end{array}$ & 2.32 & $\begin{array}{l}.92 \\
.51\end{array}$ & .38 & $\begin{array}{l}.01 / .09 \\
.52 / .00\end{array}$ \\
\hline $\begin{array}{l}\text { Attitude towards Informality } \\
\text { Protection of property right (1-7) } \\
\text { Protection of intellectual property } \\
(1-7) \\
\text { Reliability of police services (1-7) } \\
\text { Strength of auditing and reporting } \\
\text { standards (1-7) }\end{array}$ & $\begin{array}{r}4.27 \\
3.79 \\
4.25 \\
4.62\end{array}$ & & $\begin{array}{l}1.30 \\
1.09 \\
1.13 \\
.88\end{array}$ & & $\begin{array}{l}.48 / .12 \\
.02 / .00 \\
.19 / .00 \\
.40 / .93\end{array}$ \\
\hline
\end{tabular}

Source: the author

The summary outcomes from the univariate analysis of each IFT-risk variable did not provide sufficient information to detect meaningful variations of IFT-risk variables across the different countries. Therefore, the 121 selected countries were divided into several groups - according to geographical regions and national income levels - in order to obtain an overview of the variations (Table 4.4). Given that neighboring countries tend to share similar economic and social environments, this study categorized the 121 selected countries into seven groups according to their geographical

134 Central tendency and variability of data are normally measured by the mean-standard deviation combo. However, they are susceptible to outliers. The median-median absolute deviation (MAD) combo is used in situation where it is inappropriate to use the standard mean-standard deviation combo. Median absolute deviation or absolute deviation around the median is not sensitive to the presence of outliers (Leys et al., 2013). 
classification. The market size of IFT-services in North America was greater than those in other regions. This may be due to the fact that the United States and Canada are the most preferred countries of destination for immigrants (Edmond, 2017). The average number of migrants was the smallest in Sub-Saharan countries. The regions in which the average number of 'emigrants' was strikingly high are South Asia (5.0 million) and East Asia and the Pacific (2.3 million). Countries attracting large numbers of 'immigrants' were those in North America (26.7 million on average) and MENA (3.1 million on average). The region with the highest access to formal financial institutions was North America. The median percentages of adults who possess bank accounts and debit cards in North American countries were 96.35 and 84.70 respectively. The average number of ATMs per 100,00o adults amounted to 197.67. The levels of access to formal financial institutions in Sub-Saharan Africa and South Asia were quite low and comparable. As for compliance with the FATF Recommendations, the compliance levels of North America and Europe and Central Asia were assessed as higher than those of other regions. Compliance with the MVTS recommendation was highest in Europe and Central Asia. The compliance levels of South Asia and Sub-Saharan Africa were lower than those of other regions. Countries in North America are assessed to have had a more unfavorable attitude towards informality than other regions. The Latin American and Caribbean region appears to have had an equally favorable environment for informality as South Asia and Sub-Saharan Africa. In sum, North American countries may have had a greater demand for IFT-services than countries in other regions. However, it is considered that they had unfavorable environments for IFTactivities in other aspects. This is because there was good access to formal financial institutions in those countries and because they had decent AML/CFT systems in place, which were largely compliant with FAFT Recommendations. Furthermore, those countries had a negative attitude towards informality. Countries in Sub-Saharan Africa do not seem to have had many potential customers for IFT-services. However, they had attractive environments for IFT-activities, such as limited access to formal financial institutions, low adherence to FAFT Recommendations, and a positive attitude towards informality. South Asian countries were exposed to environments similar to those in 
Sub-Sahara African countries, except that South Asian countries had a large number of potential customers for IFT-services.

National income levels are also useful in gaining insight into the variations of IFT-risk variables between different income groups in countries. The market size of IFT-services was greatest in the high-income countries, and smallest in the low-income countries. The average number of immigrants was larger in the high-income countries (3.8 million) than in countries that fall under other income groups (e.g., o.9 million in upper-middle income countries). However, the average number of emigrants was larger in the lower-middle income countries (2.2 million) than in the low-income countries (1.4 million). The level of access to formal financial institutions in the high-income countries was greater than in other income groups. In the low-income countries, compliance with FAFT Recommendations was lower than in countries that fall under other income groups. Societal attitude towards informality was more favorable in the low-income countries, than in countries that fall under other income groups. Therefore, the low-income countries are likely to have been exposed to higher IFT-risk than the countries that fall under other income groups, whereas the high-income group countries seem to have had lower exposure to IFT-risk than countries that fall under other income groups. 


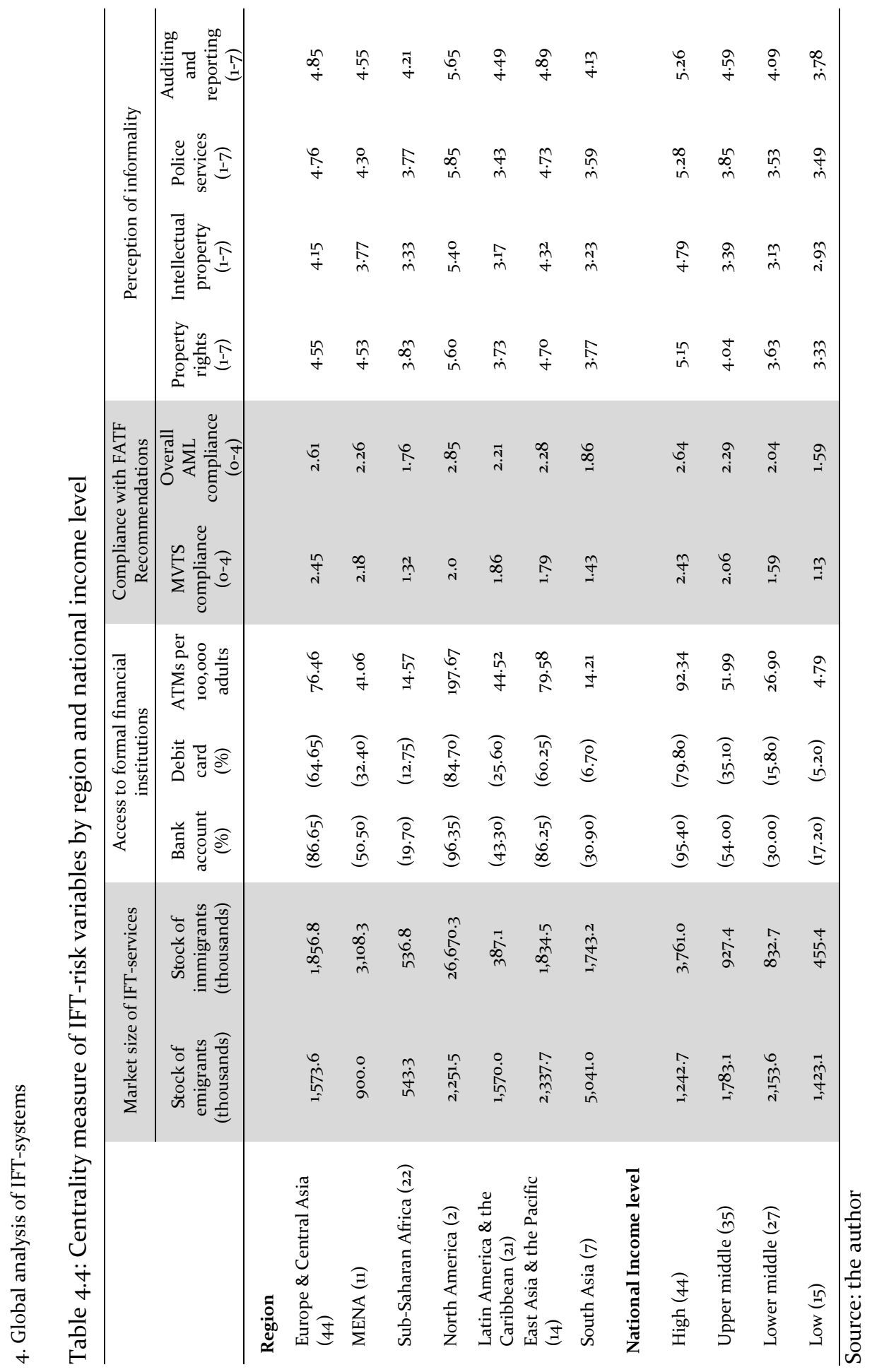




\subsubsection{Putting together of a global IFT-risk indicator}

In order to assess IFT-risk, this study used eleven variables with varying measurement units. The units of measurement for emigrants and immigrants, and for access to ATMs, is the 'number': the number of migrants and the number of ATMs per 100,000 adults. The second unit of measurement, the possession of accounts and debit cards at formal financial institutions, is expressed in the form of a 'percentage'. Compliance with FATF Recommendations, and societal attitude towards informality, are measured with 'ordinal scales' of four points and seven points respectively. As the eleven variables are based on the three different measurement units, simply aggregating them is not feasible. Therefore, normalization of the eleven variables is required prior to their aggregation. From several normalization methods, this study adopted the zscore method and converted the values of the countries of the eleven variables into eleven z-scores (Appendix 2). This approach was chosen given that the z-score standardization can achieve normalization without losing information regarding the performance level of each subject (OECD and JRC, 2008).

Before the eleven z-scores were aggregated, weights were applied to the eleven variables in this study. Irrespective of the method selected from the available weighting techniques, weights are essentially products of value judgments (OECD and JRC, 2008). This study adopted two methods - an equal weighting and a statistical method - to apply weights to the variables alternately, thereby producing two IFT-risk assessment models for a global IFT-risk indicator. Weighting variables using a statistical method requires some explanation. Usually, a statistical method is employed to avoid multiple counting by individual variables and to weight variables in a less arbitrary manner (Nardo et al., 2005). In this study, the statistical method used for weighting is principal component analysis (PCA) ${ }^{135}$. This method is normally used to reduce a number of

135 In constructing a composite indicator, not only PCA but also factor analysis is used. Whereas factor analysis is based on a special statistical model, PCA does not need any particular model (Nardo et al., 2005). 
observed variables to a smaller number of variables (called principal components) that capture most of the variations in the observed variables (O'Rourke and Hatcher, 2013). Since PCA examines redundancy between observed variables - while reducing a number of observed variables into a small number of principal components - weights to be applied to each variable are derived from the extent to which variables overlap. Although they are not a measure of importance of the associated variables, weights used for composite indicators are often derived from PCA, as weights derived from PCA reflect statistical quality of data (Nardo et al., 2005).

PCA requires a large number of samples to obtain reliable results. The number of samples for this analytical technique should be greater than 100, or five times the number of variables analyzed (O'Rourke and Hatcher, 2013). As the global analysis of this study examined the IFT-risk variables of the 121 selected countries to construct a global IFT-risk indicator, this study met the minimum number of required samples for PCA. In order to derive weights to be applied to each variable, PCA reduced the eleven variables to 'three' principal components, given that the principal components with eigenvalues ${ }^{136}$ greater than 1.00 are the first three ${ }^{137}$. After rotating the principal

136 Eigenvalues are a measure for the extents to which each principal component explains the variance in the original observed data. Principal components are often called eigenvectors. In PCA, one of the most commonly used criteria to determine how many principal components should be retained is the eigenvalue-one criterion (O'Rourke and Hatcher, 2013).

137 Figure 4.2: Scree plot of eigenvalues after PCA of IFT-risk data

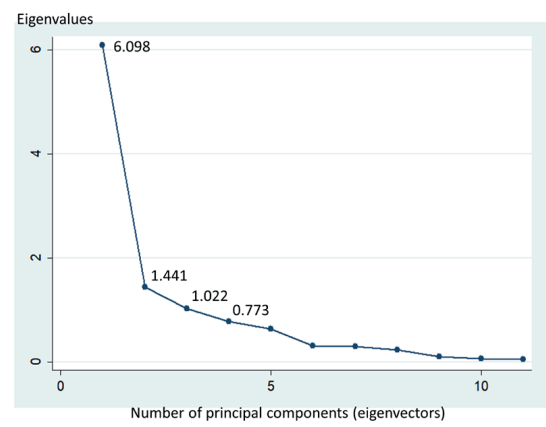

Source: the author 
components $^{138}$, individually the three principal components constitute more than $10 \%$ of the total variance $(47.12 \%, 16.88 \%$ and $13.83 \%$ respectively). Given the cumulative variance for which the three principal components are responsible, they account for approximately $77.83 \%$ of the total variance of the original data collected from the 121 selected countries (Table 4.5). Weights to be applied to each variable are derived from squared component loadings ${ }^{139}$ obtained from PCA. In particular, among the three principal components, the highest squared component loading ${ }^{140}$ for each original variable becomes the weight for each variable (OECD and JRC, 2008). For instance, the weight for the variable 'number of immigrants' is 0.279 , located in the third principal component, which is greater than the other two squared component loadings located in the first and second principal components.

Once the weights for variables are determined, the weighted values of the variables are aggregated. Among several aggregation methods ${ }^{141}$, this study employed

138 In PCA, a procedure of rotation of principal components is applied to make the pattern of component loadings clearer and more pronounced. There are two types of rotation methods: orthogonal and oblique. Orthogonal rotation methods assume that principal components in the analysis are uncorrelated whereas oblique methods are based on the assumption that principal components are correlated. Thus, if correlation coefficients between principal components are .32 and above, there is $10 \%$ (or more) overlap in variance among principal components and needs to apply oblique rotation methods (Brown, 2009). In this study, the correlation coefficients among the three principal components are .oo. Thus, this study has adopted a varimax method of orthogonal rotation methods.

139 Component loadings are correlation coefficents between the original variables and the principal components.

140 Squared component loadings used as weights are produced by dividing squared component loadings by the variances of the original data explained by each principal component (OECD and JRC, 2008). For instance, $0.023=\left(0.340^{\wedge} 2\right) / 5.135$, which is the proportion of the variance of the first principal component explained by the variable percentage of possession of a debit card.

141 Aggregation methods vary. Three methods are often used: linear aggregation, geometric aggregation, and non-compensatory aggregation. If all individual variables have the same measurement unit, the linear aggregation method is useful. Geometric aggregation $\left(=\sqrt{V_{1}+V_{2}+V_{3}+\cdots+V_{n}}\right)$ is appropriate in aggregating 'positive' variables with different ratio-scales. The absence of synergy or conflict effects among variables is necessary to use either linear or geometric aggregations. In both linear and geometric aggregations, deficits in one dimension can be offset by surplus in other dimensions. When different 
the linear aggregation method ${ }^{142}$, given that the values of the eleven variables were all normalized in the form of $\mathrm{z}$-scores, including the fact that negative values and a low score in one IFT-risk element (e.g., access to formal financial institutions) must be offset by high values in other risk elements (e.g., AML/CFT systems).

Table 4.5: Component loadings of a global IFT-risk indicator from PCA with varymax rotation with Kaiser normalization

\begin{tabular}{|c|c|c|c|c|c|c|c|}
\hline & \multicolumn{3}{|c|}{ Component loading } & \multirow{2}{*}{$\begin{array}{l}\text { Cronbach's } \\
\text { alpha }^{143}\end{array}$} & \multicolumn{3}{|c|}{$\begin{array}{c}\text { Squared component loading } \\
\text { (scaled to unity sum) }\end{array}$} \\
\hline & 1 & 2 & 3 & & 1 & 2 & 3 \\
\hline \multicolumn{8}{|l|}{ Market size } \\
\hline Stock of emigrants & .252 & -.138 & .580 & .885 & .012 & .010 & .210 \\
\hline Stock of immigrants & -.053 & .163 & .668 & .908 & .001 & .015 & .279 \\
\hline \multicolumn{8}{|l|}{ Access to formal financial institutions } \\
\hline Account at formal financial institutions & .317 & .140 & -.100 & .833 & .020 & .011 & .006 \\
\hline Debit card & .340 & .133 & -.055 & .831 & .023 & .010 & .002 \\
\hline ATMs per 10o,ooo adults & .163 & .053 & -.434 & .858 & .005 & .002 & .118 \\
\hline \multicolumn{8}{|l|}{ AML-systems } \\
\hline MVTS recommendation & -.027 & .732 & .085 & .859 & .000 & .294 & .005 \\
\hline 48 recommendations & .053 & .600 & -.080 & .849 & .001 & .197 & .400 \\
\hline \multicolumn{8}{|l|}{ Perception of Informality } \\
\hline Protection of property rights & .432 & -.058 & .017 & .834 & .036 & .002 & .000 \\
\hline Protection of intellectual property & .434 & -.071 & -.019 & .833 & .037 & .003 & .000 \\
\hline Reliability of police services & .425 & -.078 & .015 & .836 & .035 & .003 & .000 \\
\hline $\begin{array}{l}\text { Strength of auditing and reporting } \\
\text { standards }\end{array}$ & .363 & .060 & .030 & .838 & .026 & .002 & .001 \\
\hline Variance explained & 5.135 & 1.825 & 1.601 & & & & \\
\hline$\%$ of total variance (Cumulative \%) & 46.68 & $\begin{array}{c}16.59 \\
(63.27)\end{array}$ & $\begin{array}{c}14.56 \\
(77.83)\end{array}$ & & & & \\
\hline Overall Cronbach's alpha & & & & .865 & & & \\
\hline
\end{tabular}

Source: the author

dimensions of a phenomenon concerned should be treated independently in constructing a composite indicator, a non-compensatory logic may be necessary (Nardo et al., 2005).

142 Global IFT-risk indicator with PCA weights $=0.210 \mathrm{z} \_$emigrant $+0.279 \mathrm{z} \_$immigrant +0.020 z_account +0.023 z_debit +0.118 z_atm +0.294 z_MVTSrecommedation +0.400 z_overallrecommendation + 0.036 z_propertyrights + 0.037 z_IPR + 0.035 z_policing + 0.026 z_auditing .

143 Cronbach's alpha is a useful statistic to gauge the internal consistency of a questionnaire. It demonstrates how closely related a set of items or variables are as a group. Cronbach's alpha ranges from o to 1.o. Many experts suggest that the value should reach at least 0.6 to 0.7 or higher to confirm consistency (Cortina, 1993). 
The two different weights (i.e., equal weights and weights derived from PCA) produced 'two IFT-risk assessment models' for a global IFT-risk indicator. This resulted in two sets of IFT-risk values and ranks ${ }^{144}$ for the 121 selected countries, which were placed side by side according to their weighting methods (Appendixes 3 and 4 ). The higher a country's IFT-risk ranking, the higher the IFT-risk it faces. For instance, Myanmar (according to the equal-weighted score) and Bangladesh (according to the PCA-weighted score) face a higher IFT-risk than other countries. Switzerland (according to the equal-weighted score) and Belgium (according to the PCA-weighted score) face a lower risk than other countries in terms of exposure to IFT-risk.

\subsection{Analysis of IFT-risk values}

The global IFT-risk indicator(s) was developed on the basis of the general process used to construct a composite indicator. The different weighting methods resulted in different outcomes, which led to the question of which IFT-risk assessment model is better suited to the aim of this study - capturing the global landscape of IFT-risk. This section not only intends to answer this question, but also seeks to discover patterns in IFT-risk values per region and per national income level.

\subsubsection{IFT-risk values by different weighting methods}

The differences between the ranks of the 121 selected countries are the result of the different weights applied while aggregating the values of the IFT-risk variables (Appendixes 3 and 4 ). Most countries have few differences between their ranks, despite the different weights. However, there are relatively large gaps between the ranks of

\footnotetext{
144 The ranks indicated in Appendixes 3 and 4 are derived from the two different IFT-risk assessment models. They are somewhat different from each other. The reason for presenting the 'ranks' derived from the IFT-risk values instead of presenting the IFT-risk values per se for each country is that IFT-risk values per se are not approachable for policy makers and other audience although they suggest information about the differences of IFT-risk between countries.
} 
some countries. Changes in ranks that exceed a quartile merit an examination to identify the factors that explain the large gaps. The countries with a rank difference of more than 30 are listed at the top of Table 4.6.

Table 4.6: Countries with more than 30 rank difference by the two different weighting methods

\begin{tabular}{|c|c|c|c|c|c|c|c|c|c|c|c|c|c|}
\hline \multirow[t]{2}{*}{ Country } & \multirow[t]{2}{*}{ Region } & \multirow{2}{*}{$\begin{array}{c}\text { Nat'l } \\
\text { income } \\
\text { level }\end{array}$} & \multicolumn{2}{|c|}{$\begin{array}{c}\text { Market } \\
\text { size }\end{array}$} & \multicolumn{2}{|c|}{$\begin{array}{l}\text { Financial } \\
\text { inclusion }\end{array}$} & \multicolumn{2}{|c|}{$\begin{array}{c}\text { AML- } \\
\text { systems }\end{array}$} & \multicolumn{2}{|c|}{ Informality } & \multicolumn{2}{|c|}{$\begin{array}{c}\text { Overall } \\
\text { rank }\end{array}$} & \multirow[t]{2}{*}{ Difference } \\
\hline & & & $E$ & $\mathrm{~S}$ & $\mathrm{E}$ & $\mathrm{S}$ & $E$ & $\mathrm{~S}$ & $\mathrm{E}$ & $\mathrm{S}$ & $E$ & $\mathrm{~S}$ & \\
\hline US & North America & High & 1 & 1 & 118 & 119 & 113 & 114 & 99 & 99 & 74 & 2 & 72 \\
\hline UAE & MENA & High & 21 & 18 & 89 & 90 & 39 & 49 & 106 & 106 & 91 & 49 & 42 \\
\hline Colombia & L. America \& Carib. & U. middle & 30 & 36 & 46 & 47 & 119 & 119 & 50 & 49 & 71 & 112 & 41 \\
\hline Canada & North America & High & 16 & 14 & 120 & 120 & 51 & 65 & 113 & 114 & 113 & 75 & $3^{8}$ \\
\hline Egypt & MENA & L. middle & 23 & 24 & 13 & 19 & 98 & 95 & 24 & 27 & 37 & 73 & 36 \\
\hline New Zealand & E. Asia \& the Pacific & High & 59 & 55 & 105 & 97 & 40 & 52 & 119 & 119 & 108 & 72 & 36 \\
\hline Guatemala & L. America \& the Carib. & L. middle & 72 & 74 & 39 & 42 & 103 & 102 & 36 & 36 & 56 & 91 & 35 \\
\hline Mauritania & S. Saharan Africa & L. middle & 116 & 116 & 17 & 17 & 45 & 40 & 6 & 6 & 10 & 43 & 33 \\
\hline Angola & S. Saharan Africa & U. middle & 97 & 99 & 32 & 28 & 47 & 41 & 4 & 4 & 13 & 46 & 33 \\
\hline Bulgaria & Europe \& C. Asia & U. middle & 54 & 60 & 83 & 98 & 116 & 115 & 39 & 38 & 81 & 114 & 33 \\
\hline Namibia & S. Saharan Africa & U. middle & 118 & 118 & 62 & 62 & 14 & 15 & 87 & 86 & 70 & 38 & 32 \\
\hline Luxembourg & Europe \& C. Asia & High & 117 & 115 & 109 & 107 & 53 & 47 & 117 & 116 & 111 & 80 & 31 \\
\hline
\end{tabular}

Source: the author

The big differences between the IFT-risk ranks of the same countries may involve complex reasons. One plausible reason is a combination ${ }^{145}$ of some outliers ${ }^{146}$ in the

145 Whereas the IFT-risk elements with bigger variations in the equal weighted indicator are 'access to formal financial institutions' and 'attitude towards informality', those in the PCA weighted indicator are 'market size for IFT-systems' and 'compliance with the FATF recommendations.' Thus, the impacts of the market size and the compliance level are amplified in the PCA weighted indicator, compared to those in the equal weighted indicator.

Table 4.7: Standard deviation values of IFT-risk elements

\begin{tabular}{lcc}
\hline & Equal weighted & PCA weighted \\
\hline Market size & 1.56 & $\mathbf{0 . 3 8}$ \\
Financial Inclusion & 2.74 & 0.15 \\
AML-systems & 1.86 & $\mathbf{0 . 3 9}$ \\
Informality & 3.74 & 0.13 \\
\hline
\end{tabular}

Source: The author

146 There are several mechanisms that causes outliers, such as data errors, sampling error, standardization failure, and legitimate cases. When it comes to how to deal with outliers, if outliers are 
market size for IFT-systems and the greater weights on the market size for IFT-systems and the level of compliance with the FATF Recommendations (Table 4.5). The impacts of the market size and the compliance level seem to be amplified in the global IFT-risk indicator based on PCA weights (Table 4.7). The countries with relatively big markets for IFT-systems (e.g., the US, the UAE, and Canada) are assessed as having higher IFTrisks, or lower IFT-risk ranks, in the PCA weighted indicator than in the equal weighted indicator. The countries with relatively high levels of compliance ${ }^{147}$ with the FATF Recommendations (e.g., Colombia, Egypt, Guatemala, and Bulgaria) are assessed as having lower IFT-risks, or higher IFT-risk ranks, in the PCA weighted model than in the equal weighted model.

Nevertheless, the differences in ranks raise doubts regarding the validity of this composite indicator. Studies on composite indicators (OECD and JRC, 2008) emphasize that the lack of a definitive way to determine weights and an aggregation method does not necessarily lead to a rejection of the validity of a composite indicator, as long as the process of constructing a composite indicator is transparent and fully elaborated.

\subsubsection{IFT-risk values by region and national income level}

Each IFT-risk rank in itself and their IFT-risk elements provide few clues in terms of finding patterns regarding IFT-risks faced by the countries of interest. In the hope of finding hidden factors that are likely to contribute to the variations of the IFT-risk

\footnotetext{
illegitimately included in data, it would be common sense to remove them from the data. However, when outliers are a legitimate part of the data, they can be kept albeit applying transformation or truncation to them (Osborne and Overbay, 2004). Given that the discussion about removal of outliers is to enhance inference of parameters of the population from statistics of the samples, outstanding values of some countries in the IFT-risk elements were irrelevant to removal of outliers because they were parameters of the population, not statistics of the samples. The outliers identified in the IFT-risk element values are not anomalies that need to be removed, but legitimate values that reflect specific characteristics of the countries concerned.

147 A question of the validity of the FATF's evaluation on the compliances of Colombia, Egypt, Guatemala, and Bulgaria with the FATF recommendations is beyond the scope of this study.
} 
variables and the overall IFT-risk ranks, this study organized the IFT-risk values of the 121 selected countries by region and national income level (Figure 4.3 and Figure 4.4).

Figure 4.3: Overall IFT-risk values by region and national income level

$<$ IFT-risk equally weighted by region >

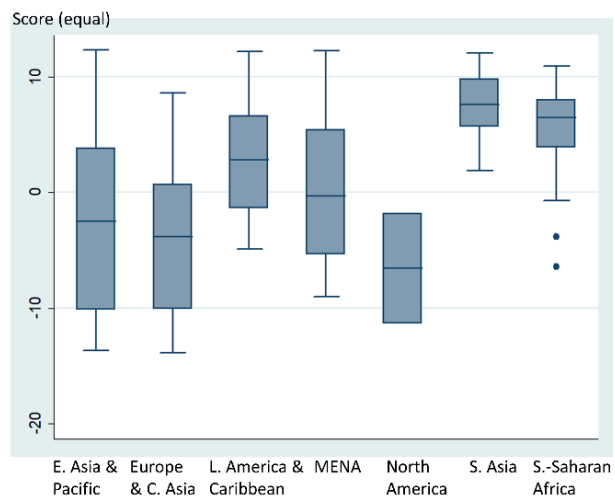

$<$ IFT-risk equally weighted by nat'l income level > Score (equal)

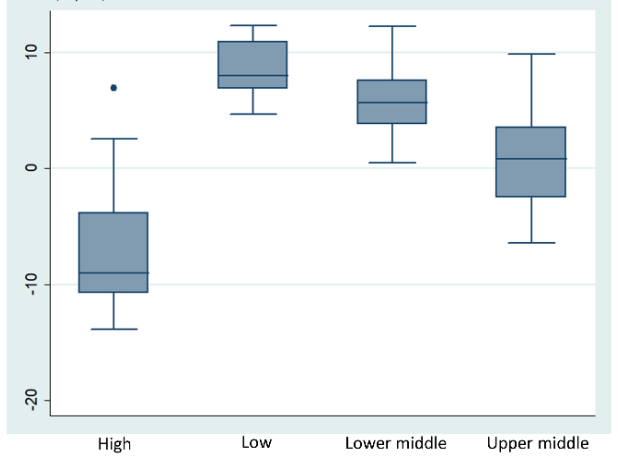

$<$ IFT-risk PCA weighted by region >

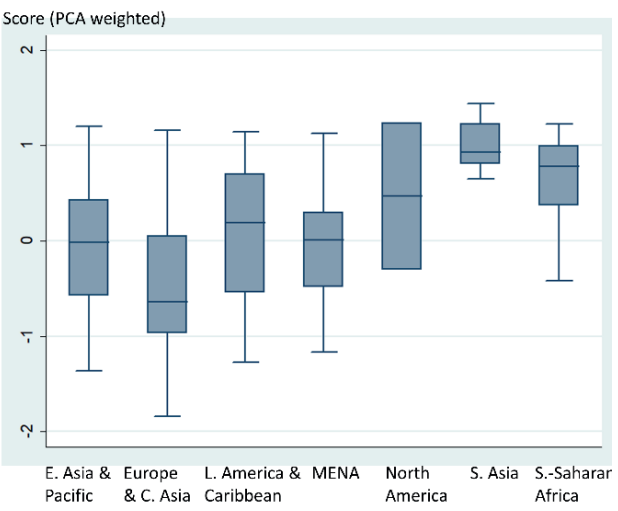

$<$ IFT-risk PCA weighted by nat'l income level >

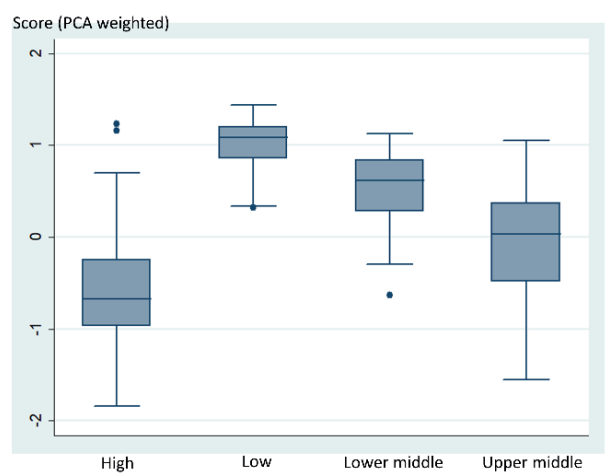

Source: the author

According to the box plots in Figure 4.3, which visualizes the 'overall IFT-risk values' by region and national income level, Southern Asian countries and Sub-Saharan African countries are rated with greater IFT-risk than other countries. Countries in Europe and the Central Asia region seem to be more protected against IFT-risk than those in other regions. The overall IFT-risk levels faced by Northern American countries differ according to the weighting methods employed. Expect for Northern American countries, the two different weights made little difference in the regional IFT-risk 
patterns. When the IFT-risk values of the 121 selected countries are also arranged by national income level, the findings confirm the general assumption that the national income levels of countries are likely to be negatively related to their IFT-risk levels. The level of IFT-risk of the high-income group is lower than the IFT-risk of countries that fall under other income groups. The IFT-risk faced by the countries that fall under the low-income group is the largest. The two different weighting methods have made little difference in the IFT-risk pattern with respect to national income levels.

The relationship between the IFT-risk elements and the national income levels ${ }^{148}$ of the 121 selected countries is also examined using box plots (Figure 4.4). The differences in the market size of IFT-services do not appear to be significant among the different national income groups. However, the market size of IFT-services appears to be slightly larger in the countries that fall under the high-income group than in the countries that fall under other income groups. There are significant differences in the level of access to formal financial institutions among the different income groups. The IFT-risk of the high-income group associated with the level of access to formal financial institutions is assessed as lower than those in other income groups. The low-income group's IFT-risk associated with the level of access to formal financial institutions seemed to be the largest.

This finding is similar to that of IFT-risk related to AML/CFT systems: the highincome group's IFT-risk element values for AML/CFT systems are the lowest on average, whereas the low-income group's IFT-risk element values for this dimension are the highest. The dimension of societal attitude towards informality in IFT-risk also demonstrates a similar pattern to that of financial accessibility and AML/CFT systems. The high-income group has the least favorable attitude towards informality, while the attitude towards informality appears to be most favorable in the low-income group. As

148 The relationship between the IFT-risk elements and the geographical regions is not as pronounced as that between the IFT-risk elements and national income levels. Thus, the relationship is not presented here. 
for the impact of the different weighting methods on the IFT-risk element values, when considering the national income levels, the IFT-risk element values for the four dimensions are not significantly different according to the two different weighting methods.

Figure 4.4: IFT-risk element values by national income level
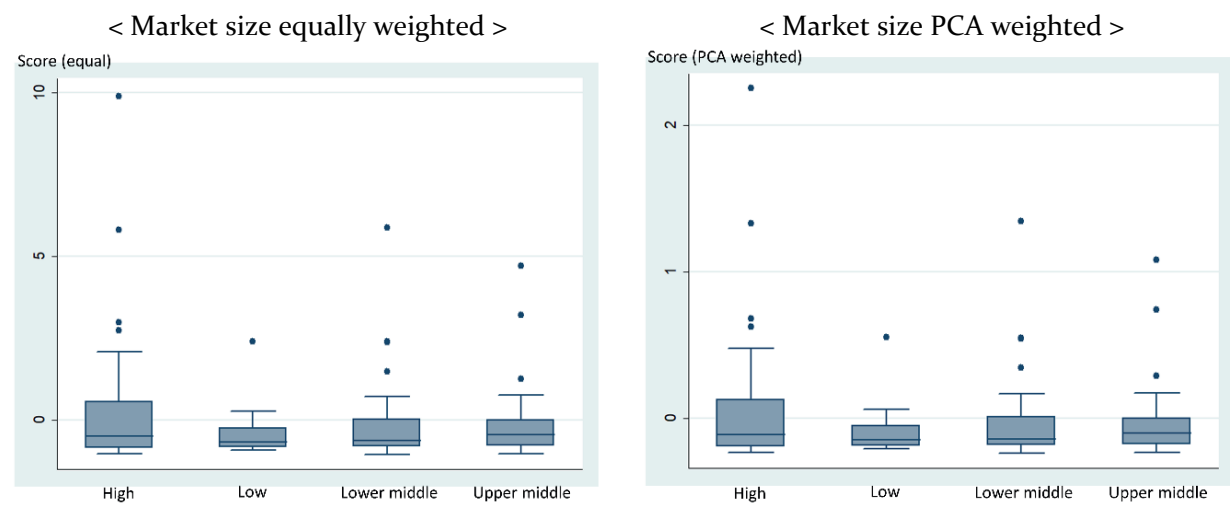

$<$ Financial accessibility equally weighted >

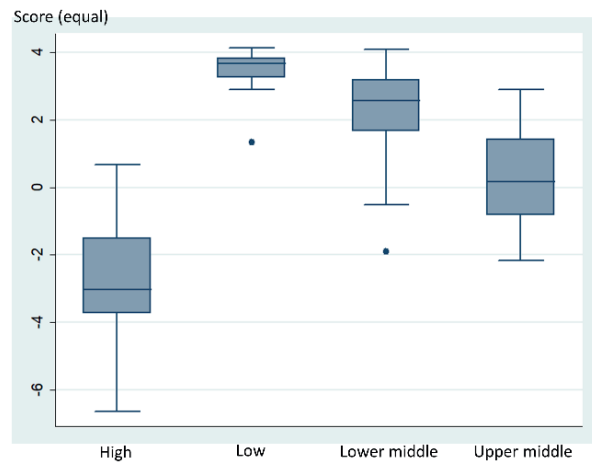

$<$ Financial accessibility PCA weighted > Score (PCA weighted)

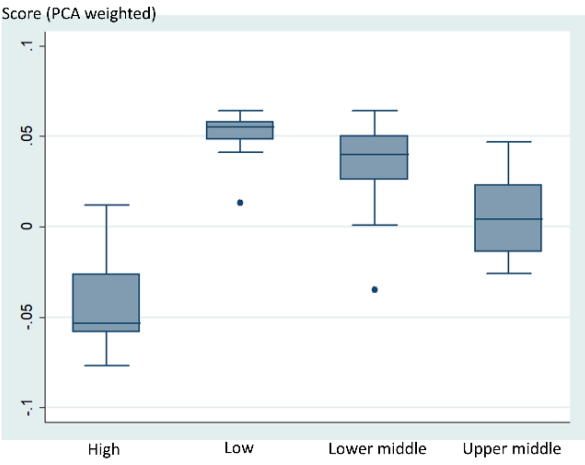

$<$ AML-systems equally weighted >
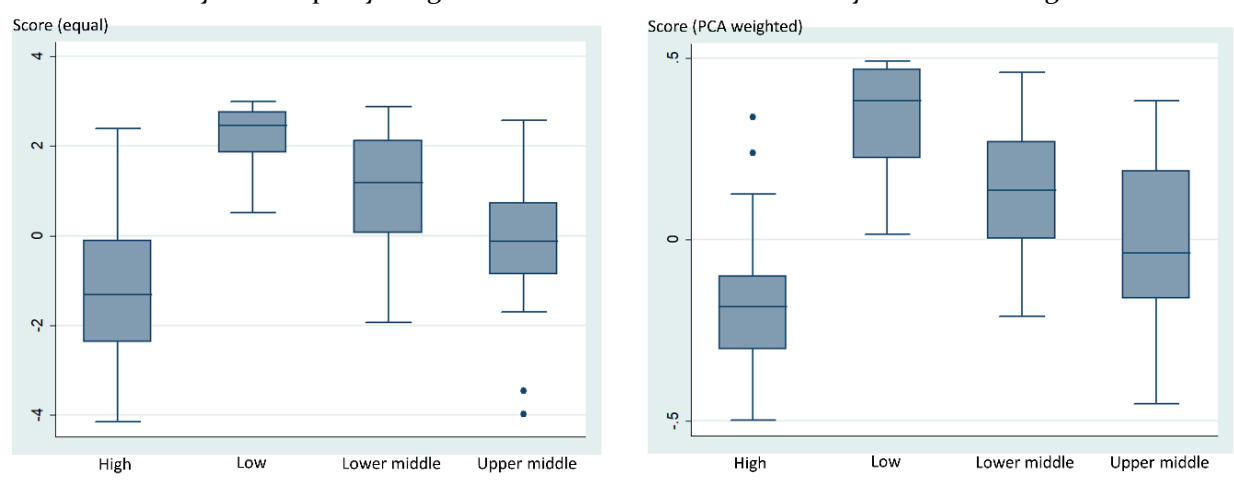

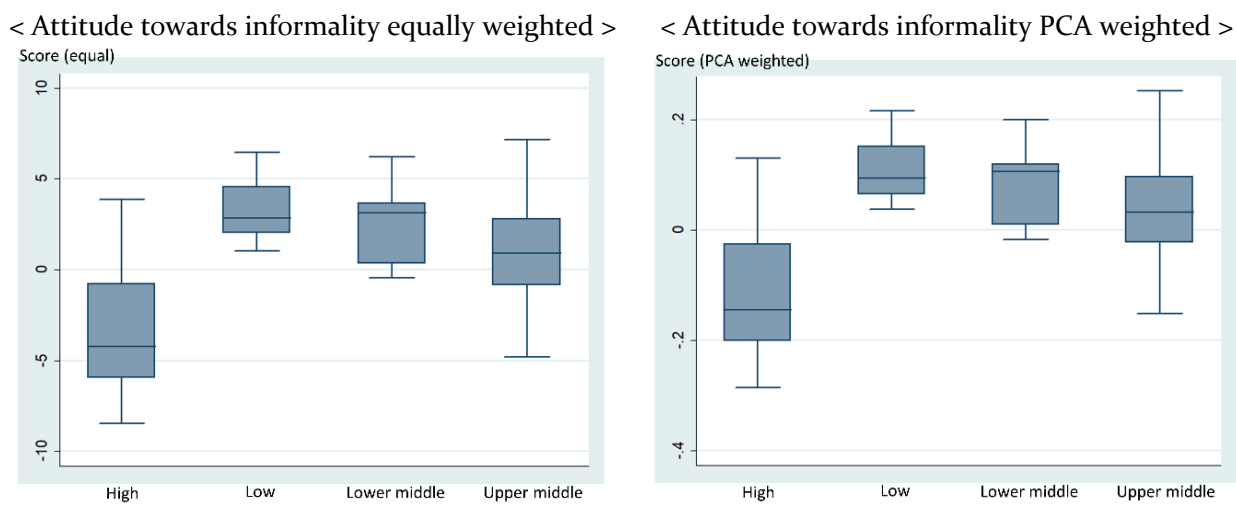

Source: the author

\subsubsection{Highest and lowest at-risk countries}

When listing the ten countries with the highest IFT-risk at the top of Table 4.8, it becomes apparent that most of them are from the low-income group. The ten countries identified as being exposed to the lowest IFT-risk (Table 4.9) are mostly from the highincome group and are concentrated in Europe and Central Asia. Although there are differences between the 10 countries with the highest IFT-risk (or with the lowest IFTrisk) according to the different weighting methods, several countries fall under the same groups. Regardless of the weighting methods applied, Bangladesh, Cambodia and Haiti were identified as the countries with the highest IFT-risk, whereas Switzerland, Belgium and Malta are identified as being those with the lowest IFT-risk. Given that the level of IFT-risk faced by developed countries is low, and that of developing countries is high, a controversial argument could be made that, despite taking into accounts various factors and exercising the complex procedures to gauge IFT-risk levels, the national income level is ultimately the decisive factor ${ }^{149}$ in determining IFT-risk levels (Dynan and

149 In finding a causal relationship, three criteria should be met: temporal precedence, covariation of the cause and the effect, and no plausible alternative explanations (Shadish et al., 2002). In the relationship between the level of IFT-risk faced by a certain country and its national income level, it may be challenging to determine which one is the cause or the effect because they may interact each other. However, the impact of national income level on IFT-risk must be greater than that of IFT-risk on national income level. National income level is determined by a number of factors perhaps including IFT-activities. 
Sheiner, 2018; Lehne et al., 2014; Oulton, 2012). This finding is consistent with studies on the relationship between economic growth and informality, proving that the level of informality within a country decreases with development (La Porta and Shleifer, 2014; Loayza and Rigolini, 2006).

Table 4.8: 10 countries with the highest IFT-risk

\begin{tabular}{|c|c|c|c|c|c|c|c|}
\hline Country & Region & $\begin{array}{c}\text { Nat'l Income } \\
\text { level }\end{array}$ & $\begin{array}{c}\text { Market } \\
\text { size }\end{array}$ & $\begin{array}{c}\text { Financial } \\
\text { accessibility }\end{array}$ & $\begin{array}{c}\text { AML- } \\
\text { Systems }\end{array}$ & $\begin{array}{l}\text { Perception of } \\
\text { Informality }\end{array}$ & Overall \\
\hline \multicolumn{8}{|c|}{ Equally weighted } \\
\hline Myanmar & E. Asia \& Pacific & Low & 27 & 12 & 25 & 3 & 1 \\
\hline Yemen & MENA & L. middle & 57 & 2 & 11 & 5 & 2 \\
\hline Haiti & L. America \& Carib. & Low & 58 & 8 & 11 & 2 & 3 \\
\hline Bangladesh & S. Asia & Low & 9 & 18 & 29 & 13 & 4 \\
\hline Guinea & S.-Saharan Africa & Low & 95 & 1 & 16 & 7 & 5 \\
\hline Mali & S.-Saharan Africa & Low & 76 & 6 & 2 & 14 & 6 \\
\hline Paraguay & L. America \& Carib. & U. middle & 75 & 24 & 9 & 10 & 7 \\
\hline Pakistan & S. Asia & L. middle & 10 & 3 & 59 & 23 & 8 \\
\hline Cambodia & E. Asia & Low & 69 & 11 & 1 & 32 & 9 \\
\hline Mauritania & S.-Saharan Africa & L. middle & 116 & 17 & 45 & 6 & 10 \\
\hline \multicolumn{8}{|l|}{ PCA weighted } \\
\hline Bangladesh & S. Asia & Low & 11 & 15 & 29 & 13 & 1 \\
\hline United States & N. America & High & 1 & 119 & 114 & 99 & 2 \\
\hline Nepal & S. Asia & Low & 33 & 20 & 5 & 31 & 3 \\
\hline Mali & S.-Saharan Africa & Low & 78 & 7 & 2 & 14 & 4 \\
\hline Cambodia & E. Asia \& Pacific & Low & 71 & 16 & 1 & 34 & 5 \\
\hline Russia & Europe \& C. Asia & High & 2 & 116 & 70 & 15 & 6 \\
\hline Haiti & L. America \& Carib. & Low & 63 & 3 & 12 & 2 & 7 \\
\hline Yemen & MENA & L. middle & 59 & 6 & 12 & 5 & 8 \\
\hline Sierra Leone & S.-Saharan Africa & Low & 106 & 2 & 3 & 43 & 9 \\
\hline Burkina Faso & S.-Saharan Africa & Low & 42 & 4 & 9 & 44 & 10 \\
\hline
\end{tabular}

Source: the author

Table 4.9: 10 countries with the least IFT-risk

\begin{tabular}{lllccccc}
\hline \multicolumn{1}{c}{ Country } & \multicolumn{1}{c}{ Region } & $\begin{array}{c}\text { Nat'l Income } \\
\text { level }\end{array}$ & $\begin{array}{c}\text { Market } \\
\text { size }\end{array}$ & $\begin{array}{c}\text { Financial } \\
\text { accessibility }\end{array}$ & $\begin{array}{c}\text { AML } \\
\text { Systems }\end{array}$ & $\begin{array}{c}\text { Perception of } \\
\text { Informality }\end{array}$ & Overall \\
\hline \multicolumn{2}{l}{ Equally weighted } & & & & & & \\
Switzerland & Europe \& C. Asia & High & 44 & 107 & 115 & 116 & 121 \\
Singapore & E. Asia \& Pacific & High & 56 & 98 & 110 & 120 & 120 \\
Belgium & Europe \& C. Asia & High & 61 & 111 & 121 & 100 & 119
\end{tabular}

The impact of IFT-risk on national income level may be limited. It thus stands to sense that the national income level of a certain country determines the level of IFT-risk faced by it rather than vice versa. 


\begin{tabular}{llllllll} 
Finland & Europe \& C. Asia & High & 101 & 96 & 72 & 121 & 118 \\
\hline Austria & Europe \& C. Asia & High & 67 & 112 & 101 & 110 & 117 \\
\hline Netherlands & Europe \& C. Asia & High & 41 & 103 & 102 & 115 & 116 \\
\hline Malta & Europe \& C. Asia & High & 120 & 94 & 117 & 102 & 115 \\
\hline Norway & Europe \& C. Asia & High & 98 & 100 & 88 & 114 & 114 \\
\hline Canada & North America & High & 16 & 120 & 51 & 113 & 113 \\
\hline United Kingdom & Europe \& C. Asia & High & 7 & 117 & 114 & 112 & 112 \\
PCA weighted & & & & & & 112 \\
\hline Belgium & Europe \& C. Asia & High & 53 & 102 & 121 & 102 & 121 \\
\hline Malta & Europe \& C. Asia & High & 120 & 88 & 117 & 100 & 120 \\
\hline Slovenia & Europe \& C. Asia & High & 104 & 104 & 118 & 82 & 119 \\
\hline Hungary & Europe \& C. Asia & U.middle & 84 & 75 & 119 & 67 & 118 \\
\hline Switzerland & Europe \& C. Asia & High & 40 & 103 & 111 & 117 & 117 \\
\hline Singapore & E. Asia \& Pacific & High & 48 & 93 & 112 & 120 & 116 \\
\hline Portugal & Europe \& C. Asia & High & 35 & 118 & 110 & 90 & 115 \\
\hline Bulgaria & Europe \& C. Asia & U. middle & 60 & 98 & 115 & 38 & 114 \\
\hline Cyprus & Europe \& C. Asia & High & 113 & 73 & 113 & 88 & 113 \\
\hline Colombia & L. America \& Carib. & U. middle & 110 & 47 & 119 & 49 & 112 \\
\hline Source: the author \& & & & & & & \\
\hline
\end{tabular}

Source: the author

In order to identify the nuanced landscape of IFT-risks, this study first examined the differences in IFT-risks faced by the high-income countries in Europe and Central Asia. The 'high-income' countries in 'Europe and Central Asia' are obviously assessed as having low IFT-risk levels (Figure 4.4), compared to other groups of countries. However, some of those countries fall outside the lower quartile (i.e., higher ranked than $90^{\text {th }}$ ) and may need more careful monitoring of their remittance markets (Table 4.10). The relatively high IFT-risks of Russia, Poland, and Italy seemed to be affected by their market sizes for informal remittance. The worrisome IFT-risks faced by Czech, Croatia, and Greece seem to be attributed to their attitude towards informality and their AML-systems' compliance with the FATF Recommendations. The IFT-risk of Germany looks somewhat alarming despite its high access to formal financial institutions and its high level of negative attitude towards informality. It seems to be associated with the large number of immigrants in Germany. The IFT-risk of Germany seems to be supported by the number of unlicensed money transfer operators investigated (i.e., 100 to 200 money transfer operators annually) (Wang, 2011). 
Table 4.10: The differences of IFT-risks faced by high income countries in the Europe and Central Asia

\begin{tabular}{|c|c|c|c|c|c|c|c|c|c|c|c|c|}
\hline \multirow[t]{2}{*}{ Country } & \multirow[t]{2}{*}{ Region } & \multirow{2}{*}{$\begin{array}{c}\text { Nat'l } \\
\text { Income } \\
\text { level }\end{array}$} & \multicolumn{2}{|c|}{ Market size } & \multicolumn{2}{|c|}{$\begin{array}{l}\text { Financial } \\
\text { inclusion }\end{array}$} & \multicolumn{2}{|c|}{$\begin{array}{c}\text { AML- } \\
\text { systems }\end{array}$} & \multicolumn{2}{|c|}{ Informality } & \multicolumn{2}{|c|}{ Overall rank } \\
\hline & & & $\mathrm{E}$ & $\mathrm{S}$ & $\mathrm{E}$ & $\mathrm{S}$ & E & $\mathrm{S}$ & $E$ & $\mathrm{~S}$ & $\mathrm{E}$ & $\mathrm{S}$ \\
\hline Switzerland & Europe \& C. Asia & High & 44 & 40 & 107 & 103 & 115 & 111 & 116 & 117 & 121 & 117 \\
\hline Belgium & Europe \& C. Asia & High & 61 & 53 & 111 & 102 & 121 & 121 & 100 & 102 & 119 & 121 \\
\hline Finland & Europe \& C. Asia & High & 101 & 102 & 96 & 72 & 72 & 72 & 121 & 121 & 118 & 96 \\
\hline Austria & Europe \& C. Asia & High & 67 & 61 & 112 & 111 & 101 & 99 & 110 & 110 & 117 & 109 \\
\hline Netherland & Europe \& C. Asia & High & 41 & 39 & 103 & 92 & 102 & 101 & 115 & 115 & 116 & 108 \\
\hline Malta & Europe \& C. Asia & High & 120 & 120 & 94 & 88 & 117 & 117 & 102 & 100 & 115 & 120 \\
\hline Norway & Europe \& C. Asia & High & 98 & 94 & 100 & 87 & 88 & 100 & 114 & 113 & 114 & 106 \\
\hline United Kingdom & Europe \& C. Asia & High & 7 & 7 & 117 & 115 & 114 & 116 & 112 & 112 & 112 & 103 \\
\hline Luxembourg & Europe \& C. Asia & High & 117 & 115 & 109 & 107 & 53 & 47 & 117 & 116 & 111 & 80 \\
\hline Estonia & Europe \& C. Asia & High & 111 & 110 & 104 & 99 & 106 & 107 & 96 & 96 & 109 & 111 \\
\hline Sweden & Europe \& C. Asia & High & 73 & 67 & 97 & 79 & 77 & 77 & 111 & 111 & 107 & 93 \\
\hline Denmark & Europe \& C. Asia & High & 99 & 98 & 101 & 91 & 93 & 87 & 101 & 103 & 104 & 105 \\
\hline Ireland & Europe \& C. Asia & High & 68 & 69 & 106 & 105 & 85 & 93 & 103 & 104 & 103 & 104 \\
\hline France & Europe \& C. Asia & High & 13 & 12 & 108 & 109 & 108 & 109 & 105 & 105 & 102 & 102 \\
\hline Slovenia & Europe \& C. Asia & High & 107 & 104 & 110 & 104 & 118 & 118 & 82 & 82 & 101 & 119 \\
\hline Portugal & Europe \& C. Asia & High & 32 & 35 & 115 & 118 & 109 & 110 & 89 & 90 & 99 & 115 \\
\hline Germany & Europe \& C. Asia & High & 6 & 5 & 116 & 113 & 94 & 88 & 109 & 109 & 98 & 71 \\
\hline Spain & Europe \& C. Asia & High & 17 & 17 & 113 & 112 & 104 & 105 & 86 & 87 & 97 & 101 \\
\hline Cyprus & Europe \& C. Asia & High & 113 & 113 & 78 & 73 & 111 & 113 & 88 & 88 & 96 & 113 \\
\hline Latvia & Europe \& C. Asia & High & 100 & 100 & 95 & 94 & 82 & 85 & 79 & 80 & 89 & 92 \\
\hline Lithuania & Europe \& C. Asia & High & 86 & 87 & 79 & 71 & 104 & 105 & 69 & 68 & 85 & 107 \\
\hline Italy & Europe \& C. Asia & High & 14 & 13 & 93 & 100 & 107 & 108 & 65 & 70 & 83 & 89 \\
\hline Slovak & Europe \& C. Asia & High & 90 & 89 & 86 & 83 & 96 & 91 & 56 & 56 & 82 & 98 \\
\hline Czech & Europe \& C. Asia & High & 81 & 79 & 82 & 70 & 79 & 79 & 61 & 60 & 75 & 79 \\
\hline Croatia & Europe \& C. Asia & High & 65 & 65 & 102 & 110 & 34 & 37 & 57 & 58 & 73 & 59 \\
\hline Greece & Europe \& C. Asia & High & 53 & 54 & 85 & 82 & 52 & 45 & $5^{2}$ & 55 & 69 & 60 \\
\hline Poland & Europe \& C. Asia & High & 20 & 21 & 73 & 81 & 38 & 48 & 72 & 71 & 62 & 44 \\
\hline Russia & Europe \& C. Asia & High & 3 & 2 & 99 & 116 & 56 & 70 & 15 & 15 & 24 & 6 \\
\hline
\end{tabular}

Source: the author

As many studies on IFT-systems attend to South Asia where hundi is a popular remittance channel outplaying formal financial institutions, Figure 4.3 shows that South Asian countries are assessed as having higher IFT-risks than the countries of other regions. When the nuanced differences between the IFT-risks faced by the South Asian countries are also observed (Table 4.11), the IFT-risk of Sri Lanka is assessed as lower than those of other countries in South Asia. Its IFT-risk level is lower than those of most Sub-Saharan African countries. It seems to be attributed to Sri Lanka's somewhat unfriendly attitude towards to informality. The IFT-risk faced by India seems to be 
affected by the market size for hundi despite its AML-systems' high compliance with the FATF Recommendations. Although Sub-Saharan Africa is also known to be plagued with IFT-systems, some countries (i.e., South Africa and Mauritius) seem to have lower IFT-risks than all South Asian countries and even some European countries. Their attitude towards informality might make a difference in their relatively low IFT-risks.

Table 4.11: The differences of IFT-risks faced by the countries in South Asia and SubSaharan Africa

\begin{tabular}{|c|c|c|c|c|c|c|c|c|c|c|c|c|}
\hline \multirow[t]{2}{*}{ Country } & \multirow[t]{2}{*}{ Region } & \multirow{2}{*}{$\begin{array}{c}\text { Nat'l } \\
\text { Income } \\
\text { level }\end{array}$} & \multicolumn{2}{|c|}{ Market size } & \multicolumn{2}{|c|}{$\begin{array}{l}\text { Financial } \\
\text { inclusion }\end{array}$} & \multicolumn{2}{|c|}{$\begin{array}{c}\text { AML- } \\
\text { systems }\end{array}$} & \multicolumn{2}{|c|}{ Informality } & \multicolumn{2}{|c|}{ Overall rank } \\
\hline & & & $\mathrm{E}$ & $\mathrm{S}$ & $\mathrm{E}$ & $\mathrm{S}$ & $\mathrm{E}$ & $\mathrm{S}$ & $\mathrm{E}$ & $\mathrm{S}$ & $E$ & $\mathrm{~S}$ \\
\hline Bangladesh & South Asia & Low & 9 & 11 & 18 & 15 & 29 & 39 & 13 & 13 & 4 & 1 \\
\hline Nepal & South Asia & Low & 33 & 33 & 23 & 20 & 5 & 5 & 29 & 31 & 12 & 3 \\
\hline Pakistan & South Asia & L. middle & 10 & 10 & 3 & 10 & 59 & 55 & 23 & 22 & 8 & 20 \\
\hline Vietnam & South Asia & L. middle & 29 & 30 & 36 & 37 & 23 & 24 & 22 & 24 & 20 & 18 \\
\hline Lao PDR & South Asia & L. middle & 64 & 68 & 22 & 26 & 4 & 4 & 48 & 52 & 27 & 12 \\
\hline India & South Asia & L. middle & 2 & 3 & 43 & 35 & 98 & 95 & 70 & 69 & 36 & 28 \\
\hline Sri Lanka & South Asia & L. middle & 42 & 44 & 57 & 39 & 26 & 27 & 73 & 73 & 55 & 34 \\
\hline Guinea & S.-Saharan Africa & Low & 95 & 96 & 1 & 1 & 16 & 17 & 7 & 9 & 5 & 17 \\
\hline Mali & S.-Saharan Africa & Low & 76 & 78 & 6 & 7 & 2 & 2 & 14 & 14 & 6 & 4 \\
\hline Tanzania & S.-Saharan Africa & Low & 96 & 91 & 15 & 14 & 6 & 6 & 35 & 37 & 16 & 14 \\
\hline Sierra Leone & S.-Saharan Africa & Low & 105 & 106 & 4 & 2 & 3 & 3 & 42 & 43 & 17 & 9 \\
\hline Burkina Faso & S.-Saharan Africa & Low & 40 & 42 & 5 & 4 & 9 & 9 & 44 & 44 & 18 & 10 \\
\hline Benin & S.-Saharan Africa & Low & 94 & 97 & 9 & 9 & 16 & 17 & 40 & 40 & 22 & 23 \\
\hline Uganda & S.-Saharan Africa & Low & 91 & 86 & 25 & 18 & 28 & 11 & 31 & 33 & 25 & 27 \\
\hline Zimbabwe & S.-Saharan Africa & Low & 70 & 70 & 16 & 13 & 49 & 43 & 34 & 25 & 32 & 47 \\
\hline Kenya & S.-Saharan Africa & Low & 80 & 76 & 47 & 31 & 6 & 6 & 47 & 46 & 39 & 16 \\
\hline Malawi & S.-Saharan Africa & Low & 104 & 103 & 14 & 12 & 37 & 46 & 51 & 51 & 40 & 48 \\
\hline Mauritania & S.-Saharan Africa & L. middle & 116 & 116 & 17 & 17 & 45 & 40 & 6 & 6 & 10 & 43 \\
\hline Cote d'lvoire & S.-Saharan Africa & L. middle & 34 & 32 & 10 & 11 & 20 & 21 & 27 & 26 & 11 & 15 \\
\hline Lesotho & S.-Saharan Africa & L. middle & 109 & 109 & 19 & 22 & 14 & 15 & 25 & 30 & 19 & 22 \\
\hline Nigeria & S.-Saharan Africa & L. middle & 45 & 46 & 44 & 36 & 42 & 34 & 19 & 17 & 33 & 39 \\
\hline Ghana & S.-Saharan Africa & L. middle & 77 & 77 & 26 & 21 & 18 & 19 & 68 & 72 & 41 & 29 \\
\hline Zambia & S.-Saharan Africa & L. middle & 112 & 112 & 28 & 23 & 8 & 8 & 76 & 76 & 43 & 24 \\
\hline Senegal & S.-Saharan Africa & L. middle & 93 & 92 & 7 & 8 & 63 & 59 & 59 & 57 & 44 & 63 \\
\hline Angola & S.-Saharan Africa & U. middle & 97 & 99 & 32 & 28 & 47 & 41 & 4 & 4 & 13 & 46 \\
\hline Botswana & S.-Saharan Africa & U. middle & 119 & 119 & 50 & 44 & 20 & 21 & 84 & 84 & 61 & 37 \\
\hline Namibia & S.-Saharan Africa & U. middle & 118 & 118 & 62 & 62 & 14 & 15 & 87 & 86 & 70 & 38 \\
\hline Mauritius & S.-Saharan Africa & U. middle & 115 & 117 & 77 & 65 & 46 & 60 & 90 & 89 & 84 & 70 \\
\hline South Africa & S.-Saharan Africa & U. middle & 38 & 37 & 71 & 84 & 73 & 73 & 104 & 101 & 94 & 78 \\
\hline
\end{tabular}

Source: the author

Although the analysis of the IFT-risks faced by each country is limited, it shows that constructing a global IFT-risk indicator and gauging the IFT-risk level of each country, can benefit the endeavors made by the global AML/CFT community to suppress money laundering activities and the financing of terrorism. This is because 
the global IFT-risk indicator not only demonstrates a 'nuanced' landscape of IFT-risk within the group of developed countries and within the group of developing countries, but also provides guidance on making recommendations regarding the economic or social policies in the fight against IFT-systems.

\subsubsection{Association between the overall IFT-risk level and the IFT-risk elements}

When it comes to the application of the global IFT-risk indicator(s) in the analysis of IFT-risk, determining which dimension(s) of IFT-risk are more conducive to the overall IFT-risk level — or which IFT-risk element(s) need(s) more active policy attention - is an important matter. This is closely related to the relationship ${ }^{150}$ between the global IFT-risk indicator and the IFT-risk elements.

This study therefore conducted a linear regression analysis of the global IFT-risk data developed for this study in order to identify critical dimension(s) of IFT-risk (Table 4.12). In the global IFT-risk indicator constructed with equal weights, societal attitude towards informality $(\beta=.509)$ and the level of access to formal financial institutions ( $\beta$ $=.378$ ) explain a higher IFT-risk variance in the 121 selected countries than in the other dimensions. In the global IFT-risk indicator developed with the weights derived from PCA, AML/CFT systems $(\beta=.733)$ and IFT-services market size $(\beta=.286)$ become strategic points to be addressed. The two IFT-risk assessment models presented

150 In examining the relationship between the global IFT-risk indicator and the IFT-risk elements, it should be noted that composite indicators, which are made of sub-indicators or individual variables, are different from ordinary outcome (dependent) variables. The latter are measured independently of predictor (independent) variables, although they are examined in relation with predictor (independent) variables. The relationships between composite indicators and individual variables are not discovered by researchers, but are devised by indicator designers on the basis of their judgement, or on the theoretical frameworks that they choose to use. Thus, values from composite indicators of the same phenomena can differ by designers. This may bring about critical views on composite indicators in terms of validity and reliability. However, as long as processes for constructing composite indicators are transparent and subject to proper scrutiny, composite indicators can benefit policy makers. They can concentrate their resources on the deficient dimensions of composite indicators. Composite indicators are therefore fairly well supported by professionals and survive proper criticism. 
different outcomes with respect to critical IFT-risk elements. The conflicting results led to the question of which model is more in line with the objective of the global analysis, i.e., capturing the global landscape of IFT-risk. To address this question, this study first examined the relationship between the global IFT-risk indicator and the IFT-risk elements. Given the adjusted $\mathrm{R}^{2}$ values of the two models, the global IFT-risk indicator constructed with equal weights (adjusted $\left.\mathrm{R}^{2}{ }_{\mathrm{ew}}=.966\right)$ demonstrated a better goodnessof-fit ${ }^{151}$ than the indicator developed with weights derived from PCA (adjusted $\mathrm{R}^{2}$ pcaw $=.856)$. However, this approach did not address a fundamental element of the question of which model is more suitable for estimating IFT-risk levels in the real world and depicting the landscape of IFT-risk. This is because the linear regression analysis presented above merely examines the closeness between the linear regression model and the IFT-risk assessment model(s), not the relationship between the IFT-risk levels gauged via the IFT-risk indicator and the actual observed IFT-risk levels. In other words, the linear regression analysis of the global IFT-risk indicator(s) raises a validity issue as discussed earlier.

Table 4.12: The regression coefficients between the overall IFT-risk rank and the IFTrisk element ranks

\begin{tabular}{lcc}
\hline & Overall rank from equal weights & Overall rank from PCA weights \\
\hline Market size & .132 & .286 \\
Accessibility of formal financial & .379 & .154 \\
institutions & .235 & .733 \\
AML-systems & .509 & .152 \\
Attitude towards informality & -15.528 & -19.679 \\
(Constant) & .966 & .856 \\
Adjusted R & & \\
\hline
\end{tabular}

Source: the author

As for the validity issue of a composite indicator, Vertesy (2016) argues that a comparative assessment of multiple indicators for the same phenomenon can be beneficial in assessing the validity of a composite indicator. However, given the absence of a valid instrument to measure IFT-activities, there may be limited ways to examine

151 The IFT-risk elements weighted equally explain the overall IFT-risk $11 \%$ more than those weighted by PCA. 
the validity of the global IFT-risk indicator(s). After all, taking into account the underlying perspective of Vertesy's suggestion, the assessments of the validity and reliability of the global IFT-risk indicator(s) can only use the professional consensus among relevant experts. Relevant experts should examine IFT-risk levels gauged using the IFT-risk indicator(s), not only in terms of the process of constructing IFT-risk indicator(s), but also with respect to the outcomes from the indicator. The experts' professional opinions may include subjective judgements that reflect what is known about IFT-risk and how IFT-risk levels are perceived (Greco et al., 2019). This study is the first attempt to construct a global IFT-risk indicator. There has not yet been an opportunity to subject this indicator to expert review. This study has therefore examined congruence between the outcomes from the two IFT-risk assessment models and the findings from previous studies on IFT-systems. As a result, the IFT-risk levels derived from the equal weighting aggregation method are likely to be more in line with a normal perception of IFT-risk levels for the countries of interest. This is especially the case given the outcome from the IFT-risk assessment model based on the equalweighting method, which is that the 10 countries with the largest IFT-risk are all developing countries and the 10 countries with the smallest IFT-risk are all developed countries. According to the PCA-weighted IFT-risk assessment model, Colombia and Cyprus fall under the countries that are faced with the lowest level of risk. Given that these countries were known for drug-related organized crimes or offshore financial centers where illegitimate funds are made or circulated (Makarenko, 2004; Orphanides, 2013), this assessment outcome may be disputable and raise concerns about the validity of the global IFT-risk indicator. The results of examining the relationships between the global IFT-risk indicator and the IFT-risk elements - and between the IFT-risk levels assessed and the IFT-risk levels perceived - therefore imply that, in terms depicting the global landscape of IFT-risk, the global IFT-risk indicator constructed with equal weights is slightly more convincing than the indicator developed with weights derived from PCA. However, this does not mean that the IFT-risk indicator constructed with PCA weights merits little attention. The PCA weighted indicator reflects well the impacts of migration and AML-systems on IFT-risks. If the validity of some underlying data (e.g., the level of compliance with the FATF Recommendations) used to construct 
this indicator were better, the PCA weighted indicator would have had better outcomes. This IFT-risk indicator suggests that high-income countries, such as the U.S. and Russia, can also be exposed to high levels of IFT-risk. This suggestion has a valuable policy implication regarding the coordination of global AML/CFT endeavors. The global AML/CFT community can request high-income countries to achieve higher standards than other countries and to devise specific measures to make improvements in certain domains, in particular where they face the highest level of risk. Examples of such measures may include improving financial inclusion within ethnic enclaves and dismantling informal markets.

\subsection{Summary and reflection}

One of the aims of this study is to construct a global IFT-risk indicator to map the landscape of IFT-risk worldwide. By means of the composite indicator methodology, this chapter focused on developing a global analysis of IFT-risk that reflects IFT-risks faced by the 121 selected countries. As a theoretical framework for the global IFT-risk indicator, this chapter - drawing on previous studies on IFT-systems - established that the level of IFT-risk is mainly associated with four factors: the market size of IFTservices (or the number of migrants), access to formal financial institutions, compliance with international AML/CFT standards, and societal attitudes towards informality. These four IFT-risk elements comprise 11 variables, extracted from the five public domain datasets, and underlie the global IFT-risk indicator(s). The global IFT-risk indicator(s) was developed in accordance with the general process required to construct a composite indicator. In the course of composing the global IFT-risk indicator(s), this study adopted two weighting methods alternately - equal weighting and PCA weighting - thereby producing two IFT-risk assessment models. The two IFT-risk assessment models produced slightly different outcomes, or different IFT-risk values and different IFT-risk rank for each country. There is no golden standard to evaluate the two models. 
The main findings from the global IFT-risk analysis confirmed those of previous studies on IFT-systems. Most of the developed countries analyzed were rated as having low IFT-risk, mainly because of a high level of access to formal financial institutions and a high level of compliance with international AML/CFT standards. However, among the developed countries, some countries considered popular destinations for immigrants were rated as having a high level of IFT-risk. On the other hand, most of the developing countries were rated as being exposed to a high level of IFT-risk because of a large number of emigrants, poor formal financial systems, low compliance levels with international AML/CFT standards, and lenient attitudes towards illegality. The finding that the level of IFT-risk is associated with the level of the economic development appears to be a foregone conclusion. However, the main advantage of the global IFT-risk indicator is that it can gauge 'nuanced' differences in IFT-risks among countries, and rank countries in terms of the level of IFT-risk that they face, even though the indicator was not constructed and tested with actual observed IFT-risks. Especially, if this indicator interacts with the governments of each country and field researchers to improve its validity, thereby approaching the prevalence of IFT-activities more closely, the indicator would play a meaningful role in providing each country with warning signals regarding IFT-systems. The global IFT-risk indicator therefore merits to be adopted as a key indicator to monitor IFT-risks across countries, even though the indicator was not constructed and tested with actual observed IFT-risks. IFT-systems may not be considered illegitimate in some developing countries given their economic and social impacts. The benefits from IFT-systems are, however, unlikely to outweigh the need for global governance of IFT-risks, given the cross-border impact of IFTsystems (Sharman, 2008). Especially if the global IFT-risk indicator is used to monitor IFT-risk levels over a period of several years, policy makers and scholars will be able to monitor not only changes in IFT-risk levels faced by countries, but also the potential impact of AML/CFT programs implemented against IFT-systems. The global AML/CFT community - including the FATF - could therefore benefit from the global IFT-risk indicator to create benchmarks that countries with high levels of IFT-risk should meet. It also can complement the FATF's mutual evaluations by providing information regarding money laundering activities faced by the various countries. 
This chapter sketched the panoramic view of the global landscape of IFT-risk, while examining the distribution of IFT-risk across countries. However, the macro quantitative assessment of IFT-risk was limited to investigating how IFT-systems work in a certain country and how they respond to or cope with the internal risks. The next chapters will provide a close-up view of IFT-systems in Korea. This country is approximately at the 7oth percentile — ranked 95th (by using the equally weighted model) or 87th (by using the PCA weighted model) in the global IFT-risk analysis. Even though the global IFT-risk indicator rated the level of IFT-risk faced by Korea as moderate or fairly low, a considerable number of IFT-systems are operational in this country. The following chapters will further zoom in on IFT-systems detected in Korea, using micro qualitative data, to investigate the dynamic interactions within IFT-systems. 


\section{Country-focused Analysis of IFT-systems in Korea: A Perspective on Illegal Markets}

\subsection{Introduction}

The global analysis in the previous chapter examined the survival and adaptation of IFT-systems to the external risks reflected in the global IFT-risk landscape. The country-specific analysis, or the local analysis in this study - the following chapters will investigate the same topic, but at a different level or angle, and with a different focus. When it comes to their internal mechanisms, IFT-systems - which are illegal in most countries and whose legitimacy is questioned and challenged - are susceptible to the internal risks, such as deception and betrayal, which result from their illegitimacy. The relationships between the actors in IFT-systems are thus fragile. Despite the threat embedded in the internal mechanism as well as the external risks, IFT-systems are able to survive in almost every society. The local analysis therefore focuses on the dynamic interactions between the actors in IFT-systems in a specific country instead of examining external factors or conditions for IFT-systems across countries. In other words, the local analysis aims to answer the second research question: why the actors in IFT-systems trust each other under social uncertainty and how they cope with it. This will be done by investigating the internal dynamics between the actors in IFT-systems in Korea.

As explained in sections 3.5 and 3.6, the local analysis used the thematic analysis for data analysis and the three theoretical frameworks - the sociology of illegal markets, social exchange theory, and the perspective of trust and risk - to examine IFT-systems in a stepwise manner. In the local analysis, the thematic analysis extracted themes and codes to be examined (Table 5.1), not only from the IFT-case reports and the interview data, but also from previous studies on IFT-systems, drawing on the three theoretical frameworks. The themes identified by the thematic analysis were categorized into two main themes - actors and activities in IFT-systems - and five (sub) themes - IFT broker, co-offender, arrangement, transaction, and abuse (Table 5.1). As for the actors 
in IFT-systems, the local analysis concentrated on IFT-brokers and their co-offenders. Unfortunately, the available information on IFT-users was insufficient for the local analysis, even though the activities of IFT-users could be estimated on the basis of the information on IFT-brokers' activities. Using the identified themes and codes, the thematic analysis first produced an overview of IFT-systems in Korea. This was done to provide the background against which the interactions between the actors in IFTsystems occur. In particular, the descriptive overview of IFT-systems focuses on their features as the illegal remittance 'market', drawing on the sociology of (illegal) markets. The next chapter will then zoom in on IFT-systems, thereby illustrating IFT-procedures sequentially and unraveling the interactions between the actors involved in IFTactivities. The relationships between the actors in IFT-systems were examined from the perspectives of 'social exchange' and 'trust and risk'. Mechanisms that IFT-users and IFT-brokers adopted to cope with the internal risks embedded in IFT-activities have been also scrutinized. In this chapter and the next one, the findings are normally from the analysis of the IFT-case reports unless it is specifically indicated that certain findings are extracted from the interviews. Essential components of 15 exemplary IFT-cases selected from the 230 cases will be used to complement the findings from the thematic analysis and to develop a tangible understanding of IFT-activities in Korea.

Table 5.1: Themes identified in the IFT-case reports and the interviews

\begin{tabular}{|c|c|c|}
\hline Grand theme & (sub) Theme & Code \\
\hline \multirow[t]{3}{*}{$\begin{array}{l}\text { Actors in IFT- } \\
\text { systems }\end{array}$} & IFT broker & $\begin{array}{ll}\text { o } & \text { Nationality and country of residence } \\
\text { ○ } & \text { Job } \\
\text { o } & \text { Launching IFT-businesses } \\
\text { o } & \text { Relationship with IFT-users } \\
\text { o } & \text { Relationship with counterpart IFT-brokers } \\
\text { O } & \text { A facade of IFT-business } \\
\text { o } & \text { Awareness of illegality of IFT-businesses }\end{array}$ \\
\hline & Co-offender & $\begin{array}{ll}\text { o } & \text { Nationality } \\
\text { ○ } & \text { Job } \\
\text { ○ } & \text { Role in IFT-activities } \\
\text { ○ } & \text { Relationship with IFT-brokers }\end{array}$ \\
\hline & IFT-users & $\begin{array}{l}\text { Limited information albeit inferred from IFT- } \\
\text { transactions }\end{array}$ \\
\hline $\begin{array}{l}\text { Activities in IFT- } \\
\text { systems }\end{array}$ & Arrangement & $\begin{array}{ll}\text { o Involvement of a bank account } \\
\text { o } & \text { Gathering IFT-users }\end{array}$ \\
\hline
\end{tabular}




\begin{tabular}{|c|c|}
\hline Transaction & $\begin{array}{l}\text { - Brokerage fee } \\
\text { - Direction and number of transactions } \\
\text { ○ Average amount of transactions } \\
\text { o Settlement } \\
\text { ○ Involvement of a trade payment } \\
\text { ○ Involvement of transportation of cash } \\
\text { ○ Involvement of a currency exchange office }\end{array}$ \\
\hline Abuse & $\begin{array}{l}\text { Involvement of illegal trade activities } \\
\text { Involvement of drug trafficking or organized crime } \\
\text { groups }\end{array}$ \\
\hline
\end{tabular}

Source: the author

\subsection{Overview of IFT-systems in Korea}

There is no reliable data that gauges the size of the informal remittance market in Korea as in other countries. The statistics regarding the number of foreigners in Korea may provide some indications regarding the prevalence of IFT-activities in Korea. The estimated number of foreigners including illegal immigrants amounts to 2.5 million (MOJ, 2019), thereby accounting for $5 \%$ of the total population of Korea. The number of foreigners who engage in economic activities in Korea stands at approximately 0.9 million $^{152}$ (KSS and MOJ, 2019). A study conducted by International Labor Organization (Kang and Lee, 2014) shows preferred remittance channels of expatriate workers in

152 The studies on IFT-systems in Korea (Lee, 2017; Shah, 2018) deal with accounts of expatriate workers who came to Korea via a particular foreign worker employment program (i.e., employment permit system). However, there are more programs or ways that foreigners can use to work in Korea. Among the foreigners who engage in economic activities in Korea, Nepali workers (Shah, 2018) account for approximately 4 percent of them.

Table 5.2: Nationalities of foreigners engaging in economic activities in Korea (as of 2018)

\begin{tabular}{lcccc}
\hline & \multicolumn{3}{c}{ Engaged in economic activities } & \multicolumn{2}{c}{ Employed } \\
\cline { 2 - 5 } & Thousands & $\%$ & Thousands & 42.7 \\
\hline Korean-Chinese & 401.3 & 43.2 & 377.6 & 8.9 \\
Vietnamese & 81.5 & 8.8 & 79.0 & 5.9 \\
Chinese & 58.2 & 6.3 & 52.4 & 4.3 \\
Uzbekistan & 39.3 & 4.2 & 37.6 & 4.4 \\
Cambodian & 38.9 & 4.2 & 38.6 & 3.7 \\
Indonesian & 33.5 & 3.6 & 33.1 & 3.7 \\
Nepali & 33.0 & 3.6 & 32.6 & 2.8 \\
Thai & 24.7 & 2.7 & 24.5 & 1.1 \\
Mongolian & 10.9 & 1.2 & 10.1 & 18.9 \\
Others & 174.8 & 18.8 & 884.3 & \\
\hline Total & 929.1 & & & \\
\hline Source: KSS and
\end{tabular}

Source: KSS and MOJ, 2019. 
Korea: while the most preferred remittance channel is banks (72.1\%), only 8.5 percent of expatriate workers preferred IFT-systems. When the preferences of remittance channels are broken down by ethnicity, Nepali (55.1\%) and Burmese (25.7\%) preferred IFT-systems more than other ethnic groups. There are a small number of studies that focus on ethnic IFT-systems in Korea. Rahman and Yeoh's study (2008) briefly deals with IFT-systems in Korea as one of several remittance sending countries, while describing how Bangladeshi emigrants ${ }^{153}$ transfer their remittances via hundi. Lee (2017) and Shah (2018) examine why Burmese workers (47\%) and Nepali workers (82\%) in Korea rely on their ethnic IFT-systems for cross-border remittance instead of making use of formal remittance channels. The working mechanism of hundi related to Korea is similar to that of the typical hundi based in several South Asian countries. These studies examine IFT-systems in Korea as a remittance channel primarily for expatriate workers in Korea. The ethnic groups covered by these studies are limited and minority given the sizes of expatriate workers by ethnicity (Table 5.2). The FATF154 (2020: 5) recently assessed that "Korea's exposure to cross-border remittance risks is much more limited as it has a relatively small foreign-born population and relatively small migrant remittance flows. Korea's foreign currency controls also help to mitigate the risks of cross-border transactions". Nevertheless, the findings from these studies underlay to some extent the analysis of the IFT-cases and the interviews which will show that IFT-

153 According to Kang and Lee (2014), the ethnic group that most preferred banks is Bangladeshi (more than 95\%).

154 The FATF's the third round mutual evaluation report on Korea (FATF, 20o9b: 157) shows a different picture on the informal remittance market in Korea in 2005 to 2007: "Korea has an immigrant population of approximately one million persons, and it is estimated that 230000 are illegal immigrants, which suggests that it is likely that Korea has some illegal remittance operators and underground banking services. The KCS works actively to uncover illegal operators. ... In 2007 KCS investigations resulted in 690 arrests of persons involved in illegal remittances, 70 of whom were involved in managing the remittances and 620 of whom were arrested for using the illegal services". Thus, the FAFT recommended that "supervisory authorities when inspecting businesses for other matters also be alert to the possibility that illegal remittance activity may be occurring. In addition, KCS and other authorities could focus more broadly at looking for signs of underground banking as well as alternative remittance” (FATF, 2009b: 157). The different assessment outcomes from the two mutual evaluation reports for Korea provide a hint as to why the KCS officials perceived IFT-systems as illegal and illegitimate but a low enforcement priority now. 
systems in Korea is more than an informal remittance channel of expatriate workers. There are newspaper articles and informal accounts describing that North Korean refugees (or defectors) settled in South Korea transfer funds to their relatives remaining in North Korea via IFT-systems ${ }^{155}$ in China (Economist, 2019; Plaza, 2011). As IFTsystems related to North Korea involve complicated political issues in Korea, they are not considered in the local analysis.

The local analysis started with shedding light on the (illegal) market dimension of IFT-systems. A brief examination of the basic features of IFT-brokers and IFT transactions captured in Korea - core themes of IFT-systems that emerged from the thematic analysis - will benefit the upcoming discussion on the theoretical framework regarding (illegal) markets. As far as IFT-brokers are concerned, this study will mainly examine their nationalities and countries of residence to find out who controls the illegal remittance market in Korea. With regard to IFT-transactions, this study will briefly examine the lifespan of IFT-businesses, the amounts and sources of funds transferred through IFT-systems, and the motives for conducting IFT-transactions.

\subsubsection{Actors involved in IFT-activities}

Actors involved in IFT-activities include IFT-brokers, counterpart IFT-brokers, and IFT-users, but also co-offenders who assist IFT-brokers. The main actors in the IFTcase reports are obviously IFT-brokers, although the case reports also contain information about co-offenders. This is because, in accordance with the Foreign Exchange Transactions Act, unauthorized actors are prohibited from running foreign exchange businesses in Korea, and law enforcement against IFT-activities are

155 As of March 2020, the number of North Koreans refugees (or defectors) in South Korea is estimated to be approximately 33,00o. There is no reliable data regarding the amount of remittances transferred from South Korea to North Korea via IFT-systems in Korea and China. Some rough estimates of the remittances range from 5 million USD to 15 million USD. As several intermediaries are involved in IFTtransactions between South Korea and North Korea, it is said that remittance transfer fees amount to $30 \%$ of the remittances (Jung, 2017). 
consequently focused on IFT-brokers ${ }^{156}$. In response to the question of why their investigations of IFT-systems were aimed at IFT-brokers, most of the interviewed investigators emphasized the efficiency of law enforcement. According to them, the number of IFT-users is much greater than that of IFT-brokers. Therefore, in the fight against IFT-systems, it may be inefficient to summon and interrogate every single alleged IFT user identified in the bank accounts or ledgers of IFT-brokers, unless those IFT-users were clearly engaged in committing crimes (e.g., tax evasion). While some investigations of IFT-brokers follow from examinations of IFT-users, they usually concentrate on IFT-brokers. In other words, since the illegality ${ }^{157}$ of IFT-brokers' IFTbusinesses causes more societal harm than the activities of IFT-users, it is more efficient to investigate IFT-brokers than IFT-users. Some investigators address another aspect of this issue: since government policy on IFT-systems may be associated with protecting the interests of formal financial institutions and the fight against money laundering, the investigation of IFT-systems should focus on IFT-brokers in competition with formal financial institutions.

The demographic aspect of IFT-brokers - especially the ethnicity of IFT-brokers - provides useful information for understanding the illegal remittance market. Several studies on IFT-systems demonstrate that IFT-systems in developed countries are able to operate within ethnic enclaves, whereas those in developing countries tend to thrive in environments where there is little intervention of law enforcement authorities (Casey, 2007; Maimbo, 2003; Soudjin, 2015). As briefly mentioned earlier, Korea has a high level of access to formal financial institutions and is rated as a country with a high level of compliance with global AML/CFT standards. The question of whether IFT-systems in

156 In tackling IFT-systems, concentrating on IFT-brokers instead of IFT-users is not stipulated by laws or regulations. It rather relates to law enforcement practice. Of course, this law enforcement practice is based on the different levels of punishments on IFT-brokers and IFT-users.

157 In Korea, IFT-brokers are more severely punished than IFT-users in accordance with the Foreign Exchange Transactions Act. Whereas IFT-brokers can be sentenced up to 3-year imprisonment or 300,00o USD fine (Article 27-2), the maximum sentence for IFT-users are either 1-year imprisonment or 10o,ooo USD fine (Article 29 or Article 32). 
Korea are also confined to ethnic enclaves therefore merits examination. The ethnicity of the IFT-brokers investigated as the primary perpetrator provides clues as to whether a certain ethnic group dominates the illegal remittance market in Korea, and whether various ethnic groups compete with one another in that market. The information on ethnic enclaves where IFT-systems are concentrated is useful for law enforcement authorities that seek to control the illegal remittance market and suppress its expansion.

According to the analysis of the IFT-case reports, the largest ethnic group is Korean (46.1\%); surprisingly however, the second largest ethnic group of IFT-brokers is Chinese $(43.5 \%)$. The number of the detected Chinese IFT-brokers is almost equal to that of Korean IFT-brokers (Table 5.3). This statistic relates to the fact that the largest foreign ethnic group living in Korea is Chinese, accounting for $51.0 \%$ of all non-Korean ethnic groups in Korea (MOJ, 2015). The distribution of ethnicities among the IFTbrokers in Korea suggests that the illegal remittance market in Korea may be a bi-ethnic market ${ }^{158}$ dominated by the Korean and Chinese.

Table 5.3: Nationalities of the main offenders in the IFT-case reports

\begin{tabular}{cccccccc}
\hline Korea & China & Bangladesh & Vietnam & Uzbekistan & Australia & Mongolia & Other \\
\hline 106 & 100 & 7 & 4 & 3 & 2 & 2 & 6 \\
\hline
\end{tabular}

Source: the author

As for the residence countries of the main perpetrators in these IFT-cases, $45.7 \%$ of the IFT-brokers resided in China when they were investigated (Table 5.5). In other words, some Koreans engaged in IFT-transactions while residing in China. This implies that the business environment for IFT-systems in China may be better than in Korea and other countries. Several factors may be responsible for this phenomenon; first of all, the fact that the demand for IFT-services in China appears to be greater than in any

158 Even though Korean and Chinese are the major ethnic groups in the illegal remittance market, as discussed later, each IFT-system is small. The illegal remittance market in Korea is not such oligopoly that is controlled by a few IFT-brokers. 
other country. This may not be surprising given the economic ties ${ }^{159}$ and geographical proximity between Korea and China. Most of the interviewed investigators also explained that the prevalence of IFT-cases involving Chinese IFT-brokers is due to two factors: strong economic ties between Korea and China, and the difficulties in sending and receiving remittances between the two countries via formal financial institutions ${ }^{160}$. Online banking services provided by Korean financial institutions seem to create a favorable business environment for Korean IFT-brokers to operate in. In fact, they may support and facilitate IFT-activities between China and Korea.

The limited number of IFT-transactions between Korea and Japan arouses curiosity, as the geographical proximity between Korea and Japan is similar to that between Korea and China. In addition, Korea has a longer economic relationship with Japan than with China ${ }^{161}$, and Japan is also a popular country of residence for Koreans. The limited number of IFT-transactions between Korea and Japan may be related to different trade structures between the trade between Korea-China and the trade between Korea and Japan. When IFT-systems are used to transfer trade payments, given

159 The economic ties between Korea and China are often represented in the form of the trade volumes between the two countries. China is the biggest trade partner to Korea and the trade volume with China accounts for approximately 30 percent of the total trade volume of Korea (KCS, 2018).

Table 5.4: The trade proportions of Korea with its major trade partners

\begin{tabular}{llllll}
\hline & 2009 & 2010 & 2011 & 2012 & 2013 \\
\hline China & 20.5 & 27.4 & 32.1 & 31.3 & 33.3 \\
Japan & 10.4 & 13.5 & 15.7 & 15.0 & 13.8 \\
United States & 9.7 & 13.1 & 14.7 & 14.8 & 15.1 \\
\hline
\end{tabular}

Source: the KCS

160 There are few data available indicating how challenging sending and receiving remittances across borders are in China. However, as discussed in Chapter 4, a proxy variable that may be applicable for gauging the difficulty in cross-border remittance is available in the World Bank's Findex inclusion dataset. According to the Findex inclusion data of 2011 and 2014, the percentages of adults with financial institution accounts in China are 63.8 in 2011 and 78.9 in 2014, whereas those in Korea are 93.0 in 2011 and 94.4 in 2014 (World Bank, 2015).

161 After the Second World War, Korea concluded a treaty with Japan for normalization of diplomatic relations in 1965. A treaty for normalization of diplomatic relations between Korea and China was concluded in 1992. 
the limited resource pools of most IFT-brokers ${ }^{162}$, IFT-systems are likely to be used to trade of consumer goods rather than raw materials and capital goods. Given that the trade volume of consumer goods between Korea and Japan is one-third of that between Korea and China ${ }^{163}$, IFT-systems are more likely to be used to support the transfer of trade payments between Korea and China than that between Korea and Japan ${ }^{164}$. The limited number of IFT-transactions between Korea and Japan may also be explained by the high degree of financial inclusion ${ }^{165}$ in Japan compared to that in China (DemirgucKunt et al., 2015). In other words, the demand for IFT-services in Japan may be lower than in China. Only several Korean IFT-brokers therefore chose Japan as their IFTbusiness base.

Table 5.5: Countries of residence of the main offenders in the IFT-case reports

\begin{tabular}{ccccccccc}
\hline Korea & China & Japan & Australia & Philippines & Vietnam & Thailand & Bangladesh & Other \\
\hline 82 & 104 & 12 & 6 & 6 & 5 & 5 & 5 & 6 \\
\hline
\end{tabular}

Source: the author

162 Even though some IFT-brokers were reported to be able to mobile large amounts of funds at short notice, their pools of funds are not likely to be larger than those of formal financial institutions.

163 According to the analysis of the data from the KCS trade database, the trade volume of consumer goods between Korea and China amounted to 99,182 million USD between 2010 and 2014, whereas that between Korea and Japan stood at 33,573 million USD during the same period.

164 According to an ILO report (Kang and Lee, 2014), Japan is one of the costliest remittance-sending countries among G-20 countries. It implies that there would be a number of IFT-brokers between Korea and Japan. However, Rahman and Yeoh's study (2008: 24) on the Bangladeshi IFT-systems in East and South-east Asia provides a hint on the small number of IFT-brokers regarding Japan: "Despite the presence of a large number of unauthorized migrant workers in all the other three countries, we have found that a substantial amount of money was remitted through formal channels, especially in Japan and Malaysia. If we compare Japan with South Korea, the complexity will further unfold. Japan lacks a legal framework to accommodate Bangladeshi migrants while South Korea hires them under legal arrangements. If we consider unauthorized status as the sole indicator for widespread use of the hundi, there should be higher proportions of formal remittance flows from South Korea compared to Japan, but this is not the case".

165 Financial inclusion refers to "the proportion of individuals and firms that use financial services" (World Bank, 2014: 1). 


\subsubsection{IFT-activities}

Each IFT-case report contains the outcome of an investigation into IFTtransactions carried out by an IFT-broker. According to the analysis of the IFT-case reports, the investigated IFT-businesses lasted 31.9 months on average until IFT-brokers were detected and charged with violations of AML-regulations by the KCS. The majority of the investigated IFT-brokers provided bilateral remittance services, which consist of sending and receiving remittances. However, some IFT-brokers offered unilateral remittance services. It is not known how IFT-brokers who provide unilateral IFT services resolve unsettled debts. Full-time professional IFT-brokers may not be able to run a unilateral IFT-business unless they have a large pool of funds. Unilateral IFTbusinesses are likely to be run by part-time IFT-brokers who run other businesses.

\section{Case 1: A unilateral IFT-business}

CHEON ran a manpower agency which hired workers in China and supplied them to Korean fishing ships wanting crews. He maintained a Chinese bank account to handle brokerage fees from Chinese workers and was requested by them to transfer their remittances to their families without the involvement of banks. He took remittances from Chinese workers via his Korean bank account and transferred them to recipients designated by the sailors via his Chinese bank account. In this manner, he transferred 1,489,243 USD from Korea to China via 375 transactions between August 2010 and August 2011.

The average amount per transaction is 13,407 USD (min value: 21 USD; max value: 5,771,016 USD). The IFT-case reports contain limited information regarding the sources of the remittances transferred by IFT-systems. Detailed information is only recorded in the IFT-case reports where trade payments are concerned. This is due to the fact that trade payments are of interest to customs investigators. Half of the interviewed investigators explained that they inquire about the sources of remittances during the interrogations of IFT-brokers, but that do not necessarily investigate their customers, or IFT-users, for the purpose of disclosing the sources of the remittances. According to 
the findings from the inquiry regarding the sources of the remittances, IFT-systems are not only used to transfer trade payments, but also to pay for tuition fees and allowances for children who reside overseas, as well as investments into (immobile) foreign assets. The analysis of the case reports revealed that one third of the investigated IFT-brokers were involved in transferring trade payments at some point. This implies that IFTsystems are predominantly used to evade taxes. The purpose of some IFT-businesses is to bypass barriers established by strict foreign exchange policies. As some countries have restrictive foreign exchange control policies, IFT-brokers who manage remittances related to such countries tend to operate IFT-businesses in combination with crossborder trade to eschew foreign exchange regulations. However, it is unlikely that there is concrete evidence that IFT-systems in Korea were abused to launder proceeds from organized crime groups or drug trafficking, in contrast to the situation in developed countries (Kleemans, 2015). This will be discussed further in the next chapter.

Case 2: IFT-systems used to bypass a restrictive foreign control policy

MOHAMED ALI traveled from Libya to Korea, to invest in Korean businesses and establish a corporation for trading auto parts. He was aware of the fact that it was quite challenging for 'individuals' to send foreign exchanges from Libya to Korea. He set up a business that allowed him to receive payments from Libyan traders importing second-hand vehicles, and auto parts from Korea to Libya via his Libyan bank account. He withdrew the corresponding amounts from his corporation's Korean bank account in cash or checks, and handed them over to the exporters. From January 2007 to November 2010, he transferred 9,259,965 USD from Libya to Korea via 208 transactions. He also engaged in different types of IFT-transactions. He was involved in importing bathroom sets and accessories from China to Libya. He soon became aware of the fact that sending foreign exchanges from Libya to China was also extremely challenging, and fabricated fake commercial invoices indicating that bathroom sets and accessories had been imported from China to Korea, not Libya. In doing so, he transferred 582,707 USD from Korea to China via 21 transactions between January 2008 and November 2008, without reporting them to the financial authorities. 


\subsection{Theoretical framework: Illegal markets}

The local analysis uses three theoretical frameworks - the sociology of (illegal) markets, social exchange theory, and the perspective of trust and risk - to examine the dynamic interactions between the actors involved in IFT-activities. This will further enhance and expand the analytical work required to answer the second sub-research question. Previous studies on IFT-systems touch upon the multidimensional aspects and dynamics of IFT-systems, but rarely examine IFT-systems based on specific theories (Lindley, 2009; Pohit and Taneja, 2003; Soudijn, 2015; Taneja, 2004; Van de Bunt 2008b). In addition, they pay little attention to the social dynamics within those IFT-systems, even though they may concentrate on illustrating business relations within IFT-systems from the perspectives of ethnic ties, social embeddedness, or informal social control (Monsutti, 2004; Rahman and Yeoh, 2008). They tend to take for granted the IFTcontracts between IFT-users and IFT-brokers, and between IFT-brokers simply because they share ethnic and cultural backgrounds ${ }^{166}$. They may have limited application to IFT-systems in the environments where ethnic ties, social embeddedness, or informal social control are weak or restricted. This study thus employed the three theoretical frameworks that are flexible to encompass various social contexts. Existing findings on IFT-systems also merit examination based on the theoretical frameworks. Before delving into each theoretical framework and its application, an overview of the three theoretical frameworks will be made to pave the way for a detailed analysis of the dynamic interactions within IFT-systems. After reviewing the theoretical frameworks, the analysis of the empirical data collected for this study will be conducted based on these theories.

5.3.1 An overview of the theoretical frameworks for the local analysis

166 Van de Bunt (2008a) and Soudijn (2015)'s studies on IFT-systems in the Netherlands are exceptions. 
As the aim of the local analysis is to investigate the internal dynamics between the actors involved in IFT-activities, the local analysis zooms in on IFT-systems in a stepwise manner, using three theoretical frameworks: the sociology of (illegal) markets, social exchange theory, and the perspective of trust and risk. These three theoretical frameworks were selected to examine the three features of interactions that occur in IFT-systems: IFT-systems can be characterized as an illegal market (the sociology of (illegal) markets) ; the basic nature of markets is exchange (social exchange theory); and, unlike in legal markets, placing trust in actors who are active in illegitimate markets involves risks (the perspective of trust and risk).

The sociology of (illegal) markets sheds light on the market aspect of IFT-systems in competition with formal remittance systems, while previous studies on IFT-systems rarely recognize IFT-systems as a 'market' for remittance services. Social exchange theory and the perspective of trust and risk address the interpersonal relationships between the actors involved in IFT-activities. Social exchange theory focuses on the interdependence between the actors to complete and benefit from IFT-transactions by examining the power relations between them. The perspective of trust and risk zooms in on the relationship between placing of trust in actors involved in IFT-transactions and coping with risks inherent in trust related to IFT-activities.

\subsubsection{The sociology of markets}

Given that a discerning feature of IFT-activities is an illegal event requiring multiple actors, three concepts that related to the engagement of multiple actors in a 
criminal event ${ }^{167}$ were identified: co-offending ${ }^{168}$, organized crime ${ }^{169}$, and an illegal market. Compared to the concept of an illegal market, the concepts of co-offending and organized crime are somewhat limited in encompassing IFT-systems and analyzing the interactions between the actors in IFT-systems, although they related to the involvement of multiple actors in IFT-activities. That is because co-offending ${ }^{170}$ and

167 With respect to multiple actors' engagement in a crime event, there are more concepts other than illegal market, co-offending, and organized crime. They include gangs, corporate crime, organizational crime, and illegal enterprise. Compared with co-offending and organized crime, gangs and corporate crime appear less relevant to IFT-systems. Illegal enterprise, which is "defined as the sale of illegal goods and services to customers who know that the goods or services are illegal”, is suggested to be treated as a separate concept in criminology (Haller, 1990: 207). IFT-business may be subsumed under the category of illegal enterprise. However, this perspective attends to the entrepreneurial aspect of illegal businesses rather than relational aspect between suppliers and customers. This study thus focuses on the three concepts - illegal market, co-offending, and organized crime - in identifying distinctive features of IFTsystems.

168 Co-offending refers to the perpetration of an offence by more than one person (Andresen and Felson, 2010; McCarthy et al., 1998; McGloin and Nguyen, 2014; Van Mastrigt, 2017; Weerman, 2003).

169 Organized crime is an elusive concept, as it involves both organizational aspects and criminal activities, and there is no consensus regarding its definition yet (Finckenauer, 2005; Paoli, 2002; Von Lampe, 2008; Varese, 2010). When it comes to identifying the main characteristics of organized crimes, criminologists suggest a continuing and structured hierarchy, violence or threats to use violence, and illegal enterprises (Hagan, 2005; Nelen and Huisman, 2008; Van Duyne, 1995; Von Lampe, 2006). There is, however, a fine line between co-offending and organized crimes. The traditional image of organized crimes portrayed as having a clear hierarchy and strict division of tasks is outdated. Organized crimes are construed as a collection of offenders that collaborate with each other in varying combinations (Bruinsma and Bernasco, 2004). In other words, organized crimes are now deemed a special type of cooffending (Felson, 2009).

170 Co-offending/organized crime and IFT-activities are distinct also in terms of the way that participants seek to achieve their aims, while engaging in a criminal event. Actors in both co-offending/organized crime and IFT-activities appear to cooperate to achieve their aims; however, the ways in which they cooperate are slightly different. For an IFT-transaction, IFT-users and IFT-brokers cooperate (actually negotiate) with each other. However, they have different aims, namely buying and selling IFT-services. In co-offending and organized criminal activities, actors engage in crime together for the purpose of efficiency. Actors with different skills and roles cooperate to complete a criminal event and they generally share a common aim. IFT-systems that involve IFT-users and IFT-brokers who make deals for funds transferring, would therefore be better addressed with a framework for illegal markets, rather than with frameworks used in examining co-offending and organized crimes. 
organized crimes ${ }^{171}$ are based on the assumption that committing crimes alone is technically possible. However, co-offending is easier and more profitable — or less risky - than solo-offending. In contrast, an IFT-transaction cannot be carried out by a single actor and requires at least three actors ${ }^{172}$ : the sender, the IFT broker, and the receiver. Thus, instead of using the concepts of co-offending and organized crime, this chapter will begin by examining the interactions between actors in IFT-systems ${ }^{173}$ based on the concept of 'illegal market'.

As for the reference to IFT-systems as an (illegal) market, many criminological studies have examined illegal markets involving the smuggling of illicit drugs or human beings (Desroches, 2007; May and Hough, 2009; Seddon, 2006; Soudijn and Kleemans, 2009; Zhang and Chin, 2002). Despite endeavors of several researchers ${ }^{174}$ to develop a general framework for illegal markets (Van Duyne et al., 2005; Von Lampe, 2016),

171 If an IFT-system is embedded in an organized crime group and IFT-brokers and IFT-users are all members of the syndicate, the perspectives for organized crime would fit the IFT-system that serves the organized crime group. Organized crime groups engaging in illegal drug businesses buy illegal drugs in bulk from wholesale illegal drug suppliers and sell them to end customers in retail. The members of an organized crime group cooperate with each other by performing their tasks to run their drug businesses. Of course, organized crime group members may be able to buy illegal drugs from their clan members; this is not a main activity in their drug businesses. There is literature on organized crime groups that analyze organized crime groups and their businesses from the perspective of markets. Nevertheless, the lens for organized crimes may not perfectly fit in explaining IFT-systems as there is little evidence that IFT-brokers are organized crime group members although they can serve organized crime groups' businesses.

172 Unconventional IFT-systems dealing with unilateral transactions also require three actors - the sender, the IFT broker, and the recipient in terms of their roles, even though some senders or recipients play the IFT broker's role.

173 IFT-systems can be addressed from the perspective of the informal economy as briefly discussed in Chapter 3. The informal economy and informal entrepreneurs may be adequate concepts to encompass IFT-systems. These concepts are normally used to focus on 'identifying' a grey sector between the lawful economy and the illegal economy, such as illegal-yet-legitimate economy (Webb et al., 2012). Like some scholars' claim, IFT-activities can fall under the category of the informal economy. However, this study views primarily IFT-systems as illegal and illegitimate.

174 Several studies attempt to construe organized crimes as illegal markets with their economic approach based upon the concepts of supply and demand (Bouchard and Wilkins, 2013). However, they rarely provide a salient and independent theoretical framework to address illegal markets. 
previous studies on illegal markets tend to focus on the 'organized crime' aspect involved in illegal markets (Bouchard and Morselli, 2014; Bouchard and Wilkins, 2012; Kleemans and Smit, 2014; Reuter, 2014). Many studies on IFT-systems also refer to the likelihood that IFT-systems are linked to organized crime groups. However, only a few studies demonstrate the link of organized crime groups with IFT-systems. It implies that although IFT-systems are susceptible to exploitation by organized crime groups, the organized crime aspect is not an essential part of IFT-systems. Given that the local analysis focuses on the dynamic interactions within IFT-systems, and more specifically within the illegal remittance market, this study first examines the 'market' aspect in illegal markets. This aspect has been systematically examined in sociology for decades under the heading 'sociology of markets'175 (Fourcade, 2007; Fligstein and Calder, 2015).

Despite varying approaches to markets in sociology (Lie, 1997), they all view markets ${ }^{176}$ as "social spaces where repeated exchanges occur between buyers and sellers under a set of formal and informal rules governing relations between competitors, suppliers, and customers" (Fligstein and Dauter, 2007: 113). From the perspective of the sociology of markets, markets are based on the following social structures: market actors are able to find one another; money is available to coordinate exchanges beyond bartering nonequivalent goods; actors (should) know what the price is; while engaging in exchange transactions, both buyers and sellers have faith that they will not be deceived; and such faith between actors derives from formal (e.g., laws) or informal (e.g.,

175 Although the sociology of markets may not be directly applied to IFT-systems, it merits examination. That is because the market of IFT-services also contains common features of markets that the sociology of markets addresses, and the theory of illegal markets applicable to IFT-systems is also derived from the sociology of markets.

176 Economists are sometimes interested in examining illegal markets and crime events (Bouchard and Wilkins, 2013; Fiorentini and Zamagni, 1999; Garoupa, 2000; Kugler et al., 2003). However, their economic models employed to analyze illegal markets are normally based on such assumptions that illegal markets are also governed by profit-maximization, and the demand and supply of illegal products or services are associated with prices. These assumptions may lead to losing opportunities to disclose detailed accounts and nuanced dynamics involved in illegal markets. Thus, this study has instead opted for the 'sociology' of (illegal) markets. 
reputation) mechanisms that govern exchanges in markets. This perspective focuses on the roles of social structures (e.g., governments, laws, and larger cultural understandings) that market actors develop to mediate the problems that they encounter in exchange, competition, and production (Ellickson, 2013; Fligstein and Dauter, 2007).

The sociology of markets in itself does not appear to fit perfectly in the analysis of IFT-systems, given that it does not address the concept of illegality in markets. This perspective, however, has an important implication for the analytical efforts related to IFT-systems: IFT-systems are not just an arena where IFT-users and IFT-brokers interact for the transfer of illegal remittance. IFT-systems compete with formal financial institutions (Freud and Spatafora, 2008) and sometimes use their competitors, for instance by settling their outstanding debts through formal remittance services or by taking advantage of online banking systems ${ }^{177}$. The survival of IFT-systems is also threatened by governments, as many governments seek to abolish IFT-systems from the remittance market or subject them to their supervision. In other words, previous studies on IFT-systems have only explored the roles of formal financial institutions and governments to a limited extent. They should have taken such factors into account more explicitly in their analyses of IFT-systems.

\subsubsection{The sociology of illegal markets}

There are a number of criminological studies on illegal markets. They tend to focus on specific goods or services (e.g., illicit drugs or prostitution) traded in markets rather than on the general mechanisms that govern illegal markets. Beckert and Wehinger (2013) have recently developed a framework to address illegal markets, which is based on the sociology of markets. They argue that markets are deemed illegal if

177 How IFT-brokers settle their outstanding debts by means of formal remittance services is explained in Chapter 2 and how IFT-brokers take advantage of online banking systems is thoroughly discussed in Chapter 6. 
goods or services to be exchanged violate legal stipulations, or if the way in which they are exchanged does not comply with rules and regulations. The authors present circumstances under which an illegal market emerges: there is no legal market to obtain goods or services, or they can be provided at lower prices than offered legally; buyers are willing to disregard the moral cost and take risks incurred from the illegality of the purchase; and sellers perceive illegal supply of goods or services as profitable, taking into account not only the cost of production and distribution, but also the risk of detection by law enforcement authorities (Beckert and Wehinger, 2013; Dewey, 2016).

Despite the heterogeneity of illegal markets, Beckert and Wehinger (2013) identify common coordination problems, which distinguish illegal markets from legal ones, by analyzing studies on illegal markets from various domains. The distinguishing features of illegal versus legal markets are: valuation (or pricing), competition, and cooperation. 'Valuation' refers to the process of assigning a value to a certain category of goods or services. Valuation in illegal markets is not as big an issue as it is in legal markets. As illegal markets are mostly demand-driven, the endogenous creation of prices by sellers in illegal markets is limited compared to legal markets. Sellers in illegal markets price their goods or services by consulting prices charged in legal markets. In addition, unlike in legal markets, the quality of goods or services in illegal markets is not properly reflected in their value. Illegal markets also lack quality assurance mechanisms to rectify information asymmetries between buyers and sellers concerning the quality of goods or services (e.g., safety regulations and quality standards). Some buyers in illegal markets simply accept a certain level of uncertainty regarding the quality of products, either out of desperation or deliberate ignorance. Buyers may be faced with a lack of financial means to buy legal products, may have difficulty finding a legal market or may be satisfied with the symbolic qualities of illegal products. Some buyers in illegal markets try to use their personal networks to overcome the uncertainty related to the quality of products. Those buyers share the reputation of sellers with whom they interact, as well as the reputation of their products, in order to reduce the information gap between buyers and sellers regarding the quality of products (Beckert and Wehinger, 2013). 
In the context of 'competition', a distinction is also made between illegal and legal markets. Sellers in legal markets use various methods, such as cartelization, product differentiation, innovation, and building entry barriers, in order to take advantage of limited competition. Many legal markets in the real world are therefore imperfect competition markets (Mankiw, 2008; Erickson, 2013). Nevertheless, in legal markets there are mechanisms (e.g., competition law) that facilitate and maintain competition, with governments playing an important role. In illegal markets, there is no such formal mechanism to promote competition. Sellers in illegal markets also obtain profit from limited competition. Sellers in illegal markets are obviously interested in moderating competition between legal and illegal markets, and within illegal markets. They may employ different strategies from those used in legal markets to avoid the impact of competition, namely corruption ${ }^{178}$ (Beckert and Wehinger, 2013). Restricting competition in illegal markets benefits both sellers in illegal markets and political (or law enforcement) officials. As corrupted officials have an interest in the success of sellers in illegal markets, they see advantages in restricting competition. They pretend to enforce the law by cracking down on outsiders in illegal markets and seek to reduce the likelihood of corruption becoming a public issue (Haller, 1990). Thus, under the protection or negligence of corrupt officials, sellers in illegal markets can gain a competitive advantage over those in legal markets, but also over outsiders in illegal markets. Limited competition in illegal markets also arises from restricted marketing activities. Any marketing activities on illegal markets are usually carried out in a disguised manner. As a result of restricted marketing activities, sellers miss out on opportunities to reach more buyers, even if they use their personal networks to compensate for those lost opportunities.

178 Illegal markets may not necessarily involve corruption. Corruption may not be necessarily confined to illegal markets. Nevertheless, corruption is more likely to be involved in illegal markets than in legal markets. Bribing public officials must be a salient strategy for sellers to adopt to protect their profit in illegal markets. Haller (1990) presents corruption relations between some illegal enterprises and local police or politicians as a factor for moderating competition. 
Buyers and sellers in illegal markets are faced with the problem of 'cooperation ${ }^{179}$ ', which rarely takes place in legal markets. Cooperation between buyers and sellers refers to the fulfillment of each party's obligations in contracts. The problem of cooperation between two parties in illegal markets can be construed as the 'risk of trust'. John Eck (1995) illustrates the risk of trust between buyers and sellers, drawing on a scenario in an illegal drug market. If a buyer of drugs contacts a potential seller, there is a risk that the potential seller could be an undercover agent, work for the police, or take the buyer's money without giving the drugs. If a drug dealer approaches a potential customer, the potential customer could also be an undercover agent, work for the police, or take the drugs and cash by force. In other words, illegal markets involve dilemmas: how can illegal goods or services be exchanged when the exchange process involves a risk of deception, and how can buyers and sellers become accessible to each other.

In illegal markets, both buyers and sellers are more likely to fail to fulfill their obligations than in legal markets, because there is no formal mechanism ${ }^{180}$ in illegal markets to enforce obligations in contracts and to punish those who violate them. As a result, actors in illegal markets are exposed to the risk of non-fulfillment of contracts. This raises the question of how actors place trust in the other party, given that there is uncertainty as to whether their trade partners will fulfill their obligations. Actors in legal markets also face the same issues regarding trust and uncertainty. Legal markets address this through institution-based trust, whereby institutions use contracts to remove uncertainty regarding trust and fulfillment of obligations. However, illegal markets are limited in their ability to develop institutional trust, as illegal markets operate in the absence of governments (Beckert and Wehinger, 2013; Von Lampe and

179 Haller (1990) also discussed cooperation in 'illegal enterprise'. Whereas cooperation in illegal markets is examined in terms of cooperation problems between sellers and buyers, cooperation in illegal enterprise means arrangement of partnerships among illegal enterprises. According to him, for those involved in illegal businesses, partnerships permit persons with political influence, capital, and managerial skills to cooperate because each has a direct economic stake in the enterprise.

180 Organized crime groups are said to employ informal means, such as violence or intimidation, against those who violate contracts with them (Anderson, 1995). 
Johansen, 2006). Eck (1995) and Reuter (1983) therefore highlight two features regarding the distinction between illegal and legal markets: the threat of interventions by law enforcement authorities, and the inability of actors to rely on formal institutions for the settlement of disputes between them ${ }^{181}$. Among the three features of illegal markets (valuation, competition, and cooperation), the issue related to cooperation between sellers and buyers (the trust-related risk between them in illegal markets) provides a bridge from illegal markets to the internal dynamics of illegal markets.

\subsection{IFT-systems as an illegal market}

IFT-systems are characterized, as discussed in Chapter 2, as the illegitimate - or at least illegal remittance market - where IFT-brokers, IFT-users, formal financial institutions, and governments interact among one another. In order to explain this basic feature of IFT-systems, this study compares IFT-systems with formal remittance services in terms of valuation, competition, and cooperation, drawing on Beckert and Wehinger's perspective on illegal markets.

First, when it comes to how IFT-brokers price their services, they determine their IFT-services fees by taking into account the foreign exchange transaction charges of formal remittance systems, in order to outperform their competitors. This is because, in addition to accessibility, the lower costs of remittance services are a major advantage of IFT-systems over formal financial institutions (Buencamino and Gorbunov, 2002). Previous studies on IFT-systems provide little specific information ${ }^{182}$ about pricing,

181 Threats of law enforcement authorities' intervention and inability of actors to rely on formal institutions underlie risks that face buyers and sellers in placing trust in the other party in illegal markets including IFT-systems. As discussed by John Eck (1995), IFT-users may submit anonymous reports to law enforcement authorities about IFT-brokers and their illegal businesses. IFT-brokers are cautious of such likelihood and attend to identifying trustworthiness of new customers. IFT-users are wary of IFT-brokers' deception that they take off with remittances without transferring them to recipients because IFT-users may not be able to receive legal protection. These risks are discussed in Chapter 6 .

182 A study on the remittance market in Korea (Kang and Lee, 2008) provides detailed information about remittance transfer fees of each remittance channels. According to the study, in transferring small 
except that IFT-brokers charge 2 to 5 percent of remittances as a transfer fee (El Qorchi et al., 2003; World Bank, 2006) or take advantage of informal exchange rates without charging remittance fees (Passas, 2005b). This is less than the fees charged by formal financial institutions, which usually charge a flat rate for the transfer of small amounts. In the empirical data collected for this study, not all IFT-case reports include information about IFT service charges; some of them provide information about the types of service charges, such as flat rates, flat amounts, and informal foreign exchange rates. According to the interviewed investigators, IFT-brokers do not seem to have fixed service charge schedules, and they have discretion to impose different service charges on different remitters. According to the investigators interviewed, they do not scrutinize each transaction recorded on the bank accounts subject to investigation. The investigators are not interested in disclosing specifically the amounts that IFT-brokers charge IFT-users, even though they have information about general guidelines for IFT service charges. A question was therefore asked regarding service charges, and the investigators replied that flat rates (e.g., $1 \%$ of a remittance) and informal foreign exchange rates are frequently used methods for service charges. Unlike other illegal goods, such as counterfeit goods, IFT-services are at least equal — or often superior to formal remittance services in terms of speed and cost, as discussed in Chapter 2. However, IFT-systems do not provide a quality assurance mechanism, which is usually included in formal remittance services. Formal financial institutions compensate remitters for the loss of remittances with their internal funds when remittances are lost. According to a few studies (Passas, 2005b; Passas and Giannakopoulos, 2017), IFTsystems deal with missing remittances ${ }^{183}$ in a similar fashion albeit unsystematic.

\footnotetext{
amounts of funds (between 100 USD and 750 USD), the cheapest remittance channel is Paypal (i.e., 3 USD to 23 USD), not IFT-systems (i.e., 4 USD to 30 USD). The most expensive remittance channel in transferring the small amounts is bank tellers (i.e., 54 USD to 75 USD). In order to develop the information of remittance transfer fees, this study introduced several assumptions. For the remittance fees of IFT-systems, this study assumed that IFT-brokers charge $4 \%$ of remittances based on previous studies on IFT-systems.

183 According to Passas (2006a: 50), "there are very few instances in which retail clients lost their money." Passas (2005b: 11) added that "informal dispute-resolution mechanisms most often resolve issues among hawaladars, and individual remitters have seldom lost their money even after law enforcement actions,
} 
However, as IFT-services are normally faster than formal remittance services, senders can quickly check whether their remittances have been received by their intended recipients as scheduled. In addition, since some IFT-brokers are known to conduct IFTbusiness at physical stores, they are unlikely to take off with senders' remittances. Nevertheless, the possibility that IFT-users being defrauded by IFT-brokers will always remain.

As for 'competition' faced by IFT-systems, there are two types of competition in the illegal remittance market: competition between IFT-systems and formal remittance systems, and competition among IFT-brokers. Competition between formal remittance systems and IFT-systems is often reported, albeit not explicitly. The interviewed KoFIU officials gave an interesting view on competition between formal financial institutions and IFT-systems. A considerable number of suspicious transaction reports submitted by formal financial institutions include information about IFT-systems; some suspicious transaction reports contain alleged links between IFT-systems and predicate offences of money laundering, others only document IFT-brokers and their IFT-transactions, with few leads about predicate offenses. Suspicious transaction reports should contain information about predicate offenses associated with suspicious financial transactions. The interviewed KoFIU officials interpreted this phenomenon to mean that some bank tellers may wittingly report alleged IFT-brokers with little association with predicate offenses, hoping that their suspicious transaction reports lead to investigations of the alleged IFT-brokers. In other words, formal financial institutions seemed to actively take advantage of suspicious transaction reports in order to keep IFT-systems in check.

Contrary to the amount of information available on the competition between the two different remittance channels, little is known about competition among IFTbrokers. The level of competition within the illegal remittance market may be associated with the societal perception of - and the response to - IFT-systems. As

accidents, or bankruptcy.... Hence, a consumer protection type of regulation is not as necessary as many a Westerner might think." 
many governments criminalize (unregistered) IFT-systems in accordance with the FAFT's recommendations, IFT-brokers - similar to other illegal service providers are reluctant to advertise their IFT-services or do so in a covert manner. However, in some receiving countries, or in some ethnic enclaves of sending countries, IFT-systems are not tightly regulated or severely suppressed. Taking advantage of such favorable environments, some IFT-businesses may advertise their services openly. Competition among IFT-systems in Korea may not be greatly different from the general picture of competition within the illegal remittance market. Competition among IFT-systems in Korea may be limited or negligible, compared to that of formal remittance systems. The KCS and KoFIU officials provided little information on the topic of competition, even among those Korean-Chinese IFT-brokers believed to be the most active. They explained that each IFT broker may operate in socially differentiated areas, and their prudent business activities may be associated with limited or passive competition among IFT-brokers.

The essence of 'cooperation' in illegal markets is trust each other, albeit under social uncertainty involving deception and betrayal. The trust issue ${ }^{184}$ is inherent in illegal markets when it comes to cooperation between actors. Broadly speaking, cooperation in IFT-systems consists of two components: cooperation between IFT-users and IFT-brokers, and between IFT-brokers in sending and receiving countries. Cooperation between the actors in IFT-systems also involves trust-related risks. Unless IFT-users and IFT-brokers know each other within ethnic enclaves, it may not be easy for IFT-users to trust unknown IFT-brokers; their concerns may include that IFTbrokers take off with the remittances, or deny the fact that they received funds from senders, taking advantage of the fact that no records exist. On the other hand, IFTbrokers are also cautious about trusting senders. For instance, they may be concerned that IFT-users report their IFT-business to law enforcement authorities once the

184 The trust issue inheres in the cooperation component of illegal markets. After being briefly introduced in terms of cooperation in Chapter 5 , the trust issue is intensively examined, drawing on the perspective of trust and risk in Chapter 6. 
transactions are complete, or that they are undercover agents investigating IFT-systems or tracking down IFT-brokers. Trust between IFT-brokers in sending and receiving countries may also be difficult to establish, or may be fragile once established. As IFTbrokers operate remotely, they do not settle their debts after each transaction and do not have a formal enforcement mechanism to resort to. It is therefore quite a challenge for IFT-brokers in sending countries to trust their partners in receiving countries. Despite these risks inherent in trust, actors in IFT-systems seem willing to take these risks, judging by the number of IFT-transactions reported in several studies. As such, the cooperation problem is a greater concern than valuation and competition problems in illegal markets.

\subsection{Summary and reflection}

In responding to the second research sub-question, this chapter narrowed down the analytical angle of this study from the global landscape of IFT-risk to IFT-systems in a specific country. This chapter also guided this study towards a focus on the illegal remittance market, drawing on the sociology of illegal markets. Furthermore, this chapter focused on the basic descriptions of the actors and their activities in IFTsystems detected in Korea from the perspective of the 'market', in order to provide a foundation for the analysis of their relationships. The analytical focus among the actors in IFT-systems was on IFT-brokers, as they are the main actors in IFT-activities and information on IFT-users is scarce. The ethnic background analysis of IFT-brokers suggests that diverse ethnic groups are involved in IFT-businesses in Korea and that half of the IFT-brokers operate in ethnic enclaves. IFT-systems embedded in a particular cultural setting (Chinese) are more salient than those in other settings (e.g., Japanese). This may be due to different trade structures and financial inclusion levels of counterpart countries. Given the amounts transferred by IFT-systems per transaction (approximately 13,00o USD on average), customers of IFT-systems in Korea do not seem to be limited to expatriate workers who normally only transfer small amounts to their home countries. Though the interviews, this study has revealed more diverse sources 
of remittances, such as trade payments, tuition fees and allowances for children staying overseas, and payments for the purchase of foreign real estate.

For the local analysis of IFT-systems, this chapter outlined the theoretical analysis on IFT-systems through the lens of 'illegal markets', as IFT-transactions involve multiple actors and are based on three relational contracts: a contract between senders and IFT-brokers in sending countries, a contract between IFT-brokers in sending and receiving countries, and a contract between IFT-brokers in receiving countries and recipients. The concept of illegal markets is embodied in the sociology of illegal markets, in which the three core elements of illegal markets - valuation, competition, and cooperation - are distilled from the comparison between legal and illegal markets. The sociology of illegal markets has advantages not only because it encompasses the entire remittance market in terms of competition between IFT-systems and formal financial institutions, but also because it acts as a link to the internal dynamics between the actors within IFT-systems. While analyzing IFT-systems in Korea based on the sociology of illegal markets, this study found that IFT-systems do not have fixed service rates, but are usually cheaper than formal remittance systems. While the sociology of illegal markets not only sheds light on competition with formal remittance systems, but also with other IFT-systems, there is limited information on competition among IFTbrokers in Korea. In this study, attention was paid to cooperation in illegal markets, since cooperation between the actors in IFT-systems involves social exchanges and requires trust between them. The next chapter will take the final 'close-up snapshot' of this study, which further explores the internal dynamics between the main actors within IFT-systems. 


\section{Country-focused Analysis of IFT-systems in Korea: Social Exchanges and Trust}

\subsection{Introduction}

The framework of illegal markets has proven useful not only in determining the basic nature of IFT-systems - and their distinctive features comparison to formal remittance systems - but also in identifying all actors in IFT-systems from a broad perspective. However, as the framework mainly analyzed IFT-systems in terms of an institution, it only touched on the (external) relationships between the various actors. In order to answer the second research sub-question in more detail, this study requires a higher resolution lens to examine the interactions that occur within IFT-systems. One of the three features of illegal markets discussed in Chapter 5 is cooperation, which zooms in on the internal dynamics between the actors within IFT-systems. The distinctive and core properties of cooperation in illegal markets are related to exchanges that take place between actors and mutual trust in social uncertainty (Schilke et al., 2015). These are addressed by the two remaining perspectives in the local analysis: the exchange structures in illegal markets discussed in social exchange theory, and the tension between collaborating actors in illegal markets in terms of trust and risk. These two perspectives seek to answer the question why actors trust each other under social uncertainty and how they deal with such risks associated with deception and betrayal in establishing and maintaining trust, while at the same time illustrating interactions between the actors recorded in the IFT-case reports and the interview data.

\subsection{Social exchange theory}

\subsubsection{Social exchange}

The term 'social exchange', coined by Homans (1961: 13) is defined as "the

exchange of activity, tangible or intangible, and more or less rewarding or costly, between two parties". Reciprocity is thus one of the defining characteristics of social 
exchange (Molm, 2003a). Social exchange theory suggests that social exchange occurs within structures of mutual dependence, in which actors depend on each other for valued outcomes. This theory analyzes social exchange activities according to four elements: actors, resources, structures, and processes (Molm, 2003a). The term 'actors' refers to the participants in an exchange. They can be individual persons or corporate groups. They are presumed to be self-serving and seek to maximize profit from exchanges, taking into account the benefits and cost of the offering and the available alternatives related to exchanges. When an actor has assets or behaviors that are valued by other actors, those assets or behaviors represent the 'resources' in the relations between that actor and other actors. 'Structures' in social exchanges refer to the relations between actors that engage in an exchange. Exchange relations develop within structures of mutual dependence. The mutual dependence between actors provides the structural basis for their power over each other; the power difference between actors produces differential distributions of exchange benefits. Less dependent (more powerful) actors receive greater benefit at lower cost than more dependent actors (Molm, 2003a). In reality, social exchange actors are embedded in a larger exchange network of social relations, which can provide them with alternative partners. The availability of alternative partners causes a shift in power, inequality, trust, commitment, and fairness between social exchange actors. For instance, actor A's power over actor B increases with B's dependence on A. B's dependence on A increases with the value of the outcomes that A controls in relation to B, and decreases with the availability of B's alternative exchange partners (Molm et al., 2000). 'Processes' describe "how interactions take place within exchange structures" (Molm, 2003b: 261). When an actor who is given exchange opportunities initiates an exchange and the initiation is reciprocated, the mutual exchange of benefits is called a 'transaction'. An ongoing series of transactions between the same actors constitutes an exchange relation (Molm, 2003b). 
Social exchange theory classifies social exchanges into two forms - negotiated and reciprocal forms of exchange - and compares them ${ }^{185}$. In 'negotiated' exchanges, actors reach an agreement on the terms of the exchange through a joint decisionmaking process. The flow of benefits in the exchange is bilateral, even if the benefits may be unequal. Most economic exchanges fall into this category. In 'reciprocal' exchanges, actors initiate exchanges by performing a beneficial act (e.g., assistance or advice) for other actors, without knowing whether, when or to what extent the other will reciprocate. As the contributions of actors to the exchange are spontaneous, the benefits do not necessarily flow bilaterally (Cook et al., 2013; Molm et al., 2000; 2009; Cropanzano and Mitchell, 2005). While the two forms of exchanges do not presuppose the involvement of illegality, the risks associated with the different forms of exchanges have implications for the understanding of illegal markets. This is because transactions in illegal markets are usually interpreted as negotiated exchanges, but on the other hand, the risks they often face are quite similar to those of reciprocal exchanges.

Exchange theorists focus on the analysis of the 'initiation' of exchanges, through the lens of resource dependence or the use of power by social actors, in order to determine which actor will take a risk according to the different forms of exchanges (Molm, 2006). This is translated into the question whether less dependent (more powerful) actors initiate exchanges or whether more dependent (less powerful) do. Negotiated exchanges requires actors to make agreements with those who offer greater rewards. Since more dependent (less powerful) actors offer better deals than less dependent (more powerful) actors, it would be more profitable in negotiated exchanges to seek less powerful actors and enter into exchanges with them. In negotiated exchanges, less dependent actors are therefore more likely to initiate exchanges than more dependent actors. However, in the case of reciprocal exchanges, it may not be a good idea to seek less powerful actors for exchange. It is believed that actors should

185 The distinction of social exchange into the two types is also useful in analyzing IFT-systems. That is because whereas the exchanges of IFT-systems are normally negotiated ones, IFT-systems face risks involved in reciprocal exchanges. 
more often give benefits to more powerful actors and less often to less powerful ones, in order to maximize the benefits of reciprocity. According to another view, however, in reciprocal exchanges, the probability of reciprocity is more important than the magnitude of its value. Actors may therefore also choose to exchange with more dependent partners, rather than maximizing their results by exchanging more often with less dependent partners and less often with more dependent partners (Molm, 2003a; 2006).

\subsubsection{Exchange relations in IFT-systems}

From the perspective of social exchange theory, IFT-transactions between IFTusers and IFT-brokers are obviously negotiated exchanges. The reason for this is that IFT-users and IFT-brokers conclude agreements for remittance transfers, and that the benefits of each party depend on the other party's adherence to the terms of the IFTtransaction. IFT-transactions between IFT-brokers in sending and receiving countries are also construed as negotiated exchanges, even though the actions of both parties are not closely linked from a temporal perspective, as both parties agree on the terms of remittance payments and debt settlements.

In IFT-systems, IFT-users are normally regarded as powerful actors ${ }^{186}$ and initiate IFT-transactions. This is because most IFT-users tend to compare formal remittance systems and IFT-systems prior to requesting a remittance transfer, and are therefore less dependent on IFT-brokers, even if some remitters (e.g., illegal migrants ${ }^{187}$ ) have no

186 Compared with formal remittance system users, IFT-users may be more dependent upon IFT-systems. However, when comparison is made between IFT-users and IFT-brokers in terms of resource dependence, IFT-users are normally more powerful than IFT-brokers.

187 Even for illegal migrants who have limited access to formal financial institutions, IFT-brokers are not necessarily more powerful actors. Illegal migrants may decide not to send remittances to their relatives in home countries. They may ask other migrants with legitimate IDs to send remittances for them via formal financial institutions. They may choose an IFT broker among several IFT-brokers competing one another. First-time IFT-users may avoid being overcharged by IFT-brokers by consulting regular IFTusers. 
choice but to rely on IFT-systems for their remittance transfers. This view is supported not only by studies on IFT-systems related to Singapore and Korea but also by the IFTcase reports and the interview data. According to the studies on hundi (Rahman and Yeon, 2008; Shah, 2018), 95\% of Bangladeshi workers in Singapore and 8o\% of Nepali workers opt to use hundi in transferring their remittances to their home countries even though they have legitimate work permits and can access to formal financial institutions for cross-border transferring. According to the KCS investigators, many IFT-users used to use formal remittance systems. They added that not all trade payments made by traders using IFT-systems are transferred via IFT-brokers; they usually settle trade payments via formal financial institutions, and only a few transactions are made via IFTsystems. In addition, IFT-brokers are in competition with formal financial institutions, and normally focus on receiving customers rather than looking for them. This is also linked to their limited in ability to advertise their services. IFT-brokers are therefore more dependent on IFT-users. Desperate remitters may of course be more dependent on IFT-brokers than the other way around, as they have no choice but to rely on IFTsystems for their remittance transfers. For instance, some remitters resort to IFTsystems to send funds to countries without reliable formal financial institutions. Some remitters who work in countries with foreign exchange controls rely on IFT-systems to circumvent such barriers. Others use IFT-systems to transfer their criminal proceeds overseas. Criminal syndicates that do not have the right documents to prove the source of their income may also rely heavily on IFT-brokers to transfer their criminal proceeds across borders. IFT-systems can play a pivotal role in hiding and circulating criminal proceeds domestically and across borders. Taking advantage of such vulnerabilities, some IFT-brokers may charge more for providing remittance services to such actors (El Qorchi et al., 2003; Maimbo, 2005). In these situations, IFT-brokers are clearly more powerful than desperate remitters, including criminal syndicates. Thus, in determining power relations between IFT-users and IFT-brokers, it should be acknowledged that the need for IFT-systems differs between different types of IFT-users. Nevertheless, IFTbusinesses are inherently dependent on IFT-users. Without IFT-users, IFT-businesses would not exist. If IFT-brokers were 'generally' more powerful than IFT-users, they would normally charge higher fees for remittance transfers than formal financial 
institutions. The costs of their IFT services are usually lower than those of formal financial institutions (Economist, 2015; El Qorchi et al., 2003; Maimbo, 2005). According to the investigators interviewed, IFT-brokers are fully aware of the fact that they are in competition with formal financial institutions, and that they run the risk of being reported to law enforcement authorities. As regards the power relations between remitters and IFT-brokers, the KoFIU officials expressed an interesting view that, as the Korean government recently lifted regulations on formal remittance services ${ }^{188}$, which has made it possible to provide cheaper cross-border remittance services, remitters may be presented with more alternatives for cross-border remittance services. They added that this could also result in IFT-brokers losing power over remitters.

The negotiated exchange mechanism of social exchange theory also applies to IFT-transactions between IFT-brokers in sending and receiving countries. The number of requests for remittance services or the number of prospective IFT-users can be a means of determining the power ratio between IFT-brokers in sending and receiving countries (Cook and Rice, 2006). It can therefore be concluded that IFT-brokers with more requests for remittance are more powerful. In other words, the power relation between IFT-brokers is influenced by the volume of funds transferred or the frequency of transfers (Cook et al., 2006). The more often IFT-brokers send funds, the more powerful they are in relation to IFT-brokers in receiving countries. However, the power gap between IFT-brokers in sending and receiving countries may be less than anticipated, even though the cross-border flows of remittances are usually asymmetrical between developed and developing countries. This is because IFT-brokers in sending countries cannot run their IFT-businesses without the cooperation of IFT-brokers in receiving countries. Moreover, IFT-systems are not as widespread as formal remittance

188 The Korean government lowered regulations on cross-border remittance services in June 2017 and allowed small-businesses to enter into the cross-border remittance market. However, they are allowed to handle 'small' amounts of remittances given their limited financial capacities. For instance, via small cross-border remittance businesses, remitters can send up to USD 3,0oo at one transaction and up to USD 20,00o in a year. As of December 2018, 24 small cross-border remittance businesses registered with the Korean government. 
systems and IFT-brokers in sending countries may have only a few candidates as their business partners in receiving countries (Molm, 2006). When it comes to initiating exchanges between IFT-brokers in sending and receiving countries, more powerful IFTbrokers - IFT-brokers with more remittance requests - are likely to be the ones initiating the relationship between the two parties. It should be noted that the IFT-case reports only contained limited information to prove this view. However, according to some IFT-case reports and the KCS investigators, IFT-brokers in Korea (e.g., Chinese Koreans who used to live or work in Korea) seem to be the initiators of IFT-businesses between Korea and China, as there is greater demand for IFT-transfers from Korea to China than vice versa ${ }^{189}$.

This study has shown that social exchange theory is a useful lens for examining the interdependence and power relations between the actors involved in IFT-activities, complementing what was revealed through the framework of illegal markets. However, social exchange theory does not provide sufficient information to fully understand the nature of trust and risk that govern the internal dynamics of IFT-systems. This aspect is essential to understand the survival and adaptation of IFT-systems in today's world where IFT-systems are illegitimate - or at least illegal — and prone to deception and betrayal between the actors concerned. Several studies on trust provide components to address this concern; they will be discussed in the next section.

189 There is no way to correctly measure the amounts of informal remittances between two countries. If the assumption that the amounts of formal remittances between two countries are proportional to those of informal remittances is taken, the bilateral remittances matrix of the IMF provides an indication regarding the relative size of informal remittance flows between Korea and China.

Table 6.1: The bilateral remittances (million USD) between Korea and China

\begin{tabular}{lcccccccc}
\hline & 2010 & 2011 & 2012 & 2013 & 2014 & 2015 & 2016 & 2017 \\
\hline Korea $\rightarrow$ China & 1,663 & 1,959 & 1,923 & 3,846 & 4,042 & 4,124 & 3,958 & 4,144 \\
Korea $\leftarrow$ China & o & o & o & 534 & 537 & 533 & 529 & 523 \\
\hline
\end{tabular}




\subsection{Risk and trust in IFT-systems}

The perspective of trust and risk will zoom in on trust-related risks embedded in social exchanges. Discussions regarding trust play a crucial role in exploring the interactions between the different actors in IFT-systems.

\subsubsection{Concepts of risk and trust}

All forms of exchange involve uncertainty and risk - the perceived probability of loss. Uncertainty about whether the other party 'intends to and will act appropriately' is a source of risk. Lack of information about the motivations and possible contributions of exchange partners may result in unfortunate outcomes, such as deception and loss, in exchange transactions (Kollock, 1994; Sheppard and Sherman, 1998). The sources of risk - and the strategies that actors employ to reduce risk - vary according to the type of exchange. While the primary risk in reciprocal exchanges is the risk of nonreciprocation (i.e., giving benefits without receiving equivalent benefits in return), the primary risk in negotiated exchanges is the risk of exclusion (i.e. failing to make an agreement with a desired partner). Negotiated exchanges involve other sources of risk, such as loosely bound agreements and delays in delivery times (McCarthy et al., 1998; Molm, 2003; Molm et al., 2000).

Risks create an opportunity for trust, even if that sounds counterintuitive. Trust arises in response to uncertainty and risk. Perspectives on trust differ from one discipline to another ${ }^{190}$. Although there are varying perspectives on trust ${ }^{191}$ (Rousseau

190 Sociologists find trust in socially embedded properties of relations among individuals or institutions; psychologists address trust in terms of attributes of trustors and trustees, attending to actors' internal cognition processes; and economists view trust as either calculative or institutional (Rousseau et al., 1998). 191 Shapiro (2012) classifies studies on trust into three perspectives: trust as encapsulated interests, trust as emotion, and trust as asymmetric agency. The encapsulated interest account views that the trustor places trust because the trustor thinks that it is in the trustee's interest to take the trustor's interest in a relevant matter (Hardin, 2001). From the perspective on trust as emotion, trust is not cognitive or rational; it cannot be calibrated by trustworthiness. This perspective views that trust is an emotional facility and 
et al., 1998; Shapiro, 2012), trust is normally defined as "expectations that an exchange partner will behave benignly, based on the attribution of positive dispositions and intentions to the partner in a situation of uncertainty and risk" (Molm et al., 2000: 1402). Two essential elements drawn from this definition are: the confident expectation that the other party will reciprocate, and a willingness to be vulnerable to the other party's non-cooperation. Trust therefore implies trustors giving discretion to, relying on, or being vulnerable to trustees under conditions of uncertainty and risk (Shapiro, 2012). Trust of trustors, and trustworthiness of trustees, emerge only in situations where trustees have both the incentive and the opportunity to exploit trustors, but instead are expected to behave benignly (Molm et al., 20oo; Sheppard and Sherman, 1998). The definition of trust used by social exchange scholars differs slightly from the definition used in everyday life. Trust is not just a choice (e.g., taking a risk) or behavior (e.g., cooperation); it is a psychological state that arises from or causes such actions (Hardin, 2001; Rousseau et al., 1998; Shapiro, 2012). For instance, while trustees must demonstrate their trustworthiness to gain trust from trustors, trustors must discern trustworthiness of trustees in a situation of uncertainty before making the decision to trust. If trustors consider trustees to be trustworthy, they become committed to specific trustworthy exchange partners (Molm et al., 200o). Trust thus involves assessing the trustworthiness of another actor in relevant circumstances.

The anticipated gains from trust can emerge when actors engage in exchanges with trustworthy partners who reciprocate what they have received. Misplaced trust, which results from engaging in exchanges with exchange partners who exploit trust, is costly. While mutual gains can be achieved through trust, there are also incentives for

\footnotetext{
is based on the trustor's feeling of confidence in the trustee's future actions and in the trustor's own judgment of the trustee (Barbalet, 2009). In the view of trust as asymmetric agency, trust is applied between the principal and the agent who act on behalf of the principal for some uncertain future return. This perspective views that trust is irrelevant to trustworthiness or feeling of confidence (Shapiro, 2012) and focuses excessively on asymmetric relationships between trustors and trustees. Shapiro's model of trust between the principal and the agent attends to conflict of interests between the two parties. The three perspectives shed light on the different aspects of trust. This study's point of view on trust is mainly based on Hardin's perspective, even though Shapiro's angle is also duly considered to some extent.
} 
trustees to choose an untrustworthy option, which results in a lack of respect for trust and opportunistic behavior (Messick and Kramer, 2001). Harvesting the benefits of trust is greatly influenced by the trustor's ability to assess the trustworthiness of prospective trustees. However, actors usually do not know in advance the intentions, motives and competence of their potential exchange partners. In other words, actors who choose to trust exchange partners always face both opportunity and vulnerability. An optimal level of trust is determined by the balance between actors' decisions to trust exchange partners and their actual trustworthiness. Although excessive trust extended without caution can be costly, too little trust can jeopardize beneficial opportunities and material gains (Kramer, 2006). On the other hand, if it were completely certain that the other party in the exchange was reciprocal, trust would not be needed (Rousseau et al., 1998).

\subsubsection{Reasons for trust}

Although social exchange theory deals with both 'social uncertainty and risk' and 'trust', it does not seem to have a salient component that explains the connections between them. Social exchange scholars assume that social uncertainty and risk automatically lead to trust. How social uncertainty and risk develop trust therefore remains unclear in social exchange theory. Scholars from other domains bridge the gap between social uncertainty and risk and trust. Rational choice theory indicates that social uncertainty and risk are endogenously reflected in a rational actor's decisionmaking process regarding whether or not to place trust in someone. For instance, a rational actor ${ }^{192}$ places trust in someone, if the ratio of the chance of gain $(\mathrm{P})$ to the

192 Rational choice theory carries several basic assumptions about rationality. Among them, an assumption that relates to identification of trustworthiness and placement of trust is: "actors possess extensive information on both the available alternatives and the likely consequences of their choices" (Monroe and Maher, 1995: 2). However, many criminologists adopt 'bounded rationality' in their models, attending to the facts that people do not necessarily make the most rational decisions as they make use of less important or accurate information for decisions or employ shortcuts in the processing information (Clarke and Cornish, 1985). Detailed discussions about rationality are not included in this study as rationality may not necessarily be essential in the local analysis in Chapter 6. 
chance of loss (1-P) is greater than the ratio of the amount of the potential loss (L) to the amount of the potential gain $(G)^{193}$ (Coleman, 1990; Von Lampe and Johansen, 2006). However, rational choice theory focuses on the decision-making process of a rational actor, and somewhat neglects the exchange partner's response to the trustor's decision. Just as game theory, which examines conflict or cooperation between rational actors, demonstrated in the Prisoner's Dilemma (Hetcher and Kanazawa, 1997), rational actors seeking self-interest are supposed to choose 'not to cooperate' under the conditions of uncertainty, unless their rationality is bounded. In practice, however, social actors choose to cooperate with one another and to trust each other (Ho and Weigelt, 2005; Lewicki and Bunker, 1995; McCarthy et al., 1998).

Social dilemma theory (Van Lange et al., 2013) addresses the question of why rational actors choose to trust exchange partners, even though it may be harmful to trust the other party under social uncertainty. This theory is based on collective rationality, whereby people pursue not only selfish but also collective interests, and are more likely to pursue cooperative rather than individual goals. Collective rationality includes the recognition that in some situations, the interests of social actors are conditioned by — or dependent on — the other party's decisions and actions. Similar to egocentric rationality, collective rationality suggests that social actors conduct costbenefit analyses in order to maximize their preferences. Collective rationality, however, takes into account the other party's wishes in the decision of social actors (McCarthy et al., 1998). Thus, contrary to the Prisoner's Dilemma, people can understand the value of cooperation and consider the interests and preferences of the other party in their decision. They are willing to risk the trust that cooperation requires. Researchers present several conditions that facilitate collective rationality, trust, and cooperation

193 Coleman's model of trust is also on the basis of rational choice theory, but its format is tailored to deal with trust. This model posits that trust between two parties depends on gain $(G)$ and loss (L) from trust and probability of gain $(\mathrm{P}): \mathrm{PG}=(1-\mathrm{P}) \mathrm{L}$, or $\mathrm{P} /(1-\mathrm{P})=\mathrm{L} / \mathrm{G}$. Thus, if a potential trustor thinks that he is more likely to gain by placing trust in someone $(P G>(1-P) L$, or $P /(1-P)>L / G)$, then he places trust. However, if he thinks that he is likely to lose by placing trust in someone $(\mathrm{PG}<(1-\mathrm{P}) \mathrm{L}$, or $\mathrm{P} /(1-\mathrm{P})<\mathrm{L} / \mathrm{G})$, then he will not give trust (Han, 2012). 
over egocentric rationality. These conditions include: the ability to communicate before making a decision; fear of revenge for non-cooperation; embeddedness in groups or communities; information on people's reputation; willingness to take risks; and also desperate situations (McCarthy et al., 1998).

In addition to the rational factors related to giving trust, several irrational factors are also involved in the development of trust. Superficial personal characteristics and behaviors often lead to conclusions about the other's trustworthiness (Von Lampe and Johansen, 2006). Knowledge of - or information about - the characteristics and dispositions of prospective exchange partners' influence the decision about whether or not to trust them. This is based on the assumption that potential exchange partners will act according to expectations based on their appearance (or characteristics presented). Trust in exchange partners can also be developed through habit in routine situations, rather than through conscious deliberation. Trust between family members, local community members, and members of the same ethnic groups is based on familiarity and conformity. The role of ethnicity as a trust-producing factor under conditions of illegality may be enhanced by a subculture that attaches high value to loyalty, and to social norms that keep matters out of reach of outsiders. For instance, actors involved in illegal transactions or activities may place trust in exchange partners simply because they share the same ethnic background. Sometimes trust is given under desperate circumstances from which actors cannot free themselves without help. In such unfavorable situations, they may have no choice but to run the risks associated with trusting the other party. Some risk-seeking or fatalistic actors trust the other party, even if this involves a high likelihood of loss (Von Lampe and Johansen, 2006).

\subsubsection{Responses to social uncertainty and risk}

Although the decision of social actors to trust inherently entails risks, few of those actors would want to be exposed to risk without any protection measures. They therefore seek various measures to avoid or reduce risk. With respect to risk management, Heimer (2001) provides a general framework for the analysis of trust- 
related issues, arguing that social or economic interactions will not occur until the two core elements of trust relations ${ }^{194}$ - uncertainty and vulnerability - are dealt with. According to the author, economic interactions based on trust relations occur not only when trustors deem it unlikely that trustees will violate their interests, but also when trustors have taken precautions to protect their interests, to the point where they do not need to worry as much about the intentions and competence of trustees. Trustors therefore adopt strategies ${ }^{195}$ that reduce uncertainty or vulnerability, taking into account particular social contexts in which the issues can occur. If information about the intentions and competence of trustees is available and inexpensive to obtain, trustors may attempt to reduce uncertainty before deciding to reduce vulnerability. If information suggests that trustees are benevolent and competent, actions for reduction of vulnerability may be unnecessary because the probability of loss is small. However, when trustors cannot easily obtain information about trustees, they need to choose whether to reduce their vulnerability by spreading their dependence across several trustees, or to arrange an insurance to cover any losses (Heimer, 2001). While in traditional societies, trustors attend to the reduction of uncertainty regarding the intentions and competence of trustees, in modern societies involving more contact with strangers, efforts to reduce vulnerability are more common (Cook, 20o1).

There are two approaches that actors can adopt to reduce uncertainty before engaging in exchanges. One approach is to try to distinguish between trustworthy and

194 Uncertainty refers to an actor's inability to predict the outcome of an event because he lacks information about the intentions and competence of another actor who controls the outcome. Vulnerability refers to the level of risk to which an actor is exposed by engaging in an interaction (Heimer, 2001).

195 Heimer (2001) present five strategies to cope with uncertainty and vulnerability: (1) trustees deny the legitimacy of trustors' feelings of uncertainty, (2) trustees obscure whom trustors raise complaints to, (3) trustees deny trustors' right to negotiate with trustees, (4) trustors try to alter the situation or to influence trustees by reducing their uncertainty about trustees' intentions or competence, and (5) trustors try to alter the situation or to influence trustees by reducing their vulnerability to trustees. However, the detailed information about the five strategies is not included in this study because it is beyond the scope of this study. 
untrustworthy actors. Based on this differentiation, trustors can identify mutually productive transactions - and selectively initiate them - with actors who are highly likely to reciprocate their trust, and shun those who are unlikely to do so. A second approach is that actors themselves engage in eliciting trustworthy behavior from exchange partners, by educating exchange partners about themselves, and shaping their partners' trust-related behavior in the direction that they want. In this way, actors can use their own behavior not only to encourage and reward exchange partners' trustworthy behavior (e.g., informing them of potential additional purchases after the current deal has proved successful), but also to send their exchange partners a signal about their unwillingness to be abused (e.g., by bringing lawyers to the bargaining table). The two approaches are not mutually exclusive. Trustors can be better off if they make use of the two approaches together (Kramer, 2006).

Many social exchange studies seem to have been conducted with little consideration for the distinction between legal and illegal markets. However, a few studies (Cook et al., 2004) on trust in transitional economies (e.g., former Soviet Union and Eastern European countries) provides important insights into trust in illegal markets, as the conditions of uncertainty in transitional economies are somewhat similar to those in illegal markets. They argue that, under uncertain conditions, trust networks emerge to provide a secure environment for exchanges. This is particularly true when the exchange of goods or services cannot be properly handled with clear contracts, or when there is no reliable legal enforcement of contracts. In situations of high uncertainty and risk (e.g., corruption and exploitation), exchange transactions are likely to take place mainly between actors who know each other well and who operate within relatively closed associations or groups (e.g., families or informal membership associations). Additional features are that the boundaries of the group are clear and that membership is easy to determine.

Committing to specific relations may be often the most viable solution to the problem of uncertainty from the risk of exploitation, as social uncertainty can also arise from the risk of exploitation that results from the opportunistic acts of one's exchange 
partners. It is difficult to prevent opportunistic acts and associated exploitation, unless the networks become closed and those who deceive can be excluded from further interactions with those in the networks. If it is proven that actors within a given opportunity structure are trustworthy exchange partners, continued exchanges with those partners protect bona fide actors against opportunistic actors. However, such closed exchange networks have limited access to opportunities outside the networks. This may end up jeopardizing potentially more profitable exchange opportunities, in favor of continuing interactions with known partners who have demonstrated their trustworthiness during previous transactions. Commitments are therefore more likely to be used as a means of reducing uncertainty when alternatives are limited and opportunity costs are low (Eck, 1995; Molm et al., 2000). Power inequality within network structures influences the commitment of exchange actors to exchange partners under social uncertainty (Rice, 2002). In networks where power differences between exchange partners are minimal, commitments to exchange partners may be a viable solution to uncertainty, all other factors being equal. In networks that involve large power differences among actors, there is an incentive to explore alternatives instead of making commitments. However, with increased risk of loss, even power-advantaged actors seek committed relations for exchange (Cook et al., 2004).

\subsubsection{Risk and trust in IFT-systems}

When placing trust in each other, both IFT-users and IFT-brokers expect the other party not to violate the specific terms stipulated in implicit agreements regarding remittance transfers. They also expect each other not to share their transactions or related information with law enforcement authorities. However, IFT-users and IFTbrokers face a similar dilemma to that illustrated by John Eck (1995). IFT-users are cautious about contacting IFT-brokers out of concern that they may be undercover agents, or may disappear with their remittances, without transferring their funds to the intended recipients. IFT-brokers are also wary of working with unknown IFT-users, as they might be undercover agents or informants working for law enforcement authorities. In IFT-transactions, IFT-brokers in sending and receiving countries also face 
uncertainty. Their major concern is whether the other party will fulfill their obligations, such as payment to recipients or settlement of outstanding debts. Under such uncertain circumstances, the actors nevertheless conclude IFT-contracts and engage in IFTtransactions. One of the main questions not clearly addressed in previous studies on IFT-systems is how IFT-users and IFT-brokers are able to trust ${ }^{196}$ each other, even if they have an incentive to exploit the other party's vulnerability incurred from engaging in illegitimate transactions. Of course, in some developing countries where the formal financial sector is underdeveloped and the AML/CFT mechanism is not working well, IFT-users and IFT-brokers may have little awareness of the fact that IFT-transactions are illegal or believe that IFT-systems are (illegal yet) legitimate (Rees, 2010). Nevertheless, in the absence of a formal mechanism to enforce IFT-contracts and protect actors from fraud, they are exposed to the risk of being deceived or betrayed.

\subsection{Analysis of dynamic interactions between the actors}

In order to obtain a clear holistic picture of the internal dynamics within IFTsystems, this study has adopted a temporal analytic approach inspired by Cornish's crime scripts approach. The crime scripts approach analyzes the modus operandi of complex forms of criminal events by focusing on the step-by-step accounts of the procedures undertaken by criminals when engaging in a particular crime (Cornish,

196 Lascaux (2015) claims that on completion of IFT-transactions, the impacts of reputation building, community demands, and other forms of social embeddedness are greater than that of interpersonal trust and thus the role of trust in blocking opportunistic activities in IFT-systems is overrated. However, Lascaux' view on the role of trust in IFT-systems may be based on such misunderstanding that trust works as an instrument to protect against opportunism in IFT-systems. Multilateral social controls, such as social embeddedness, reputational effects, community pressure, and social obligations, may greatly contribute to developing interpersonal trust in IFT-systems. However, one of discussion focuses on trust in informal economic transactions including IFT-transactions must be how trust occurs despite social uncertainty. Trust between actors in IFT-systems occurs irrespective of involvement of such social controls in IFT-transactions. Social controls may facilitate interpersonal trust but cannot ensure occurrence of trust or be the basis of trust. The more social devices make outcomes predictable or reduce vulnerability, the less trust can be required (Shapiro, 2012). Social controls cannot replace trust in IFTsystems because IFT-transactions are made where social controls are weak or absent. 
1994). Thus, the local analysis first identifies the role of each actor within the basic mechanism of IFT-systems and reorganized them in a temporal order. The local analysis then shows step-by-step accounts of IFT-activities, drawing on the perspective of trust and risk, to illustrate the internal dynamics between the actors involved in IFTactivities (Table 6.2).

Table 6.2: Procedures of IFT-activities

\begin{tabular}{l|l}
\multicolumn{1}{c|}{ Procedure } & \multicolumn{1}{c}{ Sub-procedure } \\
$\begin{array}{l}\text { (1) Preparation of } \\
\text { an IFT-business }\end{array}$ & $\begin{array}{l}\text { (1.1) Coming up with the idea of setting up an IFT-business } \\
\text { (1.2) Deciding on an IFT-business model } \\
\text { (1.3) Obtaining at least one bank account } \\
\text { (1.4) Establishing a business relationship with a counterpart IFT broker } \\
\text { (1.5) Advertising the IFT-business and gathering IFT-users }\end{array}$ \\
\hline $\begin{array}{l}\text { (2) Making IFT } \\
\text { transactions }\end{array}$ & $\begin{array}{l}\text { (2.1) Assessing trustworthiness of prospective IFT-users and IFT-brokers } \\
\text { (2.2) Receiving remittances from the senders }\end{array}$ \\
(2.3) Sending remittance orders to the counterpart IFT broker \\
(2.4) Paying the funds to the recipients \\
made from IFT- \\
transactions
\end{tabular}

Source: the author

From the perspective of IFT-brokers, this study divides the process of IFTactivities into three steps: (1) preparation of an IFT-business, (2) making IFTtransactions, and (3) settling debts resulting from IFT-transactions. The preparation of an IFT-business is a step that IFT-brokers take to enter the illegal remittance market before they carry out IFT-transactions for IFT-users. This procedure includes various activities for setting up an IFT-business. Performing IFT-transactions is the main step of an IFT-business, including activities ranging from receiving funds from remitters to transferring funds to recipients. The procedure for settling debts resulting from IFTtransactions is an ex post step taken between IFT-brokers to resolve outstanding debts. Each procedure is divided into more specific sub-procedures, which are shown in Table 6.1. Of the 11 sub-procedures, the majority - from advertising the IFT-business and 
gathering customers (1.5), to settling outstanding debts with the counterpart IFT broker, and monitoring the trustworthiness of business partners (3.2) - are recurring as long as an IFT-broker continues the IFT-business. Each sub-procedure includes several options that IFT-brokers and IFT-users can use.

Since an IFT-business is a business, IFT-brokers make a number of decisions and preparations prior to launching their IFT-business. The preparation stage of an IFTbusiness can be divided into several sub-procedures: coming up with the idea of setting up an IFT-business, deciding on a IFT-business model, obtaining bank accounts, establishing a business relationship with a counterpart IFT broker, and advertising the IFT-business and gathering IFT-users. The IFT-case reports did not provide specific information as to how IFT-brokers launch their IFT-businesses. Even though IFTtransactions between IFT-brokers and IFT-users have not yet taken place at this stage, the element of trust and risk is already relevant in this step, especially in obtaining bank accounts, in establishing a business relationship with a counterpart IFT broker, and in advertising the IFT-business and gathering IFT-users.

\subsubsection{Coming up with the idea of setting up an IFT-business}

Entrepreneurs normally come up with ideas for new businesses before starting those businesses (Scarborough and Cornwall, 2016). Their experience, skills and knowledge underlie business ideas and greatly contribute to the survival of new businesses (Watson et al., 1998). According to the KCS investigators interviewed, IFTbusinesses do not require creative ideas or advanced skills, even if most ordinary people are unfamiliar with the concept of IFT-systems. Entrepreneurs who have only engaged in cross-border trade once can easily come across - or come up with an idea related to - IFT-businesses. Nearly all expatriates may require IFT-services at some point. The resulting demand for IFT-services can be met by anyone with a small pool of funds, and a trustworthy business partner in another country. The investigators added that IFTbusinesses are a somewhat well-known business model to Korean-Chinese people who used to live or work in Korea, and required remittance transfers under the government's 
radar. IFT-brokers are generally aware of the illegality of IFT-businesses. They use various methods in the IFT-steps described below to manage the uncertainties associated with running an IFT-business.

\subsubsection{Deciding on an IFT-business model}

When deciding to launch a business, business founders develop new business models - or adopt existing ones - to realize their business ideas. The concept of a business model encompasses several dimensions, and there is little consensus on its definition (George and Bock, 2011). However, there are commonalities between the different definitions. Business models primarily describe how firms 'do business' and seek to explain how value is created (Zott et al., 2011). Business models obviously play an important role in 'doing business', given that a mediocre idea or technology pursued through a great business model, may be more valuable than a great idea or technology exploited through a mediocre business model (Chesbrough, 2010; Magretta, 2002). Like ordinary businesspeople, IFT-brokers make a number of decisions while developing or adopting their IFT-business models. Their decisions are made to increase the revenue of their IFT-business and to protect their business from risks.

Case 3: A stereotypical IFT-business where two IFT-brokers work together KIM is Korean and used to run a machinery exporting business in Korea. He also operated an IFT-business, which was connected to an IFT broker in Bangladesh RAHMAN who once worked in Korea. At first, it was unknown how the two parties got to know each other. Their relationship was enhanced with respect to KIM's trading business. KIM took funds from remitters via his four bank accounts, and fabricated export invoices to make the sending of funds to RAHMAN in Bangladesh look legitimate. RAHMAN handed over the corresponding amounts of funds in the local currency (TAKA) to the recipients designated by remitters. KIM transferred 28,927,651 USD from Korea to Bangladesh in this manner between October 2007 and August 2011. 
Generally speaking, IFT-brokers will first decide whether to work alone or to hire someone for their IFT-business. As mentioned in Chapter 2, an IFT-transaction theoretically requires at least two IFT-brokers: an IFT broker in a sending country and a counterpart IFT broker in a receiving country. In practice, IFT-transactions do not necessarily require two separate IFT-brokers. They can be made by one IFT broker, which is often referred to as a 'solo IFT broker'. What makes solo IFT-brokers interesting is the fact that they play a dual role in IFT-transactions - receiving funds and paying funds - without counterpart IFT-brokers. Solo IFT-brokers are somewhat different from IFT-brokers who make unilateral transactions ${ }^{197}$, as they work with counterpart IFT-brokers. Of course, some solo IFT-brokers only seem to carry out unilateral transactions when they do not have customers for inverse transactions. Solo IFT-brokers account for approximately two-thirds of all IFT-brokers investigated by the KCS between 2011 and 2013. They transfer remittances to overseas recipients without collaborating with counterpart IFT-brokers or couriers, only by using bank accounts that they control. This suggests that, contrary to the conventional notion of a IFT mechanism, where two IFT-brokers are required to complete an IFT transaction, the majority of the IFT-businesses investigated in Korea were run by solo IFT-brokers.

197 As briefly mentioned earlier, it is mysterious that how some IFT-brokers can provide unilateral IFTservices, as IFT-businesses necessarily involve settlement of outstanding debts between IFT-brokers. Possible conjectures are either that IFT-brokers who allegedly make unilateral IFT-transactions are cracked down on before they settle outstanding debts with counterpart IFT-brokers, or that IFT-brokers with debts to pay off make unilateral IFT-transactions, or that outstanding debts between IFT-brokers are settled in unknown ways. 
Figure 6.1: Solo IFT broker transmitting remittances

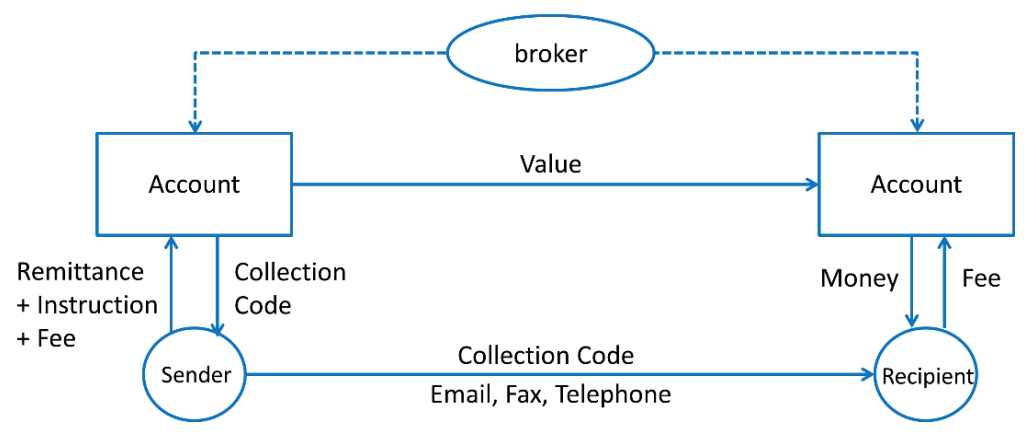

Source: Han and Ireland, 2013

The IFT-case reports describe how solo IFT-brokers transmit remittances from remitters to overseas recipients. This type of IFT-business was not possible until the introduction of online banking services ${ }^{198}$ by formal financial institutions. For this type of IFT-business, the first step for IFT-brokers is to open bank accounts in Korea, or borrow bank account from their family members, relatives, or acquaintances in Korea. The second step consists of moving to China, where the government still strictly controls foreign exchange transactions and where it is difficult for people living in suburban or rural areas to access formal financial institutions. IFT-brokers would then accept remittances from senders in Korea on their bank accounts via online banking systems or ATMs, and hand over the corresponding amounts of funds to recipients in China. They also made use of online banking systems in Korea to send remittances from China to Korea. They accepted remittances from senders in China, and transferred remittances by transmitting the corresponding amounts from their bank accounts in Korea to recipients. In other words, IFT-brokers ironically use the online banking

198 According to Lascaux (2015), an important protective mechanism in IFT-systems is closely associated with the relations of familiarity between IFT-brokers and IFT-users. Many studies argue that IFTtransactions are normally grounded in face-to-face interactions and long-term personal connections between IFT-brokers and IFT-users as opposed to anonymous environment of contemporary formal remittance systems. However, it turns out that as IFT-brokers make use of online banking services in the course of receiving and handing over remittances, such conventional notion about IFT-systems may not be valid any longer. 
systems of formal financial institutions to facilitate their IFT-businesses. Solo IFTbrokers generally live and operate in countries with low financial inclusion to receive and hand over funds in person, while using the online banking services provided by countries with high financial inclusion to manage funds. This way of doing business differs somewhat from the way IFT-brokers use of formal financial institutions - they mainly use formal financial institutions to settle debts (FATF, 2013a).

Most IFT-brokers, even solo IFT-brokers, need co-offenders. Co-offenders of IFT-brokers are not confined to their counterparts. Some IFT-brokers need the assistance of couriers to transport large sums of cash overseas. Some IFT-brokers borrow bank accounts from their family members, relatives or acquaintances to avoid the attention of law enforcement authorities to their IFT-businesses and to facilitate IFT-transactions. According to the analysis of the IFT-case reports, most of the IFTbrokers had more than one co-offender.

When IFT-brokers decide whether to run their IFT-business alone or work with someone else, this decision involves trust issues. In particular, trust in IFT-brokers in receiving countries should be more important for IFT-brokers in sending countries, than trust in other co-offenders. The analysis of the IFT-case reports suggests that the business relationship between IFT-brokers in sending and receiving countries is mostly based on their previous relationships. Only a small proportion of IFT-brokers in sending and receiving countries are connected in ties of 'kinship'. The majority of the IFT-brokers working with their counterparts are linked through other conventional business relationships. It would be almost impossible for total strangers to develop mutual trust to carry out credit transactions (not actual movement of funds) between them.

The decision to work alone or with someone else is a risk mitigation strategy. Some IFT-brokers only work with compatriots in order to reduce risks of being deceived or betrayed by co-offenders. IFT-brokers who have difficulty obtaining trustworthy counterparts seem to be inclined to run their IFT-businesses alone and to use online 
banking systems. Solo IFT-brokers may be able to earn more profit and be safer than those working with others, because they can save costs involved in working with cooffenders. They are also less exposed to the risk of detection via co-offenders. However, solo IFT-brokers may be limited in their ability to expand their businesses through counterpart IFT-brokers or to more than one country.

IFT-brokers must also decide whether they want to work on their IFT-businesses full-time. Some studies on IFT-systems assume that IFT-brokers are full-time professionals dealing with the funds of others. However, the IFT-case reports reveal that IFT-businesses are not necessarily a full-time job and do not necessarily deal with third parties funds. Sometimes IFT-users themselves somehow play the role of IFTbrokers. According to the case reports, some businesspeople wanted to transfer their own funds to their business partners without relying on formal financial institutions. Fortunately for them, they had connections with IFT-brokers in receiving countries who are indebted to them. In those cases, their business partners appointed IFT-brokers in receiving countries, who were responsible for accepting funds from sending countries. They transferred their own funds to their business partners only through IFT-brokers in receiving countries, without using IFT-services in sending countries. Therefore, this type of IFT transaction does not necessarily require two separate IFT-brokers in sending and receiving countries. The interviewed investigators also indicated that there are a number of part-time IFT-brokers with their own legitimate full-time businesses. Some businesspeople worked as part-time IFT-brokers in receiving countries ${ }^{199}$. While running IFT-businesses part-time, they could write off their own business debts to IFTbrokers in sending countries. According to the investigators, unlike full-time professional IFT-brokers, most of them do not have a clear sense of the illegality of IFTactivities in which they are involved while managing their own business agendas.

199 This type of part-time IFT-brokers should be distinct from professional IFT-brokers who run legitimate businesses as a façade; which was discussed below. 


\section{Case 4-5: Unconventional IFT-brokers}

\#4. JUNG (Mr.) ran a trading business in Korea. He was acquainted with KIM (Ms.) who ran a grocery store in China. They colluded to undertake a cross-border trade business without leaving trails. For instance, if JUNG sent 10 electrical cookers and 10 thermo-mats to KIM via shuttle traders, she would then pay for the goods via several Korean bank accounts that she had borrowed from her acquaintances. In this way, between January 2008 and August 2008, KIM sent a total of 95,640 USD to JUNG via 23 domestic transactions. In this case, KIM played the role of IFT broker both in sending and receiving countries.

\#5. ROH was Korean and ran a bag manufacturing business in China. Some of the bags manufactured in his factory were exported to Korea. In the course of running his business in China, he became acquainted with another Korean, YOON, who ran a ceramic manufacturing business in China. YOON looked for a way to send his business profits to Korea because it was challenging to wire foreign exchanges outside China without solid supportive documents. In order to obtain foreign exchange margins by transferring YOON's funds to Korea, ROH asked YANG - his business partner who imported bags from China - to wire the corresponding funds to the bank accounts designated by YOON, instead of paying the trade payment that YANG owed ROH. In this manner, ROH transferred 566,270 USD from China to Korea via 85 transactions. In this case, YOON - who wanted to send his funds to Korea - was an IFT user; ROH played the role of IFT broker in the sending country, and YANG was the counterpart IFT broker in the receiving country.

\subsubsection{Obtaining at least one bank account}

Unlike the conventional notion that IFT-brokers do not use formal banking services, or find them irrelevant, most of the IFT-brokers investigated by the KCS used formal financial institutions. Nearly all of them actively used bank accounts to accept remittances from senders and to disburse them to recipients. As the IFT-case reports provide little information as to why IFT-brokers used formal financial institutions for 
their IFT-businesses, the investigators were asked about this. They all replied that the use of bank accounts benefits both IFT-brokers and IFT-users in terms of risk reduction.

Approximately half of the officers felt that the services of formal financial institutions enable IFT-users to gain 'easy' access to IFT-brokers. Only a few IFT-users meet IFT-brokers in person when they want to send remittances. A third of those interviewed replied that the involvement of formal financial institutions in IFT-systems appears to lessen IFT-users' concern about being deceived by IFT-brokers. As bank accounts leave traces, the bank accounts of IFT-brokers can send a signal to IFT-users regarding their trustworthiness. They added that the involvement of formal financial institutions in IFT-systems also dilutes the perception of IFT-users regarding the illegality of IFT-brokers. IFT-systems linked to online banking systems seem to lead to misunderstandings among some IFT-users about IFT-systems that they use or are likely to use: IFT-brokers may be remittance agents who operate new remittance programs ${ }^{200}$ developed in cooperation with formal financial institutions.

The average number of bank accounts used by IFT-brokers is 4.6. As mentioned earlier, not all bank accounts used by IFT-brokers are their own. Half of the IFT-brokers investigated borrowed bank accounts from others. Some IFT-brokers opened accounts with different banks ${ }^{201}$ using their real name, others borrowed bank accounts from family members for free. Some bought the right to manage bank accounts from their acquaintances. They received - from the holders of bank accounts - not only bank account numbers, but also the encryption keys and passwords required to access those bank accounts via online banking systems. According to the KCS investigators and

200 As briefly discussed earlier, small cross-border remittance services are actually provided by nonfinancial businesses in collaboration with formal financial institutions. Thus, there is a high likelihood that prospective IFT-users may perceive IFT-brokers with bank accounts as new formal remittance service providers.

201 In Korea there are eight formal financial institutions which have their own branches in nearly every city and in which individuals including legal immigrants have few restrictions in opening accounts for deposits and withdrawals. 
KoFIU officials, it was legal in Korea to borrow and lend out bank accounts if both parties agreed. This was until the revision of the Act on Real Name Financial Transactions and Confidentiality in 2014, which made it illegal to conduct financial transactions in someone else's name for criminal purposes, such as concealing criminal proceeds, money laundering, and tax evasion. In practice, however, it is difficult for banks to determine whether bank account holders manage their own bank accounts or whether this is done by someone else. Even after the revision of the Act, it is said that many IFT-brokers still make use of borrowed bank accounts for their IFT-businesses.

The average number of transactions of the IFT-brokers investigated amounted to 5,421, while their IFT-businesses lasted 31.9 months on average. This means that the IFT-brokers investigated are estimated to handled approximately six IFT-transactions per day, or 170 IFT-transactions per month. However, there is limited information on the number of IFT-users for which each IFT-broker provided IFT-services. Too many transactions in one bank account are likely to draw the attention of bank tellers, which may result in the submission of suspicious transaction reports to the KoFIU. The interviewed investigators mentioned that bank accounts are borrowed from others not only to conceal the identities of IFT-brokers, but also to avoid the attention of bank tellers or law enforcement authorities. The majority of the interviewed investigators felt that hiding identities is a slightly more important reason than avoiding the attention of law enforcement authorities ${ }^{202}$, although the two reasons are related. Some investigators noted that IFT-brokers make use of 'several' bank accounts in order to bypass the daily remittance transfer limit (e.g., 10,000 USD) ${ }^{203}$, and that they split large amounts into several smaller remittances. The IFT-case reports provide few clues as to whether the actual owners of the bank accounts involved were investigated and prosecuted. The interviewed investigators mentioned that most actual owners of bank

202 In order to avoid law enforcement authorities' attention, several methods can be employed — not only dispersing funds into several bank accounts but also mis-invoicing.

203 Formal financial institutions normally set different daily remittance limits according to their clients' backgrounds and credit levels. If a client has an unstable job or business or has a short relational history with formal financial institutions, they tend to set his daily remittance limit low. 
account were seemingly aware that their bank accounts would be or were being used for illegal businesses, such as IFT-businesses. Nevertheless, the investigators are reluctant to investigate the actual owners of bank accounts, as they do not have the authority $^{204}$ to conduct investigations with respect to the violation of the Act on Real Name Financial Transactions and Guarantee of Secrecy, which regulates the lending and borrowing of bank accounts ${ }^{205}$.

IFT-brokers who use bank accounts to manage cash flows may be concerned about the risk of their IFT-businesses being detected by law enforcement authorities in charge of monitoring suspicious financial transactions. However, according to the KCS investigators, IFT-brokers consider the likelihood of their businesses being detected by law enforcement authorities to be rather low. This is because their IFT-transactions via online banking systems are hidden 'in plain sight'; it is difficult to detect IFTtransactions among a myriad of financial transactions, like looking for a needle in a haystack. In fact, cash transactions ${ }^{206}$ between senders (or recipients) and IFT-brokers at physical stores can draw unnecessary attention of neighbors or law enforcement authorities. The KoFIU officials explained that frequent cash deposits or withdrawals

204 Even though customs investigators do not have authority to conduct 'criminal investigations' of offences violating Act on Real Name Financial Transactions and Guarantee of Secrecy, they can 'examine' the alleged offences and report them to prosecutors. However, they have rarely done that.

205 Act on Real Name Financial Transactions and Guarantee of Secrecy stipulates that financial institutions shall undertake financial transactions with customers' genuine names (Article 3 (1)); no one shall undertake financial transactions with others' names in order to conceal illegal assets, launder criminal proceeds, finance terrorism, and support any other illegal activities (Article 3 (3); no one at financial institutions shall conciliate or mediate financial transactions prohibited at Article 3 (3) (Article 3 (4)); and anyone who violates Article 3 (3) and Article 3 (4) is sentenced up to 5-year imprisonment or 50,00o USD fine.

206 According to Kim and Song (2015), in Korea, the ratio of using credit or debit cards in payment amounts to $70.2 \%$ but that of using cash stands at $17 \%$. The use of payment methods in the Netherlands is similar to that of Korea (i.e., credit or debit card: $64 \%$, cash: $34 \%$ ). 
at banks ${ }^{207}$ draw the attention of bank tellers, as do large number of suspicious transaction reports submitted to the KoFIU concern such cash transactions.

For IFT-users (both senders and recipients) the use of online banking systems has its advantages and disadvantages. Wire transferring may leave trails on bank statements, which can provide clues that enable law enforcement authorities to identify the sources of funds or the motives of fund transferring. Nevertheless, IFT-users may choose to use online banking systems when sending funds to - and receiving them from IFT-brokers. It sounds paradoxical that IFT-users who want to hide their remittance transactions prefer IFT-brokers who use online banking systems to those who do not. This is because in the event that their requests to conduct IFT-transactions are not met, they can request a refund based on the information on their bank statements. In other words, from the point of view of IFT-users, online banking systems are not only a convenient way to send remittances to IFT-brokers who can operate in remote locations, but also a backup or safeguard that protects their funds from fraudulent IFT-brokers. A bank statement indicating that funds were sent to an IFT broker serves not only as the basis for claiming a refund directly from the IFT broker, but also as a tool to threaten the IFT broker with disclosing their IFT activities to law enforcement authorities.

\subsubsection{Establishing a business relationship with a counterpart IFT broker}

Two types of relationships constitute the foundation of IFT-systems: the relationships between IFT-users and IFT-brokers, and those between IFT-brokers in sending and receiving countries. These relationships do not include a third party to coordinate conflicts between the actors involved in IFT-transactions, and are therefore inherently prone to the risks of deception and betrayal. Establishing relational trust

207 If IFT-brokers take cash from their customers (senders) and unless they use the cash to pay to another kind of customers (recipients), they may need to deposit large amounts of cash in their bank accounts and in turn which can draw attention of bank tellers. 
between the actors in IFT-systems is therefore an important challenge. The relationships that IFT-brokers in sending countries must develop first — prior to those with IFT-users - are with IFT-brokers in receiving countries. Given that solo IFT-brokers account for a significant proportion of IFT-systems in Korea, the establishment of a business relationship with a counterpart IFT-broker may not be a mandatory step. However, solo IFT-businesses also result from the deliberation about whether or not to establish a business relationship with a counterpart IFT-broker. In addition, the prototype of IFTsystems is based on the interactions between IFT-brokers in sending and receiving countries. Thus, this is an important step that merits an examination. Compared to the relationships between IFT-brokers and IFT-users that can be short-lived, those between IFT-brokers tend to last longer (Schaeffer, 2008). How IFT-brokers trust each other, and how they overcome the risk of deception and betrayal by counterpart IFT-brokers, may need a more structural approach. This will be discussed with respect to Schaeffer's four mechanisms that bind exchanges between IFT-brokers in section 6.4.11. Thus, the relationships between IFT-brokers are likely to be the backbone of IFT-systems.

With regard to the relationships of trust between IFT-brokers, Schaeffer (2008) divided the process of developing relationships between IFT-brokers into three stages the inducement of trust, the establishment of a trust relationship, and the continuation of the trust relationship - and addressed them from different angles. Since the continuation of a relationship of trust is only determined after the completion of an IFTtransaction, this will be discussed in the final stage of the cycle of IFT-procedures: reviewing trustworthiness of the counterpart IFT broker. In examining the inducement of trust, in addition to family ties and the same ethnic and cultural backgrounds, Shaeffer focuses on sending a signal about the trustworthiness of IFT-brokers through the concept of the ex ante signaling mechanism. For instance, IFT-brokers with legitimate conventional businesses can send signals regarding their reliability to other IFT-brokers. Nevertheless, the ex ante signaling mechanism is more suitable to explain the relationships between IFT-brokers and prospective IFT-users than those between IFTbrokers. The details of this mechanism will be discussed later. 
As for the relationships between IFT-brokers in Korea, the IFT-case reports do not provide sufficient information about counterpart IFT-brokers in other countries. There is no doubt that such information would enhance the understanding of the interaction between IFT-brokers in sending and receiving countries. However, it is difficult to capture the opinions of counterpart IFT-brokers in person. This study thus attempted to obtain this information from the interviews with the investigators. The investigations of IFT-systems usually focus on IFT-brokers operating in their home countries, as the investigative powers of law enforcement authorities normally do not include other jurisdictions. The interviewed investigators explained that they could not interrogate IFT-brokers operating in other countries, unless the IFT-brokers agreed to come to Korea to be interrogated. Only a third of the investigators had experience investigating IFTbrokers operating in other countries who had been persuaded to come to Korea. Investigators often conduct inquiries into the relationship between IFT-brokers in sending and receiving countries. During the interviews, the investigators were therefore asked a question about mutual trust between IFT-brokers. The interview data helped to map the relationships between IFT-brokers in sending and receiving countries, taking a critical approach to the conventional notion of the relationship.

Many investigators believed that IFT-brokers in sending and receiving countries are closely connected or at least acquainted with each other. Some investigators mentioned that they had experienced strange IFT-cases in which IFT-brokers who had never met - but knew of each other - worked together through remote communication, such as relying on emails or mobile phones. This may be due to the fact that, according to the IFT-case reports, many IFT-brokers on both sides had the same ethnicity. However, this was not a general pattern discovered among IFT-systems in Korea. The data also showed that a significant number of IFT-brokers work with individuals from different ethnic groups. These findings support the social dilemma theory (Van Lange et al., 2013), given that the IFT-brokers on both sides are aware of the fact that they require their counterpart's cooperation to complete an IFT-transaction, regardless of their ethnic or cultural backgrounds. As regards the networks among IFT-brokers, the IFT-case reports and the interview data do not support the conventional view that since IFT-brokers are 
connected to multiple counterpart IFT-brokers, IFT-systems are interconnected and form large and complex IFT-business networks, covering several countries as their business territories (FATF, 2013a) ${ }^{208}$. Given the empirical data showing that most of the IFT-brokers investigated have small and narrow IFT-business networks, most IFTsystems in Korea seem to operate independently from each other.

As discussed earlier, although IFT-systems where two different IFT-brokers work together to carry out IFT-transactions represent the basic structure of IFT-systems, a considerable proportion of IFT-brokers run IFT-businesses without counterpart IFTbrokers. This type of business structure is a variant, but should not be neglected. Solo IFT-brokers may find it difficult to find trustworthy business partners, or they may not want to be exposed to the risk of deception or betrayal by their counterpart IFT-brokers. They overcome the absence of a counterpart IFT-broker by using online banking systems, which enable IFT-brokers to monitor and control the flows of deposits and withdrawals from several bank accounts, even when they are abroad. In other words, the trust issues between IFT-brokers are resolved by online banking systems. Solo IFT-brokers, who play a dual role in IFT-businesses, can transfer funds almost instantly without being exposed to the uncertainty and vulnerability related to relationships with counterpart IFT-brokers operating in remote places.

\subsection{5 'Advertising' IFT-business and gathering IFT-users}

As entrepreneurs, IFT-brokers choose their own target groups: they choose whether to concentrate on the same ethnic group or to include other communities as well. This involves decisions about how to advertise their IFT-businesses to potential

208 Schaeffer (2008) presents four mechanisms that bind exchanges between IFT-brokers — shared belief systems, repeated dealings, the structure of debts and credits, and interconnectedness of additional business practices. There may be a view that his four mechanisms can be applicable to the 'placement' of trust between IFT-brokers as well. However, the empirical data collected in Korea fail to provide a full support for the four mechanisms in IFT-systems in Korea. The four mechanisms are discussed at the stage of reviewing trustworthiness of the counterpart IFT broker in detail as they mainly contribute to continuation of exchanges of IFT-brokers. 
IFT-users and how to reach their customers. IFT-brokers may rely on their social networks in a covert manner, or adopt public advertisement methods, such as online advertisements or advertisements in ethnic newspapers. In doing so, IFT-brokers take into account the perception of IFT-systems in specific communities, as well as the extent to which laws and regulations are enforced. How to advertise IFT-businesses and reach potential IFT-users involves power relations between IFT-brokers and IFT-users. From the perspective of power relations of social exchange theory, most IFT-users are more powerful than IFT-brokers, even though some IFT-users (including criminal syndicates) may rely heavily on IFT-systems. While IFT-brokers advertise their IFT-services in various ways to attract remitters, desperate IFT-users endeavor to locate IFT-brokers. Risk-averse IFT-brokers, or IFT-brokers in developed countries where AML/CFT measures are well implemented, may choose to advertise their businesses in a covert manner or to restrict the scope of their business to ethnic enclaves. IFT-brokers in developing countries - where the informal economy tends to be tolerated or governments have little competence to implement global AML/CFT standards - may adopt more active or aggressive IFT-business strategies.

The IFT-case reports provide detailed information on how IFT-brokers draw the attention of prospective IFT-users. Some IFT-brokers used various businesses as a front to make their IFT-businesses look lawful and reach (prospective) IFT-users without drawing the attention of law enforcement authorities. The analysis of the IFT-case reports shows that about half of the IFT-brokers were unemployed or had no specific jobs when they were being investigated. However, some of the IFT-brokers investigated operated cross-border businesses (e.g., tourism business, currency exchange business (e.g., GWK Travelex in the Netherlands), trading business, and freight forwarding business ${ }^{209}$ ). The other IFT-brokers had local jobs or businesses (e.g., student, construction worker, inn business, beauty shop, restaurant, and grocery store). IFTbrokers who ran local businesses, such as grocery stores, or restaurants, took advantage

209 Freight forwarding agents, often known as non-vessel operating common carriers, refer to businesses to organize shipments to take goods from manufacturers to customers or final points of distribution. 
of their existing business networks to advertise their IFT-businesses to potential IFTusers who visited their legitimate businesses. IFT-brokers who ran cross-border businesses also made use of their legitimate businesses to solicit their regular clients as IFT-users. Some IFT-brokers placed advertisements for their businesses on the online bulletin boards for Korean communities in foreign countries, where potential IFT-users often gather to obtain information.

\section{Case 6-7: Combination of an IFT-business and cross-border trade}

\#6. KAMOL was from the Ukraine and ran a textile exporting business in Korea. He also operated an IFT-business. He took remittances from his compatriots who worked in Korea, via three Korean bank accounts that were opened in his name. He took advantage of the remittances, which he was asked to send to Ukraine, for his own business. With the remittances he purchased textiles and exported them to his company in the Ukraine. After selling the textiles in the Ukraine, he completed the requested IFT-transactions by disbursing money to the intended recipients. He charged $1 \%$ of the remittance converted into USD as a transaction fee. Between April 2005 and November 2008, he sent 8,778,032 USD from Korea to the Ukraine via his own IFT channel.

\#7. ASLIDDIN, who was Uzbek, ran a textile and vehicle exporting business, but also engaged in an IFT-business in Korea. His motive for running the IFT-business was to mobilize capital to purchase textiles and vehicles, with the aim exporting them to Uzbekistan. He took remittances from Uzbek compatriots in Korea via two bank accounts, and charged $1 \%$ of the remittance as a transaction fee. After receiving the remittances, he purchased textiles and second-hand vehicles, and exported them to Uzbekistan. His business partner in Uzbekistan sold the goods on the domestic market, and handed over the corresponding amounts of funds to the recipients designated by the remitters. In this manner, he transferred 4,788,220 USD from Korea to Uzbekistan via 2,861 transactions from May 2005 to August 2010. 
The IFT-case reports, on the other hand, provided only limited information on how prospective IFT-users search for - and locate - trustworthy IFT-brokers. The interviewed KCS investigators explained that some IFT-users and IFT-brokers knew each other prior to carrying out their IFT-transactions; some IFT-users approached IFTbrokers through their social networks, and some IFT-users contacted IFT-brokers directly after seeing their advertisements. Among the various channels, the investigators placed more importance on social networks than on advertisements. According to them, most IFT-brokers tend to be cautious about running their IFTbusinesses, even if some IFT-brokers boldly advertise their IFT-services on several websites. The majority of the investigators stated that IFT-users first approach IFTbrokers. A study on Nepali IFT-systems in Korea (Shah, 2018) provides a nuanced finding. Nepali IFT-brokers hardly advertise their IFT-businesses for fear of being detected by law enforcement authorities in Korea. Nepali IFT-users normally contact Nepali IFT-brokers via their social networks. Some Nepali hundi agents entice Nepali workers who remit funds via formal remittance channels, to use Nepali hundi.

Case 8-9: IFT-businesses covered by other legitimate businesses

\#8. HAOZHE was Korean Chinese and operated a textile importing business in Korea. He also engaged in an IFT-business, with a bank account in his name and another account borrowed from an acquaintance. Taking advantage of long-standing business relationships with his business partners in China, he sent the requested funds to his business partners in China and made it look like the funds related to trade payments. Their business partners played the role of counterpart IFT-brokers in China, and wired the funds to the recipients designated by remitters in Korea. Between August 2010 and January 2011, HAOZHE transferred 452,383 USD from Korea to China via 119 transactions.

\#9. KIM was the director of a real estate investment company specialized in real estate in the Philippines. He managed 9 bank accounts in Korea and one bank account in the Philippines, to help his customers transfer payments to purchase real estate in the Philippines. He took payments in Korean currency from his customers via the 9 bank 
accounts in Korea, and withdrew the corresponding amounts of funds in local currency (Philippine peso) from the bank account of his company in the Philippines. Conversely, he transferred funds from Philippines to Korea. Between December 2007 and June 2011, he transferred 4,649,410 USD from Korea to Philippines via 1,034 transactions and 4,527,514 USD from the Philippines to Korea via 1,158 transactions.

\subsubsection{Assessing the trustworthiness of prospective IFT-users and IFT-brokers}

As prospective IFT-users and IFT-brokers are aware of the risks of engaging in illegal business activities, they try to ensure the trustworthiness of the other party involved in IFT-activities. Many previous studies on IFT-systems examine small social networks, such as ethnic enclaves, to explain how both parties reduce uncertainty related to IFT-activities, and how they trust each other when engaging in such illegal transactions. As mentioned earlier, some empirical studies show that many IFTtransactions are made with individuals from different ethnic or cultural backgrounds. How IFT-brokers find their customers and how prospective IFT-users find trustworthy IFT-brokers is closely linked to how IFT-brokers and prospective IFT-users assess the other party in terms of reducing uncertainty and vulnerability.

Illegality underpins the other party's assessment of the reliability of IFT-users or IFT-brokers. Even if IFT-activities were legal, prospective IFT-users and IFT-brokers who do not known each other would want to know whether or not the other party is trustworthy. Curiosity about the trustworthiness of the other party in IFT-systems is reinforced when IFT-activities are perceived as illegal and illegitimate. With regard to the recognition of the illegality of IFT-systems, all interviewed investigators mentioned that they had had little difficulty in proving IFT-brokers' criminal intents. One of the reasons for this is that all investigated IFT-brokers were fully aware of the illegality of their IFT-businesses. This is evidenced by the fact that IFT-brokers used bank accounts borrowed from others to avoid the attention of law enforcement authorities and had knowledge of foreign exchange regulations. However, most investigators believed that 
only a few IFT-users ${ }^{210}$ were fully aware of the illegality of IFT-transactions, even though none of the IFT-users believed that their use of IFT-services was clearly lawful. In other words, most IFT-users seem to believe that although the use of IFT-services may not be protected by the government, the use of IFT-services is allowed as long as they are willing to take the associated risk. This explains the subtle tension, or the risk of trust - rather than full trust - between the two parties.

When an unknown IFT-user approaches an IFT-broker, the IFT-broker may scan the prospective customer in order to assess their trustworthiness. The risk to which IFTbrokers are exposed in relationships with IFT-users is simple but important; betrayal by an IFT-user can lead to investigations by law enforcement authorities. However, IFTbrokers are unlikely to reduce the risk in practice. IFT-brokers have few methods for responding to the uncertainty and vulnerability relating to IFT-users. The only measure they can take is to roughly screen their prospective IFT-users on the basis of feelings or suspicions they have about them or based on information regarding their reputation, which is generally extremely limited. There is little empirical information on how IFTbrokers screen prospective IFT-users. According to the interview data, IFT-brokers simply receive a request from a prospective IFT user to transfer funds, even without verifying their identities. They generally seem to take the risk of being betrayed by IFTusers. This implies that the risk of betrayal by IFT-users may be negligible for IFT-brokers.

When prospective IFT-users contact unknown IFT-brokers, they are normally more cautious of the possibility of being deceived by IFT-brokers. When IFT-users lose remittances due to the failure of IFT-brokers to fulfill their obligations regarding fund transfers, it may not be as easy as they think to report fraudulent IFT-brokers to law enforcement authorities. Indeed, IFT-users are also likely to become the subject of investigation and prosecution. IFT-users are therefore concerned with assessing the

210 According to a study on Nepali IFT-systems in Korea (Shah, 2018), Nepali IFT-users are normally fully aware of the illegality of IFT-systems. Nevertheless, they take the risk of remitting their funds via the Nepali hundi channel in order to take advantage of their inexpensive remittance cost. 
trustworthiness ${ }^{211}$ of IFT-brokers. They seek to obtain information about the reputation $^{212}$ of IFT-brokers from experienced IFT-users or to use various signals that IFT-brokers give explicitly or implicitly (e.g., physical stores or receiving remittances through bank accounts). Schaeffer (2008) examines how IFT-brokers send signals to potential IFT-users with respect to the assessment of trustworthiness. Bona fide IFTbrokers may indeed try to demonstrate their trustworthiness. Communication about the reputation of IFT-brokers between IFT-brokers and prospective IFT-users is referred to as the ex ante signaling mechanism (Schaeffer, 2008). As discussed earlier, a considerable number of IFT-brokers run small conventional businesses, such as travel agencies and merchandise shops, in parallel with their IFT-businesses. Conventional businesses often require initial investments, such as registration with local authorities, renting physical stores, and purchasing fixed telephone numbers. Such investments play a role in giving a credible signal that the IFT-brokers concerned are unlikely to deceive their customers. Because of the amounts invested in legal conventional businesses, IFT-brokers with legal conventional businesses pay little for ex ante signaling, compared to IFT-brokers without such businesses ${ }^{213}$ (El Qorchi et al., 2003).

211 When prospective IFT-users assess trustworthiness of IFT-brokers, they gauge IFT-brokers' IFTservice quality as well. Trustworthiness of IFT-brokers and their service quality are inseparable. Trustworthiness of IFT-brokers is assessed in terms of how IFT-brokers honor their obligations and how their services are likely to meet their customers' expectation.

212 When facing strange IFT-brokers, IFT-users may employ the ex post reputation mechanism to deter IFT-brokers from deceiving them. However, it may not be as effective as that between IFT-brokers. IFTbrokers can be interconnected with one another via multiple relationships. The relationship between IFT-users and IFT-brokers may be ephemeral and occasional rather than lasting and frequent. The relationship between IFT-users and IFT-brokers may not be as intertwined as that between IFT-brokers although IFT-users tend to contact the same ethnic IFT-brokers to transfer their funds across borders. Thus, the 'ex post' reputation mechanism that focuses on punishing fraudulent IFT-brokers is not likely to work for prospective IFT-users effectively, even if this mechanism may help prospective IFT-users shun fraudulent IFT-brokers by obtaining reputation of IFT-brokers from experienced IFT-users.

213 IFT-brokers without conventional businesses may need to pay costs (e.g., advertising costs) to signal their trustworthiness to prospective IFT-users. However, IFT-brokers running conventional businesses simultaneously do not need to pay costs related to setting up and advertising their IFT-businesses. Their IFT-businesses piggyback on their conventional businesses' infrastructures. 
When information about IFT-brokers is not available, IFT-users may resort to reducing vulnerability instead of dealing with uncertainty. However, only few methods are available to reduce vulnerability in the illegal market. There is no insurance for activities that take place in the illegal remittance market. It may make no sense to distribute ${ }^{214}$ remittances among several IFT-brokers to avoid losing the full remittance, as it may not be easy to locate several IFT-brokers. According to one third of the interviewed investigators, IFT-users seem to rely heavily on checking that the amounts received by the recipients are equivalent to what they sent, immediately after they have asked the IFT-brokers to disburse the funds. Some investigators stated that IFT-users have few reliable methods to respond to the risk of deception and therefore prefer IFTbrokers who do business by using bank accounts. The investigators added that most IFTbrokers do not seem to exploit the vulnerability of IFT-users. From the perspective of the social dilemma theory (Van Lange et al., 2013), IFT-brokers are aware of the fact that they cannot sustain their IFT-businesses if they deceive their customers, and their revenue and profit rely heavily on the continuation of their businesses.

Both IFT-brokers and prospective IFT-users also conduct assessments of the trustworthiness of the other party, raising concerns that law enforcement officers may disguise themselves as IFT-users or IFT-brokers. These concerns are not confined to this procedure, but emerge at all stages of IFT-activities. The interviewed investigators stated that they rarely conduct sting operations to tackle IFT-systems, although some IFT-users or IFT-brokers are recruited as informants of law enforcement authorities. In their view, IFT-systems do not pose such a serious threat that they need to be addressed through sting operations. The likelihood of law enforcement authorities raiding IFTsystems is also not a significant threat to the actors in IFT-systems. The countries receiving remittances are usually developing countries where AML/CFT measures may not be fully enforced. IFT-brokers in receiving countries and remittance recipients may

214 Of course, remitters can adopt a half-half strategy in sending remittances - transferring half of their remittances via formal remittance systems and the other half via IFT-systems simultaneously. Taking advantage of this strategy, IFT-users may get to know IFT-brokers, thereby reducing uncertainty as well. 
therefore rarely worry about the likelihood of sanctions by law enforcement authorities. Even if countries that send remittances tend to be developed countries where AML/CFT measures are relatively well implemented, IFT-brokers and IFT-users in sending countries are also unlikely to worry about raids by law enforcement authorities. IFTsystems usually operate within ethnic enclaves or in a covert manner. As discussed in section 2.5, IFT-systems are generally treated as a low priority by law enforcement, even though IFT-systems are deemed illegitimate ${ }^{215}$ in Korea according to the interview data. They are therefore less often subjected to monitoring and sanctions by law enforcement authorities than other illegal markets, such as illicit drug markets or counterfeit markets (Han and Ireland, 2016).

\subsubsection{Receiving funds from the senders}

The preparatory steps to be taken by IFT-brokers to enter into an IFT-transaction have been discussed. An IFT-transaction does not start until these steps have been taken. An IFT-transaction is normally comprised of this step and the following two steps: sending remittance orders to the counterpart IFT broker and paying the funds to the recipients. Contrary to the conventional notion that IFT-users visit the shops of IFTbrokers and hand over funds to them, the IFT-case reports show that many IFT-users wire remittances to IFT-brokers. Studies on ethnic IFT-systems in Korea (Lee, 2017; Shah, 2018) provide similar findings: most Nepali and Burmese workers ${ }^{216}$ in Korea have bank

215 If IFT-systems are deemed legitimate in a certain society, law enforcement authorities would be reluctant to tackle them. Even though IFT-systems are deemed illegitimate, law enforcement authorities might neglect to fight them, taking into account the immediacy of threat of IFT-systems and (limited) resources to fight them. In other words, even though (il)legitimacy of IFT-systems and law enforcement against them are associated, the assessment of IFT-systems as illegitimate does not automatically lead to law enforcement against them. Law enforcement is influenced not only by illegitimacy but also other factors, such as immediacy of threats and (limited) resources (Chapman et al., 2017; Garoupa, 1997; Homes et al., 1998).

216 According to Lee's study (2017) and Shah's study (2018), one of the reasons that Burmese workers and Nepali workers in Korea opt for hundi over formal financial institutions is that it is challenging for them to access formal financial institutions (e.g., weekend problem, language barrier, and heavy paperwork). 
accounts and send remittances to hundi agents via formal financial institutions. As discussed earlier, bank accounts may play an important role in coping with uncertainty and vulnerability from the perspectives of both parties.

Given the likelihood that the funds that remitters hand over to IFT-brokers are criminal proceeds, this step is suited to the discussion on the role of IFT-systems in laundering criminal proceeds. Some IFT-brokers may be aware of the fact that the funds received from remitters originate from illegal businesses. Some IFT-brokers may not be interested in identifying the sources of the funds or the intentions of the remitters using IFT-services. According to the interviewed investigators, professional IFT-brokers are normally not interested in the sources of the funds they are asked to transfer across borders. Of course, some IFT-users might inadvertently reveal their motives for sending funds across borders to IFT-brokers. However, the IFT-brokers are not interested in whether or not they are dealing with funds related to illegal businesses. There is limited empirical information on how IFT-brokers (differently) manage criminal proceeds. The sources of funds may have little impact on how IFT-brokers process IFT-users' requests to transfer funds. However, if the sources of funds were known to IFT-brokers, some IFTbrokers might charge more for transferring criminal proceeds in exchange for handling risky requests (Maimbo and Passas, 2005). If IFT-brokers were exposed by law enforcement authorities, some of them may reveal the identities of customers with criminal proceeds to law enforcement authorities. The main motivation for this would be to avoid prosecution or reduce their sentence ${ }^{217}$. In order to cope with the uncertainty and vulnerability related to the sources of funds, IFT-users must be careful not to disclose the sources of funds to IFT-brokers. On the other hand, information about the sources of funds can serve as a safeguard for IFT-brokers to prevent IFT-users from betraying them.

However, most of them send their funds to hundi operators via formal financial institutions. Of course, the strongest reason for the preference of hundi is low remittance transfer cost.

217 The Korean criminal justice system does not have an U.S.-style plea bargaining. However, prosecutors have great discretion in prosecution including proposal for sentences. 
Case 10: Source money transferred by IFT-systems

M. PARK (Mr.) and LEE were Korean and resided in Australia. F. PARK (Ms.) was Korean Australian. It was unknown how they first became acquainted with each other. However, it became clear that they had conspired to run an IFT-business in Sydney, Australia. They made use of a total of 11 Korean bank accounts for the IFT-business. Among them, four accounts were borrowed from their acquaintances. They posted advertisements about their business on websites for the Korean community in Australia. They took remittances from Koreans in Korea via the 11 bank accounts and handed over the funds in Australian currency to recipients in Australia. Most of their customers in Korea were parents who sent tuition fees and allowances to their children studying in Australia. They also took remittances in Australian currency from Koreans in Australia who wanted to send funds to Korea. They then wired the corresponding amounts to the designated recipients in Korean currency via the 11 bank accounts. Between Feb 2009 and April 2011, they transferred 6,436,210 USD from Korea to Australia via 1,346 transactions, and 6,303,703 USD from Australia to Korea via 2,977 transactions.

As regards the involvement of IFT-transactions in illegal activities, such as illegal trade, the analysis of the IFT-case reports has shown that given that they received trade payments based on undervalued or falsified invoices, some investigated IFT-brokers engaged in illegal trade activities. Examples of such activities include evasion of customs duties and VATs, smuggling of counterfeit goods, and violations of rules of origin. However, there is little evidence in the investigated IFT-cases that IFT-systems are used to launder criminal proceeds from organized crime groups or illicit drug trafficking. In order to verify the findings from the analysis of the IFT-case reports, the investigators were asked questions about the involvement of IFT-systems in organized crimes or drug trafficking. Most investigators replied that they had not dealt with IFT-brokers who had laundered criminal proceeds of drug trafficking or who had been involved in drug trafficking, and few prosecutors found additional offences for the investigated IFTbrokers (e.g., assistance of drug trafficking). They added that the main countries of 
origin of illegal drugs (e.g., methamphetamine) trafficked into Korea are Myanmar, Cambodia and Malaysia. Only few IFT-brokers detected by the KCS were involved in doing business with counterpart IFT-brokers in those countries. In other words, there may be a mismatch between the country which IFT-brokers in Korea usually do business with (e.g., China) and the countries from which drug trafficking groups take illegal drugs to Korea. They speculated that drug trafficking groups in Korea used cash smuggled to purchase illegal drugs, given that some Korean couriers who engaged in bulk cash smuggling in Myanmar were arrested for drug trafficking in Korea. Only one senior investigator mentioned that he had investigated an IFT-broker who was handling money related to drug trafficking. The investigator had attempted to track down the suspicious money trails associated with drug trafficking, but was unable to interrogate members of the drug trafficking ring due to the limitations of his investigative authority ${ }^{218}$. According to the customs investigators, the association of IFT-systems with organized crime groups was also rare. Some investigators stated that they had investigated IFT-brokers involved in organized crime groups. However, they added that the organized crime groups that made use of IFT-systems were fraud rings or gambling rings, rather than violent crime groups, such as Mafia in Italy or Russia, the Triad in China or the Yakuza in Japan. Since the turf of organized crime groups in Korea is primarily confined to Korea, they run few cross-border businesses and, in turn, have few chances of exploiting IFT-systems.

As for the unexpected finding from the IFT-case reports that IFT-systems in Korea rarely receive funds related to drug trafficking or organized crime groups, two prosecutors and a police official at the KoFIU were questioned about the involvement of IFT-systems in drug trafficking or organized crime groups. That is because this involvement is known to exist in other countries. The interviewed KoFIU officials were also unable to provide tangible evidence that proves the association between IFT-systems and drug trafficking or organized crime groups. They claimed that there is either little

218 In Korea, the KCS has limited authority to investigate drug trafficking, even though the drugs seized by customs officers at borders accounts for the largest share (approximately $80 \%$ in 2018) of drugs seized in Korea. Prosecutors normally take drug trafficking cases from customs officers who detected drugs trafficked at borders. Prosecutors in Korea have authority not only to prosecute but also investigate. 
connection between IFT-systems and drug trafficking or organized crime groups, or it is very difficult to establish the connection between them. The interviewed KoFIU prosecutors pointed out that of suspicious transaction reports and currency transaction reports submitted from financial institutions to KoFIUs, few related to both IFT-systems and drug trafficking or organized crime groups. The KoFIU police official interviewed explained that in the fight against violent crimes and drug trafficking, the police tend to focus on tackling primary perpetrators of organized crime groups or drug trafficking rings. This is more important to them than dealing with IFT-brokers, as they only play a supporting role in violent crimes and drug trafficking. The police official added that in relation to IFT-systems, organized crime groups or drug trafficking rings are rarely prosecuted only for sending or receiving funds via IFT-systems. Thus, even though IFTsystems may be exploited by organized crime groups or drug trafficking rings, it is difficult to find links between IFT-systems and organized crime groups or drug trafficking rings by examining organized crime cases. This can be explained by the fact that law enforcement officials are inclined to regard drug trafficking activities and the abuse of IFT-systems as two separate offences.

\subsubsection{Sending remittance orders to the counterpart IFT broker}

This procedure involves communication between IFT-brokers in sending and receiving countries for the purpose of transferring funds. A physical transfer of funds may take place between senders and IFT-brokers in sending countries. However, transferring funds between IFT-brokers in sending and receiving countries is normally not physical but virtual. In other words, the transfer of 'credits' takes place between the two IFT-brokers. With regard to the way funds are transferred across borders, the IFTcase reports show that the view that IFT-systems work in the same way as traditional hawala is a prejudice. In fact, there are several ways to transfer funds across borders without the involvement of formal remittance systems. According to the IFT-case reports, three methods of transferring funds can be distinguished: the prototypical illegal fund transfer and two variant fund transfer methods. The variant methods are wire transferring and the physical transfer of cash. In other words, in addition to the method 
that resembles traditional hawala, some IFT-brokers simply wire remittances to their counterpart IFT-brokers or recipients as if they were banks. The smuggling of large sums of cash and the false invoicing of trade transactions are also used to transfer remittances to receiving countries.

Prototypical IFT-transactions refer to the transfer of funds between IFT-brokers in sending and receiving countries, without the involvement of formal financial institutions. Such transactions also include IFT-transactions made by solo IFT-brokers, given that solo IFT-brokers work as IFT-brokers in both sending and receiving countries simultaneously. In many IFT-transactions that involve China, (solo) IFT-brokers operate in China rather than in Korea. Even for foreigners, there are few restrictions with regard to opening bank accounts in Korea. Online banking systems are easy to access - even from abroad. IFT-brokers in China can monitor and control deposits to - and withdrawals from - bank accounts opened in Korea. In contrast, despite significant progress in financial inclusion through mobile banking, a large proportion of Chinese people in rural and suburban areas are still unbanked ${ }^{219}$ (World Bank, 2018). It is difficult for foreigners to open bank accounts ${ }^{220}$ in China. Chinese mobile banking (e.g., WeChat) ${ }^{221}$, which is the most popular banking method in China, requires a local mobile phone number connected to a bank account in China. For IFT-brokers residing in other countries, it is difficult to control deposits and withdrawals that take place in China.

219 According to the World Bank (2018: 14, 17), China's bank branch network is sparse (19 branches per 100,000 adults). 19 percent of adults without a bank account in China report that they do not have a bank account because financial institutions are too far away. China's banking agent density (88 agents per 100,000 adults) is roughly equivalent to that of Brazil but lower than those of Kenya (156), Peru (344), and Bangladesh (505).

220 Not every Chinese bank branch opens accounts for foreigners. Even Chinese banks that open accounts for foreigners require challenging documentation (e.g., a mobile phone number, a work permit, and a document proving residence) for ordinary foreigners to prepare.

221 The World Bank (2018) presents that while 97 percent of Chinese adults surveyed in 2014 has access to a mobile phone, 14 percent reported they made a payment from their account using a mobile phone. 
When remitters ask IFT-brokers to send funds to recipients in other countries, some IFT-brokers transfer funds via wire transferring services provided by formal financial institutions. This business model is not in line with conventional IFTtransactions, where formal financial institutions do not act as a bridge between IFTbrokers in sending and receiving countries for the transfer of funds. This type of IFTtransaction may not be deemed an IFT-transaction in other countries. Although formal financial institutions link IFT-brokers in sending and receiving countries, this type of remittance transferring is also referred to as an IFT-transaction in Korea. This is because unauthorized entities other than formal remittance channels take funds from remitters to provide services, such as the transfer of funds across borders. As discussed in section 2.5, according to the Foreign Exchange Transactions Act, cross-border foreign exchange transactions must be carried out via authorized entities, such as formal financial institutions. The Act also stipulates that anyone who seeks to send or receive foreign exchanges via a third party other than authorized entities, shall report their transactions to the central bank ${ }^{222}$. This regulation was implemented to prevent criminal proceeds from being concealed and laundered via third parties, while they are sent or received from overseas.

222 The Foreign Exchange Transactions Act stipulates that anyone who sends or receives foreign exchange funds to other countries for the following reasons shall report to the Bank of Korea: (1) offsetting claims and obligations, (2) payment after the periods set by the Minister of Economy and Finance, and (3) payment or reception via an unauthorized entity other than formal financial institutions (Article 16). 
Figure 6.2: Three types of IFT-transactions

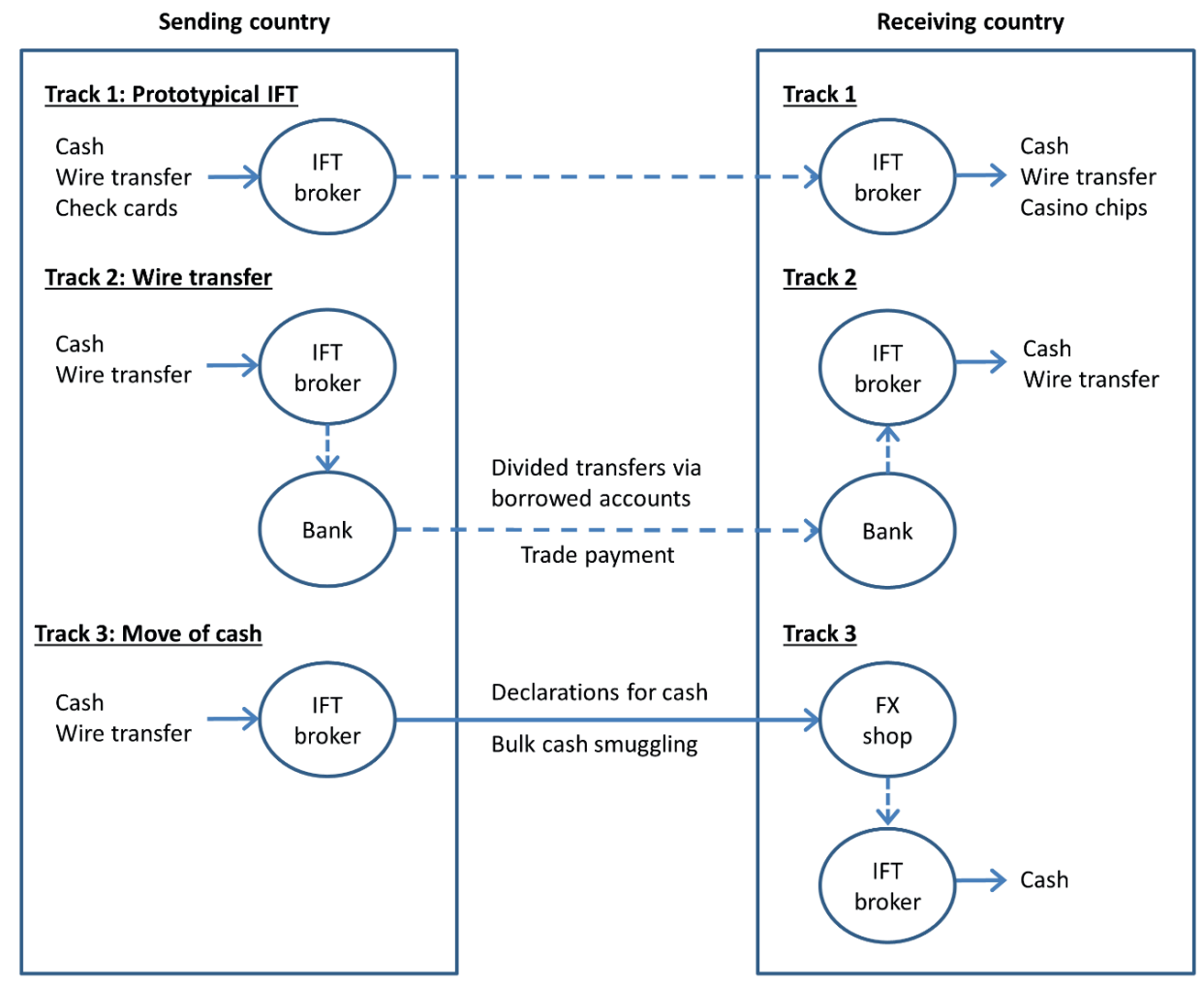

Source: the author

Most IFT-users who want to send funds across borders do not care about the way the funds are sent overseas, as long as their funds are paid to their recipients designated by them. According to the interviewed investigators, IFT-brokers do not explain to the remitters how they send funds to the designated recipients and are not questioned about this by remitters. Some IFT-brokers take advantage of this situation. They use borrowed bank accounts with different names in order to prevent bank tellers from suspecting them of illegal activities based on large amounts - and large numbers - of foreign exchange transactions. In Korea, formal financial institutions report every outbound foreign exchange transaction in excess of 2,00o USD ${ }^{223}$, and outbound foreign

223 In July 2017, Ministry of Economy and Finance allowed cross-border transferring of up to 3,00o USD without supportive documents for the sources of funds by revising the Enforcement Decree of the Foreign 
exchange transactions with an annual amount in excess of 10,000 USD ${ }^{224}$ to the central bank. In accordance with the Enforcement Decree of Foreign Exchange Transactions Act, the central bank relays this information to the competent authorities, such as the financial supervisory authority, the national tax authority, and the customs administration. IFT-brokers who use the wire-transfer services of formal financial institutions therefore split remittances into amounts of less than 2,0oo USD, and wire them through different bank accounts. IFT-brokers can send funds to the recipients' bank accounts without the involvement of IFT-brokers in receiving countries. They avoid the risks associated with collaborating with IFT-brokers overseas by using the remittance transferring services of formal financial institutions. IFT-services that use the wire transferring services of formal financial institutions are likely to be at least as costly as formal remittances services. Nevertheless, some IFT-users choose to use the services of these expensive IFT-brokers, either because access to formal financial institutions is limited or because it is not possible to find affordable IFT-brokers.

Case 11-12: Wire transferring via the third party's bank accounts

\#11. PAK (Mr.) was Korean Chinese and resided in Korea. He borrowed 12 Korean bank accounts from his acquaintances in order to run an IFT-business in Korea. SONN (Ms.) was also Korean Chinese and used to work in Korea for a short period of time. She was in China while engaging in an IFT-business with 29 Korean bank accounts obtained from her acquaintances. She took remittances from those who wanted to send funds from Korea to China through the 29 accounts and had PAK wire the remittances to recipients in China. They took advantage of a loophole in the foreign exchange transactions checks, namely that bank tellers do not ask for supportive documents for remittances unless the annual sum of someone's remittances exceeds 50,00o USD and

Exchange Transactions Act. Before the revision, cross-border transferring of up to 2,ooo USD was allowed without supportive documents.

224 According to the Enforcement Decree of the Foreign Exchange Transactions Act, unless annual sum of someone's remittances exceeds 50,0oo USD, he does not need to submit supportive documents to prove the sources of the funds. However, remittances whose annual sum exceeds 10,ooo USD are reported to law enforcement authorities via the central bank. 
the amount of each remittance exceeds 2,00o USD. PAK therefore split a remittance into several small amounts (of less than 2,0oo USD each) and wired them via the various bank accounts to recipients in China. PAK and SONN charged 300 USD per 50,000 USD remittance. They sent 119,269,716 USD from Korea to China via 49,977 transactions between February 2006 and February 2011. Two bank tellers were involved in their IFT-business. The bank tellers were aware that PAK wired remittances in other peoples' names in order to avoid submission of supportive documents for amounts in excess of 2,00o USD; however, they overlooked the IFT-business in order to benefit from the foreign exchange transactions, which entail transaction fees for the bank.

\#12. JIN (Mr.) was Korean Chinese and resided in Korea. He became acquainted with KIM (Ms.), the owner of a bistro, as he was a regular customer at the bistro. While discussing how to make easy money, they decided to engage in an IFT-business together. JIN took on the role of taking remittances via bank accounts, which he could control, and he transferred the remittances in the name of others to China. KIM's role was to solicit Koreans who lent their names (to act as remitters) to the IFT-business, earning 100 USD per person as commission from JIN: 50 USD was given to each person who lent their name and 50 USD was given to KIM. From April 2011 to August 2011, KIM solicited 172 Koreans to let JIN use their names as official remitters. JIN managed 16 bank accounts borrowed from his Korean Chinese acquaintances and transferred 12,580,281 USD from Korea to China via 663 transactions.

Some IFT-brokers hire couriers to transport cash from remitters to recipients. This type of IFT-transaction was discovered in the IFT-case reports that involved Japan. Although the number of IFT-systems involving Japan is smaller than that of those involving China, the way of transferring funds between Korea and Japan is distinctive and rarely found in IFT-systems involving other countries. The context in which this type of IFT-transaction can take place seems be related to the fact that there is more 
demand in Korea for Japanese currency 225 (Yen) than for Chinese currency (Renminbi); and that local currency exchange offices in Korea prefer Yen over Renminbi. Therefore, cash transportation mainly takes place in IFT-transactions involving Japan rather than China. This type of IFT-transactions is simpler than other types. Some IFT-brokers who operated in Japan took funds in Japanese currency from remitters and transported them to Korea via couriers. While they exported cash from Japan in a legitimate manner, they sometimes smuggled cash, or imported it through the formal process of declarations in Korea. Customs officers normally question the source of cash subject to declaration in a routine and absent-minded way ${ }^{226}$. They are, however, interested in the motives of cash declarations. Couriers can easily come up with motives such as gambling or the need for start-up funds for businesses in Korea. The Japanese currency brought to Korea was usually exchanged in currency exchange offices that took on the role of IFT-brokers in receiving countries. Couriers (are supposed to) submit their IDs to currency exchange offices in order to exchange Japanese currency into Korean currency, which leaves trails in the ledgers of currency exchange offices. Because of the traces, couriers and currency exchange offices often exchange currencies by appropriating the copies of the IDs of former ordinary customers, which currency exchange offices keep for their business transaction records. Currency exchange offices that exchanged currencies either wire the funds to recipients or hand them over to them in cash.

IFT-transactions involving cash couriers appear to be riskier than other types of IFT-transactions; there is always a risk that cash couriers take off with remitters' funds during the journey from sending countries to receiving countries. Currency exchange offices in receiving countries are always at risk of an unexpected investigation by law enforcement authorities. According to the investigators interviewed, family members are generally used as cash couriers for this type of IFT-transactions. Owners of currency

225 Japanese Yen is one of six major currencies of the world with US dollar, Euro, Great British Pound, Canadian Dollar, and Swiss Franc. The U.S. Dollar Index includes Euro, Japanese Yen, Pound Sterling, Canadian Dollar, Swedish Krona, and Swiss Franc.

226 When customs officers take declarations of cash at borders, they do not have enough time to track down on the sources of cash. They usually accept travelers' claims about the sources of cash as they are. 
exchange offices tend to coordinate or manage the entire process of IFT-transactions in order to reduce uncertainty. Cash couriers normally declare the export and import of cash to customs to avoid unnecessary further investigations by law enforcement authorities into the origin of the funds. They do not need to hide the transportation of cash from customs. On the contrary, declarations of cash to customs actually provide good supportive documents to prove the origins of the funds, since customs normally simply take declarations.

Case 13-14: Couriering of cash and exchanging of cash in currency exchange offices

\#13. M. WOO (Mr.) was Korean and ran a café business in Tokyo, Japan. He also managed an IFT-business, using the café business as a façade. F. WOO (Ms.), M. WOO's older sister, ran a currency exchange office in Seoul, Korea. He and his fellow IFT-brokers took remittances from people who wanted to remit funds from Japan to Korea. JUNG (Ms.), one of M. WOO's colleagues, played the role of transporting funds in Japanese currency (YEN) from Japan to Korea. She declared the Japanese currency to customs and exchanged the funds into Korean currency at the currency exchange office that was operated by F. WOO in Seoul. F. WOO then wired the funds to recipients designated by senders in Japan. Between December 2008 and September 2010, M. WOO illegally sent Japanese currency worth 104,524,020 USD to Korea via 2,740 domestic transactions.

\#14. M. SONG (Mr.) was Korean and ran a Korean grocery store in Osaka, Japan. He collaborated with his de facto wife, F. KIM (Ms.), and his little sister, F. SONG (Ms.), who operated a currency exchange office in Seoul, Korea, which operated an IFTbusiness between Japan and Korea. M. SONG supervised all IFT operations and transactions. F. SONG managed eight bank accounts, which she borrowed from her relatives for the IFT-business. F. KIM played a role in transporting funds in Japanese currency to Korea. M. SONG took Japanese currency from remitters who wanted to send funds to Korea via his Japanese bank account. He telephoned his sister and instructed her to wire the corresponding amounts of funds to the bank accounts designated by remitters. His de facto wife regularly visited Korea with Japanese 
currency and declared the funds to customs as business earnings. She exchanged the Japanese currency to Korean currency via F. SONG's currency exchange offices and deposited the funds into the eight bank accounts for the IFT-business. They also engaged in inverse IFT-transactions that transferred funds from Korea to Japan. However, the physical transfer of cash was not involved in the inverse transactions. They transferred 43,709,135 USD from Japan to Korea via 17,182 transactions and 20,907,001 USD from Korea to Japan via 4,336 transactions between January 2007 and November 2011.

Most IFT-transactions fall under one of three types of IFT-transactions. The 'prototypical' type of IFT-transactions accounts for the majority of IFT-cases analyzed. IFT-transactions involving wire transfers and cash transactions between IFT-brokers in sending and receiving countries account for a small proportion of the IFT-cases. While wire transfers between IFT-brokers and IFT-users is common, those between IFT-brokers in sending and receiving countries may be rare. The variant IFT methods used by IFTbrokers may be viewed as a proactive way to reduce uncertainty regarding debt settlement between IFT-brokers.

\subsubsection{Paying the money to the recipients}

This procedure is the final step in the illegal transfer of funds and is quite straightforward, as IFT-brokers simply hand over the corresponding funds requested from their counterparts in sending countries to the recipients designated by senders. As regards the specific ways of disbursing funds, the IFT-case reports reveal several unconventional methods of paying funds to recipients. As discussed above, some IFTbrokers in sending countries directly wire remittances to the recipients. Some IFTbrokers in receiving countries use bank accounts to pay funds to the recipients. The relationship between IFT-brokers in receiving countries and the recipients is normally temporary and intermittent. Unless the recipients have designated IFT-brokers in receiving countries in advance, there may not be much room for trust between the two parties. This procedure has therefore received only little attention from previous 
studies on IFT-systems. The payment of funds is rather a matter of trust between the IFT-brokers in the sending country and the receiving country. Trust between IFTbrokers in sending and receiving countries is projected on - and linked to - the fulfillment of obligations by IFT-brokers in receiving countries.

Trust between IFT-brokers in receiving countries and the recipients is based on the assumption that recipients who contact or approach IFT-brokers are identical to those designated by senders. IFT-brokers who operate in countries where people have limited access to formal banking services hand over cash to the supposedly rightful recipients. They check the ID of the allegedly rightful recipients to reduce the likelihood (uncertainty) of paying the funds to the wrong persons. The IFT-case reports do not reveal how IFT-brokers pay the funds to recipients who live in remote areas. According to the investigators interviewed, most recipients in Korea want to receive funds from IFT-brokers through their bank accounts. When IFT-brokers pay the funds to recipients via online banking systems, uncertainty regarding payment to rightful recipients is greatly reduced. Unlike most recipients in IFT-transactions who receive funds from IFT-brokers, some IFT-users wire funds to an IFT broker in a sending country and receive 'casino chips' from another IFT broker in a receiving country ${ }^{227}$.

Case 15: Symbiosis between IFT-business and gambling business

PARK was Korean and lived in the Philippines. He ran an IFT-business at a hotel casino in Manila, using two Korean bank accounts that he had borrowed from his relative. He received funds in Korean currency from Korean tourists or gamblers in advance via the two bank accounts, and paid them the corresponding amounts in Philippine currency (Philippine Peso) at the hotel casino. He transferred funds from the Philippines to Korea the other way around. He received funds in Philippine Peso from Korean tourists or gamblers, and had his sister withdraw the corresponding amounts in Korean currency from one of the two Korean bank accounts and hand them over to those who

227 There are some cases that remitters are the same as recipients unlike the conventional notion that remitters are different from recipients. 
asked for the exchange of funds. Between May 2010 and November 2011, PARK transferred 415,00o USD from Korea to the Philippines via 48 transactions, and 415,00o USD from the Philippines to Korea via 46 transactions.

This procedure also has implications for the relationship between IFT-users in sending countries and IFT-brokers. From the senders' perspective, the safe arrival of the agreed amounts of funds at the recipients is the ultimate goal when using IFT-systems, and represent a benchmark in the decision to continue relying on IFT-brokers. The level of trust between IFT-users and IFT-brokers can be assessed by looking at the number of recurring IFT-users. Unfortunately, the IFT-case reports do not contain explicit information on the relationships between returning IFT-users and IFT-brokers. According to the investigators, this is because the recurring relationships can be identified through additional detailed investigations of IFT-brokers' bank accounts ${ }^{228}$. The investigators interviewed stated that many IFT-brokers have regular customers. IFTusers who use IFT-systems for business purposes are usually returning customers. The same applies to expatriate workers, who use IFT-systems to send their remittances to their families in home countries. Parents whose children study overseas may also be returning IFT-customers. In other words, IFT-users and IFT-brokers may want to continue their relationship unless there is a specific reason to discontinue the transactions.

When an IFT-user becomes aware of the fact that an IFT-broker is not fulfilling his obligations related to an IFT-transaction, or if the IFT-broker's services do not meet the IFT-user's expectations, they may decide to suspend or withdraw trust in the IFT broker. It is challenging to identify the point at which trust is broken between IFT-users and IFT-brokers. According to the interviewed investigators, few IFT-users fully rely on IFT-systems. The trust-based relationship between IFT-users and IFT-brokers may be

228 This study could not obtain from the KCS the IFT-brokers' bank accounts including detailed transaction records with other actors in IFT-systems; which are normally submitted to prosecutors' offices and judges as evidence to prove IFT-businesses. 
more fragile than anticipated. Minor breaches in trust between IFT-users and IFTbrokers (e.g., delay of arrival of funds to recipients) may result in the discontinuation of the use of IFT-services. Serious breaches in trust between the two parties may result in conflict - for example, reporting the other party to law enforcement authorities. When the investigators were questioned about betrayal - a form of breach of trust - between the two parties, most of them said that they had not experienced this. Only a quarter of the interviewees replied that they had investigated cases related to betrayal, in which IFT-users had reported IFT-brokers to customs. None of the investigators witnessed IFT-cases whereby IFT-brokers had complained about IFT-users. However, the termination of the relationships between IFT-users and IFT-brokers does not necessarily mean that trust between them no longer exists. Some IFT-users stop using IFT-systems regardless of changes in the level of trust in IFT-brokers. If IFT-users no longer have business (e.g., the termination of contracts for the smuggling of counterfeit goods) or affairs (e.g., the end of children's studies abroad) that require IFT-service, they simply stop using of IFT-systems. Some IFT-users (senders) may discontinue IFTtransactions when their relationship with the recipients ends. Some IFT-users may stop using IFT-systems when a rumor of a law enforcement raid on IFT-systems is spreading. Some IFT-users do so when they are given access to formal financial institutions.

\subsubsection{Settling reciprocal debts made from IFT-transactions}

From a remitter's point of view, an IFT-transaction is completed when the payment of the appropriate funds is made by an IFT broker in a receiving country to a rightful recipient. However, the IFT-transaction does not end for both IFT-brokers, as outstanding debt remains between both parties. This step involves the trust-related issue between IFT-brokers in sending and receiving countries. It is linked to the procedure for sending remittance orders to the counterpart IFT broker. This issue is rarely addressed in the IFT-case reports, possibly because it is not a core element for the prosecution of IFT-brokers. Some investigators admitted that they had not dealt with the debt settlement procedure in the course of investigations into IFT-brokers. There 
is little doubt about the importance of this procedure for IFT-brokers in terms of coping with the risk involved in settling outstanding debts between both parties.

When it comes to the settlement of outstanding debts between IFT-brokers, previous studies on IFT-systems briefly introduce several methods. The IFT-case reports also confirm these methods. Some outstanding debts between the two parties can be cancelled through inverse IFT-transactions between the two parties. However, this method cannot be applied to all IFT-transactions, given that the amounts transferred between IFT-brokers are normally asymmetrical. As with remittances via formal financial institutions, funds via IFT-systems tend to flow from developed countries to developing countries. IFT-brokers use additional methods to settle outstanding debts, such as wire-transfers, cross-border trade, or bulk cash smuggling. Regardless of what methods are employed to settle outstanding debts, it is important to recruit trustworthy counterpart IFT-brokers to prevent deception and betrayal. The trustworthiness of counterpart IFT-brokers cannot be verified until IFT-brokers are victimized by their counterparts. No matter how long counterpart IFT-brokers behave in a reliable manner, once they deceive the other party, they become untrustworthy. It is therefore necessary to take measures to reduce vulnerability, such as shortening the interval for outstanding debt settlement (e.g., changing from a quarter to a month). However, some investigators stated that many IFT-brokers work alone and use online banking systems, and are therefore not faced with uncertainty regarding the settlement of mutual debts. It can therefore be concluded that debt settlement in IFT-systems may not constitute a major issue in Korea.

\subsubsection{Reviewing trustworthiness of the counterpart IFT broker}

Upon completion of an IFT-transaction, or when settling mutual outstanding debts between IFT-brokers, IFT-brokers assess the trustworthiness of their counterpart IFT-brokers and may share their experiences with other IFT-brokers. This assessment is not visible to IFT-users and is not a clearly defined step, as it takes place in the mind of IFT-brokers. However, this step is just as important as other steps for IFT-brokers in 
terms of trust and risk, as this procedure determines whether an IFT-broker will continue the relationship or consider a change in partnership. According to several studies on IFTsystems, trust between IFT-brokers is usually honored and their business relationship is maintained. An understanding of the mechanisms between the two parties is essential to investigate whether IFT-systems are stable and long-lasting.

Schaeffer (2008) identifies four mechanisms that bind exchanges between IFTbrokers: the shared belief systems, repeated dealings, the structure of debts and credits, and interconnectedness of additional business practices ${ }^{229}$. First, given the regions where IFT-systems prosper, IFT-brokers tend to share common religious beliefs, which provide a basis for a mutual understanding of values (Schramm and Taube, 2003). Exchanges between people with similar cultural backgrounds can reduce risk of deception and betrayal, and lower transaction costs through a common understanding of trading conditions, compared to exchanges with outsiders. However, a shared religious or ethnic affiliation does not explain the continuation of all IFT-transactions between IFT-brokers. Recent qualitative studies on IFT-systems (Passas, 20o6b; Soudjin, 2015; Teichmann, 2018) demonstrate that since IFT-systems support a large number of trade across borders, IFT-systems may stretch far beyond family ties and may not be confined to ethnic boundaries (Schaeffer, 2008). Therefore, there must be other factors involved that keep FT-brokers from deceiving their IFT-business partners.

Second, a single IFT transaction between two IFT-brokers 'within an IFT network' integrates each IFT broker into an ongoing trading 'game' with multiple other IFTbrokers. This continues as long as the two IFT-brokers are active within the network. Within the IFT network, IFT-brokers are intertwined with respect to credits and debts. Although the same IFT-brokers do not necessarily trade on a regular basis, as long as the two IFT-brokers continue to trade with other IFT-brokers within the network, such

229 The four mechanisms that bind exchanges between IFT-brokers are bases or conditions where ex post reputation and ex ante signaling mechanisms come into play. Ex post reputation and ex ante signaling mechanisms used in the domain of IFT-systems are analogous to Kramer's approaches (2006) to reduce uncertainty in exchange transactions. 
recurring transactions prevent IFT-brokers from deceiving other IFT-brokers within the network. That is because a network connecting IFT-brokers acts as a conduit, circulating information about the reputation of IFT-brokers (Schaeffer, 2008). In this way, honest dealings are rewarded with recurring IFT-transactions within the network, whereas fraudulent dealings are penalized with exclusion from the network.

Third, the complex credit and debt structure created through the IFT-business relationships of an IFT broker with other IFT-brokers makes it difficult for an IFT broker to deceive their IFT-business partners. An IFT broker usually has business relationships with multiple IFT-brokers. An IFT broker may have outstanding debts to another IFT broker as well as credits to be paid by other IFT-brokers. Therefore, if IFT brokers deceive other IFT brokers by not paying their debts, they will most likely not receive the credits that their business partners owe them. As a result, the intertwined debt settlement among IFT-brokers reduces the chances of opportunistic behavior by an individual IFT broker within the network.

The interconnectedness of IFT-services and other conventional businesses also strengthens ties between IFT-brokers and prevents them from deceiving their IFTbusiness partners. Remittance transferring may not be the sole or primary occupation of most IFT-brokers. Most IFT-brokers are known to run small businesses, such as travel agencies or merchandise shops, in parallel with their IFT-businesses (Schaeffer, 2008). This is in line with the historical background of IFT-systems. While IFT-brokers manage their primary businesses, they engage in IFT-activities with their business partners, who are also active IFT-brokers in receiving countries. Their primary businesses are used to settle debts incurred from IFT-transactions. For instance, when an IFT broker operating a textile business owes remittances to its business partner in another country, the IFT broker imports (or exports) textiles from (or to) its business partner and settles payments for the textiles by taking into account the outstanding debt incurred from IFT-transactions. Thus, if an IFT broker deceives a IFT-business partner in the course of conducting IFT-transactions, it also damages the reputation of their conventional businesses. 
Schaeffer (2008) was interested in a system that underpins or reinforces the four mechanisms that encourage IFT-brokers in sending and receiving countries to honor their obligations. The system that enforces obligations of contracting parties without an independent third party, by circulating information regarding the reputation of contracting parties' past behavior, is referred to as ex post reputation mechanisms. Although this is a posteriori measure, it may work in encouraging trustworthiness and discouraging untrustworthiness within the IFT-broker community. Ex post reputation mechanisms rely on communication between members of a network. The application of an ex post reputation mechanism is limited to particular settings or particular groups, as communication costs increase in proportion to the amount of information shared, the number of members involved, and the distance between members. However, the development of information and communication technology has dramatically reduced the cost of communication within and among networks. Ex post reputation mechanisms are therefore likely to be applied to broader settings and bigger networks than before (Schaeffer, 2008).

The empirical data collected in Korea provide mixed evidence or limited support for Schaffer's four mechanisms that encourage IFT-brokers to honor their obligations related to IFT-businesses. This may be construed to mean that the Korean data collected for this study are somewhat limited in capturing the situations in which Schaffer's four mechanisms work. On the other hand, this may mean that IFT-systems work well despite limited involvement of Schaffer's four mechanisms, and that other factors may also contribute to the fulfilment of obligations of IFT-brokers. As the IFT-case reports indicate, IFT-brokers in Korea and its partner countries have few commonalities except ethnicity (Asian) and language (Korean used between Korean IFT-brokers and KoreanChinese IFT-broker). There are few common religious beliefs ${ }^{230}$ that bind IFT-brokers in Korea and its partner countries. As Schaffer points out, recurring transactions between

230 The Spectrum of religious beliefs and practices in Korea is wider than almost any other place on earth (Baker, 2007: 1). 
IFT brokers in Korea and its partner countries may not only be a cause, but also a consequence of compliance with the obligations of IFT brokers. This seems to be aligned with the finding that the IFT-brokers investigated had been operating in Korea for about three years before their activities were terminated as a result of customs investigations. However, contrary to Schaffer's view that the entanglement of several IFT-brokers contributes to the continuation of IFT-systems, IFT-business networks in Korea appear to be small and narrow. Most individual (dyadic) IFT-systems seem to work separately. There is little evidence that individual (dyadic) IFT-systems are linked. IFT-brokers working within small IFT-business networks may have difficulty in locating other prospective counterpart IFT-brokers to share their experiences with. Thus, the threat of circulating information regarding the reputation of counterpart IFT-brokers within or across their IFT-business networks may not work as effectively as anticipated. However, some IFT-brokers with legitimate businesses work together for IFT-businesses. IFTbrokers' social networks based on their legitimate businesses, which are usually wider than their IFT-business networks, may prevent them from deceiving counterpart IFTbrokers. In sum, IFT-systems in Korea may not have the social environment in which all of Schaffer's four mechanisms work. Some mechanisms - the shared belief systems and the structure of debt and credit - do not seem to fit in the context of Korean IFT-systems. This observation implies that not all of the four mechanisms are required to encourage IFT-brokers to fulfill their obligations related to IFT-businesses. The IFT-case reports and interview data do not provide any indication as to which mechanism is the most important in maintaining IFT-systems. It may depend on the contexts in which specific IFT-systems operate.

\subsection{Summary and reflection}

The aim of this chapter was to answer the second sub-question of this research, which is why the actors in IFT-systems trust each other under social uncertainty and how they cope with it. This sub-question was answered by examining the interpersonal dynamics within IFT-systems as social exchanges between the actors in the illegal remittance market. In particular, following the two pictures from the panoramic and 
medium shots in Chapters 4 and 5 respectively, this chapter provided the final picture: the interactions between the actors in IFT-systems in Korea. Many studies on IFTsystems have illustrated the interactions between the actors in IFT-systems. However, they were rarely addressed from the perspective of trust and risk, even though trust and risk within IFT-systems are key elements ensuring that IFT-systems are sustained and IFT-transactions take place. In identifying the procedures of IFT-activities in temporal order, this chapter examined how trust relations develop between the actors involved in IFT-activities, and how they manage trust-related risks.

To address the interpersonal dynamics within IFT-systems, this chapter used social exchange theory and the perspective of trust and risk. Social exchange theory has played a role in shedding light on the power relations between the actors in the illegal remittance market. It has shown that while IFT-users are normally more powerful than IFT-brokers, desperate IFT-users, including criminal syndicates, may become so dependent on IFT-systems that the balance of power is reversed. According to this theory, although the contracts between the actors within IFT-systems appear to be a negotiated exchange, their inherent attribute is similar to a reciprocal exchange. This is because it can be difficult for actors to expect the other party to fulfill his obligations related to IFT-transactions, given the illegitimacy of IFT-transactions. In other words, contracts for illegal transactions involve the risks of deception and betrayal. The conclusion and enforcement of contracts are therefore a major challenge in IFTactivities because there is no third party that oversees conflicts between the actors within IFT-systems. Despite such risks of deception and betrayal, IFT-systems in practice generate countless IFT-transactions. From the perspective of the social dilemma theory, IFT-users and IFT-brokers, based on collective rationality, place trust in the other party. In other words, IFT-users and IF-brokers work together to achieve their common interest - completion of IFT-transactions - despite the risks involved in trusting the other party. They also take various measures to manage the risks, including reducing uncertainty and vulnerability to the risks. 
The thematic analysis combined with the crime script approach has zoomed in on each procedure for IFT-activities, based on the perspective of trust and risk. The main findings of this analysis are broadly in line with those from previous studies on IFT-systems. A significant number of IFT-brokers investigated by the KCS ran legitimate businesses to camouflage their IFT-businesses. IFT-users and IFT-brokers seemed to approach each other mainly via social networks: while IFT-brokers aim to send signals about their trustworthiness to IFT-users, prospective IFT-users seek to distinguish and locate trustworthy IFT-brokers to avoid falling victim to deceptive IFTbrokers. The empirical data have thus demonstrated how the ex ante signaling and the ex post reputation mechanisms between IFT-users and IFT-brokers can work as useful measures to deal with social uncertainty, especially given that those received during IFT-transactions cannot rely on formal legal systems to compensate for their losses.

Several new findings were presented in this chapter. IFT-users and IFT-brokers actively use online banking services provided by formal financial institutions in Korea. This finding somewhat contradicts the general assumption that IFT-systems are isolated from formal financial institutions, except with regard to the procedure for the settlement of outstanding debts. Through online banking services, solo IFT-brokers, who operate without counterpart IFT-brokers, provide IFT-services in both sending and receiving countries. By using these services, remitters can easily send funds to IFTbrokers operating in remote places, leaving trails that work as a safeguard to protect them from possible deception by IFT-brokers. Online banking systems therefore play an important role in reducing the vulnerability of both IFT-brokers and IFT-users. In other words, IFT-systems use their competitor's strength - formal financial institutions' online banking systems - to survive. Indeed, online banking systems are beneficial in resolving interpersonal tension. In addition to the 'prototypical' IFT-transactions, two additional types of IFT-transactions were revealed: the use of wire-transfers and the recruitment of cash couriers. In these types of IFT-transactions, IFT-users are generally unaware of the procedures for the cross-border transferring of funds. IFT-brokers, on the other hand, are responsible for paying the funds to recipients and assume all the risks that may arise in the course of the transfer of funds. Of the three types of IFT- 
transactions, IFT-transactions through wire-transfers are the least risky and those involving cash couriers are the riskiest in terms of deception and betrayal by actors involved in the transactions.

In sum, by zooming in on IFT-systems, this chapter has shown that IFT-systems are inherently susceptible to deception and betrayal between actors. This is mainly to the illegitimacy of IFT-systems, which makes them vulnerable. This chapter has also demonstrated that the actors involved in IFT-activities overcome such vulnerability with measures to gain the trust of the other party or to protect themselves from deception or betrayal by the other party, thereby making IFT-systems and transactions sustainable. The findings are expected to be helpful in understanding why the actors involved in IFT-activities (appear to) trust each other and continue to engage in IFTactivities. 


\section{Conclusion}

This study, which has been unfolded over the previous six chapters, will now be summarized in this conclusion. This chapter will first revisit the aims of the research, the research questions, and the research methodology. After reflecting on the main findings of this study, this chapter will conclude with the academic and societal relevance of this study, its limitations, and several recommendations for future research and policy.

\subsection{Aims, research questions, and methodology}

\subsubsection{Rationale for the research and research questions}

Lay people who live in western countries may be unfamiliar with IFT-systems. They may think that IFT-systems are outdated in the 21st century, where formal financial institutions bring their services within everyone's reach through the Internet. Most customers experience few challenges in accessing formal financial institutions and in using their financial services, including cross-border fund transfers. However, many professionals and scholars have demonstrated that IFT-systems not only flourish in developing countries where formal financial services are less accessible, but also survive in competition with formal financial institutions in developed countries. The appeal of IFT-systems in both developed and developing countries is related to their two functions: remittance transferring and money laundering. The potential of IFT-systems as an inexpensive and fast cross-border remittance channel has been long recognized. Before the 9/11 attacks, concerns were rarely raised about the misuse of IFT-systems for money laundering and the financing of terrorism. In response to the threat, the global AML/CFT community adopted new standards for enhanced international AML/CFT measures, one of which puts MVTS under government oversight (Todoroki et al., 2014). Following on from this example, several scholars and professionals have since shed light on the vulnerability of IFT-systems to money laundering and the financing of terrorism. 
This observation - recent interest in IFT-systems after long neglecting that there is a possibility that they could be abused - inspired this study, which asks an essential but somewhat ignored question, namely why and how IFT-systems, a primitive remittance transfer system, can continue to operate today and adapt to changing environments. Specifically, the question given to this study is how IFT systems can survive despite increased global concerns about IFT systems, but also the increased accessibility of formal financial institutions, and the inherently vulnerable character of IFT systems due to their illegality. Despite an increase in the number of studies on IFTsystems, the issue of survival and adaptation of IFT-systems in a globally connected world has barely been addressed.

This study has divided the (overarching) research question into two subquestions. The two sub-questions reflect the two risks arising from the illegitimacy of IFT-systems. A distinction can be made between external and internal risks. External risks include the global concern about - and actions against - IFT-systems, and the fact that IFT-systems are in competition with formal financial institutions. Examples of internal risks include the risk of deception and betrayal between the actors within IFTsystems. More specifically, the first research sub-question looks at how IFT-risks are distributed across the world. The second research sub-question addresses the dilemma that both IFT-users and IFT-brokers face, namely how IFT-transactions can be carried out despite the internal risks that threaten their functioning.

Previous studies on IFT-systems provide little information about the global landscape of IFT-risks for each country. Each country's social and economic environments may have different effects on IFT-systems, and IFT-risks may therefore be distributed differently across countries. A lack of information at a global level about IFT-risk may hamper the development of effective measures against IFT-systems across countries. This does not mean that the global AML/CFT community aims for a onesize-fits-all approach. A lack of comparative information on IFT-risks, it has made it difficult for the global AML/CFT community to devise feasible and enforceable AML/CFT measures, taking into account the social and economic environments of each 
country. On the other hand, the survival of IFT-systems is threatened not only by external but also by internal risks. If IFT-systems are assessed as illegitimate, the interactions between the actors within IFT-systems become more vulnerable. However, some IFT-systems, especially in developed countries, survive, even though they are exposed to increased external risks and retain the internal risks. While several testimonies were given on how IFT-systems avoid external risks in developed countries, information on how they cope with internal risks is scarce.

The two research sub-questions posed in this study — namely, how IFT-risks are distributed across countries despite (taking advantage of) external adverse (beneficial) environments, and how IFT-transactions are carried out despite the associated internal risks - are essential in understanding how seemingly outdated IFT-systems still survive and even prosper in today's world in some regions. In order to respond to the two research sub-questions, this study gradually narrowed down its focus in terms of the survival and adaptation of IFT-systems. First, the panoramic view captured the landscape of IFT-risks across countries. Next, the medium view shed light on IFTsystems as a remittance channel in competition with formal remittance systems. And finally, the close-up view focused on the internal dynamics between the actors within IFT-systems.

\subsubsection{Methodology}

To address the research questions, this study employed the following two research designs: a cross-sectional design and a case study design.

In this study, the cross-sectional design served to capture the landscape of IFTrisks of the 121 selected countries using the global IFT-risk indicator, which has been constructed on the basis of five datasets collected by four international entities. The composite indicator is based on the assumption that the (overall) IFT-risk faced by each country is closely associated with four IFT-risk elements: IFT-services market size, 
access to formal financial institutions, compliance of AML/CFT systems with the FATF Recommendations, and societal attitudes towards informality.

A case study design was used to examine the link between the survival of IFTsystems and the coping mechanisms of the actors involved in IFT activities, focusing specifically on Korean IFT-cases. The selection of IFT-systems in Korea, among other countries, stemmed not only from the accessibility of the empirical data, but also its interesting features for research on IFT-systems. This study obtained access to 230 IFTcase reports. Furthermore, the researcher was able to interview 40 Korean government officials through his social network. As several previous studies on IFT-systems have demonstrated, IFT-systems are often observed in developing countries with a low level of access to formal financial institutions. This is mainly due to the fact that the services of IFT-systems complement those of formal financial institutions. On the other hand, only a few studies have looked into IFT-systems in developed countries. Thus, little data is available on the characteristics of IFT-systems in different types of economies. IFT-systems in Korea, a country that does not fall under the group of developed countries but has a high level of access to formal financial institutions, may be able to provide indications on the patterns of IFT-systems in different social and economic environments.

As part of the case study methodology, 230 IFT-case reports provided by the Korea customs administration and the transcripts of interviews with 50 Korean government officials were analyzed. In particular, the case study methodology used the thematic analysis to delineate the working mechanisms of IFT-systems in Korea and to reveal the dynamic interactions between the actors in IFT-activities.

In sum, the cross-sectional design was used to gauge the global landscape of IFTrisks, with a focus on disclosing how IFT-risks are distributed according to the IFT-risk elements. The case study was used to investigate the dynamic interactions between the actors in IFT-systems by unpacking the internal mechanisms of IFT-systems operating in an adverse environment. 


\subsection{Main research findings}

This study investigated the survival and adaptation of IFT-systems in a globally connected world. When it comes to the first research sub-question regarding the global distribution of IFT-risks across countries, this study presented the IFT-risks faced by the 121 selected countries by means of the global IFT-risk indicator. Most developed countries analyzed were assessed as having low IFT-risk levels, mainly because of their high level of access to formal financial institutions and high level of compliance with international AML/CFT standards. Within the group of developed countries, those countries considered to be the favorite destinations of immigrants were assessed as having somewhat - or relatively - high IFT-risk levels. In contrast, most of the developing countries were assessed as countries with high levels of IFT-risk due to a large number of emigrants, underdeveloped formal financial systems, low compliance levels with international AML/CFT standards, and lenient attitudes towards informality. These findings, which show that the level of IFT-risk is related to the level of economic development of each country, may seem evident. However, the two different IFT-risk assessment models yielded slightly different results according to their weighting methods (Table 7.1). In addition, some counterintuitive outcomes suggest that caution is required when using the global IFT-risk indicator and interpreting its outcomes. For instance, some developed countries (e.g., the United States) were assessed as having very high IFT-risk. On the other hand, some countries plagued with (drug-related) organized crime and money laundering (e.g., Colombia ${ }^{231}$ ), or countries known as tax havens (e.g., Malta and Cyprus), are assessed as having very low IFT-risk. This shows that it is challenging to map complex local realities with several noncontextualized factors captured through surveys (i.e., each variable used in the IFT-risk indicator). Nevertheless, one of the major virtues of the global IFT-risk indicator lies in being able

231 Colombia is known for the origin country of 'Black Market Peso Exchange (BMPE)', one of tradebased money laundering methods. "The BMPE is one of the primary means by which drug cartels launder the proceeds of their drug money back into the countries where the narcotics are produced" (Weitz and Porter, 2013: 29). 
to gauge 'nuanced' differences in IFT-risks within different country groups and in ranking the countries in terms of the IFT-risks that they are faced with. The global IFTrisk indicator has thus observed differences in IFT-risk levels among developed countries and identified countries with lower risk levels among developing countries. This composite indicator can be used to keep track of each country's IFT-risks over time, as long as the indicator is updated with longitudinal data. This could be an incentive for policy makers to improve the social and economic environment of IFT-systems, and to develop better measures for the management and evaluation of IFT-systems.

Table 7.1: Countries with the highest and the lowest IFT-risk levels

\begin{tabular}{|c|c|c|c|c|c|c|}
\hline \multirow{2}{*}{ Rank } & \multicolumn{3}{|c|}{ Equal weighted } & \multicolumn{3}{|c|}{ PCA weighted } \\
\hline & Country & Region & $\begin{array}{c}\text { Nat'l Income } \\
\text { level }\end{array}$ & Country & Region & $\begin{array}{c}\text { Nat'l Income } \\
\text { level }\end{array}$ \\
\hline \multicolumn{7}{|c|}{10 countries with the largest IFT-risk } \\
\hline 1 & Myanmar & E. Asia \& Pacific & Low & Bangladesh & S. Asia & Low \\
\hline 2 & Yemen & MENA & L. middle & United States & N. America & High \\
\hline 3 & Haiti & L. America \& Carib. & Low & Nepal & S. Asia & Low \\
\hline 4 & Bangladesh & S. Asia & Low & Mali & S.-Saharan Africa & Low \\
\hline 5 & Guinea & S.-Saharan Africa & Low & Cambodia & E. Asia \& Pacific & Low \\
\hline 6 & Mali & S.-Saharan Africa & Low & Russia & Europe \& C. Asia & High \\
\hline 7 & Paraguay & L. America \& Carib. & U. middle & Haiti & L. America \& Carib. & Low \\
\hline 8 & Pakistan & S. Asia & L. middle & Yemen & MENA & L. middle \\
\hline 9 & Cambodia & E. Asia & Low & Sierra Leone & S.-Saharan Africa & Low \\
\hline 10 & Mauritania & S.-Saharan Africa & L. middle & Burkina Faso & S.-Saharan Africa & Low \\
\hline \multicolumn{7}{|c|}{ 1o countries with the small IFT-risk } \\
\hline 121 & Switzerland & Europe \& C. Asia & High & Belgium & Europe \& C. Asia & High \\
\hline 120 & Singapore & E. Asia \& Pacific & High & Malta & Europe \& C. Asia & High \\
\hline 119 & Belgium & Europe \& C. Asia & High & Slovenia & Europe \& C. Asia & High \\
\hline 118 & Finland & Europe \& C. Asia & High & Hungary & Europe \& C. Asia & U. middle \\
\hline 117 & Austria & Europe \& C. Asia & High & Switzerland & Europe \& C. Asia & High \\
\hline 116 & Netherlands & Europe \& C. Asia & High & Singapore & E. Asia \& Pacific & High \\
\hline 115 & Malta & Europe \& C. Asia & High & Portugal & Europe \& C. Asia & High \\
\hline 114 & Norway & Europe \& C. Asia & High & Bulgaria & Europe \& C. Asia & U. middle \\
\hline 113 & Canada & North America & High & Cyprus & Europe \& C. Asia & High \\
\hline 112 & United Kingdom & Europe \& C. Asia & High & Colombia & L. America \& Carib. & U. middle \\
\hline
\end{tabular}

Source: the author 
This study addressed the second research sub-question regarding trust-related risks between the actors within IFT-systems by analyzing the IFT-case reports and the interview data. Three theoretical frameworks were used: the sociology of (illegal) markets, social exchange theory, and the perspective of trust and risk. This study found that despite the fact that IFT-users and IFT-brokers seem to have incentives to deceive each other due to the lack of formal supervision or mediation mechanisms in IFTsystems, they rarely do so. In other words, IFT-users and IFT-brokers trust each other despite facing internal risks associated with IFT-systems, arising from their inherent illegitimacy. This is because actors seem to (unconsciously) know that their cooperation with each other will help them achieve their collective interests. As a result, the actors take some manageable risks and take various measures to deal with the internal risks, rather than distrusting the other party and refusing to cooperate with each other. In fact, most IFT-users would benefit very little from deceiving IFT-brokers. Most IFT-users wish to assess the likelihood that they will be victimized by fraudulent IFT-brokers. They can try to assess the trustworthiness of IFT-brokers before or during the execution of IFT-transactions, as IFT-brokers will somehow try to demonstrate their trustworthiness. For instance, some IFT-brokers may run IFT-businesses from fixed stores, which implies that they are unlikely run off. Some IFT-brokers also run legitimate businesses associated with IFT-businesses, which suggests that they may lose more if they deceive IFT-users. The remitters can also check whether the correct amounts are paid immediately after requesting IFT-brokers to transfer funds to designated recipients. IFT-brokers, on the other hand, have few methods for assessing the trustworthiness of IFT-users, as they simply accept requests for the transfer of funds. In order to deal with uncertainty and vulnerability, IFT-users and IFT-brokers not only use the ex ante signaling and ex post reputation mechanisms, but also the online banking services of formal financial institutions to carry out IFT-transactions. In addition, IFT-systems that are limited to ethnic enclaves have a low priority for law enforcement authorities. Therefore, even in adverse conditions, IFT-systems may shrink slightly, but they survive because they can avoid the increased external risks and cope with the internal risks. 
In examining the IFT-case reports and interview data in Korea, this study has produced several new findings on IFT-systems that have rarely been addressed in previous studies.

The empirical data showed that the IFT-systems detected in Korea operated mainly between Korea and China, rather than between Korea and other neighboring countries, such as Japan. This finding suggests that IFT-transactions between sending and receiving countries may be influenced not only by geographical or social proximity between IFT-brokers, but also by the economic structures of the sending and receiving countries (e.g. the levels of financial inclusion and major exporting and importing goods).

When it comes to how remittances between IFT-users and IFT-brokers are handled, this study has revealed that in Korea, many IFT-users and IFT-brokers actively use online banking services offered by formal financial institutions. This somewhat contrasts with the general assumption that IFT-systems are isolated from formal financial institutions, except with regard to the procedure for the settlement of outstanding debts between IFT-brokers.

This study also identified 'solo IFT-brokers', whose existence contradicts the conventional IFT-systems where separate IFT-brokers in sending and receiving countries work together to transfer funds. Through online banking services, solo IFTbrokers can provide IFT-services in both sending and receiving countries without counterpart IFT-brokers. The existence of solo IFT-brokers implies that the IFT network may be smaller than envisaged and that the traditional ex post reputation mechanism may not work as effectively as expected. The ex post reputation mechanism is based on the network of several IFT-brokers and prevents IFT-brokers from deceiving other IFT-brokers by circulating information about someone's reputation within the network. Solo IFT-brokers who rarely work with other IFT-brokers do not have to deal with the potential impact of spreading information about their reputation. 
This study found that online banking services also benefit IFT-users. By using these services, remitters can easily send funds to IFT-brokers in remote places, leaving trails that work as a safeguard to protect them from IFT-brokers who fail to meet their obligations. Online banking systems therefore play an important role in reducing the vulnerability of both IFT-users and IFT-brokers facing social uncertainty.

This study identified some variant IFT-transactions, which differ from the traditional hawala-style IFT-transactions. In finding variant IFT-systems in the IFT-case reports, this study categorized the IFT-transactions included in the 230 IFT-cases into three groups based on the way funds are transferred between IFT-brokers: the 'prototypical' IFT-transactions, the use of wire-transfers, and the physical transfer of cash. Prototypical IFT-transactions, whereby funds are transferred between IFTbrokers without the involvement of formal financial institutions and the physical transfer of cash, include not only the traditional hawala-style IFT-transactions, but also IFT-transactions by solo IFT-brokers. Some IFT-brokers 'wire-transfer' funds via formal financial institutions, even though this may seem counterintuitive. Some IFT-brokers make use of 'cash couriers' to transfer funds across borders and exchange the transported cash via currency exchange offices in receiving countries. Among the three types of IFT-transactions, the prototypical IFT-transactions are the most common. IFTtransactions between Korea and Japan usually involve cash couriers and currency exchange offices. In terms of the likelihood of deception and betrayal between the actors during IFT-transactions, IFT-transactions through wire-transfer are the least risky and those involving cash couriers are the riskiest.

Regarding the misuse of IFT-systems by organized crime groups, this study led to a different finding from previous studies that focused on IFT-systems in Western countries. This study suggests that IFT-systems in Korea are rarely used for laundering the criminal proceeds of drug trafficking or other forms of organized crimes. IFTsystems in Korea seem to be exploited primarily for economic crimes, especially tax evasion. Apart from little evidence regarding the link between IFT-systems and organized crimes in Korea, this study has an implication for the abuse of IFT-systems 
by organized crime groups with respect to IFT-risks across countries. According to the crime prism (Lanier and Henry, 2010), the threat posed by IFT-systems to the security of society may not be as visible and direct as that of organized crime groups. However, IFT-systems may function as a financial conduit for criminal syndicates and play a role in strengthening their capacity (Van de Bunt, 20o8a); in turn, they can cause serious harm to society. Global IFT-risks do not provide specific indication of the involvement of IFT-systems in organized crimes. However, some countries where IFT-systems are known to be exploited by organized crime groups, such as terrorist groups, should take their IFT-risks seriously, compared to other countries that have few signals about the connection.

\section{7·3 Scientific implications}

This section will address the academic relevance, methodological contribution, and limitations of the research.

\subsubsection{Academic relevance}

This study conducted research on IFT-systems using innovative approaches, which are expected to add value to future criminological studies on IFT-systems. The main approaches chosen were: the assessment of the (criminological) conceptualization of IFT-systems, the use of theoretical frameworks, and the description of the sequence of IFT-activities.

This study sought to conceptualize IFT-systems regardless of their legal status. In the conceptualization of IFT-systems, two conflicting perspectives can be distinguished; by adopting the FATF Recommendations, most countries treat unregistered (or unlicensed) IFT-systems as 'illegal'. However, many economists believe that IFT-systems manage the remittances of expatriate workers and, although they are unregistered, they are considered 'legitimate'. Many studies on IFT-systems took an equivocal stance on the conceptualization of IFT-systems. This ambiguous status makes 
it difficult to take coordinated actions against IFT-systems. This study examined the concept and status of IFT-systems from various angles to address the conflicting views on the status of IFT-systems. By determining the status of IFT-systems, this study recognized the importance of the context in which IFT-systems operate. For instance, some IFT-systems in fragile states or conflict zones with limited access to formal financial institutions may be deemed illegal yet legitimate. In addition to IFT systems operating in such specific contexts, this study assessed IFT-systems in environments with decent financial inclusion as illegal and illegitimate. The victims of IFT-systems are not always clearly visible. This is mainly due to the fact that the direct damage resulting from IFT-systems is hardly disclosed. However, their negative consequences for society, such as undermining the integrity of formal financial institutions and promoting the informal economy, are not negligible and can last a long time. In addition, IFT-brokers have few reasons to refuse requests for transferring suspicious funds, including criminal proceeds. The impact of IFT-systems spreads across multiple countries. Reportedly, legitimate IFT-systems in developing countries are also always at risk of being misused for money laundering and for the financing of terrorism, mainly with funds from developed countries. There are few reasons to promote IFT-systems as legitimate in countries with a high degree of financial inclusion. The fact that converting IFT-systems into MVTS is a challenge should not be a reason to treat IFTsystems as legitimate and for ignoring the misuse of IFT-systems for criminal purposes. The assessment of the status - legitimate or illegitimate - of IFT-systems can help answer the research questions, as the conceptualization of IFT-systems is closely linked to the nature and level of external and internal risks to which IFT-systems are exposed. For instance, in societies that consider IFT-systems legitimate, the actors involved in IFT-activities perceive little risk of being subjected to law enforcement investigations. They will also have little concern about the internal risks related to IFT-transactions. However, in societies that consider IFT-systems illegitimate, the actors participating in IFT-activities are exposed to greater external and internal risks related to IFT-systems and require measures to cope with them. 
This study differs from previous studies in that it adopts theoretical perspectives to explain IFT-systems. The theoretical frameworks adopted for the global and local analyses have rarely been used in previous studies. In order to assess global IFT-risk distribution, this study, which consulted previous studies on IFT-systems, presented four socio-economic variables - or IFT-risk elements - as determinants of the level of IFT-risk. Since previous studies have addressed only a few factors when examining IFTsystems, this attempt, albeit not exhaustive, may contribute to a better understanding of the relationship between IFT-systems and relevant socio-economic factors. For the local analysis of the dynamic interactions within IFT-systems, this study used three theoretical frameworks: the sociology of (illegal) markets, social exchange theory, and the perspective of trust and risk. This study demonstrated that IFT-systems are a remittance market where remitters and IFT-brokers interact to buy and sell crossborder remittance services, drawing on the sociology of (illegal) markets. Social exchange theory provides a lens to analyze the relationships of dependency on resources or use of power, not only between remitters and IFT-brokers, but also between remitters, IFT-brokers, and formal financial institutions. The perspective of trust and risk works as a framework to examine why and how IFT-users and IFT-brokers trust each other, and enter into IFT-transactions under social uncertainty. However, trust issues may be less relevant to IFT-systems in developing countries that consider IFT-systems as legitimate, as the involved actors in developing countries may have little tension or risk to overcome or cope with. In sum, the three theoretical frameworks applied to IFTsystems may contribute to a better understanding of the multi-dimensional aspects of IFT-systems: the illegal remittance market in competition with formal remittance systems, power relations among IFT-users and IFT-brokers, and trust and risk in IFTactivities.

This study presented a temporal sequence of IFT-activities consisting of 11 procedures, inspired by crime script analysis (Cornish, 1994). They have all been analyzed in terms of trust and risk. Some procedures were not addressed in previous studies, perhaps because they do not seem to be closely related to IFT-transactions, even though they play important roles in IFT-systems. The added value of the case study 
method applied in this research is its holistic approach. This study shed light on the entire sequence of activities of IFT-schemes, not just on IFT-transactions. This has revealed that IFT-users and IFT-brokers assess the trustworthiness of the other party, even before carrying out an IFT-transaction.

\subsubsection{Methodological contribution}

This study also made a few innovative methodological attempts to capture IFTrisks and IFT-activities that are difficult to identify and address. These efforts may benefit research into elusive subjects in the field of criminology and crime science.

Despite an increase in the media coverage of IFT-systems, but also in the number of studies on them, IFT-systems still seem to be a somewhat unknown phenomenon, even to scholars. In order to explore the survival and adaptation of IFT-systems from different angles and reveal the hidden aspects of IFT-systems, this study took three pictures of IFT-systems in a stepwise manner: a panoramic shot of the global landscape of IFT-risks, a medium shot of IFT-systems as the illegal remittance market, and a closeup shot of the dynamic interactions between the actors within IFT-systems. The three pictures showed how IFT-systems respond to the external and internal risks and helped in answering the two research sub-questions. The panoramic shot was taken using the global IFT-risk indicator - a composite indicator constructed to gauge the distribution of IFT-risks faced by each country. This was never attempted in previous studies on IFT-systems or even in the field of criminology in general. The medium shot focused on IFT-systems in Korea as an illegal remittance market, by depicting the relationships between IFT-systems, formal financial institutions, and the government, drawing on the sociology of illegal markets. This medium shot plays a role in bridging the global landscape of IFT-risk and the dynamic interactions between the actors within IFTsystems. The aim of the close-up shot was to zoom in on the internal dynamics of IFTsystems and to illustrate the detailed steps of IFT-activities, drawing on social exchange theory and the perspective of trust and risk. The three pictures taken at different levels made it possible to examine the multi-dimensions of IFT-systems from multiple angles. 
The second step in this study was to develop the global IFT-risk indicator - or a composite indicator - to gauge the distribution of IFT-risks across countries. A composite indicator - an instrument to measure a multi-dimensional concept that cannot be captured by a single indicator - may be an unknown tool in the domain of criminology and crime science. The global IFT-risk indicator was constructed based on the findings from previous studies on IFT-systems that IFT-risk is associated with four IFT-risk elements. Composite indicators may become a helpful tool for criminologists who want to study crime risks at macro level and include 'big data' in their risk analysis.

\subsubsection{Limitations}

This study has several limitations. One limitation relates to two research designs at different levels used in one study. Some limitations are related to the methodology used to construct the composite indicator (Freudenberg, 2003). Other shortcomings are due to the fact that data collection for the case study took place in law enforcement agencies.

This study posits that IFT-systems are exposed to the external and internal risks and the survival of IFT-systems depends on how they cope with these risks. Thus, the global analysis intended to address how IFT-systems respond to the external risks by examining IFT-risks across countries. In order to examine how IFT-systems respond to the internal risks, this study had to focus on a specific country, which is Korea. This study employed two different research designs - cross-sectional design and case study design - but at different levels - across countries and at a specific country, in order to examine the relationships between IFT-systems and the external and internal risks faced by IFT-systems. This study also used the metaphor of a camera with zoom lens taking three different levels of pictures - the panoramic shot, medium shot, and close-up shot - in order to combine the findings from the mixed research methods and from the different angles. Mixed research methods are recently more often discussed and used by many scholars in order to investigate a complex phenomenon that would otherwise 
not have been accessible by using one approach one (Feilzer, 2010; Shannon-Baker, 2016). Even though the global analysis was conducted to compare the IFT-risks faced by each country, thereby identifying the relative level of the IFT-risk of Korea, the global analysis might look separated from - or loosely connected to - the local analysis that focuses on IFT-systems in Korea because of the two different subjects and focuses.

Regarding the composite indicator, scholars and policy makers should be cautious not only when using the global IFT-risk indicator, but also when interpreting its outcomes. The global IFT-risk indicator was not designed to measure the prevalence of IFT-activities or IFT-transactions in certain countries. It was not developed and tested with actual observed IFT-risks of each country. It was constructed to provide an instrument to gauge the level of risk in countries where IFT-activities are likely to occur. The relationship between the (overall) level of IFT-risk and the IFT-risk elements is therefore not between a response (dependent) variable and explanatory (independent) variables. IFT-risk is a construct designed with the IFT-risk elements likely to significantly affect the prevalence of IFT-activities. In other words, the global IFT-risk indicator is a tool used to provide data for the analysis of IFT-risks. It is not a diagnostic tool for measuring IFT-risk per se. For instance, there is no way to measure actual IFTrisks $^{232}$ faced by each country. Instead, the global IFT-risk indicator produces (IFT-risk) values relating to the likelihood that IFT-systems will prosper in a certain country. This is done on the basis of the IFT-risk elements likely to be associated with the viability of IFT-systems. The IFT-risk values for certain countries in the composite indicator may differ from the actual IFT-risk in those countries. This is because the actual IFT-risk is influenced by many factors, some of which were not taken into account when constructing the indicator. Some IFT-risk levels may look counterintuitive. However, each IFT-risk value is only an indicative number of the probability that IFT-systems will

\footnotetext{
232 Many studies on IFT-systems have been conducted from the perspective of IFT-users. Some studies examined that IFT-brokers run their IFT-businesses in an overt manner. IFT-systems are sort of an elusive subject. In a methodological sense, there is no way to capture the actual prevalence of IFTactivities. The empirical data captured in field research on IFT-systems may represent some pieces of puzzles in an elusive big picture.
} 
prosper, not a value that reflects the actual success of IFT-systems. As the global IFTrisk indicator plays a role in providing each country with warning signals regarding IFTsystems, the countries that are assessed with having higher IFT-risk than normally conceived may need to monitor their remittance markets more in-depth instead of simply disregarding the IFT-risks with a thought that the assessed IFT-risks do not make sense at all. On the other hand, as for the countries that are assessed as having lower IFT-risks than normally known, researchers should check the composition and validity of the underlying variables (e.g., compliance with the FATF Recommendations) used to construct the indicator. In other words, the global IFT-risk indicator should interact with the governments of each country and field researchers to improve its validity, thereby approaching the prevalence of IFT-activities more closely. In addition, if caution is exercised in using this composite indictor and in interpreting its outcomes, it is possible to distinguish nuanced differences between IFT-risk that each country faces and to learn more about IFT-systems.

There may be some concern about whether the datasets used to construct the global IFT-risk indicator adequately reflect the IFT-risk elements. This is an issue related to the operationalization of variables. When a study uses secondary data, it must address issues of operationalization and validity of variables (Gertz and Myers, 1992). Most composite indicators encounter the same issues, given that all composite indicators are constructed on the basis of secondary datasets. According to studies on composite indicators, the selection of datasets to construct a global IFT-risk indicator is a matter of judgement. The five datasets developed and maintained by the World Bank, the IMF, the FATF, and the WEF that cover the same themes - remittance, financial inclusion, AML/CFT efforts, and societal attitudes towards (in)formality that this study sought to reflect in the composite indicator. These datasets contain sufficient variables and reliable questions that many studies, including this study, have used. Although the selected variables from the secondary datasets seem to reflect well what the IFT-elements sought to capture for this study, the five datasets may affect the validity of the global IFT-risk indicator, given that the datasets were not initially designed to capture IFT-risk. The global IFT-risk indicator avoids only to a limited 
extent the inherent limitations about which other composite indicators also have concerns.

As for the local analysis of IFT-systems, concerns about data validity may arise. This study was not able to collect primary data from IFT-brokers ${ }^{233}$ or IFT-users to examine the internal dynamics of IFT-systems. Instead, this study used data provided by the customs administration in Korea. There is concern that the interactions between the actors in IFT-activities recorded in the law enforcement case reports may not fully represent the real relationships between the various actors involved in IFT-systems. The research methodology literature refers to this concern as 'dark figure' (Coleman and Moynihan, 1996). This is due to the fact that the KCS might provide information on a specific group of IFT-systems that can be easily identified by customs officers. Another concern is that data from law enforcement authorities may not properly reflect the rather intangible concept of trust. Nevertheless, the IFT-case reports and the interview data are not only a feasible option for this study but also a useful data source of information on IFT-systems. Law enforcement officers investigating IFT-systems are likely to have more and better information on IFT-activities than IFT-users. IFT-brokers are not necessarily better informed than law enforcement officers, as each IFT broker usually only knows about their IFT-business, whereas law enforcement officers are likely to be exposed to different types of IFT-systems. Although IFT-brokers and IFT-users could not be interviewed for this study, the IFT-case reports and the interview data provided fairly detailed, albeit not comprehensive, information about the dynamic interactions between the various actors involved in IFT-activities. Information on relationships of trust between the actors involved in IFT-activities could also be derived from the interactions between them, albeit interpreted from the IFT-brokers' perspective.

233 Even though the self-reports of offenders were introduced to overcome the deficiencies of official crime data, the self-reports are troubled with the validity issues as well (Gill, 2005; Farrington, 2001). 
With regard to the local analysis of IFT-systems in Korea, already there were many reasons for selecting this country, it is a limitation in some respects. This study provided little evidence that IFT-systems in Korea are associated with organized crime. This could be due to selection bias or a reflection of the situation in Korea, which is different from that in Western countries, where IFT-systems are often abused by organized crime groups. As the IFT-systems detected by the Korean police were not included in the data for this study, there are concerns about the possibility that the police records reveal the association between IFT-systems and organized crime, but that this study missed it. However, according to an interviewed KoFIU police official ${ }^{234}$, IFTsystems have low priority for the police in Korea. Furthermore, the IFT-cases investigated by the police usually focus on IFT transactions involving the remittances of expatriate workers. He added that organized crime groups may use IFT-systems for their own businesses, but that police investigations focus more on primary criminal activities rather than on supporting activities, such as the transfer of illegally obtained profits. Despite the likelihood that customs investigators systematically miss some IFTsystems that work closely with organized crime groups, this study adopted the view that IFT-systems in Korea are different from those in Western countries. The reason for this is that the networks of organized crime groups in Korea are usually limited to Korea, and that only few foreign organized crime groups are active in Korea.

Another concern arising from the choice to focus on IFT-systems in Korea is whether the findings of the local analysis can be generalized to other countries, as external validity is one of the criteria for assessing the quality of research (Shadish et al., 2002). As mentioned earlier, with regard to IFT-systems, Korea has a different social and economic environment than other countries. The policies or measures adopted by the Korean government are somewhat different from those of other governments. It is therefore difficult to apply the findings from the analysis of IFT-systems in Korea

234 Even though this study interviewed one police official at the KoFIU, he was a management-level official supervising decades of police officers working at the KoFIU. His answers to the questions for this study seemed to be representative of the police force at the KoFIU. 
directly to those in other environments in a statistical sense. However, there is a different approach to generalization which is referred to as analytical generalization ${ }^{235}$ and focuses on transferability of the findings from qualitative studies (Maxwell and Chmiel, 2014; Polit and Beck, 2010; Yin, 2013). Whether the findings from the local analysis can be transferrable to other environments or contexts should be examined with care in follow-up studies.

\subsubsection{Future research directions}

In answering the research questions, this study addressed several issues relating to IFT-systems. On several points that were seldom examined in previous studies, this study yielded a few findings that merit in-depth follow-up research. For instance, this study uncovered new patterns in IFT-businesses. This finding raises the question whether these new types of IFT-businesses are unique features in Korea or also common types of IFT-businesses in other countries that have not yet been reported. Specifically, it is interesting to examine: whether and in what ways IFT-brokers in other countries use online banking services; whether solo IFT-brokers can also be observed in other countries; whether IFT-brokers in other countries also make use of wire-transferring methods for cross-border transferring of funds; and, whether this type of fundtransferring is also referred to as IFT-system in other countries. As regards other aspects, some of the findings of this study differ from those of other studies. For instance, unlike studies on IFT-systems in Western countries, no link was found between IFT-systems and organized crime groups in Korea. It is a challenge for future research to specify conditions under which - and contexts in which - IFT-systems are prone to abuse by organized and terrorist groups.

235 According to Yin $(2003,2013)$, case studies findings are also generalizable or transferable, but their (analytical) generalizability is based on a different generalization approach than that of quantitative studies. Analytical generalization refers to making projections of the findings of a study to similar or other environments, based on a theoretical analysis of the factors producing outcomes and the effect of context. 
The limitations of this study may also raise several future research questions. One of the limitations of this study is the reliance on the IFT-case reports of a law enforcement authority that may be limited in being able to fully reflect the perspectives of IFT-brokers and IFT-users. Future research involving the recruitment of IFT-brokers or IFT-users may challenge the findings of this study, or reveal new aspects of IFTactivities that this study has missed. In particular, it would be useful to investigate whether trust in IFT-systems is different from that in formal remittance systems. Furthermore, it would be interesting to ask more specific questions, such as which type of risk IFT-brokers and IFT-users consider more serious: external or internal risk? And which coping mechanism works better from the point of view of IFT-brokers and IFTusers.

This study has made a few innovative attempts to investigate IFT-systems. Findings from such new approaches normally lead to follow-up research for verification and replication. This study constructed a global IFT-risk indicator, which is something that was never attempted in previous studies on IFT-systems. Thus, the findings of the global IFT-risk indicator are expected to generate more discussions and criticism than any other component of this study. While focusing on the construction of a composite indicator, this study seems to miss several aspects in the analysis of the relationship between the (overall) IFT-risk and the IFT-risk elements. In future research that may refine this instrument, it would be useful to investigate which IFT-risk element is more closely related to the (overall) IFT-risk 'within a specific income (or regional) group'.

In analyzing the data collected, this study came across several unfamiliar IFTtransactions ${ }^{236}$ that were not included in the research data. These challenging IFT-cases

\footnotetext{
236 Based on the IFT cases detected by the KCS in 2018 with respect to involvement of cryptocurrencies in IFT-systems, two types of abuse of cryptocurrencies by IFT-brokers can be distinguished: a means of cross-border transferring of funds and a means of settlement of outstanding debts between IFT-brokers. For instance, IFT broker A in Japan took funds from remitters who want to send funds from Japan to Korea. He bought cryptocurrency with the funds at a cryptocurrency market in Japan and sent it from his Japanese cryptocurrency wallet to his Korean cryptocurrency wallet. He sold it at a Korean cryptocurrency market. He transferred the funds in Korean currency to recipients via online-banking
} 
are expected to be used as a source for future research questions. After analyzing the 230 IFT-case reports, this study extracted three types of IFT-transactions - the prototypical type of IFT-transactions, the use of wire transfer, and the physical transfer of cash - according to how funds are transferred across borders. This classification is quite comprehensive in terms of encompassing all types of IFT-transactions. However, the KCS recently disclosed that several IFT-brokers transfer funds using 'cryptocurrencies' (Raymaekers, 2015; Scott, 2016). The emergence of IFT-transactions combined with cryptocurrency raises questions about how this new type of IFTtransactions differs from existing IFT-transactions, but also about what types of IFTusers prefer to use this type of IFT-transactions, and under what conditions or settings this type of IFT-transactions are usually carried out. More generally, as regards the use of new technologies by IFT-systems, it would be interesting to examine the impact new technologies, such as mobile technology, cryptocurrency, and big data, on the remittance market.

\subsection{Policy implications}

As discussed earlier, IFT-systems span multiple dimensions and involve a range of conflicting perspectives. Policy implications for IFT-systems accordingly include several policy issues. Previous studies on IFT-systems have referred to a number of different policies (Passas and Maimbo, 2008; Wang, 2011). Nevertheless, the main policies used to tackle IFT-systems merit to be re-examined for a better understanding of societal responses to IFT-systems. Specific policy recommendations derived from the global and local analyses were then presented. The review of the existing policies and

services. IFT broker B is a solo IFT broker operating in both Australia and Korea, making use of onlinebanking systems. Her IFT-business is primarily based on the normal IFT-business model. However, when the reserve fund at either bank account that she controls is about to be depleted, she transfers funds between the bank accounts by moving cryptocurrencies between his cryptocurrency wallets. In this respect, the roles of cryptocurrencies in the two cases are nearly the same as those of wire-transferring of formal financial institutions. However, no IFT-brokers detected relied totally on cryptocurrencies for cross-border transferring of funds. They mixed the other methods with cryptocurrencies. 
policy recommendations were made in terms of the use of the external and internal risks faced by IFT-systems.

\subsubsection{Two approaches to IFT-systems}

The attention on IFT-systems as an alternative channel for money laundering and the financing of terrorism technically stems from the development of AML/CFT regulations for 'the formal banking sector'. Increased supervision of the formal banking sector reportedly caused this shift. It encouraged criminal syndicates to look for alternative channels to launder their criminal proceeds; one of the possible channels for money laundering and the financing of terrorism were IFT-systems. According to Webb and his colleagues (2009), rapid policy changes disrupt the congruence between formal and informal institutional boundaries and generate create new opportunities in the informal economy. Likewise, the efforts of the global AML/CFT community focused on the formal banking sector offered IFT-systems new or expanded opportunities for money laundering and the financing of terrorism. In turn, increased concerns about the abuse of IFT-systems for money laundering and the financing of terrorism led to the development of various measures against IFT-systems (Razavy and Haggerty, 2009).

A number of countries have implemented enhanced regulatory measures to address IFT-systems, in accordance with the FATF Recommendations revised following the $9 / 11$ attacks. Actual responses to regulatory and supervisory measures vary from country to country (FATF, 2013a; Wang, 2011). The various measures against IFTsystems can be categorized into two groups according to the perspectives on IFTsystems: those who seek to suppress IFT-systems and those who support assimilation of IFT-systems into formal remittance systems. Those advocating the suppression of IFTsystems stress the potential for IFT-systems to be misused as a channel for money laundering and the financing of terrorism, tax evasion, or capital flight. They are also concerned about the unfair competition between IFT-systems and formal financial systems. They believe that the relative superiority of IFT-systems over formal financial institutions in terms of speed, cost and secrecy is attributed to the lack of formal 
supervision. They therefore argue that IFT-systems should be subject to the same rules and regulations that formal financial institutions comply with. Furthermore, according to them, IFT-systems that do not meet the standard regulations should be penalized (Van de Bunt, 2008a). However, those seeking to integrate IFT-systems into formal remittance systems in the form of MVTS claim that rigorous measures against IFTsystems not only block the necessary money flows to the least developed countries, but also push IFT-systems further 'underground'. They thus suggest that IFT-systems should not be placed under the same level of financial supervision as formal financial institutions, in order to preserve the advantages of IFT-systems in transferring small amounts (Passas, 2005b; Soudijn, 2015). In other words, while the 'tough' approach focuses on detecting and tackling IFT-systems that do not comply with regulations, the 'soft' approach seeks to provide incentives for IFT-systems to come under government supervision of their own accord (Todoroki et al., 2014). Predicate offenses that frequently involve the use of IFT-systems may influence the determination of a stance with respect to IFT-systems. For instance, countries where IFT-systems are often associated with organized crimes are likely to take a tough approach to IFT-systems. Countries with an extensive informal economy may also adopt a tough approach to IFTsystems that play a role in supporting and expanding the informal economy. Both approaches aim to place IFT-systems under government supervision, although they differ in terms of the level of control. It should be noted that it is a challenging task to bring to light IFT-systems operating in secret, with the aim of regulating them.

Measures against IFT-systems also tend to vary according to the sending and receiving countries. Sending countries usually have more developed financial sectors and have fairly liberal foreign exchange policies (Passas, 2006a). Receiving countries use different approaches to IFT-systems depending on their foreign exchange policies, the quality of their formal financial sectors, and their level of political stability. Therefore, sending countries put measure in place to prevent the potential abuse of IFTsystems by criminals. Their primary policy measures include requirements related to registration or licensing, customer reporting, and record keeping. The regulatory measure of receiving countries range from prohibition to neglect (El Qorchi et al., 2003). 
This proves how challenging it is to develop globally harmonized measures against IFTsystems (El Qorchi et al., 2003). This study did not attempt to find a harmonized solution to the conflicting approaches. Based on findings from studies on the informal economy, which includes IFT-systems, this study provides suggestions to consider when developing and applying AML/CFT measures against IFT-systems.

\subsubsection{Considerations in developing anti-IFT-systems measures}

According to scholars examining the relationships between the informal economy and the 'competence of governments' (Webb et al., 2012), there is a general belief in developing countries that it is more efficient for businesses to operate informally. The governments of developing countries are generally incompetent in providing social security and social infrastructure, and in ensuring compliance with rules and regulations. Thus, the benefits (e.g., certain social security and reliable infrastructure) of working within the formal economy do not outweigh the disadvantages (e.g., paying taxes and compliance with regulatory constraints) (Todoroki et al., 2014; Webb et al., 2012). Likewise, since governments in fragile states are often either absent or weak, there are few competent authorities to implement global AML/CFT standards and to suppress money laundering and the financing of terrorism via IFT-systems (Houssein, 2005; Omer, 2002; Passas, 2015; Passas and Maimbo, 2008). In fragile states, the benefits of IFT-systems outweigh the costs that IFT-users or IFTbrokers must bear. Thus, fragile states where remittances are primarily received via IFT-systems are exposed to higher IFT-risk levels than other countries ${ }^{237}$ (Kimenyi et al., 2010). In contrast, the governments of developed countries, which are mostly remittance-sending countries, have enough 'capacity' to comply with global AML/CFT standards and implement AML/CFT regulations; they have more resources and more sophisticated regulatory authorities with experienced supervisors (Todoroki et al., 2014). However, the ways of addressing and regulating IFT-systems somewhat differ from country to country (FATF, 2013a; Todoroki et al., 2014; Wang, 2011). Strict AML/CFT

237 The IFT-risk values from the global IFT-risk indicator have verified this proposition. 
regulations ${ }^{238}$ can lead to small-scale MVTS becoming IFT-systems. In some developed countries, for instance, AML/CFT regulations impose strict requirements on remittance service providers. This makes it costly to register small-scale MVTS with the government. It also makes it difficult to maintain partnerships with formal financial institutions ${ }^{239}$. In addition, heightened enforcement of AML/CFT regulations leads to the exclusion of marginalized customers (e.g., illegal immigrants) from using formal remittance services. This, in turn, prompts those customers to search for IFT-systems (Todoroki et al., 2014). As a result, strict registration and reporting requirements, and strict enforcement in the regulated sector can only mitigate the risks 'within the sector'. Such financial exclusion to mitigate the risks of money laundering and the financing of terrorism within the formal remittance network may lead to increased risks related to money laundering and the financing of terrorism via IFT-systems. For instance, the improved oversight of formal remittance institutions over the sources of remittances may result in small businesses without proper documents relying on IFT-systems. This in turn could lead to IFT-users abusing IFT-systems to launder proceeds obtained from tax evasion or other criminal businesses, which probably would not have occurred within the formal remittance network. Therefore, measures against IFT-systems must find a balance ${ }^{240}$ between maintaining financial integrity and ensuring financial inclusion (Todoroki et al., 2014; Passas and Maimbo, 2008).

238 A survey study conducted by the World Bank (Todoroki et al., 2014) shows that remittance-sending countries are stricter in controlling remittance market entry than remittance-receiving countries, in terms of legal status, experience, fit and proper due diligence, AML compliance plan, and capital requirement. In addition, all the surveyed remittance-sending countries viewed unauthorized provision of remittance transfer services as a criminal violation and applied sanctions such as imprisonment and criminal fines. However, some remittance-receiving countries dealt with unauthorized remittance transfer operations with administrative fines only.

239 Many entrepreneurs favor operating in the formal economy. However, they face numerous sources of costs and lengthier process of acquiring licenses or authorization. The costs imposed by bureaucracy force some entrepreneurs to operate informally (Portes and Haller, 2005; Webb et al., 2012).

240 Portes and Haller (2005) provide a view that excessive tolerance of informal economic activities would compromise the credibility of the rule of law and the willingness of formal businesses and taxpayers to take on their obligations; on the other hand, repressive stances against informal businesses would get rid of the buffer provided by informal activities or drive them further underground. 
Another element to consider when designing and implementing AML/CFT measures against IFT-systems is that IFT-systems are informal businesses that can easily transform to the formal economy. According to Webb and his colleagues (2009), the more informal businesses grow, the more they are exposed to the risk of detection by law enforcement authorities because of their increased visibility. The increased risk of detection may provide informal businesses with a motive to transfer to the formal economy. However, not all informal businesses exposed to a higher risk of detection can successfully switch to the formal economy. Webb and his colleagues (2009) argue that informal businesses that are under great pressure to transfer immediately are least likely to be able to do so successfully. As informal businesses that 'produce clearly illegal products or services' (e.g., counterfeit goods) are exposed to a greater risk of being targeted by law enforcement authorities, they may be under greater pressure to switch to the formal economy - or leave the informal economy - than those that 'use illegal elements' in the producing process (e.g., hiring illegal migrants). Informal businesses 'using illegal means' in the production process may have less difficulty in redefining their businesses and in adapting to the formal economy than those 'producing illegal products or services'. This is because replacing illegal means with lawful means involves less uncertainty and less risk than developing new products or services that comply with rules and regulations. IFT-systems provide an illegal form of remittance services. Since their illegality stems from non-compliance with the conditions for providing remittance services stipulated by governments, the illegality is not likely to be removed by changes in the remittance procedures. Most IFT-brokers may refuse to transfer to formal MVTS because the qualifications for formal MVTS are demanding, and IFT-brokers who transfer to formal MVTS may not be able to provide the same competitive remittance services as before.

In addition to government policies and law enforcement efforts, some scholars (Portes and Haller, 2005) call on civil society to engage in the fight against the informal economy. They argue that the informal economy is likely to shrink when effective regulation of informal economic activities is strengthened by a civil society that strongly 
endorses the formal economy and makes use of legal means to resolve complaints. In these situations, it is civil society itself rather than governments that acts as the enforcer of legal rules. Informal businesses that civil society rejects usually disappear. Despite the valuable role that civil society can play in the fight against the informal economy, this approach is only part of the broader fight against IFT-systems. In developed countries, which provide prominent access to formal remittance systems, IFT-systems normally just remain 'in existence' although they can proper - to some extent prosper in ethnic enclaves. Civil society in developed countries can play a role in restricting IFT-activities within ethnic enclaves. In developing countries with limited access to formal remittance systems, IFT-systems may work as an important crossborder remittance channel that replace formal remittance networks of poor quality. As such, civil society in developing countries may support or promote IFT-systems rather than suppress them, given that IFT-systems addressed the need of civil society for inexpensive cross-border remittance services.

When the responses of the Korean government and civil society to IFT-systems are assessed based on the three aforementioned considerations, the question may arise whether they deal adequately with IFT-systems. The Korean government has implemented regulations prohibiting IFT-systems that are compliant with the FATF Recommendations, but its law enforcement authorities give low priority to IFT-systems. It can therefore be argued that the Korean government's approach is not stringent enough to suppress the flows of remittances via IFT-systems in the fight against IFTsystems. Instead, as discussed earlier, the Korean government has recently allowed nonconventional financial companies to transfer small amounts across borders. However, this policy is unlikely to contribute to the reduction of IFT-systems in Korea, although some IFT-users may switch from IFT-systems to small formal remittance companies for their transfers. Given that the policy is based on strict requirements that most IFTbrokers will not be able to meet, they are unlikely to give up their IFT-businesses. When it comes to the role of Korean civil society in the fight against IFT-systems, there are few data to showing its position - i.e., in favor of or against IFT-systems. Given an estimate on the size of the informal economy in Korea $22.5 \%$ in Korea and $8.6 \%$ in the 
Netherlands in 2014) (Medina and Schneider, 2019), the role of Korean civil society in suppressing IFT-systems may be somewhat limited.

\subsubsection{Policy Recommendations}

All discussions considered, however mature the formal financial sector may be, and however seriously AML/CFT measures are implemented, IFT-systems can survive in the remittance market. Conditions for their survival may be that the incentives to use IFT-services outside the formal financial institutions continue to exist, and that IFTsystems can avoid the external risks and cope with the internal risks. The existing measures against IFT-systems generally aim to increase the external risks faced by IFTsystems. Governments may either tackle IFT-systems, make formal remittance systems more accessible (e.g., lowering remittance fees), or encourage IFT-systems to transfer to the formal remittance system through registration or licensing (e.g., lowering the threshold for registration or licensing) (Passas and Maimbo, 2008; Wang, 2011). That said, IFT-systems continue to survive, albeit in their social niches. The harm caused by IFT-systems may not be clearly visible and direct; law enforcement authorities therefore seem to give low priority to IFT-systems ${ }^{241}$. As Lanier and Henry's crime prism (Lanier and Henry, 2010) suggests, the lack of interest from law enforcement authorities in IFTsystems does not necessarily mean that the societal harm caused by IFT-systems is negligible and that societal responses to IFT-systems are unnecessary. IFT-systems play a pivotal role in supporting and expanding the informal economy as they act as a conduit that circulates the proceeds obtained from informal economic activities. IFT-systems tend to grow by applying new methods and adapting to evolving environments, especially if AML/CFT measures against IFT-systems are not strict. In order to tackle steadfast and competitive IFT-systems that refuse to transition to formal remittance channels, withstand law enforcement operations, and survive measures that attack their

\footnotetext{
241 In fact, containment of IFT-systems in ethnic enclaves might have been achieved with a considerable amount of law enforcement attention. As long as IFT-systems stay within ethnic enclaves, societal responses to them may be minimal. However, once IFT-systems creep out of social niches, they may draw a great deal of law enforcement attention.
} 
edges (e.g., lowering barriers to access formal remittance channels), this study, based on the findings of the analysis of the Korean IFT-systems, suggests a two-pronged strategy: to make it difficult for IFT-brokers to handle IFT-related external and internal risks, and to ensure that IFT-users leave IFT-systems by removing (or reducing) incentives to use IFT-systems. Both proposed strategies are based on a situational crime prevention approach and a behaviorally informed approach. The established approach to IFT-systems seem to assume that most IFT-systems are identifiable and susceptible to remittance policies and AML/CFT measures. However, IFT-systems are an inherently elusive subject and take advantage of the absence of government control. It may be effective and efficient to tackle the social ecology on which IFT-systems are dependent. A situational crime prevention approach and a behaviorally informed approach would benefit this strategy given that the two approaches have strength in addressing specific contexts.

The situational crime prevention approach ${ }^{242}$ is based on the assumption that "rather than large-scale changes influencing crime, it is small changes that matter" (Coyne and Eck, 2015: 15). The situational crime prevention approach provides five strategies ${ }^{243}$ that modify situations conducive to the occurrence of crime: increasing the perceived effort that the offender must make, increasing the perceived risks that the offender faces, reducing the rewards that the offender expects to obtain, removing the excuses that the offender may use to rationalize his actions, and reducing the provocations that may tempt the offender (Cornish and Clarke, 2003). The situational crime prevention approach can offer a great number of intervention measures, as this approach focuses on specific types of crimes and specific opportunity structures for them (Clarke, 2005). Among possible tactics derived from the situational crime prevention approach, this study attends to the role of situational crime prevention that

242 The situational crime prevention approach focuses on the role that immediate circumstances play in producing criminal acts, thereby aiming to prevent crime by reducing opportunities for offending (Bowers and Johnson, 2016; Clarke, 1997; Wortley and Tilley, 2014).

243 Cornish and Clarke (2003) categorized 25 situational crime prevention techniques into the five strategies. Expounding 25 situational crime prevention techniques is beyond the scope of this study. 
restricts 'resources ${ }^{244}$ ' for offending, given that offenders can only exploit potential crime opportunities if they have the resources to use them. In other words, as the existing 25 techniques for situational prevention are mostly associated with street or violent crimes (Von Lampe, 2011), this study instead focuses on the principle of the situational crime prevention — reducing opportunities for crime (Clarke, 2005), and in particular the findings from the local analysis showing the importance of resources that IFT-brokers mobilize for IFT-transactions. Resources are thus essential for committing crimes, as they help offenders manage all types of risks and take advantage of more and different opportunities. According to scholars and law enforcement authorities, resources for offending can help explain patterns of crime events, as well as identify potential ways to prevent crime. A potential offence may therefore be prevented when a motivated offender lacks the skills, knowledge, and tools to commit the offence (Ekblom and Tilley, 2000; Gill, 2005). This study suggests addressing the 'resources' that strengthen IFT-systems in order to suppress them (Ekblom and Tilley, 20oo; Gill, 2005). According to the findings on IFT-systems in Korea, IFT-brokers, among others, actively use two types of resources: legitimate businesses and the online banking services of formal financial institutions. Therefore, in order to suppress IFT-systems, policy makers should develop measures to prevent IFT-brokers from using these resources. This is consistent with the three strategies ${ }^{245}$ of the situational crime prevention approach: increasing the effort involved in offending, increasing the risk associated with offending, and reducing the excuses for offending behavior (Gill, 2005). For instance, when IFT-brokers who use legitimate businesses as a cover for IFT-systems are sentenced, their legitimate businesses that benefit IFT-businesses should also be

\footnotetext{
244 Reiner (2000) indicates 'resources' as one element of five elements for crime occurrence: labelling of a certain behavior as criminal, at least one motivated offender, the means for the offender to commit crime, crime opportunities, and the absence of effective control. Gill (2005) expands the scope of resources for offending to include not only facilitatory resources (e.g., tools and weapons) but also personal resources, cognitive resources, moral resources, and collaborative resources.

245 Among the five situational crime prevention strategies, the reward reduction strategy and the provocation reduction strategy may not fit in the fight against IFT-systems. It is infeasible for the governments or formal financial institutions to raise costs or reduce rewards of IFT-brokers. The emotions of IFT-brokers or IFT-users are rarely involved in IFT-transactions.
} 
shut down ${ }^{246}$. IFT-brokers who have lost legitimate businesses may have difficulty recovering lost customers. They would soon realize that running IFT-businesses without legitimate veneers requires more effort and is riskier than before. This measure should also empower local governments to tackle IFT-systems as it would allow them to better monitor legitimate businesses operating in conjunction with IFT-systems. As discussed earlier, the use of online banking services by IFT-brokers may not yet have been frequently reported in other countries. Since online banking services provide IFTbrokers with a powerful tool to manage internal risks, they may be a strategic element in the fight against IFT-systems in Korea. However, it may not be feasible to systematically prevent IFT-brokers from using online banking services, as not a single IFT-broker would inform a bank teller of their IFT-business plans before or while carrying out IFT-transactions. Instead, formal financial institutions should intensively monitor and examine bank accounts that are managed in foreign countries through online banking services and where domestic deposits or withdrawals frequently take place. Since many IFT-brokers use bank accounts borrowed from others, formal financial institutions can tackle the exploitation of bank accounts by IFT-brokers through removing excuses for ignorance of lending (or borrowing) bank accounts to (from) someone else. Formal financial institutions should regularly inform the actual owners of bank accounts, not only of the rule that bank accounts must not be lent to or shared with - anyone else, but also of the types of transactions that occur on their bank accounts (i.e., how their accounts are exploited). This could for example be done by means of mobile phone ${ }^{247}$ messages. In addition, financial supervisory authorities, in consultation with law enforcement authorities, should consider suspending — or closing -, all bank accounts, including borrowed ones, that are involved in IFTbusinesses for a certain period time. Consideration should also be given to imposing restrictions on people who have a history of working in — or with - IFT-businesses,

246 This suggestion shares the basic idea with the confiscation or seizure of vehicles or vessels carrying smuggled goods or illegal migrants exercised in many countries.

247 IFT-brokers can borrow bank accounts from someone else. However, mobile phones whose numbers are submitted to formal financial institutions for opening bank accounts are rarely lent to someone else. 
when opening bank accounts. When it comes to the effectiveness of the recommended interventions, there is no evaluation on the effectiveness of them yet. However, business management scholars (Webb et al., 2012) discussed a policy that formal companies cut their ties with informal suppliers to reduce the scope of the informal economy ${ }^{248}$. The measure of closing the bank accounts of IFT-brokers was already adopted in the U.S. ${ }^{249}$ and the U.K.; other countries followed suit (Gordon et al., 2018). There was a critical view that this would involve collateral damage on the Somali economy (Passas and Maimbo, 2008; Plaza, 2014). Nevertheless, the closing of bank accounts seems to be widely used in a way of tackling and preventing crime in several countries (Monaghan, 2019). With respect to the effectiveness of the situational crime prevention approach, there are a few studies that simply present ideas regarding application of the situational crime prevention approach to money laundering (Gilmour, 2016; Kleemans et al., 2013; Von Lampe, 2011). However, According to Bowers and Johnson's study (2016) that conducted a systematic review of situational crime prevention measures, most situational measures (e.g., CCTV, street lighting, public area surveillance, repeat victimization strategies, and neighboring watch) are effective in reducing the levels of crime or victimization. Clarke and Newman argue (2007) that the success of situational crime prevention depends on gaining sufficient control over particular environments or situations.

A behaviorally-informed approach - or nudging techniques - recently developed by behavioral scientists can also be adopted to tackle IFT-systems. According

248 According to Webb and his colleagues (2009), development of effective laws to remove economic barriers to the formal economy as well as specific policies targeting informal businesses may reduce the scope of the informal economy and motivate informal businesses to transit to the formal economy. They also argue that policies that require large formal economy firms to sever their ties with informal suppliers can be useful in limiting the scope of the informal economy. Given that many IFT-brokers make use of formal financial institutions' services, national authorities may need to adopt a policy that requires formal financial institutions to close bank accounts of IFT-brokers disclosed.

249 Many US banks, in consultation with federal supervisory authorities, closed the bank accounts of some MVTS who allegedly failed to comply with due diligence and know your customer rules, and refused to open new ones (Passas and Maimbo, 2008). 
to behavioral scientists, "nudges are private or public initiatives that steer people in particular directions but that also allow them to go their own way" (Sunstein, 2018: 61). They argue that small changes in choice architecture can have a significant impact on behavior (Halpern, 2015; Sunstein, 2017). In other words, relatively minor pressures "can launch potent forces that are stored within a system" because those potent forces are often associated with basic human motivations (Cialdini et al, 2015: 25). According to Baldwin (2014: 835), nudges "vary in the degree to which they impact on the autonomy of individuals as decision-makers." He categorizes various nudges into three degrees according to the extent nudges intrude the decision-making autonomy of individuals. First degree nudges respect the decision-making autonomy of individuals and aim to enhance decision-making through 'the supply of simple information or the imparting of reminders ${ }^{250}$ (e.g., reminders to fill in tax return).' Second degree nudges "build on behavioral or volitional limitations so as to bias a decision in the desired direction" (e.g., opt-out organ donor regime) (Baldwin, 2014: 835). Third degree nudges involve behavioral manipulation by shaping the decisions and preferences of individuals (e.g., photographs of lung cancer victims on cigarette packs). The targeted individuals automatically respond to the second- and third-degree nudges with limited or no awareness and reflection. Baldwin differentiates between the degree of a nudge and a way of nudging. A nudging technique, such as supplying information, can be used for first, second, or third-degree nudging. Among the various nudging techniques, this study recommends the provision of 'information, reminders, or warnings ${ }^{251}$ ' as a way of making IFT-systems collapse, or at least hemorrhage.

250 Some scholars argue that simple provision of information does not fall under nudges (John et al., 2009). However, Thaler and Sunstein (2008) provide a number of examples of simple information provision as nudging techniques. According to John and his colleagues (2009), whereas the essence of 'nudging' is to control individuals by exploiting their cognitive and emotional limitations, 'think' strategy seeks to improve individuals' capacities to exercise informed, rational, and conscious choices by supplying information that will be used in reflective decision-making (Baldwin, 2014). A discussion of whether simple information provision falls under nudging techniques is beyond the scope of this study. This study follows Thaler and Sunstein's work and Baldwin's perspective on nudges.

251 According to Cialdini and his colleagues (2015), providing information, reminders, or warning is associated with 'accuracy motivation' among the three basic human motivations - accuracy motivation, affiliation and approval, and seeing oneself positively. In other words, as "people are motivated to be 
Unlike IFT-brokers in sending and receiving countries who are, as the core actors, aware of the illegality of IFT-businesses in IFT-systems, the peripheral actors, such as facilitators (e.g., bank account lenders and cash couriers) and IFT-users, might not have full knowledge of the status of IFT-businesses. They may also not be fully aware of the intentions of IFT-brokers and of the repercussions of IFT-systems. It would therefore be useful to inform prospective IFT-users (or recurrent IFT-users) of the illegality of IFT-systems in order to stop (or prevent) IFT-users from trusting IFT-brokers and to keep them away from (or make them cut ties with) IFT-brokers. Many IFT-systems tend to camouflage their IFT-businesses as informal foreign exchange businesses. Formal remittance systems should therefore notify remitters or prospective IFT-users that the use of informal exchange businesses is illegal. This idea might not have been subject to empirical study or evaluation. However, according to a survey study recently conducted in the U.K. (Alpin and Holkar, 2019), many people believe that their financial data should be used to identify financial problems and offer help. Financial institutions are recently asked to do more to protect their customers from fraud or scams (Cook, 2018).

A leniency program can also be considered in the fight against IFT-systems. As discussed earlier, IFT-systems are rarely visible and pose little immediate threat - and cause no direct harm - to society, apart from the serious consequences of involvement in money laundering and the financing of terrorism. The 'crime stoppers programs' implemented in most countries to acquire anonymous crime tips may not be effective in detecting IFT-systems. It is difficult to detect IFT-activities without the cooperation of the insiders of IFT-systems. In the area of antitrust law and policy, leniency programs

accurate in their perceptions, decisions, and behaviors", "they must have an accurate perception of reality." Thus, reminders or warnings informing "how similar others are acting or were acting in a particular way within a situation" suggest what a good choice is (Cialdini et al, 2015: 26). The nudge scientists (Cialdini et al, 2015; Halpern, 2015) take as example the UK tax authority's nudge letter that collected 560 million GBP out of 650 GBP owed with a simple new sentence saying that the vast majority of UK citizens who pay their taxes on time. 
that offer immunity or reduced sanctions ${ }^{252}$ to cartel member who provide information to antitrust authorities are used to detect cartel activities (Luz and Spagnolo, 2017). Some studies have proven that leniency can also be effective in curtailing tax evasion and corruption (Buckenmaier et al., 2018). If experienced IFT-users who provide information about IFT-brokers are provided immunity in return ${ }^{253}$, law enforcement authorities would be able to easily detect IFT-systems. IFT-brokers also can provide law enforcement authorities with information ${ }^{254}$ regarding the IFT-transactions of their customers, for example in the case of drug traffickers or organized crime groups, in exchange for immunity. A leniency program can play an important role in amplifying the internal risks related to IFT-activities and in hindering the development of mutual trust.

\subsection{Epilogue}

This study may increase criminologists' attention to IFT-systems, not only because of their intriguing working mechanisms and alleged connections to organized

\footnotetext{
252 Even though leniency programs may look somewhat similar to plea bargaining in terms of reduced sanctions, they differ in several dimensions. Whereas leniency programs aim to induce spontaneous selfreports from cartel members, thereby launching investigations based on the self-reports, plea bargaining occurs after the start of an investigation. Whereas leniency programs guarantee automatic leniency, the amount of amnesty in plea bargaining is uncertain and depends more closely on the evidence held by prosecutors (Choi and Gerlach, 2015).

253 IFT-users can inform law enforcement authorities of IFT-brokers by means of crime stoppers programs. However, as mentioned earlier in Chapter 6, unless IFT-users use IFT-systems for money laundering or financing of terrorism, IFT-users are normally not a target of law enforcement authorities in the fight of IFT-systems. However, there is no guarantee that IFT-users who report IFT-brokers to law enforcement authorities are excluded from investigations and sanctions. In addition, crime stoppers programs may be limited in encouraging IFT-brokers to report their customers to law enforcement authorities.

254 According to Passas's study (2015: 5), "terrorist and drug trafficking operations have been discovered in India and the UAE, thanks to the cooperation of hawaladars. Funds sent from Yemen to Kenya to finance the bombing of the US embassy were recorded in hawala ledgers that were kept for years and produced in New York courts as evidence." "When properly approached, hawala networks can be a great asset against money laundering and terrorism financing, rather than the obstacle they are often considered to be."
} 
crime groups, including terrorist groups, but also because of the ambiguity of the concept in various circumstances and the different societal responses to them.

Discussions will continue to take place about the legitimacy and the harm inflicted by IFT-systems. Some scholars may not be convinced that IFT-systems merit a law enforcement response at all in some (developing) countries. However, even in countries where IFT-systems are considered illegal and illegitimate, law enforcement may not be able to be mobilized to tackle IFT-systems as often as envisaged or expected. This is mainly due to limited resources and the fact that violent crimes are prioritized by law enforcement agencies. The findings of this study suggest that, in addition to law enforcement efforts, many crime prevention practices and 'nudge' measures can be used to tackle IFT-systems. Societal responses to IFT-systems could serve as a reference for combating similar crimes falling into the lower part of the crime prism.

In order to investigate IFT-systems, it may be necessary to use two lenses crime and informal economy - at the same time. This approach may sound contradictory, as informal fund transfer systems are illegal. As illustrated by the three 'pictures' - the panoramic shot, medium shot, and close-up shot - described in this study, IFT-systems cannot be properly illustrated with a single picture. IFT-systems merit future research from the perspective of informal economies, as this perspective examines both the ecosystem in which IFT-systems are embedded and IFT-systems on their own. This would make it possible to examine IFT-systems as a whole.

This study could serve as the basis for a more detailed photo album that would include future research on this subject. 
References

\section{References}

Agran, P., Castillo, D., and Winn, D. (1990). Limitations of Data Compiled from Police Reports on Pediatric Pedestrian and Bicycle Motor Vehicle Events. Accident Analysis and Prevention, 22(4): 361-370.

Al-Hamiz, S. (2005). Hawala: A U.A.E. Perspective. In International Monetary Fund (eds.), Regulatory frameworks for hawala and other remittance systems (pp. 3034). Washington D.C.: IMF.

Alpin, K. and Holkar, M. (2019). Data Protecting: Using Financial Data to Support Customers. London: Money and Mental Health.

Andresen, M. and Felson, M. (2010). The Impact of Co-offending. British Journal of Criminology, 50(1): 66-81.

Anderson, A. (1995). Organized Crime, Mafia, and Governments. In G. Fiorentini and S. Peltzman (eds.), The Economics of Organized Crime (pp. 33-53). New York: Cambridge University Press.

Anfara, V. and Mertz, N. (2015). Setting the Stage. In V. Anfara and N. Mertz (eds.), Theoretical Frameworks in Qualitative Research (pp. 1-20). Thousand Oaks: Sage.

Antia, K., Bergen, M., Dutta, S., and Fisher, R. (2006). How Does Enforcement Deter Gray Market Incidence? Journal of Marketing, 70(1): 92-106.

Arezki, R., Rota-Graziosi, G., and Senbet, L. (2013). Capital Flight Risk. Finance and Development, 50(3): 26-28.

Ashforth, B. and Mael, F. (1989). Social Identity Theory and the Organization. Academy of Management Review, 14(1): 20-39.

Arndt, C. and Oman, C. (2006). Uses and Abuses of Governance Indicators. Paris: Organization for Economic Cooperation and Development.

Baker, D. (2007). Introduction. In R. Buswell (eds.), Religions of Korea in Practice (pp. 1-34). Princeton: Princeton University Press.

Baker, S. and Edwards, R. (2012). How Many Qualitative Interviews are Enough? Expert Voices and Early Career Reflections on Sampling and Cases in Qualitative Research. National Centre for Research Methods Review Paper. 
Baldwin, R. (2014). From Regulation and Behavior Change: Giving Nudge the Third Degree. The Modern Law Review, 77(6): 831-857.

Ballard, R. (2005). Coalitions of Reciprocity and the Maintenance of Financial Integrity within Informal Value Transmission Systems: The Operational Dynamics of Contemporary Hawala Networks. Journal of Banking Regulation, 6(4):319-352. Bank for International Settlements (BIS). (2015). Corresponding Banking. Basel: BIS. Bank for International Settlements (BIS). (2006). General Guidance for National Payment System Development. Basel: BIS.

Bank for International Settlement (BIS) and the World Bank. (2007). General Principles for International Remittance Services. Basel: BIS.

Basit, T. (2003). Manual or Electronic? The Role of Coding in Qualitative Data Analysis. Educational Research, 45(2): 143-154.

Beck, T. Demirguc-Kunt, A., and Martinez Peria, M. (2005). Reaching Out: Access to and Use of Banking Services Across Countries. World Bank Policy Research Working Paper 3754. Washington D.C.: The World Bank Group.

Beck, T. and Martínez Pería, M. (2011). What Explains the Price of Remittances? An Examination Across 119 country Corridors. The World Bank Economic Review, 25(1): 105-131.

Beckert, J. and Wehinger. F. (2013). In the Shadow: Illegal Markets and Economic Sociology. Socio-Economic Review, 11 (1): 5-30.

Blommaert, J. (2001). Context is/as Critique. Critique of Anthropology, 21(1): 13-32.

Boeije, H. (2002). A Purposeful Approach to the Constant Comparative Method in the Analysis of Qualitative Interviews. Quality and Quantity, 36(4): 391-409.

Booysen, F. (2002). An Overview and Evaluation of Composite Indices of Development. Social Indicators Research, 59(2): 115-151.

Botero, J., Nelson, R., and Pratt, C. (2011). Indices and Indicators of Justice, Governance, and the Rule of Law: An Overview. Hague Journal on the Rule of Law, 3(2): 153-169.

Bouchard, M. and Morselli, C. (2014). Opportunistic Structures of Organized Crime. In L. Paoli (eds.), The Oxford Handbook of Organized Crime (pp. 288-302). New York: Oxford University Press. 
Bouchard, M. and Wilkins, C. (2012). Illegal Markets and the Economics of Organized Crime. New York: Routledge.

Bowen, G. (2009). Document Analysis as a Qualitative Research Method. Qualitative Research Journal, 9(2): 27-40.

Bowen, G. (2008). Naturalistic Inquiry and the Saturation Concept: A Research Note. Qualitative Research, 8(1): 137-152.

Bowers, K. and Johnson, S. (2016). Situational Prevention. In D. Weisburd, D.

Farrington, and C. Gill (eds.), What Works in Crime Prevention and Rehabilitation: Lessons from Systematic Reviews (pp. 111-135). New York: Springer.

Boyatzis, R. (1998). Transforming Qualitative Information: Thematic Analysis and Code Development. Thousand Oaks: Sage.

Braun, V. and Clarke, V. (2006). Using Thematic Analysis in Psychology. Qualitative Research in Psychology, 3(2): 77-101.

Brown, J. (2009). Choosing the Right Type of Rotation in PCA and EFA. JALT Testing and Evaluation SIG Newsletter, 13(3): 20-25.

Brown-Hruska, S. (2016). Developments in Bank Secrecy Act and Anti-Money Laundering Enforcement and Litigation. New York: NERA Economic Consulting.

Bruinsma, G. and Bernasco, W. (2004). Criminal Groups and Transnational Illegal Markets. Crime, Law, and Social Change, 41(1): 79-94.

Buckenmaier, J., Dimant, E., and Mittone, L. (2018). Effects of Institutional History and Leniency on Collusive Corruption and Tax Evasion. Journal of Economic Behavior and Organization. Advance online publication. doi: 10.1016/j.jebo.2018.04.004.

Burstein, P. (2003). The impact of Public Opinion on Public Policy: A Review and an Agenda. Political Research Quarterly, 56(1): 29-40.

Busuioc, E. (2007). Defining Money Laundering. In B. Unger (eds.), The Scale and Impacts of Money Laundering. Cheltenham: Edward Elgar Publishing Limited. 
Buencamino, L. and Gorbunov, S. (2002). Informal Money Transfer Systems:

Opportunities and Challenges for Development Finance. DESA Discussion Paper No. 26. Washington D.C.: United Nations.

Casey, J. (2007). Dealing with Hawala: Informal Financial Centers in the Ethnic

Community. FBI Law Enforcement Bulletin, 76(2): 10-14.

Chapman, J., Higgins, A., and Hales, G. (2017). Police Effectiveness in a Changing

World: Slough Site Report. London: The Police Foundation.

Cheng, H. and Philips, M. (2014). Secondary Analysis of Existing Data: Opportunity and Implementation. Shanghai Archives of Psychiatry, 26(6): 371-375.

Chesbrough, H. (2010). Business Model Innovation: Opportunities and Barriers. Long Range Planning, 43(2-3):354-363.

Choi, J. and Gerlach, H. (2015). Cartels and Collusion: Economic Theory and Experimental Economics. In R. Blair and D. Sokol (eds.), Oxford Handbook of International Antitrust Economics, Volume 2 (pp. 415 441). New York: Oxford University Press.

Cialdini, R., Martin, S., and Goldstein, N. (2015). Small Behavioral Science - Informed Changes Can Produce Large Policy-relevant Effects. Behavioral Science and Policy, 1(1): 21-27.

Clarke, R. (2005). Seven Misconceptions of Situational Crime Prevention. In N. Tilley (eds.), Handbook of Crime Prevention and Community Safety (pp. 39-70). Devon: Willan Publishing.

Clarke, R. (1997). Introduction. In R. Clarke (eds.), Situational Crime Prevention: Successful Case Studies (pp. 2-43). Guilderland: Harrow and Heston.

Clarke, R. and Cornish, D. (1985). Modeling Offenders' Decisions: A Framework for Research and Policy. Crime and Justice, 6: 147-185.

Coleman, J. (1990). Foundations of Social Theory. Cambridge: Harvard University of Press.

Coleman, C., and Moynihan, J. (1996). Understanding Crime Data: Haunted by the Dark Figure. Buckingham: Open University Press.

Cook, K. (2001). Trust in Society. In K. Cook (eds.), Trust in Society (pp. xi-xxviii). Thousand Oaks: Sage. 
Cook, K., Cheshire, C., and Gerbasi, A. (2006). Power, Dependence, and Social Exchange. In P. Burke (eds.), Contemporary Social Psychological Theories (pp. 194-216). Stanford: Stanford University Press.

Cook, K., Cheshire, C., Rice, E., and Nakagawa, S. (2013). Social Exchange Theory. In J. DeLamater and A. Ward (eds.), Handbook of Social Psychology (pp. 61-88). Dordrecht: Springer.

Cook, K. and Rice, E. (2006). Social Exchange Theory. In J. Delmater (eds.), Handbook of Social Psychology (pp. 53-76). New York: Springer.

Cook, K., Rice, E., and Gerbasi, A. (2004). The Emergence of Trust Networks under Certainty: The Case of Transitional Economies - Insights from Social Psychological Research. In J. Kornai, B. Rothstein, and So. Rose-Ackerman (eds.), Creating Social Trust in Post-Socialist Transition (pp. 193-212). New York: Palgrave Macmillan.

Cook, L. (2018, March 6). What More can Banks and their Customers Do to Fight Fraud. Financial Times.

Cornish, D. and Clarke, R. (2003). Opportunities, Precipitators, and Criminal Decisions: A Reply to Wortley's Critique of Situational Crime Prevention. In M. Smith and D. Cornish (eds.), Crime Prevention Studies, Volume 16 (pp.41-96). Monsey: Criminal Justice Press.

Cornish, D. (1994). The Procedural Analysis of Offending and Its Relevance for Situational Prevention. In R. Clarke (eds.), Crime Prevention Studies, Volume 3 (pp. 151-196). Monsey: Criminal Justice Press.

Cortina, J. (1993). What is Coefficient Alpha? An Examination of Theory and Applications. Journal of Applied Psychology, 78(1): 98.

Coyne, I. (1997). Sampling in Qualitative Research, Purposeful and theoretical Sampling: Merging or Clear Boundaries? Journal of Advanced Nursing, 26(3): 623-630.

Coyne, M. and Eck, J. (2015). Situational Choice and Crime Events. Journal of Contemporary Criminal Justice, 31(1): 12-29. 
Crabtree, B. and Miller, W. (1999). Using Codes and Code Manuals: A Template Organizing Style of Interpretation. In B. Crabtree and W. Miller (eds.), Doing Qualitative Research (pp. 163-178). Thousand Oaks: Sage.

Creswell, J. (2009). Research Design: Qualitative, Quantitative, and Mixed Methods Approaches. Thousand Oaks: Sage.

Croley, S. (2008). Regulation and Public Interests: The Possibility of Good Regulatory Government. Princeton: Princeton University Press.

Cropanzano.R. and Mitchell, M. (2005). Social Exchange Theory: An Interdisciplinary Review. Journal of Management, 31(6): 874-90o.

Cross, J. and Pena, S. (2006). Risk and Regulation in Informal and Illegal Markets. In P. Fernández-Kelly and J. Shefner (eds.) Out of the Shadows: Political action and the Informal Economy in Latin America (pp. 49-8o). University Park: The Pennsylvania State University Press.

De Haas, H. (2005). International Migration, Remittances and Development: Myths and Facts. Third World Quarterly, 26(8): 1269-1284.

De Vaus, D. (2001). Research Design in Social Research. Thousand Oaks: Sage.

Desroches, F. (2007). Research on Upper Level Drug Trafficking: A Review. Journal of Drug Issues, 37(4): 827-844.

Demirguc-Kunt, A., Klapper, L., Singer, D., and Van Oudheusden, P. (2015). The Global Findex Database 2014: Measuring Financial Inclusion around the World, Policy Research Working Paper 7255. Washington D.C.: The World Bank Group.

Demirguc-Kunt, A. and Klapper, L. (2012). Measuring Financial Inclusion: The Global Findex Database, Policy Research Working Paper 6025. Washington D.C.: The World Bank Group.

Dewey, M. (2016). Porous Borders: The Study of Illegal Markets from a Sociological Perspective, MPIfG Discussion Paper 16/2. Cologne: Max Plank Institute for the Study of Societies.

Dworkin, S. (2012). Sample Size Policy for Qualitative Studies Using In-Depth Interviews. Archives of Sexual Behavior, 41(6): 1319-1320. 
Dynan, K. and Sheiner, L. (2018). GDP as a Measure of Economic Well-Being. Washington D.C.: Brookings Institution.

Economist. (2019, February 21). A Surprising Number of North Korean Refugees Send Money Home. London: The Economist.

Economist. (2015, October 16). How Hawala Money-transfer Schemes are Changing. London: The Economist.

Economist. (2001, November 22). Terrorists and hawala banking Cheap and Trusted. London: The Economist.

Edmond, C. (2017, November 22). Which Countries Do Migrants Want to Move to? Global Agenda. Geneva: The World Economic Forum. Retrieved from https://www.weforum.org/agenda/2017/11/these-are-the-countries-migrantswant-to-move-to/

Ekblom, P. and Tilley, N. (200o). Going Equipped: Criminology, Situational Crime Prevention and the Resourceful Offender. British Journal of Criminology, 40(3): 376-398.

El Qorchi, M. (2002). Hawala. Finance and Development, 39(4). Washington D.C.: IMF.

El Qorchi, M, Maimbo, S. and Wilson, J. (2003). Informal Funds Transfer Systems: An Analysis of the Informal Hawala System, IMF Occasional Paper No. 222. Washington D.C.: IMF.

Ellickson, P. (2013). Market Structure and Performance. In N. Smeiser and P. Baites (eds.), International Encyclopedia of the Social and Behavioral Sciences (pp: 9211-9216). Oxford: Elsevier.

Eisenhardt, K. and Graebner, M. (2007). Theory Building from Cases: Opportunities and Challenges. Academy of Management Journal, 50(1): 25-32.

Entorf, H. (2014). Certainty, Severity, and Their Deterrent Effects. In G. Bruinsma and D. Weisburd (eds.), Encyclopedia of Criminology and Criminal Justice. New York: Springer.

Evans, M. (1989). Immigrant Entrepreneurship: Effects of Ethnic Market Size and Isolated Labor Pool. American Sociological Review, 54(6): 950-962. 
Fallon, R. (2005). Legitimacy and the Constitution. Harvard Law Review, 118(6): 17871853.

Fantom, N. and Serajuddin, U. (2016). The World Bank's Classification of Countries by Income, Policy Research Working Paper 7528. Washington D.C.: The World Bank Group Group.

Farrington, D. (2001). What Has Been Learned from Self-Reports about Criminal Careers and the Causes of Offending? Cambridge: University of Cambridge.

Feige, E. (1990). Defining and Estimating Underground and Informal Economies: The New Institutional Economics Approach. World Development, 18(7): 989-1002.

Feilzer, M. (2010). Doing Mixed Methods Research Pragmatically: Implications for the Rediscovery of Pragmatism as a Research Paradigm. Journal of Mixed Methods Research, 4(1): 6-16.

Felson, M. (2009). The Natural History of Extended Co-offending. Trends in Organized Crime, 12(2): 159-165.

Fereday, J. and Muir-Cochrane, E. (2006). Demonstrating Rigor Using Thematic Analysis: A Hybrid Approach of Inductive and Deductive and Theme Development. International Journal of Qualitative Methods, 5(1): 80-92. Fernandez-Kelly, P. (2006). Introduction. In P. Fernandez-Kelly and J. Shefner (eds.), Out of the Shadows: Political Action and Informal Economy in Latin America (pp: 23-48). University Park: The Pennsylvania State University.

Foa, R, and Tanner, J. (2012). Methodology of the Indices of Social Development. ISD

Working Paper Series, No. 2012-04. Rotterdam: Erasmus University.

Freund, C. and Spatafora, N. (2008). Remittances, Transaction Costs, and Informality. Journal of Development Economics, 86(2): 356-366.

Financial Action Task Force (FATF). (2020). Anti-Money Laundering and CounterTerrorist Financing Measures: Republic of Korea, Mutual Evaluation Report. Paris: FATF/APG.

Financial Action Task Force (FATF). (2017). Annual Report 2015-2016. Paris: FATF/OECD.

Financial Action Task Force (FATF). (2016). Guidance for a Risk-Based Approach: Money or Value Transfer Services. Paris: FATF/OECD. 
Financial Action Task Force (FATF). (2015). International Standards on Combating Money Laundering and the Financing of Terrorism and Proliferation: The FATF Recommendations. Paris: FATF/OECD.

Financial Action Task Force (FATF). (2013a). The Role of Hawala and Other Similar

Service Providers in Money Laundering and Terrorist Financing. Paris: FATF/OECD.

Financial Action Task Force (FATF). (2013b). Methodology: For Assessing Technical

Compliance with the FATF Recommendations and the Effectiveness of AML/CFT Systems. Paris: FAFT/OECD.

Financial Action Task Force (FATF). (2010). Money Laundering Using New Payment Methods. Paris: FATF/OECD.

Financial Action Task Force (FATF). (2009a). Third Round of AML/CFT Mutual Evaluations: Process and Procedure. Paris: FATF/OECD.

Financial Action Task Force (FATF). (2009b). Mutual Evaluation Report - Korea. Paris: OECD/APG.

Financial Action Task Force (FATF). (2004). Methodology for Assessing Compliance with the FATF 40 Recommendations and the FATF 9 Special Recommendations. Paris: FATF/OECD.

Financial Action Task Force (FATF). (2003a). FATF 4o Recommendations. Paris: FATF/OECD.

Financial Action Task Force (FATF). (2003b), Combating the Abuse of Alternative Remittance Systems: International Best Practices. Paris: OECD/FATF.

Finckenauer, J. (2005). Problems of Definition: What is Organized Crime? Trends in Organized Crime, 8(3): 63-83.

Fiorentini, G., and Zamagni, S. (1999). The Economics of Corruption and Illegal Markets. Cheltenham: Edward Elgar Publishing.

Fitzmaurice, G., Kenward, M., Molenberghs, G., Verbeke, G., and Tsiatis, A. (2015). Introduction and Preliminaries. In G. Molenberghs, G. Fitzmaurice, M. Kenward, A. Tsiatis, and G. Verbeke (eds.), Handbook of Missing Data Methodology. New York: Chapman \& Hall/CRC. 
Fligstein, N. and Calder, R. (2015). Architecture of Markets. In R. Scott and S. Kosslyn (eds.), Emerging Trends in the Social and Behavioral Sciences: An Interdisciplinary, Searchable, and Linkable Resource. Hoboken: John Wiley \& Sons.

Fligstein, N. and Dauter, L. (2007). The Sociology of Markets. Annual Review of Sociology, 33(6): 1-24.

Flinders, D. and Mills, G. (1993). Theory and Concepts in Qualitative Research: Perspectives from the Field. New York: Teachers College Press.

Fourcade, M. (2007). Theories of Markets and Theories of Society. American Behavioral Scientist, 50(8): 1015-1034.

Freudenberg, M. (2003). Composite Indicators of Country Performance: A Critical Assessment. OECD Science, Technology, and Industry Working Papers, 2003/16. Paris: OECD Publishing.

Fylan, F. (2005). Semi Structured Interviewing. In J. Miles and P. Gilbert (eds.), A Handbook of Research Methods for Clinical and Health Psychology (pp. 65-78). New York: Oxford University Press.

Gadanecz, B. and Tissot, B. (2016). Measures of Financial Inclusion - a Central Bank Perspective: 2015 Survey Conducted by the Irving Fisher Committee on Central Bank Statistics (IFC). Basel: Bank for International Settlements.

Garoupa, N. (2000). The Economics of Organized Crime and Optimal Law Enforcement. Economic Inquiry, 38(2): 278-288.

Garoupa, N. (1997). The Theory of Optimal Law Enforcement. Journal of Economic Surveys, 11(3): 267-295.

George, G. and Bock, A. (2011). The Business Model in Practice and its Implications for Entrepreneurship Research. Entrepreneurship: Theory and Practice, 35(1): 83111.

Gertz, M. and Myers, L. (1992). Impediments to Cross-national Research: Problems of Reliability and Validity. International Journal of Comparative and Applied Criminal Justice, 16(1-2): 57-65.

Gibson, J., McKenzie, D., and Zia, B. (2012). The Impact of Financial Literacy Training for Migrants. The World Bank Economic Review, 28(1): 130-161. 
Gill, M. (2005). Reducing the Capacity to Offend: Restricting Resources for Offending. In N. Tilley (eds.), Handbook of Crime Prevention and Community Safety (pp. 306-328). Devon: Willan Publishing.

Gill, M. and Taylor, G. (2004). Preventing Money Laundering or Obstructing Business?: Financial Companies' Perspectives on 'Know Your Customer' Procedures. The British Journal of Criminology, 44(4): 582-594.

Gilmour, N. (2016). Preventing Money Laundering: A Test of Situational Crime Prevention Theory. Journal of Money Laundering Control, 19(4): 376-396. Godfrey, P. (2011). Toward a Theory of the Informal Economy. The Academy of Management of Annals, 5(1): 231-277.

Gordon, S., Robinson, A., Goulding, H. and Mahyub, R. (2018). The Impact of Bank DeRisking on the Humanitarian Response to the Syrian Crisis. London: Overseas Development Institute.

Grattet, R. (2011). Societal Reactions to Deviance. The Annual Review of Sociology 37: 185204.

Gravetter, F. and Wallnau, L. (2014). Statistics for the Behavioral Sciences. Belmont: Wadsworth.

Greco, S., Ishizaka, A., Tasiou, M., and Torrisi, G. (2019). On the Methodological Framework of Composite Indices: A Review of the Issues of Weighting, Aggregation, and Robustness. Social Indicator Research, 141(1): 61-94. Greenwood, C. (2009, December 8). 'Hawala King' is Arrested After Global Hunt. London: Independent.

Guiora, A. and Field, B. (2007). Using and Abusing the Financial Markets: Money Laundering as the Achilles' Heel of Terrorism. The University of Pennsylvania Journal of International Law, 29(1): 59-104.

Guest, G., Bunce, A., and Johnson, L. (2006). How Many Interviews are Enough? An Experiment with Data Saturation and Variability. Field Methods. 18(1): 59-82.

Freeman, L. (2004). The Development of Social Network Analysis. Vancouver: Empirical Press.

Hagan, F. (2005). “Organized crime” and "organized crime”: Indeterminate Problems of Definition. Trends in Organized Crime, 9(4): 127-137. 
Hagan, J. (1985). Modern Criminology: Crime, Criminal Behavior, and Its Control. New York: McGraw-Hill.

Haller, M. (1990). Illegal Enterprise: A Theoretical and Historical Interpretation. Criminology, 28(2): 207-235.

Halpern, D. (2015). Inside the Nudge Unit. London: Ebury Press.

Hambrick, D. (2007). The Field of Management's Devotion to Theory: Too Much of a Good Thing? Academy of Management Journal, 50(6): 1346-1352.

Han, C. and Ireland, R. (2016). A Survey of Customs Administration Approaches to Money Laundering, WCO Research Paper No. 36. Brussels: World Customs Organization.

Han, C. and Ireland, R. (2013). Informal Funds Transfer Systems as a Target of Customs Enforcement. World Customs Journal, 7(1): 3-12.

Hardin, R. (2001). Conceptions and Explanation of Trust. In K. Cook (eds.), Trust in Society (pp. 3-39). Thousand Oaks: Sage.

Heimer, C. (2001). Solving the Problem of Trust. In K. Cook (eds.), Trust in Society (pp. 40-88). Thousand Oaks: Sage.

Henry, S. (2009). Social Construction of Crime. In J. Miller (eds.), 21st Century Criminology: A Reference Handbook. Thousand Oaks: Sage Publications. Henry, S. and Lanier, M. (1998). The Prism of Crime: Arguments for an Integrated Definition of Crime. Justice Quarterly, 15(4): 609-627.

Hernandez-Coss, R. (2005a). A Proposed Framework to Analyze Informal Funds Transfer System. In S. Maimbo and D. Ratha (eds.), Remittances: Development Impact and Future Prospects (pp. 211-226). Washington D.C.: The World Bank Group.

Hernandez-Coss, R (2005b). The Canada-Vietnam Remittance Corridor: Lessons from on Shifting from Informal to Formal Transfer Systems, World Bank Working Paper No, 48. Washington D.C.: The World Bank Group.

Hernandez-Coss, R. and Bun, C. (2007). The UK-Nigeria Remittance Corridor:

Challenges of Embracing Formal Transfer Systems in a Dual Financial Environment. World Bank Working Paper No, 92. Washington D.C.: The World Bank Group. 
Hetchter, M. and Kanazawa, S. (1997). Sociological Rational Choice Theory. Annual Review of Sociology, 23(1): 191-214.

Hillyard, P. and Tombs, S. (2007). From 'Crime' to Social Harm. Crime, Law and Social Change. 48(1-2): 9-25.

Hinds, P., Vogel, R., and Clarke-Steffen, L. (1997). The Possibilities and Pitfalls of Doing a Secondary Analysis of a Qualitative Dataset. Qualitative Health Research, 7(3): 408-424.

Ho, T. and Weigelt, K. (2005). Trust Building Among Strangers. Management Science, 51(4): 519-530.

Hollway, W. and Jefferson, T. (200o). Doing Qualitative Research Differently: Free Association, Narrative and the Interview Method. Thousand Oaks: Sage.

Homans, G. (1961). Social Behavior: Its elementary forms. New York: Harcourt, Brace and World.

Houssein, M. (2005). Somalia: The Experience of Hawala Receiving Countries. In International Monetary Fund (eds.), Regulatory frameworks for hawala and other remittance systems (pp. 87-93). Washington D.C.: IMF.

IHS Markit. (2018, March 2). Organized Crime Groups in South Korea increasingly Operating Hybrid Licit-illicit Businesses, Hampering Law Enforcement efforts. Retrieved from https://ihsmarkit.com/country-industryforecasting.html?ID=10659123051.

International Labor Organization (ILO). (2013). Measuring Informality: A Statistical Manual on the Informal Sector and Informal Employment. Geneva: ILO. International Monetary Fund (IMF). (2009). International Transactions in Remittances: Guide for Compilers and Users. Washington D.C.: IMF. International Monetary Fund (IMF). (2005). Approaches to a Regulatory Framework for Formal and Informal Remittance Systems: Experiences and Lessons. Washington D.C.: IMF.

Joffe, H. and Yardley, L. (2004). Content and Thematic Analysis. In D. Marks and L. Yardley (eds.), Research Methods for Clinical and Health Psychology (pp. 5668). Thousand Oaks: Sage. 
Johannesen, N. and Pirttila, J. (2016). Capital Flight and Development: An Overview of Concepts, Methods, and Data Sources, WIDER Working Paper 2016/95. Helsinki: UNU-WIDER.

John, P., Smith, G., and Stoker, G. (2009). Nudge Nudge, Think Think: Two Strategies for Changing Civic Behaviour. The Political Quarterly, 8o(3): 361-37o.

Johnson, J. (1990). Selecting Ethnographic Informants. Qualitative Research Methods Volume 22. Newbury Park: Sage.

Johnston, R. (2005). Work on the IMF in Informal Funds Transfer Systems. In International Monetary Fund(eds.), Regulatory Frameworks for Hawala and Other Remittance Systems (pp. 1-6). Washington D.C.: IMF.

Johnston, R. and Carrington, I. (2006). Protecting the Financial System from Abuse:

Challenges to Banks in Implementing AML/CFT Standards. Journal of Money Laundering, 9(1): 48-61.

Jung, E. (2017). The Origin and Development of Informal Remittance System in North Korea in Association with Trade between North Korea and China. Sejong Policy Briefing, 2017-31 (in Korean). Seongnam: Sejong Institute.

Kang, D. and Lee, K. (2014). Remittance Services in the Republic of Korea. Bangkok: International Labor Organization ILO Regional Office for Asia and the Pacific. Kapur, D. (2005). Remittances: The New Development Mantra? In S. Maimbo and D. Ratha (eds.), Remittances: Development Impact and Future Prospects (pp. 331360). Washington D.C.: The World Bank Group.

Kearney, K. and Hyle, A. (2015). A Look Through the Kubler-Ross Theoretical Lens. In V. Anfara and N. Mertz (eds.), Theoretical Frameworks in Qualitative Research (pp. 149-163). Thousand Oaks: Sage.

Kim, K. and Song, E. (2015). Analysis of Factors Affecting the Choice of Payment Methods. Monthly Report of Research and Statistics, 4: 17-44 (in Korean). Kleemans, E. (2015). Follow the Money: Introduction to the Special Issue 'Financial Aspect of Organized Crime'. European Journal of Criminal Policy and Research, 21(2): $213-216$. 
Kleemans, E. and Smit, M. (2014). Human Smuggling, Human Trafficking, and Exploitation in the Sex Industry. In L. Paoli (eds.), The Oxford Handbook of Organized Crime (pp. 381-401). New York: Oxford University Press.

Kleemans, E., Soudijn, M., and Weenink, A. (2013). Situational Crime Prevention and Cross-border Crime. In R. Clarke, K. Bullock, and N. Tilley (eds.) Situational Prevention of Organised Crimes (pp. 35-52). Devon: Willan.

Kleinig, J. (1978). Crime and the Concept of Harm. American Philosophical Quarterly, 15(1): $27-36$.

Kollock, P. (1994). The Emergence of Exchange Structures: An Experimental Study of Uncertainty, Commitment, and Trust. American Journal of Sociology, 100(2): 313-345.

Komai, A. and Richardson, G. (2011). A brief History of Regulations Regarding Financial Markets in the United States: 1789 to 2009, NBER Working Paper 17443. Cambridge: National Bureau of Economic Research.

Korea Customs Service. (2018). Trade Statistics (in Korean). Daejeon: Korea Customs Service.

Korea Statistics Service (KSS) and Ministry of Justice (MOJ). (2019). Immigration and Employment Statuses of Foreigners in Korea (in Korean). Daejeon: Korea Statistics Service.

Kosse, A. and Vermeulen, R. (2014). Migrants' Choice of Remittance Channel: Do General Payment Habits Play a Role? European Central Bank Working Paper Series, No 1683. Frankfurt: European Central Bank.

Kramer, R. (2006). Trust as Situated Cognition: An Ecological Perspective on Trust Decisions. In R. Bachmann and A. Zaheer (eds.), Handbook of Trust Research (pp. 68-84). Cheltenham: Edward Elgar Publishing Limited.

Kugler, M. Verdier, T., and Zenou, Y. (2003). Organized Crime, Corruption and Punishment, IUI Working Paper, No. 6oo. Stockholm: The Research Institute of Industrial Economics.

Kuzel, A. (1992). Sampling in Qualitative Inquiry. In B. Crabtree and W. Miller (eds.), Doing Qualitative Research (pp 31-44). Newbury Park: Sage. 
La Porta, R. and Shleifer, A. (2014). Informality and Development. Journal of Economic Perspectives, 28(3): 109-126.

Lacey, N. and Zedner, L. (2012). Legal Constructions of Crime. In M. Macquire, R. Morgan, and R. Reiner (eds.), The Oxford Handbook of Criminology. Oxford: Oxford University Press.

Lanier, M. and Henry, S. (2010). Essential Criminology, Boulder: Westview Press. Lascaux, A. (2015). Crowding Out Trust in the Informal Monetary Relationships: The Curious Case of Hawala System. Forum for Social Economics, 44(1): 87-107. Laville, S. (2009, December 8). India Arrests Hawala Money Laundering Suspect Naresh Jain. London: The Guardian.

Lee, H. (2017). Patterns of Myanmar Workers' Remittance Sending Behaviors in the Republic of Korea. (unpublished master's thesis, Ewha Womans University, Korea).

Lewicki, R. and Bunker, B. (1995). Trust in Relationships: A Model of Development and Decline. Administrative Science Quarterly, 5(1): 583-601.

Lie, I. (1997). Sociology of Markets. Annual Review of Sociology, 23(1): 341-360.

Lehne, J., Mo, J., and Plekhanov, A. (2014). What Determines the Quality of Economic Institutions? Cross-Country Evidence. Working Paper No. 171. London: European Bank for Reconstruction and Development.

Levi, M., Nelen, H., and Lankhorst, F. (2005). Lawyers as Crime Facilitators in Europe: An Introduction and Overview. Crime, Law and Social Change, 42(2): 117-121. Leys, C., Ley, C., Klein, O., Bernard, P., and Licata, L. (2013). Detecting Outliers: Do not Use Standard Deviation Around the Mean, Use Absolute Deviation Around the Median. Journal of Experimental Social Psychology, 49(4): 764-766.

LexisNexis Risk Solutions. (2017). The True Cost of Anti-Money Laundering Compliance - European Edition. Retrieved from https://risk.lexisnexis.com/global/-/media/files/corporations-and-nonprofits/research/true-cost-of-aml-compliance-europe-survey-report-pdf.pdf. LexisNexis Risk Solutions. (2016). Uncover the True Cost of Anti-Money Laundering \& KYC Compliance. Retrieved from 
https://www.lexisnexis.com/risk/intl/en/resources/research/true-cost-of-amlcompliance-apac-survey-report.pdf.

Lindley, A. (2009). Between 'Dirty Money' and 'Development Capital': Somali Money Transfer Infrastructure under Global Scrutiny. Africa Affairs, 108(433): 519-539.

Little, R. and Rubin, D. (2020). Statistical Analysis with Missing Data. Hoboken: John Wiley \& Sons.

Loayza, N. and Rigolini, J. (2006). Informality Trends and Cycles. World Bank Policy Research Working Paper 4078. Washington D.C.: The World Bank Group.

Loftin, C. and McDowall, D. (2010). The Use of Official Records to Measure Crime and Delinquency. Journal of Quantitative Criminology, 26(4):527-532.

Long, S. (2018, May 3). Financial Inclusion is Making Great Strides. The Economist. Luz, R. and Spagnolo, G. (2017). Leniency, Collusion, Corruption, and Whistleblowing. Journal of Competition Law and Economics, 13(4): 729-766.

Lynch, M., Stretesky, P., and Long, M. (2015). Defining Crime. New York: Palgrave Macmillan.

Maimbo, S. (2005). The Regulation and Supervision of Informal Remittance: Emerging Oversight Strategies. In International Monetary Fund (eds.), Current Development in Monetary and Financial Law, Volume 4. Washington D.C.: IMF.

Maimbo, S. (2003). The Money Exchange Dealers of Kabul: A Study of the Hawala System in Afghanistan. World Bank Working Paper No. 13. Washington D.C.: The World Bank Group.

Maimbo, S. and Passas, N. (2005). The Regulation and Supervision of Informal Funds Transfer Systems. In S. Maimbo and D. Ratha (eds.), Remittances: Development Impact and Future Prospects (pp. 211-226). Washington D.C.: The World Bank Group.

Maimbo, S., Adams, Jr., R., Aggarwal, R., and Passas, N. (2005). Migrant Labor Remittances in South Asia. Washington D.C.: The World Bank. Makarenko, T. (2004). The Crime-Terror Continuum: Tracing the Interplay between Transnational Organised Crime and Terrorism. Global crime, 6(1): 129-145. 
Malit, F., Al Awad, M., and Naufal, G. (2017). More Than a Criminal Tool: The Hawala System's Role as a Critical Remittance Channels for Low-income Pakistan Migrants in Dubai. Remittances Review, 2(2): 63-88.

Maltz, M. (1999). Bridging Gaps in Police Crime Data. Washington D.C.: U.S. Department of Justice.

Manning, N., Mukherjee, R., and Gokcekus, O. (2000). Public Officials and Their Institutional Environment: An Analytical Model for Assessing the Impact of Institutional Changes. Washington D.C.: The World Bank Group.

Manyika, J., Lund, S., Bughin, J., Woetzel, J., Stamenov, K., and Dhingra, D. (2016). Digital Globalization: The New Era of Global Flows. London: McKinsey Global Institute.

Martinez, C., Cummings, M., and Vaaler, P. (2015). Economic Informality and the Venture Funding Impact of Migrant Remittances to Developing Countries. Journal of Business Venturing, 30(4): 526-545.

Magretta, J. (2002). Why Business Models Matter. Harvard Business Review, May: 3-8. Marshall, B., Cardon, P., and Poddar, A. (2013). Does Sample Size Matter in Qualitative Research? A Review of Qualitative Interviews in IS Research. Journal of Computer Information Systems, 54(1): 11-22.

Marshall, M. (1996). Sampling for Qualitative Research. Family Practice, 13(6): 522526.

Martin, M. (2009). Hundi/Hawala: The Problem of Definition. Modern Asian Studies, 43(4): 909-937.

Mankiw, G. (2008). Principles of Economics. Mason: South-Western Cengage Learning.

Mauthner, N., Parry, O., and Backett-Milburn, K. (1998). The Data Are Out There, or Are They? Implications for Archiving and Revisiting Qualitative Data. Sociology, 32(4): 733-745.

Maxfield, M. and Babbie, E. (2004). Research Methods for Criminal Justice and Criminology. Belmont: Wadsworth.

Maxwell, J. (2004). Qualitative Research Design: An Interactive Approach, Applied Social Research Methods Series Volume 41. Thousand Oaks: Sage Publications. 
Maxwell, J. and Chmiel, M. (2014). Generalization in and from Qualitative Analysis. In U. Flick (eds.), The Sage Handbook of Qualitative Data Analysis (pp. 540-553). Thousand Oaks. Sage.

May, T. and Hough, M. (2009). Drug Markets and Distribution Systems. Addiction Research and Theory, 12(6): 549-563.

McCarthy, B., Hagan, J., and Cohen, L. (1998). Uncertainty, Cooperation, and Crime: Understanding the Decision to Co-offend. Social Forces, 77(1): 155-176.

McCloskey, D. and Ziliak, S. (1996), The Standard Error of Regressions, Journal of Economic Literature, 34: 97-114.

McCusker, R. (2005). Underground Banking: Formal remittance Network or Money Laundering System? Trends and Issues in Crime and Criminal Justice, No. 300. Canberra: Australian Institute of Criminology.

McGloin, J. and Nguyen, H. (2014). The Importance of Studying Co-offending Networks for Criminological Theory and Policy. In C. Morselli (eds.), Crime and Networks. New York: Taylor and Francis.

McIntosh, D. (2016). The Costs of Anti-Money Laundering Enforcements to Noncompliant Banks. Journal of Finance and Bank Management, 4(1): 1-14. McKinley, J. (1998, August 8). Bombings in East Africa: The Overview; Bombs Rip Apart 2 U.S. Embassies in Africa; Scores Killed; No Firm Motive or Suspects. New York Times.

Medina, L. and Schneider, F. (2019). Shedding Light on the Shadow Economy: A Global Database and the Interaction with the Official One. CESifo Working Paper No. 7981. Munich: CESifo.

Merriam, S. (1998). Qualitative Research and Case Study Applications in Education. San Fancisco: Jossey-Bass Publishers.

Middleton, D., and Levi, M. (2015). Let Sleeping Lawyers Lie: Organized Crime, Lawyers and the Regulation of Legal Services. British Journal of Criminology, 55(4): 647-668.

Mills, M. and Bettis, P. (2015). Using Multiple Theoretical Frameworks to Study Organizational Change and Identity. In V. Anfara and N. Mertz (eds.), 
Theoretical Frameworks in Qualitative Research (pp. 85-102). Thousand Oaks: Sage.

Miles, M. Huberman, M., and Saldana, J. (2014). Qualitative Data Analysis: A Methods Sourcebook. Thousand Oaks: Sage.

Milovanovic, D. and Henry, S. (2001). Constitutive Definition of Crime: Power as Harm. In S. Henry and M. Lanier (eds.), What is Crime? Controversies over the Nature of Crime and What to Do about It. New York: Rowman \& Littlefield Publishers.

Minoiu, C. and Reyes, J. (2013). A Network Analysis of Global Banking: 1978-2010. Journal of Financial Stability, 9(2): 168-184.

Mitsilegas, V and Vavoula, N. (2016). The Evolving EU Anti-Money Laundering Regime: Challenges for Fundamental Rights and the Rule of Law. Maastricht Journal of European and Comparative Law, 23(2): 261-293.

Mohapatra, S. and Ratha, D. (2011). Migrant Remittances in Africa: An Overview. In S.

Mohapatra and D. Ratha (eds.), Remittance Markets in Africa. Washington

D.C.: The World Bank Group.

Molm, L. (2006). The Social Exchange Framework. In P. Burke (eds.), Contemporary Social Psychological Theories (pp. 24-45). Stanford: Stanford University Press. Molm, L. (2003a). Theoretical Comparisons of Forms of Exchange. Sociological Theory, 21(1): 1-17.

Molm, L. (2003b). Theories of Social Exchange and Exchange Networks. In G. Ritzer and B. Smart (eds.), Handbook of Social Theory. Thousand Oaks: Sage.

Molm, L., Schaefer, D., and Collett, J. (2009). Fragile and Resilient Trust: Risk and Uncertainty in Negotiated and Reciprocal Exchange. Sociological Theory, 27(1): 1-32.

Molm, L., Takahashi, N., and Peterson, G. (2000). Risk and Trust in Social Exchange: An Experimental Test of a Classical Proposition. American Journal of Sociology, 105(5): 1396-1427.

Monaghan, A. (2019, February 13). Banks Close Thousands of 'Money Mule' Accounts, MPs told. The Guardian. 
Monroe, K. and Maher, K. (1995). Psychology and Rational Actor Theory. Political Psychology, 16(1): 1-21.

Monsutti, A. (2004). Cooperation, Remittances, and Kinship among the Hazaras. Iranian Studies, 37(2): 219-240.

Morse, J. (2000). Determining Sample Size. Qualitative Health Research 10(1): 3-5.

Morse, J. (1995). The Significance of Saturation. Qualitative Health Research, 5(2): 147149 .

Nardo, M., Saisana, M., Saltelli, A., and Tarantola, S. (2005). Tools for Composite Indicators Building. Ispra: Joint Research Centre of the European Commission.

Nelen, H. and Huisman, W. (2008). Breaking the Power of Organized Crime? The Administrative Approach in Amsterdam. In D. Siegel and H. Nelen (eds.), Organized Crime: Culture, Markets and Policies. New York: Springer.

Nelen, H. and Lankhorst, F. (2008). Facilitating Organized Crime: The Role of Lawyers and Notaries. In D. Siegel and H. Nelen (eds.), Organized Crime: Culture, Markets and Policies. New York: Springer.

Nelson, D. (2009, December 7). 'Hawala King' Naresh Jain Arrested in India. London: Telegraph.

North, D. (1990). Institutions, Institutional Change, and Economic Performance. New York: Cambridge University Press.

Oliver, C. (1991). Strategic Responses to Institutional Processes. Academy of Management, 16(1): 145-179.

Oliver, K. (2002). International Taxation: Tax Evasion as a Predicate Offence to Money Laundering. International Legal Practitioner, 27(2): 55-63.

Omer, A. (2002). Supporting Systems and Procedures for the Effective Regulation and Monitoring of Somali Remittance Companies (Hawala). Somalia: United Nations Development Program.

Ong, A. and Weiss, D. (200o). The Impact of Anonymity on Responses to Sensitive Questions. Journal of Applied Social Psychology, 30(8): 1691-1708.

Onwuegbuzie, A. and Leech, N. (2007). A Call for Qualitative Power Analyses. Quality and Quantity, 41(1): 105-1210. 
Organization for Economic Co-operation and Development (OECD) and Joint of Research Centre (JRC) of the European Commission. (2008). Handbook on Constructing Composite Indicators: Methodology and User Guide. Paris: OECD.

Orozco, M. (2004). The Remittance Marketplace: Prices, Policy and Financial Institutions. Washington, D.C.: Pew Hispanic Center.

Orphanides, A. (2013). What Happened in Cyprus. SAFE Policy Letter Series No, 6. Frankfurt: Goethe University.

Osili, U. and Paulson, A. (2008). What Can We Learn about Financial Access from U.S. Immigrants? The Role of Country of Origin Institutions and Immigrant Beliefs. The World Bank Economic Review, 22(3): 431-455.

Oulton, N. (2012). Hooray for GDP! CentrePiece, 17(3): 6-11.

Palinkas, L., Horwitz, S., Green, C., Wisdom, J., Duan, N., and Hoagwood, K. (2015). Purposeful Sampling for Qualitative Data Collection and Analysis in Mixed Method Implementation Research. Administration and Policy in Mental Health and Mental Health Services Research, 42(5): 533-544.

Paoli, L. (2002). The Paradoxes of Organized Crime. Crime, Law and Social Change, 37(1): 51-97.

Passas, N. (2015). Financial Intermediaries - Anti-Money Laundering Allies in Cashbased Societies? U4 Issue April 2015 No 9. Bergen: Anti-Corruption Resource Centre.

Passas, N. (2006a). Demystifying Hawala: A Look into its Social Organization and Mechanics. Journal of Scandinavian Studies in Criminology and Crime Prevention, $7\left(\mathrm{~S}_{1}\right): 46-62$.

Passas, N. (2006b). Fighting Terror with Error: The Counter-productive Regulation of Informal Value Transfers. Crime, Law, and Social Change, 45(4-5): 315-336.

Passas, N. (2005a). Informal Value Transfer Systems and Criminal Activities. The Hague: WODC.

Passas, N. (2005b). Formalizing the informal? Problems in the National and International Regulation of Hawala. In International Monetary Fund (eds.), 
Regulatory Frameworks for Hawala and Other Remittance Systems (pp. 7-16). Washington D.C.: IMF.

Passas, N. (2005c). Informal Value Transfer Systems, Terrorism and Money Laundering. 2002-IJ-CX-ooo1. Washington D.C.: National Institute of Justice. Passas, N. (2003). Hawala and Other Informal Value Transfer Systems: How to Regulate Them? Risk Management, 5(2): 49-59.

Passas, N. (1999). Informal Value Transfer Systems and Criminal Organizations: A Study into So-Called Underground Banking Networks. The Hague: Ministry of Justice.

Passas, N. and Giannakopoulos, N. (2017). Afghan Narcotrafficking: Illicit Financial Flow. New York: EastWest Institute.

Passas, N., and Maimbo, S. (2008). The Design, Development, and Implementation of Regulatory and Supervisory Frameworks for Informal Funds Transfer Systems. In T. Biersteker and S. Eckert (eds.), Countering the Financing of Terrorism (pp: 174-192). Routledge: New York.

Patton, M. (2002). Qualitative Research and Evaluation Methods. Sage: Thousand Oaks.

Patton, M. (1999). Enhancing the Quality and Credibility of Qualitative Analysis. Health Services Research, 34(5): 1189-1208.

Payne, G. and Williams, M. (2005). Generalization in Qualitative Research. Sociology, 39(2): 295-314.

Pieke, F., Van Hear, N., and Lindley, A. (2007). Beyond Control? The Mechanics and Dynamics of Informal Remittance between Europe and Africa. Global Networks, 7(3): 348-366.

Plaza, S. (2014, February 11). Anti-Money Laundering Regulations: Can Somalia Survive Without Remittances? [Blog Post] Retrieved from https://blogs.worldbank.org/peoplemove/anti-money-laundering-regulationscan-somalia-survive-without-remittances.

Plaza, S. (2011, July 28). Is It Possible to Send Remittances to North Korea? [Blog Post] Retrieved from https://blogs.worldbank.org/peoplemove/is-it-possible-to-sendremittances-to-north-korea.Pohit, S. and Taneja, N. (2003). India's Informal 
Trade with Bangladesh: A Qualitative Assessment. The World Economy, 26(8): 1187-1214.

Polit, D. and Beck, C. (2010). Generalization in Quantitative and Qualitative Research: Myths and Strategies. International Journal of Nursing Studies, 47(11): 1451-1458. Polletta, F. and Jasper, J. (2001). Collective Identity and Social Movements. Annual Review of Sociology, 27(1): 283-305.

Ponsaerts, P., Shapland, J., and Williams, C. (20o8). Does the Informal Economy Link to Organized Crime? International Journal of Social Economics, 35(9): 644-65o.

Portes, A. and Haller, W. (2005). The Informal Economy. In N. Smelser and R. Swedberg (eds.), The Handbook of Economic Sociology (pp. 403-425). New York: Russell Sage.

Proverbio, M., Gera, P., and Burelli, F. (2016). ATM Benchmarking Study 2016 and Industry Report. Stockholm: Accenture/ATMIA.

Rahman, M. and Yeoh, B. (20o8). The Social Organization of Hundi: Channelling Migrant Remittances from East and South-east Asia to Bangladesh. Asian Population Studies, 4(1): 5-29.

Ratha, D. (2005). Workers' Remittances: An Important and Stable Source of External Development Finance. In S. Maimbo and D. Ratha (eds.), Remittances: Development Impact and Future Prospects (pp. 19-52). Washington D.C.: The World Bank Group.

Ratha, D. and Riedberg, J. (2005). On Reducing Remittance Costs. Washington D.C.: The World Bank Group.

Raymaekers, W. (2015). Cryptocurrency Bitcoin: Disruption, Challenges and Opportunities. Journal of Payments Strategy and Systems, 9(1): 30-46. Razavy, M. and Haggerty, K. (2009). Hawala under Scrutiny: Documentation, Surveillance and Trust. International Political Sociology, 3(2): 139-155.

Rees, D. (2010). Alternative Remittance Systems in Australia: Perceptions of Users and Providers. Trends \& Issues in Crime and Criminal Justice, No. 393. Canberra: Australian Institute of Criminology.

Reiner, R. (200o). Crime and Control in Britain. Sociology, 34(1): 71-94. 
Reuter, P. (2014). Drug Markets and Organized Crime. In L. Paoli (eds.), The Oxford Handbook of Organized Crime (pp. 359-380). New York: Oxford University Press.

Reuter, P. (1983). Disorganized Crime: The Economics of the Visible Hand. Cambridge: The MIT Press.

Reuter. P and Truman, E. (2004). Chasing Dirty Money: The Fight against Money Laundering. Washington D.C.: Institute for International Economics.

Robinson, O. (2014). Sampling in Interview-based Qualitative Research: A Theoretical and Practical Guide. Qualitative Research in Psychology, 11(1): 25-41.

Rosenbaum, D. Lurigio, A., and Lavrakas, P. (1989). Enhancing Citizen Participation and Solving Serious Crime: A National Evaluation Crime Stoppers Programs. Crime and Delinquency, 35(3): 401-420.

Roth, J., Greenburg, D., and Wille, S. (2004). Monograph on Terrorist Financing: Staff Report to the Commission. Washington D.C.: National Commission on Terrorist Attacks Upon the United States.

Rousseau, D., Sitkin, S., Burt, R., and Camerer, C. (1998). Not So Different After All: A Cross-Discipline View of Trust. Academy of Management Review, 23(2): 393404 .

Saisana, M. and Saltelli, A. (2011). Rankings and Ratings: Instructions for Use. Hague Journal on the Rule of Law, 3(2): 247-268.

Saltelli, A. (2007). Composite Indicators Between Analysis and Advocacy. Social Indicators Research, 81(1): 65-77.

Sandelowski, M. (2000). Focus on Research Methods: Combining Qualitative and Quantitative Sampling, Data Collection, and Analysis Techniques in MixedMethod Studies. Research in Nursing and Health, 23(3): 246-255.

Scarborough, N. and Cornwall, J. (2016). Essentials of Entrepreneurship and Small Business Management. Essex: Pearson.

Schramm, M. and Taube, M. (2003). Evolution and Institutional Foundation of the Hawala Financial System. International Review of Financial Analysis, 12(4): $405-420$. 
Schaeffer, E. (2008). Remittances and Reputations in Hawala Money-Transfer Systems: Self-Enforcing Exchange on an International Scale, 24(1): 95-117.

Schilke, O., Reimann, M., and Cook, K. (2015). Power Decreases Trust in Social Exchange. Proceedings of the National Academy of Sciences, 112(42): 1295012955.

Schwab, K. and Sala-i-Martín, X. (2103). The Global Competitiveness Report 2013-2014: Full Data Edition. Geneva: The World Economic Forum.

Scott, B. (2016). How Can Cryptocurrency and Blockchain Technology Play a Role in Building Social and Solidarity Finance? UNRISD Working Paper 2016-1. Geneva: United Nations Research Institute for Social Development.

Scott, W. (1995). Institutions and Organizations. Newbury Park: Sage.

Seddon, T. (2006). Drugs, Crime and Social Exclusion. British Journal of Criminology, 46(4): 680-703.

Shadish, W., Cook, T., and Campbell, D. (2002). Experimental and Quasi-Experimental Designs for Generalized Causal Inference. Boston: Houghton Mifflin.

Shah, D. (2018). The Use of the Hundi System for Remittance by Nepali Workers in Korea (unpublished Master's thesis, Kyung Hee University, Korea).

Shannon-Baker, P.A. (2016). Making Paradigms Meaningful in Mixed Methods Research. Journal of Mixed Methods Research, 10(4):319-334.

Shapira, Z. (2011). I've Got a Theory Paper - Do you?: Conceptual, Empirical, and Theoretical Contributions to Knowledge in the Organizational Sciences. Organization Sciences, 22(5): 1312-1321.

Shapiro, S. (2012). The Grammar of Trust. In J. Pixley (eds.), New Perspectives on Emotions in Finance: The Sociology of Confidence, Fear and Betrayal (pp. 99118). New York: Routledge.

Sharma, D. (2006). Historical Traces of Hundi, Sociocultural Understanding, and Criminal abuses of hawala. International Criminal Justice Review, 16(2): 99-121. Sharman, J. (2008). Power and Discourse in Policy Diffusion: Anti-Money Laundering in Developing States. International Studies Quarterly, 52(3): 635-656.

Sheppard, B. and Sherman, D. (1998). The Grammars of Trust: A Model and General Implications. Academy of Management Review, 23(3); 422-437. 
Shinar, A. (2013). Dissenting from Within: Why and How Public Officials Resist the Law. Florida State University Law Review, 40(3): 601-657.

Sim, J., Saunders, B., Waterfield, J., and Kingstone, T. (2018). Can Sample Size in Qualitative Research be Determined a Priori? International Journal of Social Research Methodology, 21(5): 619-634.

Sinha, G. (2014). To Suspect or Not to Suspect: Analysing the Pressure on Banks to be 'Policemen'. Journal of Banking Regulation, 15(1): 75-86.

Soudijn, M. (2015). Hawala and Money Laundering: Potential Use of Red Flags for Persons Offering Hawala Services. European Journal of Criminal Policy and Research, 21(2): 257-274.

Soudijn, M. (2014). Using Strangers for Money: A Discussion on Money-launderers in Organized Crime. Trends in Organized Crime, 17(3), 199-217.

Soudijn, M. and Kleemans, E. (2009). Chinese Organized Crime and Situational

Context: Comparing Human Smuggling and Synthetic Drugs Trafficking. Crime, Law and Social Change, 52(5): 457-474.

Suchman, M. (1995). Managing Legitimacy: Strategic and Institutional Approaches. Academy of Management Review, 20(3): 571-610.

Sunstein, C. (2018). Misconceptions about Nudges. Journal of Behavioral Economics, 2(1): 61-67.

Sunstein, C. (2017). Nudges that Fail. Behavioral Public Policy, 1(1): 4-25.

Svirydzenka, K. (2016). Introducing a New Broad-based Index of Financial Development, IMF Working Paper WP/16/5. Washington D.C.: IMF.

Taneja, N. (2004, December 18). Informal Trade in the SAARC Region - Implications for FTA. Economic and Political Weekly: 5367-5371.

Teichmann, F. (2018). Financing Terrorism through Hawala Banking in Switzerland. Journal of Financial Crime, http://doi.org/10.1108/JFC-06-2017-0056.

Thompson, E. (2015). Technical Assessment: Humanitarian Use of Hwala in Syria. London: Beechwood International.

Thompson, E. (2008). An Introduction to the Concept and Origins of Hawala. Journal of the History of International Law, 10(1): 83-118. 
Thompson, E. (2007). Misplaced Blame: Islam, Terrorism and the Origins of Hawala. Max Planck Yearbook of United Nations Law, 11(1), 279-305.

Thornberry, T. and Krohn, M. (2003). Comparison of Self-Report and Official Data for Measuring Crime. In J. Pepper and C. Petrie (eds.), Measurement Problems in Criminal Justice Research (pp.43-94).

Tilcsik, A. (2010). From Ritual to Reality: Demography, Ideology, and Decoupling in a Post-Communist Government Agency. Academy of Management Journal, 53(6): 1474-1498. Washington D.C.: The National Academies Press.

Todoroki, E., Noor, W., Celik, K., and Kulathunga, A. (2014). Making Remittances Work: Balancing Financial Integrity and Inclusion. Washington D.C.: The World Bank.

Tsingou, E. (2010). Global Financial Governance and the Developing Anti-Money Laundering Regime: What Lessons for International Political Economy? International Politics, 47(6): 617-637.

Unger, B. and den Hertog, J. (2012). Water Always Finds its Way: Identifying New Forms of Money Laundering. Crime, Law and Social Change, 57(3): 287-304. United States General Accounting Office (GAO). (2003). Terrorist Financing, U.S. Agencies should Systematically Assess Terrorists' Use of Alternative Financing Mechanisms. Washington D.C.: GAO.

Vaismoradi, M., Turunen, H., and Bondas, T. (2013). Content Analysis and Thematic Analysis: Implications for Conducting a Qualitative Descriptive Study. Nursing and Health Sciences, 15(3): 398-405.

Van de Bunt, H. (20o8a). The Role of Hawala Bankers in the Transfer of Proceeds from Organized Crime. In D. Siegel and H. Nelen (eds.), Organized Crime: Culture, Markets, and Policies. New York: Springer.

Van de Bunt, H. (2008b). A Case Study on the Misuse of Hawala Banking. International Journal of Social Economics, 35(9): 691-702.

Van Duyne, P. (1995). The Phantom and Threat of Organized Crime. Crime, Law and Social Change, 24(4): 341-377. 
Van Duyne, P., Von Lampe, K., Van Dijck, M., and Newell, J. (2005). The Organized Crime Economy: Managing Crime Markets in Europe. Wolf Legal Publishers: Nimegen.

Van Mastrigt, S. (2017). Co-offending and Co-offender Selection. In W. Bernasco, J. Van Gelder, and H. Elffers (eds.), The Oxford Handbook of Offender Decision Making, pp. 338-36o. New York: Oxford University Press.

Van Lange, P., Joireman, J., Parks, C., and Van Dijk, E. (2013). The Psychology of Social Dilemmas: A Review. Organizational Behavior and Human Decision Processes. $120(2): 125^{-141 .}$

Varese, F. (2010). What is Organized Crime. In F. Varese (eds.), Organized Crime (Critical Concepts in Criminology). London: Routledge.

Vartanian, T. (2011). Secondary Data Analysis. New York: Oxford University Press.

Vertesy, D. (2016, September 19). A Critical Assessment of Quality and Validity of Composite Indicators of Innovation. In Proceedings of the OECD Blue Sky Forum on Science and Innovation Indicators. Retrieved from http://oecd.org/sti/114\%20-\%2oInnovationComposites_VertesyD_BlueSkyIIIpa per.pdf.

Veneziano, L. and Veneziano, C. (1993). Are Victimless Crimes Actually Harmful? Journal of Contemporary Criminal Justice, 9(1): 1-14.

Vitale, A. (2001). U.S. Banking: An Industry’s View on Money Laundering. Economic Perspectives, 6(2): 24-25.

Vlcek, W. (2017). Global Financial Governance and the Informal: Limits to the Regulation of Money. Crime, Law and Social Change: doi.org/10.1007/s10611-0179754-7.

Vold, G., Bernard, T., and Snipes, J. (2002). Theoretical Criminology. New York: Oxford University Press.

Von Hirsch, A. and Jareborg, N. (1991). Gauging Criminal Harm: A Living-Standard Analysis. Oxford Journal of Legal Studies, 11(1): 1-38.

Von Lampe, K. (2016). Organized Crime: Analyzing Illegal Activities, Criminal Structures, and Extra-legal Governance. Thousand Oaks: Sage. 
Von Lampe, K. (2011). The Application of the Framework of Situational Crime Prevention to 'Organized Crime'. Criminology \& Criminal Justice, 11(2): 145-163.

Von Lampe, K. (2008). Organized Crime in Europe: Conceptions and Realities. Policing: A Journal of Policy and Practice, 2(1): 7-17.

Von Lampe, K. (2006). The Interdisciplinary Dimensions of the Study of Organized Crime. Trends in Organized Crime, 9(3): 77-95.

Von Lampe, K. and Johansen, P. (2006). Organized Crime and Trust; On the Conceptualization and Empirical Relevance of Trust in the Context of Criminal Networks. Global Crime, 6(2): 159-184.

Wang, J. (2011). Regulating Hawala: A Comparison of Five National Approaches. Journal of Money Laundering Control, 14(3): 210-224.

Wasserman, S. and Faust, K. (1994). Social Network Analysis: Methods and Applications. New York: Cambridge University Press.

Watson, K., Hogarth-Scott, S., and Wilson, N. (1998). Small Business Start-ups: Success factors and Support Implications. International Journal of Entrepreneurial Behavior and Research, 4(3): 217-238.

Watters, J. and Biernacki, P. (1989). Targeted Sampling: Options for the Study of Hidden Populations. Social Problems, 36(4): 416-430.

Webb, J., Bruton, G., Tihanyi, L., and Ireland, D. (2012). Research on Entrepreneurship in the Informal Economy: Framing a Research Agenda. Journal of Business Venturing, 28(5): 598-614.

Webb, J., Tihanyi, L., Ireland, D., and Sirmon, D. (2009). You Say Illegal, I Say Legitimate: Entrepreneurship in the Informal Economy. Academy of Management Review: 34(3): 492-510.

Weerman, F. (2003). Co-offending as Social Exchange: Explaining Characteristics of Co-Offending. British Journal of Criminology, 43(2): 398-416.

Weitz, E. and Porter, C. (2013). Understanding and Detecting the Black Market Peso Exchange. United States Attorneys' Bulletin, 61(5): 29-35.

World Bank. (2018). Toward Universal Financial Inclusion in China: Models, Challenges, and Global Lessons. Washington D.C.: The World Bank Group. 
World Bank. (2015). The Little Data Book on Financial Inclusion 2015. Washington D.C.: The World Bank Group.

World Bank. (2014). Global Financial Development Report: Financial Inclusion. Washington D.C.: The World Bank Group.

World Bank. (2011). Payment Systems Worldwide: A Snapshot - Outcomes of the Global Payment Systems Survey 2010. Washington D.C.: The World Bank Group.

World Bank. (2006). Global Economic Prospects: Economic Implications of Remittances and Migration. Washington D.C.: The World Bank Group. World Bank and International Monetary Fund (IMF). (2005). Financial Sector Assessment: A Handbook. Washington D.C.: The World Bank Group. World Justice Project (WJP). (2018). Rule of Law Index 2017-2018. Washington D.C.: WJP.

Wortley, R. and Tilley, N. (2014). Theories for Situational and Environmental Crime Prevention. In G. Bruinsma and D. Weisburd (eds.), Encyclopedia of Criminology and Criminal Justice. New York: Springer.

Yepes, C. (2011). Compliance with the AML/CFT International Standard: Lessons from a Cross-Country Analysis. IMF Working Paper, WP/11/177. Washington D.C.: IMF.

Yin, R. (2013). Validity and Generalization in Future Case Study Evaluations. Evaluation, 19(3): 321-332.

Yin, R. (2003). Case Study Research and Applications: Design and Methods. Thousand Oaks: Sage.

Zhan, M. Anderson, S., and Scott, J. (2009). Banking Knowledge and Attitudes of Immigrants: Effects of a Financial Education Program. Social Development Issues 18(3): 15-32.

Zhang, S., and Chin, K. (2002). Enter the Dragon: Inside Chinese Human Smuggling Organizations. Criminology, 40(4), 737-768.

Ziliak, S. and McCloskey, D. (2004). Size Matters: The Standard Error of Regressions in the American Economic Review. The Journal of Socio-Economic, 33: 527-46. 
Zott, C., Amit, R., and Massa, L. (2011). The Business Model: Recent Developments and Future Research. Journal of Management, 37(4): 1019-1042. 


\begin{tabular}{|c|c|c|c|c|c|c|c|c|c|c|c|c|c|c|c|c|c|c|c|c|c|}
\hline & 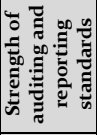 & $\stackrel{\infty}{m}$ & $m$ & $\hat{i}$ & $\stackrel{\infty}{m}$ & $\stackrel{+}{+}$ & $\begin{array}{l}\infty \\
\text { in }\end{array}$ & $\hat{\text { in }}$ & $\stackrel{\text { Pे }}{+}$ & $\begin{array}{l}\infty \\
\text { in }\end{array}$ & $\stackrel{\varphi}{\dot{m}}$ & $\stackrel{+}{\dot{n}}$ & $\stackrel{\infty}{m}$ & $\hat{m}$ & $\dot{m}$ & in & $\hat{n}$ & $\stackrel{\text { in }}{\dot{f}}$ & $\vec{j}$ & $\dot{m}$ & 6 \\
\hline & 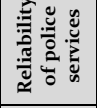 & $\dot{m}$ & $\hat{m}$ & $m$ & $\underset{i}{\infty}$ & $\sigma$ & 0 & in & $\stackrel{m}{f}$ & in & $\begin{array}{l}0 \\
i\end{array}$ & $\stackrel{\circ}{\text { in }}$ & $\stackrel{+}{\dot{r}}$ & $\underset{N}{N}$ & iे & $\stackrel{+}{+}$ & $\stackrel{m}{f}$ & $\dot{m}$ & $\bar{f}$ & $\stackrel{m}{m}$ & 6 \\
\hline & 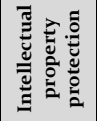 & $\stackrel{\vec{i}}{ }$ & $\underset{\mathrm{N}}{N}$ & ì & $\hat{i}$ & $\stackrel{0}{\dot{m}}$ & $\hat{n}$ & 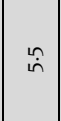 & $\dot{m}$ & $\stackrel{\infty}{+}$ & $\underset{i}{0}$ & ก้ & $\vec{m}$ & $\underset{m}{\sim}$ & $\stackrel{n}{i}$ & 7 & $\stackrel{n}{\dot{m}}$ & $m$ & $\stackrel{+}{m}$ & $\stackrel{\sim}{m}$ & i̊ \\
\hline & 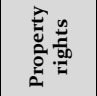 & $\begin{array}{l}\infty \\
\dot{i}\end{array}$ & $\dot{m}$ & $\stackrel{\infty}{i}$ & 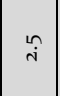 & $\stackrel{6}{\dot{\sigma}}$ & ஸे & iे & $\sigma$ & $\stackrel{\text { in }}{i n}$ & $\dot{\dot{m}}$ & $\stackrel{+}{\text { in }}$ & $\stackrel{+}{m}$ & $\stackrel{\sim}{m}$ & $\hat{m}$ & $\stackrel{q}{\dot{q}}$ & $\stackrel{\circ}{+}$ & $\stackrel{i m}{m}$ & $\hat{m}$ & $\stackrel{\bullet}{\dot{m}}$ & 6 \\
\hline & 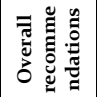 & $\underset{\tilde{i}}{\tilde{i}}$ & 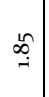 & $\stackrel{\circ}{\rightarrow}$ & $\underset{i}{\mathbb{T}}$ & $\begin{array}{l}\hat{\imath} \\
\text { i }\end{array}$ & $\stackrel{\substack{\hat{h} \\
i}}{ }$ & 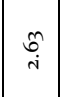 & $\underset{i}{\stackrel{R}{i}}$ & $\stackrel{\substack{\hat{i} \\
i}}{n}$ & $\mid \begin{array}{c}\infty \\
\infty \\
-\rightarrow+1\end{array}$ & $\begin{array}{l}\stackrel{\bullet}{1} \\
\text { ming }\end{array}$ & $\underset{\sim}{\stackrel{\leftrightarrow}{\circ}}$ & $\stackrel{ }{\stackrel{N}{*}}$ & $\stackrel{\mathscr{n}}{\mathfrak{j}}$ & $\underset{\text { T }}{\mathbb{N}}$ & $\underset{i}{\vec{j}}$ & $\underset{\dot{i}}{\sigma}$ & 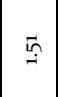 & গิ & $\stackrel{\substack{i \\
i}}{i}$ \\
\hline & 帘 & N & - & a & - & $m$ & ה & $m$ & N & + & - & r & $r$ & - & N & $\tau$ & m & $\sigma$ & $\tau$ & - & - \\
\hline & 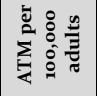 & $\begin{array}{l}\hat{\imath} \\
\dot{m} \\
\dot{m}\end{array}$ & f̊ & $\begin{array}{l}\tilde{N} \\
\infty \\
\infty\end{array}$ & $\begin{array}{l}\text { of } \\
\infty \\
\text { in }\end{array}$ & $\begin{array}{l}\text { J } \\
\text { in }\end{array}$ & 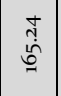 & $\begin{array}{l}\hat{\alpha} \\
\stackrel{0}{\Rightarrow}\end{array}$ & $\begin{array}{l}m \\
\dot{m} \\
m\end{array}$ & $\begin{array}{l}0 \\
\vdots \\
\dot{m}\end{array}$ & $\begin{array}{l}\vec{b} \\
\dot{i n}\end{array}$ & $\begin{array}{l}\alpha \\
\dot{\kappa}\end{array}$ & 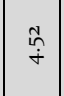 & $\begin{array}{c}\hat{+} \\
\dot{m}\end{array}$ & $\begin{array}{l}+ \\
0 \\
0 \\
\mathscr{b}\end{array}$ & 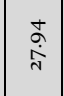 & $\stackrel{\curvearrowleft}{=}$ & $\begin{array}{l}\infty \\
\alpha \\
\dot{\alpha}\end{array}$ & $\overrightarrow{\tilde{m}}$ & $\stackrel{\sigma}{\stackrel{\sigma}{\dot{0}}}$ & $\begin{array}{l} \pm \\
\text { J } \\
\text { J }\end{array}$ \\
\hline & 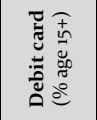 & $\begin{array}{l}\infty \\
\dot{\vec{H}}\end{array}$ & $\begin{array}{l}\stackrel{0}{\vec{N}} \\
\end{array}$ & $\underset{\vec{n}}{+}$ & $\underset{\sim}{\stackrel{\sim}{f}}$ & $\stackrel{+}{+}$ & $\stackrel{\vec{\infty}}{\infty}$ & 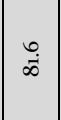 & 阜 & $\stackrel{a}{\dot{L}}$ & 瓷 & 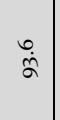 & in & $\overline{\tilde{n}}$ & $\stackrel{+}{+}$ & $\overrightarrow{\dot{m}}$ & กั & iे & $\stackrel{m}{f}$ & i் & Nָ \\
\hline & 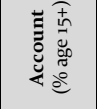 & $\infty_{m}$ & $\begin{array}{l}\stackrel{n}{0} \\
\text { in }\end{array}$ & $\stackrel{m}{i}$ & $\begin{array}{l}\text { Tr } \\
\text { in }\end{array}$ & $\stackrel{\mathbb{N}}{\stackrel{2}{I}}$ & $\stackrel{\infty}{\alpha}$ & $\hat{\leftrightarrow}$ & ઼ָ & $\stackrel{\vec{\phi}}{\vec{\phi}}$ & $\vec{i}$ & مू & $\stackrel{\square}{\circ}$ & $\stackrel{\hat{\dot{g}}}{ }$ & î. & $\stackrel{N}{\alpha}$ & $\overrightarrow{00}$ & $\hat{\sigma}$ & $\stackrel{+}{m}$ & $\begin{array}{l}\text { I } \\
\stackrel{\text { }}{ }\end{array}$ & $\bar{\alpha}$ \\
\hline 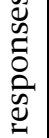 & 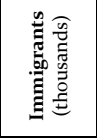 & $\begin{array}{l}\hat{\dot{\theta}} \\
\stackrel{\infty}{\sim}\end{array}$ & 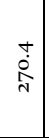 & $\underset{\infty}{\stackrel{+}{\Delta}}$ & $\begin{array}{c}+ \\
\stackrel{0}{\circ}\end{array}$ & $\stackrel{\infty}{m}$ & $\begin{array}{l}0 \\
0 \\
0 \\
0 \\
0\end{array}$ & $\stackrel{\infty}{\stackrel{\leftrightarrow}{\circ}}$ & 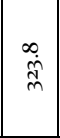 & 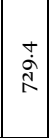 & $\begin{array}{l}1 n \\
\dot{\delta} \\
\dot{m}\end{array}$ & 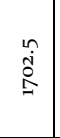 & ָे & $\cong$ & $\underset{\sim \widetilde{N}}{\tilde{N}}$ & 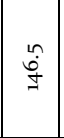 & 㑒 & $\underset{\infty}{+}$ & ถิ & 它 & $\begin{array}{l}\text { I } \\
\stackrel{+}{+}\end{array}$ \\
\hline 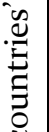 & 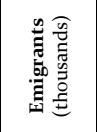 & 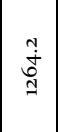 & 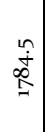 & $\underset{\substack{\hat{D} \\
\text { in }}}{ }$ & $\begin{array}{l}\infty \\
\stackrel{\infty}{0} \\
\infty \\
\infty\end{array}$ & $\begin{array}{l}\hat{\dot{b}} \\
\stackrel{\infty}{\wedge}\end{array}$ & $\underset{\substack{\infty \\
\sim}}{m}$ & 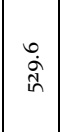 & 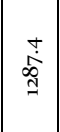 & $\begin{array}{l}\stackrel{0}{0} \\
\stackrel{0}{0}\end{array}$ & $\begin{array}{l}\vec{i} \\
\hat{N} \\
\kappa\end{array}$ & $\begin{array}{l}+ \\
\dot{\hat{n}}\end{array}$ & 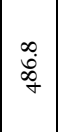 & શิ & فे & $\stackrel{\text { n }}{i \hat{n}}$ & $\begin{array}{l}\stackrel{m}{+} \\
\stackrel{+}{\infty}\end{array}$ & $\begin{array}{l}0 \\
\stackrel{0}{\sigma} \\
\exists\end{array}$ & 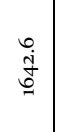 & 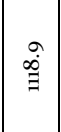 & 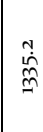 \\
\hline$\frac{\vec{J}}{\tilde{Z}}$ & 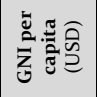 & $\stackrel{\circ}{\stackrel{\circ}{q}}$ & $\stackrel{0}{\tilde{m}}$ & 号 & : & $\stackrel{\circ}{\stackrel{一}{m}}$ & \begin{tabular}{l}
8 \\
\multirow{+}{0}{} \\
th
\end{tabular} & $\begin{array}{l}\text { \&ิ人ે } \\
\text { in }\end{array}$ & 品 & 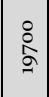 & $\stackrel{\circ}{\circ}$ & $\begin{array}{l}\stackrel{0}{\hat{m}} \\
\stackrel{\sigma}{+}\end{array}$ & $\stackrel{2}{\circ}$ & 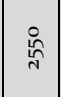 & 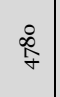 & $\stackrel{R}{\hat{k}}$ & $\begin{array}{l}\circ \\
\stackrel{\circ}{\Rightarrow}\end{array}$ & $\stackrel{\circ}{\circ}$ & 员 & 号 & 离 \\
\hline 苞 & 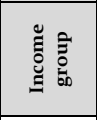 & 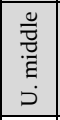 & 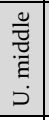 & 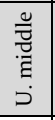 & 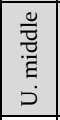 & 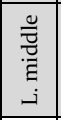 & 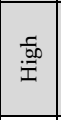 & 点 & 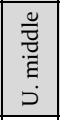 & $\frac{c}{.00}$ & 3 & 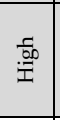 & ]$_{0}^{3}$ & 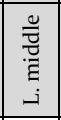 & 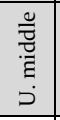 & 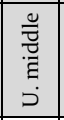 & 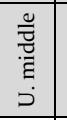 & 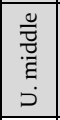 & క్ & కె & 点总 \\
\hline 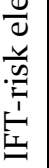 & 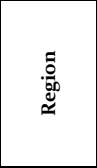 & 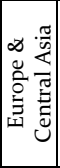 & 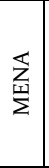 & 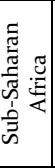 & 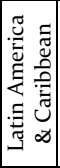 & 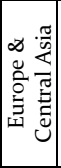 & 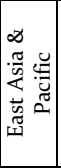 & 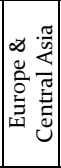 & 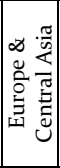 & 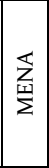 & 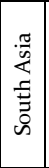 & 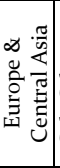 & 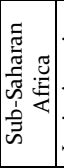 & 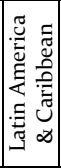 & 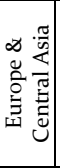 & 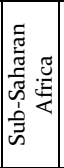 & 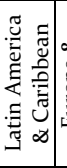 & 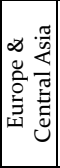 & 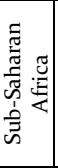 & 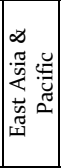 & 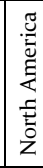 \\
\hline 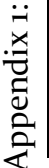 & 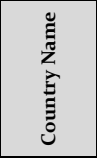 & 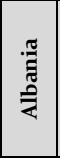 & 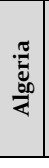 & $\begin{array}{l}\frac{\pi}{0} \\
\frac{8}{5} \\
\frac{5}{4}\end{array}$ & 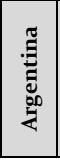 & 离 & 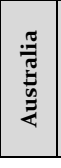 & 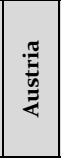 & 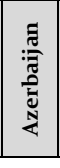 & 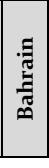 & 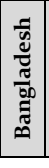 & 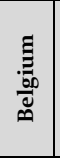 & 苛 & : & 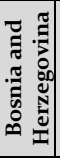 & $\begin{array}{l}\pi \\
\tilde{\pi} \\
\frac{\pi}{2} \\
0 \\
0 \\
0\end{array}$ & 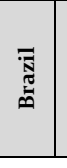 & 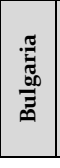 & 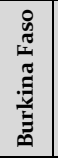 & 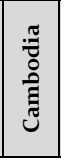 & 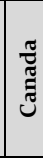 \\
\hline
\end{tabular}




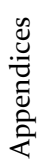

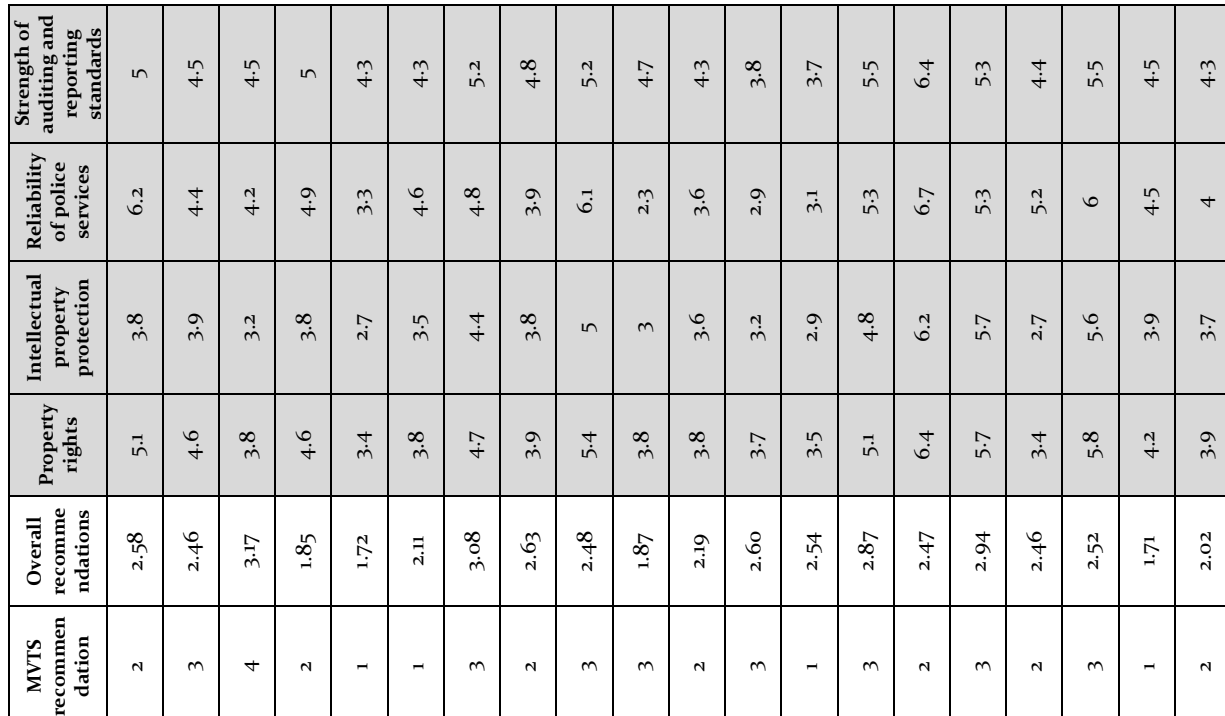

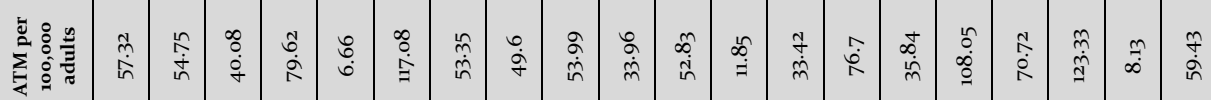

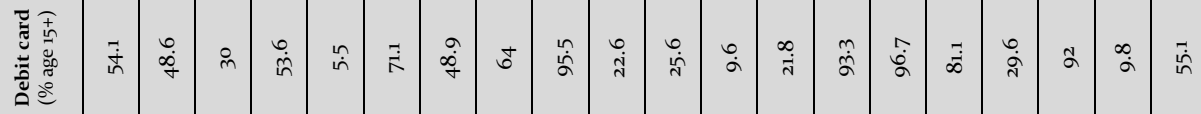

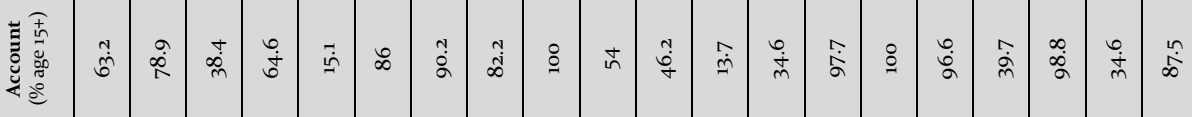

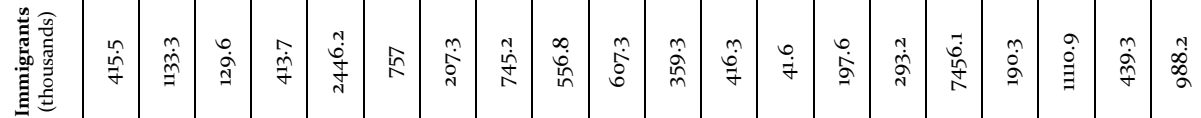

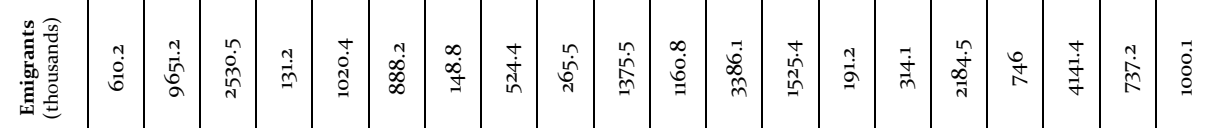

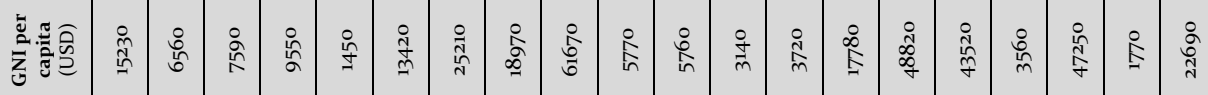

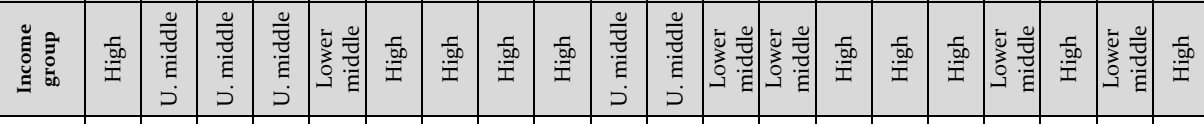

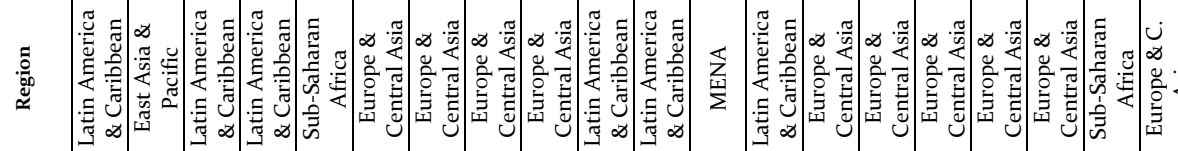

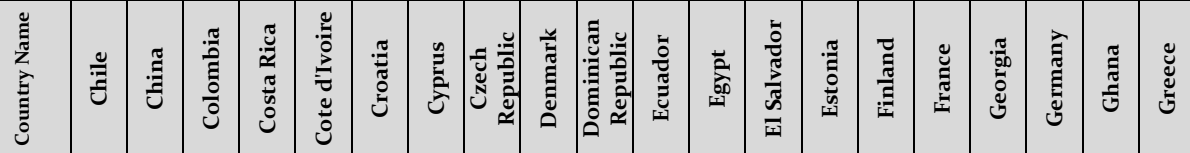




\begin{tabular}{|c|c|c|c|c|c|c|c|c|c|c|c|}
\hline & $\Rightarrow=$ & 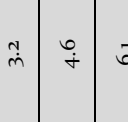 & & & & & & 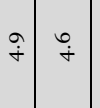 & & $=9 \%$ & \\
\hline 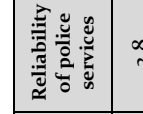 & & & & & 57 & & & ing & & $=m$ & $=7$ \\
\hline & & $4 \bar{s}$ & 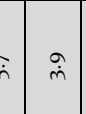 & & 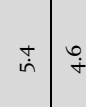 & & & $\because$ & & $=8$ & $: \approx$ \\
\hline 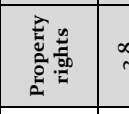 & & $\bar{a} \quad \neq$ & $\Rightarrow$ & & $\therefore 0$ & & $={ }^{\infty}$ & $\therefore 7$ & & 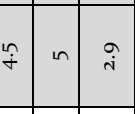 & $2: 7$ \\
\hline$\frac{1}{n}$ & 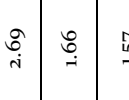 & 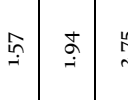 & 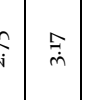 & & $\bar{\sigma} \bar{\sigma}$ & & $\hat{i}$ & $\frac{2}{1}$ & & $\frac{8}{2}=$ & 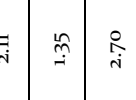 \\
\hline 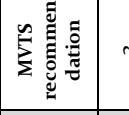 & & $-\cdots$ & + & & $\cdots$ & & 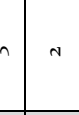 & 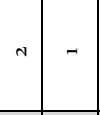 & - & $\cdots "$ & $\ldots$ \\
\hline 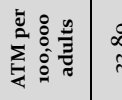 & $\stackrel{g}{8 g}$ & 结 & 总 & & 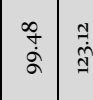 & 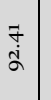 & 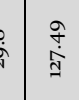 & 骨高 & & 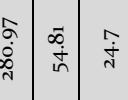 & 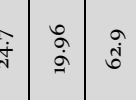 \\
\hline 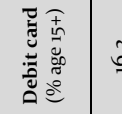 & & $\exists \exists$ & 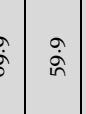 & & $\because$ & & $=$ & 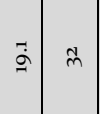 & & $\frac{10}{8}$ & 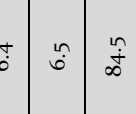 \\
\hline 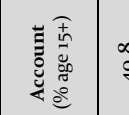 & 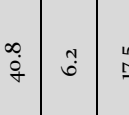 & 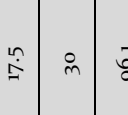 & $=8$ & & f: & & & $g)$ & & 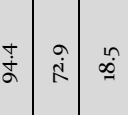 & $\frac{2}{2}: \frac{8}{8}$ \\
\hline & 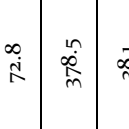 & 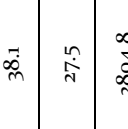 & & & 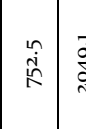 & & & 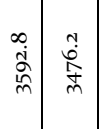 & & & 月。 \\
\hline & 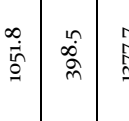 & 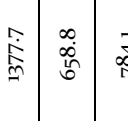 & & & 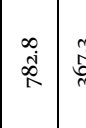 & & & 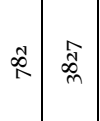 & & $\begin{array}{l}a^{3} \\
\vdots\end{array}$ & 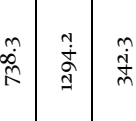 \\
\hline 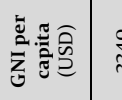 & $\frac{8}{2}$ & $\frac{8}{6} \frac{8}{7}$ & $\frac{8}{2}$ & & 量 & 葛 & & $\stackrel{g}{q} \stackrel{q}{q}$ & & & $\frac{1}{12} \frac{2}{2} \frac{8}{2}$ \\
\hline 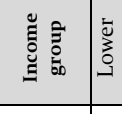 & & 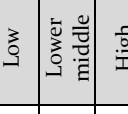 & 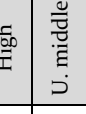 & & 豊高 & & & 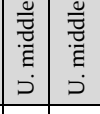 & & & 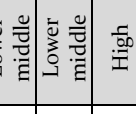 \\
\hline & 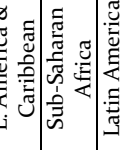 & 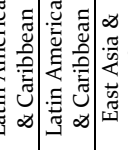 & & & & & & & & $\begin{array}{l}2 \\
2\end{array}$ & 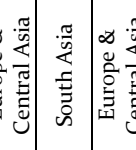 \\
\hline & 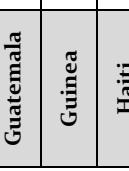 & $\frac{1}{2}$ & & & $=1$ & & & 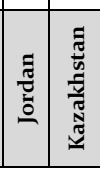 & & $\frac{8}{8}$ & 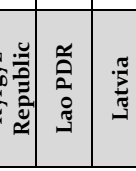 \\
\hline
\end{tabular}




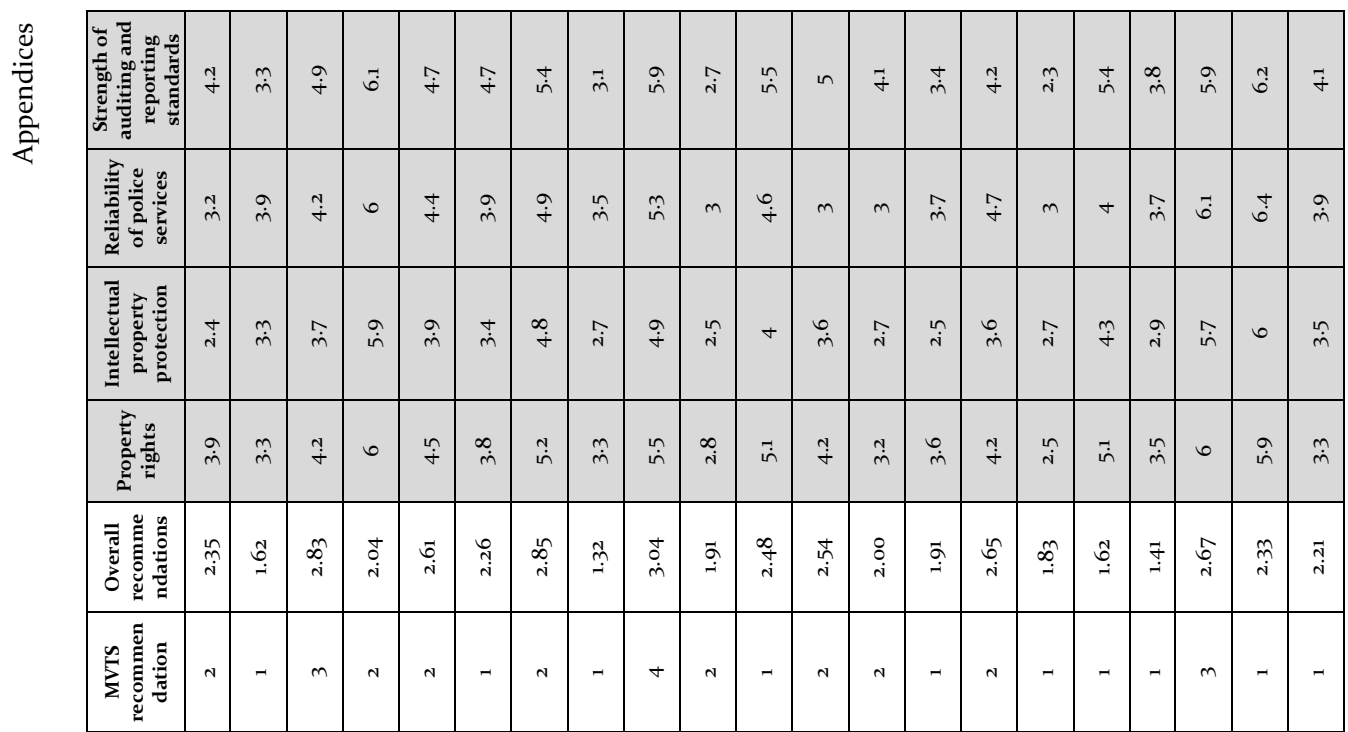

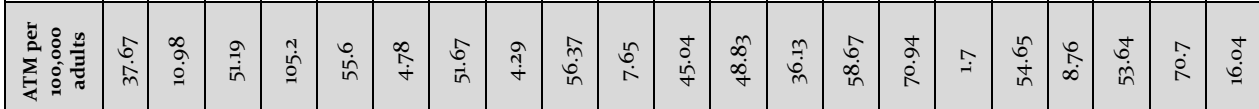

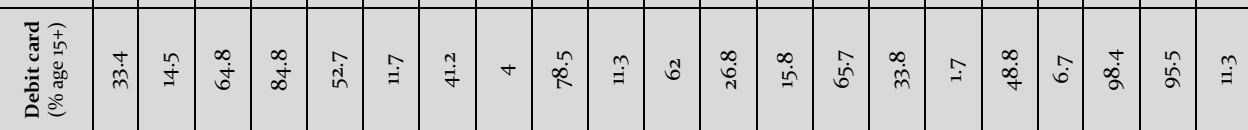

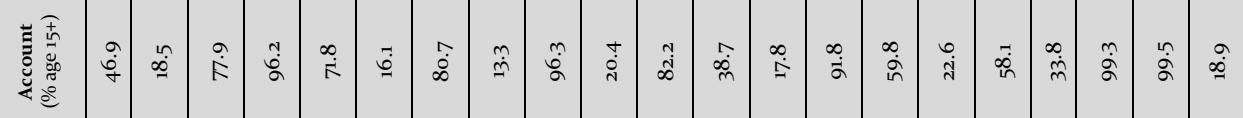

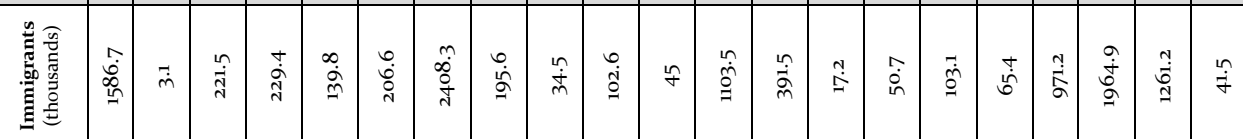

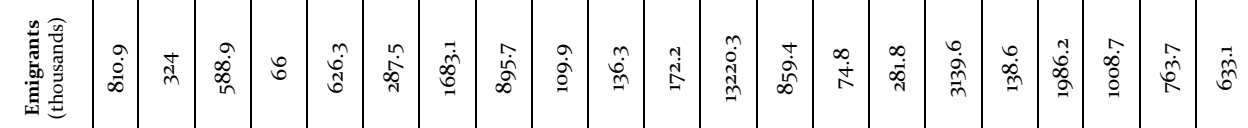

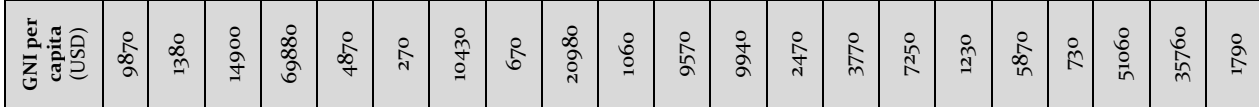

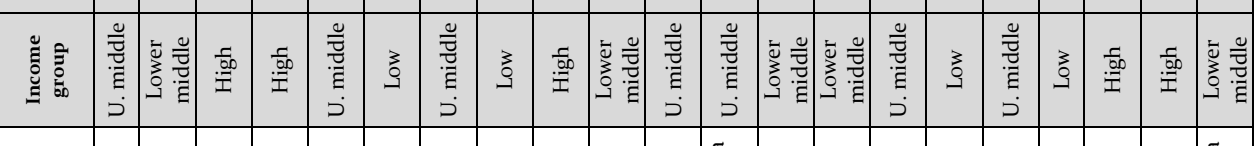

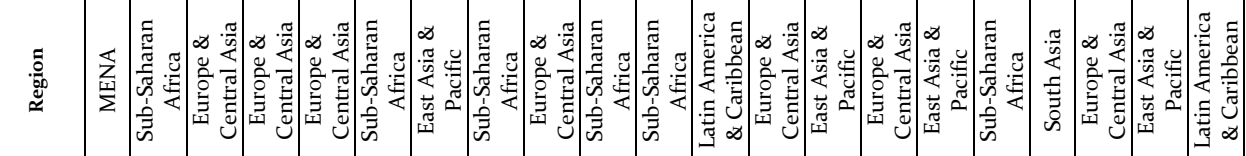

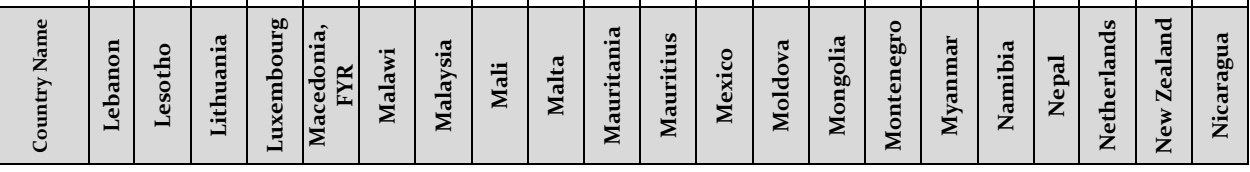




\begin{tabular}{|c|c|c|c|c|c|c|c|c|c|c|c|c|c|c|c|c|c|c|c|c|}
\hline 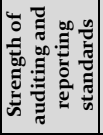 & + & $\overline{6}$ & $\stackrel{+}{+}$ & $\hat{n}$ & + & $q$ & ஸื & in & $\stackrel{\infty}{+}$ & t & r & $\begin{array}{l}0 \\
\text { in }\end{array}$ & $\stackrel{\text { nq }}{f}$ & $\dot{m}$ & $\sigma$ & กู & $\stackrel{\infty}{+}$ & $\stackrel{\text { in }}{f}$ & $\hat{\sigma}$ & $\stackrel{+}{+}$ \\
\hline 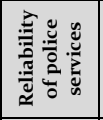 & $\vec{i}$ & 6 & $\stackrel{\infty}{i}$ & 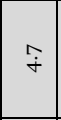 & I & $\stackrel{\infty}{i}$ & $\stackrel{\infty}{m}$ & F & $\stackrel{n}{n}$ & $\stackrel{b}{\dot{m}}$ & $m$ & ì & $\stackrel{\text { in }}{f}$ & t & $\stackrel{\infty}{\dot{m}}$ & $\hat{\omega}$ & $\stackrel{0}{\dot{m}}$ & in & $\stackrel{\infty}{m}$ & in \\
\hline 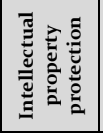 & $\underset{\substack{\infty \\
i}}{ }$ & $\hat{i n}$ & iे & $\stackrel{0}{\dot{r}}$ & $\hat{i}$ & $\stackrel{\infty}{i}$ & $\stackrel{\varphi}{\dot{m}}$ & $\dot{m}$ & $\stackrel{\text { in }}{f}$ & $\hat{i}$ & $\vec{i}$ & in & $\stackrel{N}{m}$ & $\stackrel{i}{i}$ & $\dot{m}$ & $\overline{6}$ & $\hat{m}$ & $\stackrel{N}{+}$ & in & $\sigma$ \\
\hline 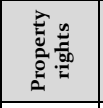 & $\stackrel{+}{\dot{m}}$ & 6 & $\stackrel{m}{m}$ & $\stackrel{\infty}{+}$ & $\vec{m}$ & $\hat{m}$ & $\hat{q}$ & $\stackrel{m}{f}$ & $\stackrel{\infty}{+}$ & $\dot{\dot{m}}$ & $m$ & $\hat{i n}$ & $\sigma$ & $\stackrel{\sim}{m}$ & $\hat{m}$ & $\hat{\theta}$ & $\dot{m}$ & $\hat{f}$ & in & $\stackrel{\Upsilon}{\dot{f}}$ \\
\hline 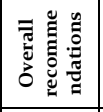 & $\stackrel{n}{\stackrel{n}{+}}$ & 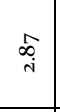 & $\stackrel{\overrightarrow{\mathrm{i}}}{\mathrm{i}}$ & $\stackrel{m}{\stackrel{i}{+}}$ & 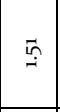 & $\stackrel{\leftrightarrow}{\stackrel{i}{i}}$ & $\widehat{\widehat{N}}$ & $\stackrel{\infty}{\underset{i}{N}}$ & $\stackrel{\infty}{a}$ & $\begin{array}{l}\tilde{J} \\
\text { i }\end{array}$ & $\begin{array}{l}\hat{\mathrm{i}} \\
\mathrm{i}\end{array}$ & $\begin{array}{l}\stackrel{\circ}{0} \\
\dot{i}\end{array}$ & กิ & $\stackrel{\infty}{\stackrel{i}{i}}$ & $\stackrel{m}{i}$ & $\stackrel{\leftrightarrow}{\dot{m}}$ & $\stackrel{\hat{n}}{i}$ & $\stackrel{\circ}{\dot{m}}$ & 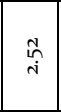 & $\stackrel{\substack{\infty \\
i}}{ }$ \\
\hline 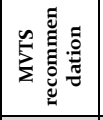 & a & N & N & - & - & a & N & - & m & $r$ & - & $m$ & N & N & - & $m$ & m & + & N & $m$ \\
\hline 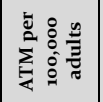 & $\stackrel{\infty}{\stackrel{0}{0}}$ & 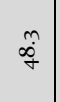 & 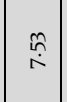 & 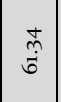 & $\begin{array}{l}\stackrel{一}{+} \\
\stackrel{+}{+}\end{array}$ & $\begin{array}{l}\stackrel{2}{\circ} \\
\dot{+} \\
\text { ஸे }\end{array}$ & $\underset{\tilde{n}}{\stackrel{\Re}{\tilde{n}}}$ & $\begin{array}{l}\stackrel{0}{0} \\
\tilde{\emptyset}\end{array}$ & 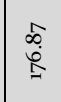 & $\begin{array}{l}\hat{0} \\
\dot{\leftrightarrow} \\
\hat{\sigma}\end{array}$ & $\begin{array}{l}\tilde{N} \\
\dot{\infty} \\
\infty\end{array}$ & $\begin{array}{l}\tilde{n} \\
0 \\
0 \\
0 \\
0\end{array}$ & $\stackrel{+}{\dot{q}}$ & 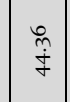 & $\hat{\hat{o}}$ & 華 & 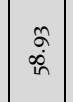 & $\begin{array}{l}\hat{n} \\
\hat{\leftrightarrow} \\
\stackrel{\leftrightarrow}{0}\end{array}$ & $\begin{array}{l}\infty \\
\stackrel{0}{0} \\
0\end{array}$ & $\begin{array}{l}\stackrel{0}{0} \\
\stackrel{0}{\Rightarrow}\end{array}$ \\
\hline 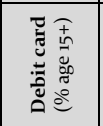 & $\begin{array}{l}\dot{\dot{m}} \\
\dot{m}\end{array}$ & $\begin{array}{l}0 \\
\infty \\
\infty\end{array}$ & $\vec{i}$ & 率 & $\stackrel{M}{=}$ & 芶 & 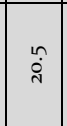 & 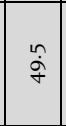 & $\hat{\emptyset}$ & $\begin{array}{l}\infty \\
\text { if }\end{array}$ & $\stackrel{m}{\dot{f}}$ & $\begin{array}{l}0 \\
\stackrel{\mathscr{\vartheta}}{ }\end{array}$ & iे & $\stackrel{\infty}{\stackrel{\infty}{i n}}$ & in & ڤે & $\stackrel{\text { nn }}{\grave{R}}$ & $\stackrel{\tilde{a}}{ }$ & $\stackrel{a}{\dot{+}}$ & $\begin{array}{l}0 \\
\text { ij }\end{array}$ \\
\hline 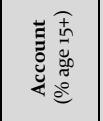 & $\stackrel{\sim}{\underset{J}{J}}$ & 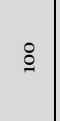 & $\hat{\infty}$ & $\stackrel{m}{\tilde{f}}$ & $\hat{\vec{\pi}}$ & iे & $\vec{\phi}$ & 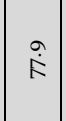 & $\underset{\infty}{\stackrel{+}{\Delta}}$ & $\begin{array}{l}\infty \\
\stackrel{0}{0}\end{array}$ & $\stackrel{+}{\stackrel{+}{0}}$ & बें & $\stackrel{\leftrightarrow}{\dot{I}}$ & $\vec{\infty}$ & $\bar{j}$ & ฉั๋ & $\stackrel{n}{R}$ & 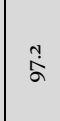 & $\begin{array}{l}\infty \\
\infty \\
\infty \\
0\end{array}$ & $\stackrel{\circ}{\stackrel{\sigma}{\sigma}}$ \\
\hline 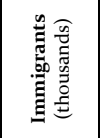 & $\begin{array}{l}0 \\
\stackrel{\tilde{\aleph}}{\tilde{d}}\end{array}$ & ฮૂ & $\begin{array}{l}\infty \\
\dot{0} \\
\infty \\
0 \\
+\end{array}$ & 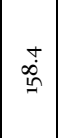 & $\begin{array}{l}\infty \\
\stackrel{\infty}{\dot{\varphi}} \\
\infty\end{array}$ & 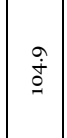 & ָָָ & $\begin{array}{l}\infty \\
\hat{\leftrightarrow} \\
\hat{\emptyset}\end{array}$ & $\begin{array}{c}\infty \\
\hat{\alpha} \\
\infty\end{array}$ & $\begin{array}{c}\infty \\
\stackrel{\infty}{\infty} \\
\stackrel{0}{0}\end{array}$ & $\begin{array}{c}\overrightarrow{0} \\
0 \\
0 \\
g\end{array}$ & 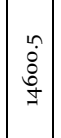 & 苟 & 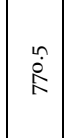 & 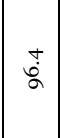 & $\underset{\substack{\tilde{N} \\
\tilde{N}}}{ }$ & $\overrightarrow{0}$ & 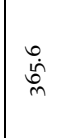 & 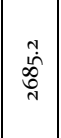 & 龸 \\
\hline 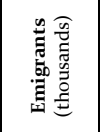 & 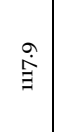 & $\underset{\dot{d}}{\stackrel{N}{d}}$ & $\begin{array}{l}\stackrel{+}{0} \\
\stackrel{8}{0}\end{array}$ & $\hat{\tilde{y}}$ & $\begin{array}{l}\stackrel{\hat{\phi}}{\alpha} \\
\hat{\alpha}\end{array}$ & 辛 & $\begin{array}{l}\hat{0} \\
\stackrel{0}{0}\end{array}$ & $\stackrel{\substack{\infty \\
\infty}}{m}$ & 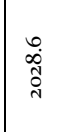 & $\begin{array}{l}\stackrel{n}{\dot{m}} \\
\stackrel{m}{m}\end{array}$ & $\begin{array}{l}\stackrel{n}{0} \\
\stackrel{\circ}{\circ} \\
\stackrel{0}{0}\end{array}$ & ث્ત & 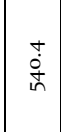 & 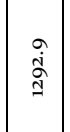 & $\stackrel{m}{m}$ & $\begin{array}{c}\text { N } \\
\text { D } \\
\text { N }\end{array}$ & 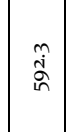 & $\stackrel{M}{\stackrel{M}{\sigma}}$ & $\begin{array}{l}m \\
\stackrel{0}{\infty} \\
\end{array}$ & $\overline{\tilde{\Omega}}$ \\
\hline 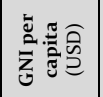 & 옥 & 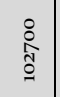 & 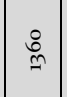 & \begin{tabular}{l}
$\stackrel{+}{\$}$ \\
$\vdots$ \\
\hdashline
\end{tabular} & $\stackrel{\circ}{\circ}$ & 옹 & $\underset{\substack{0 \\
\text { M }}}{ }$ & $\begin{array}{l}\stackrel{\circ}{\text { ch }} \\
\stackrel{m}{m}\end{array}$ & $\begin{array}{l}\text { Rे } \\
\text { त̂̀ }\end{array}$ & 苍 & 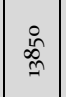 & 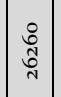 & $\stackrel{\circ}{\wp}$ & ڤ̊̊ & ه & $\begin{array}{l}\text { ơ } \\
\text { ơ } \\
\text { in }\end{array}$ & $\begin{array}{l}\stackrel{\circ}{\circ} \\
\stackrel{D}{=}\end{array}$ & $\begin{array}{l}\text { స్ } \\
\text { }\end{array}$ & $\underset{ }{\stackrel{一}{1}}$ & $\begin{array}{l}\text { ơ } \\
\text { aे } \\
\text { ì }\end{array}$ \\
\hline 彦 & 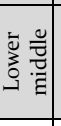 & 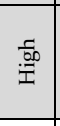 & 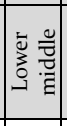 & 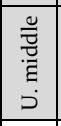 & 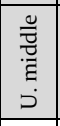 & 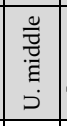 & 节 & $\frac{.5}{.00}$ & 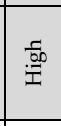 & 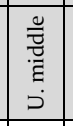 & 点 & 总 & 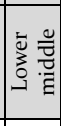 & 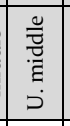 & 3 & 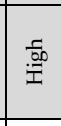 & 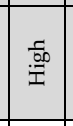 & $\stackrel{\text { 몽 }}{=0}$ & $\begin{array}{l}\frac{\vartheta}{\bar{z}} \\
\overrightarrow{\tilde{E}} \\
\dot{\partial} \\
\end{array}$ & 总 \\
\hline 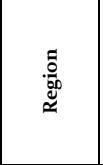 & 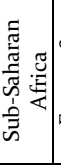 & 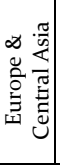 & 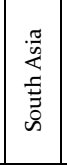 & 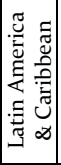 & 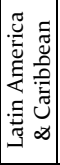 & 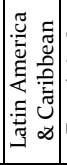 & 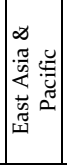 & 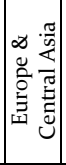 & 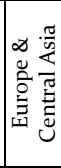 & 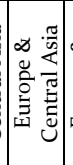 & 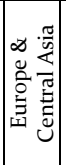 & 辛 & 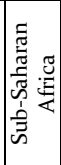 & 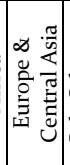 & 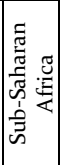 & 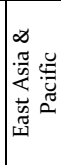 & 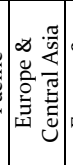 & 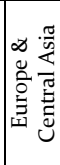 & 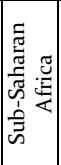 & 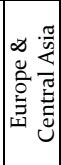 \\
\hline 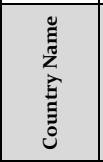 & $\begin{array}{l}\stackrel{\pi}{\vec{J}} \\
\stackrel{.00}{z}\end{array}$ & 离 & 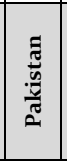 & 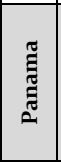 & 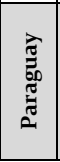 & $\stackrel{\Xi}{\tilde{J}}$ & 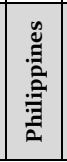 & 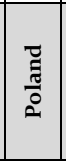 & 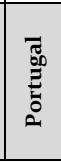 & 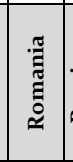 & 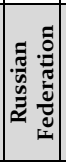 & 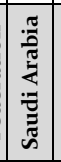 & 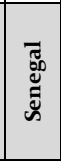 & מ⿱艹 & 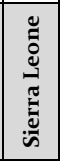 & 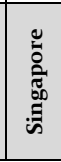 & 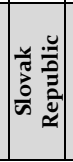 & $\begin{array}{l}\stackrel{5}{\Xi} \\
\text { के }\end{array}$ & 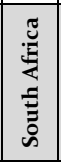 & 䒕 \\
\hline
\end{tabular}




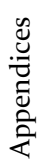

\begin{tabular}{|c|c|c|c|c|c|c|c|c|c|c|c|c|c|c|c|c|c|c|c|}
\hline 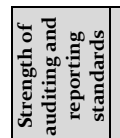 & $\overline{\text { in }}$ & in & in & $\dot{m}$ & in & $\stackrel{\text { N }}{+}$ & $\stackrel{\text { In }}{\dot{f}}$ & in & $\stackrel{\infty}{m}$ & $\hat{m}$ & $\stackrel{+}{i}$ & $\stackrel{\infty}{\text { in }}$ & $\hat{n}$ & $\stackrel{\infty}{+}$ & $\stackrel{\sim}{+}$ & $\stackrel{+}{\dot{m}}$ & $\hat{i}$ & $\stackrel{0}{+}$ & ํำ \\
\hline 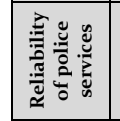 & $\dot{m}$ & ì & $\hat{\sigma}$ & $\stackrel{n}{m}$ & $\stackrel{i n}{m}$ & $\bar{m}$ & $\dot{\dot{m}}$ & $\sigma$ & $\hat{m}$ & $\stackrel{\infty}{i}$ & $\overrightarrow{6}$ & in & in & $\dot{m}$ & $\stackrel{9}{-}$ & $\stackrel{\infty}{m}$ & $\stackrel{\hat{i}}{ }$ & $\stackrel{\text { ก }}{\text { ก }}$ & $m$ \\
\hline 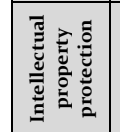 & $\stackrel{\infty}{m}$ & in & 0 & $\underset{m}{N}$ & $\bar{m}$ & $\stackrel{m}{m}$ & $\tilde{m}$ & $\stackrel{0}{\dot{m}}$ & $\stackrel{\infty}{\substack{i \\
i}}$ & $\stackrel{\text { in }}{\mathrm{i}}$ & $\hat{i n}$ & $\stackrel{\infty}{\text { in }}$ & ஸี & $\vec{j}$ & $\stackrel{\circ}{-}$ & $\hat{i}$ & ते & $\dot{m}$ & $m$ \\
\hline 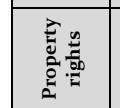 & $\stackrel{+}{+}$ & $\dot{\dot{n}}$ & ชี & $\stackrel{\infty}{m}$ & $F$ & $\stackrel{\sim}{+}$ & $\stackrel{m}{\dot{f}}$ & $\stackrel{\leftarrow}{\dot{f}}$ & $\dot{m}$ & $\stackrel{\text { in }}{\mathrm{i}}$ & $\stackrel{+}{i}$ & ชู่ & in & $\stackrel{q}{\dot{q}}$ & $\stackrel{0}{-}$ & $\stackrel{n}{\dot{m}}$ & $\stackrel{N}{m}$ & $\stackrel{\leftarrow}{\dot{f}}$ & $\stackrel{\bullet}{i}$ \\
\hline 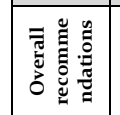 & $\stackrel{\text { }}{\stackrel{\leftrightarrow}{\rightarrow}}$ & $\begin{array}{l}\vec{i} \\
\text {. }\end{array}$ & $\begin{array}{l}\overrightarrow{0} \\
\vec{i}\end{array}$ & $\stackrel{\mathcal{F}}{I}$ & ه્ণ & مْنِ & సै & $\stackrel{\mathscr{N}}{\mathrm{i}}$ & $\stackrel{\widetilde{F}}{\rightarrow}$ & సָ & तु & $\vec{m}$ & $\stackrel{m}{m}$ & $\begin{array}{c}\infty \\
\stackrel{i}{i}\end{array}$ & $\underset{\mathrm{N}}{\overrightarrow{\mathrm{N}}}$ & 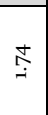 & 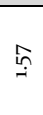 & $\stackrel{\infty}{\underset{I}{q}}$ & $\underset{i}{\stackrel{i}{i}}$ \\
\hline 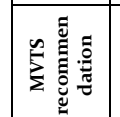 & $r$ & N & + & $\tau$ & a & $\tau$ & $m$ & $\mathrm{~N}$ & N & N & - & $m$ & $m$ & N & N & $\tau$ & $\tau$ & $r$ & N \\
\hline
\end{tabular}

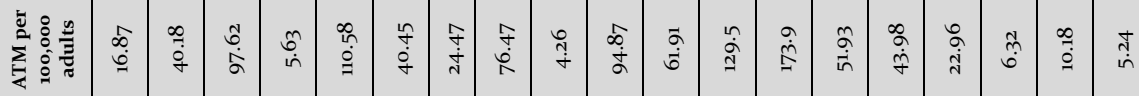

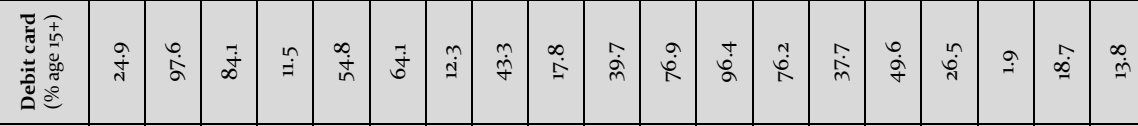

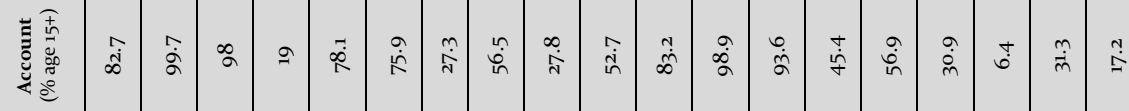

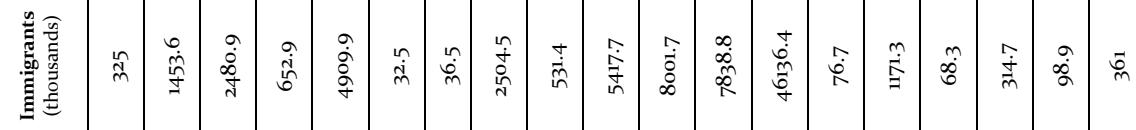

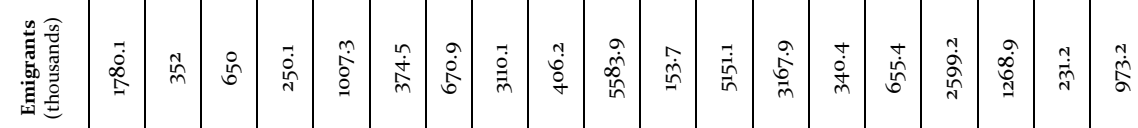

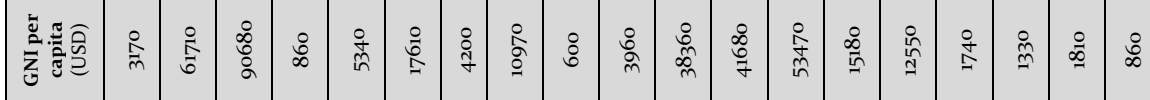

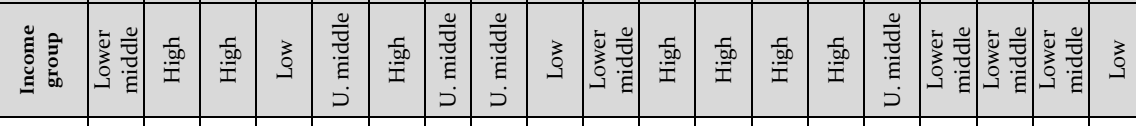

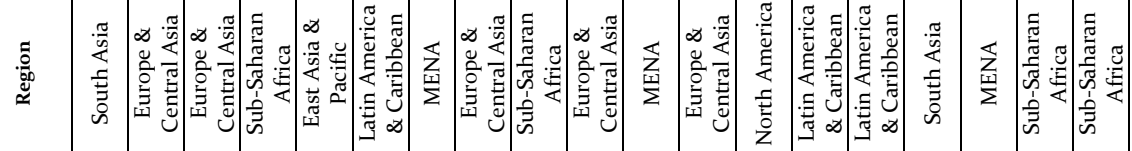

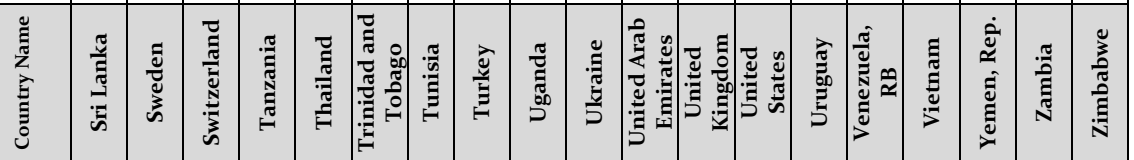




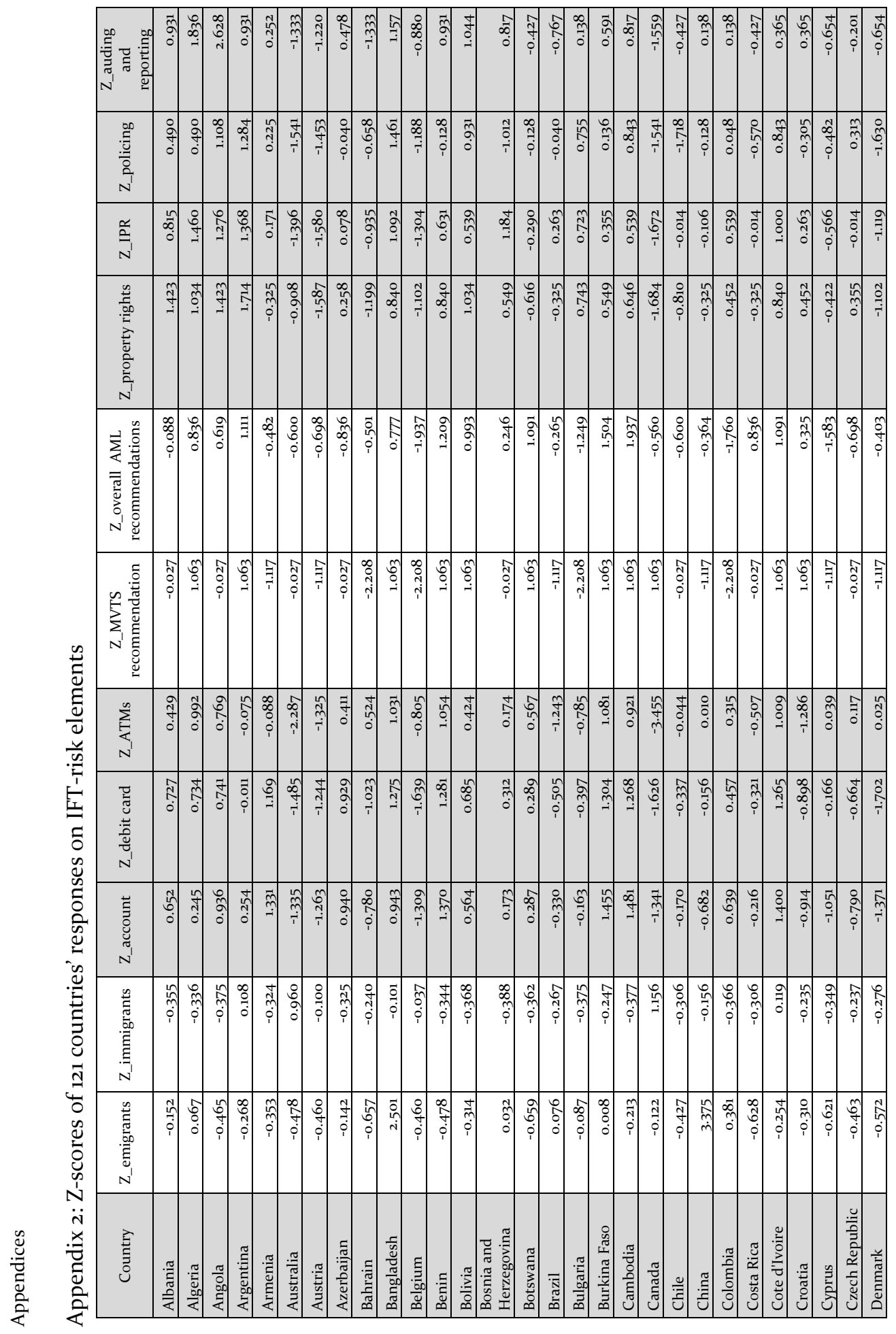




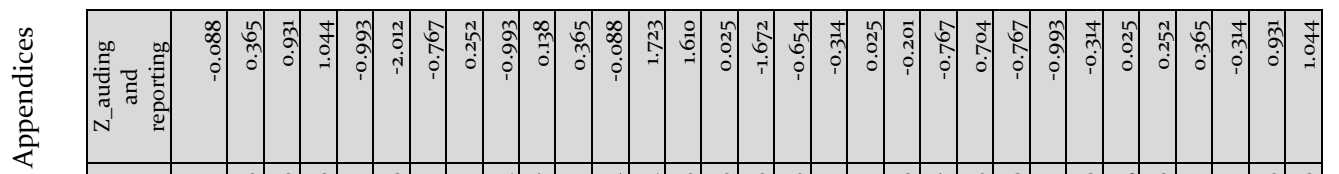

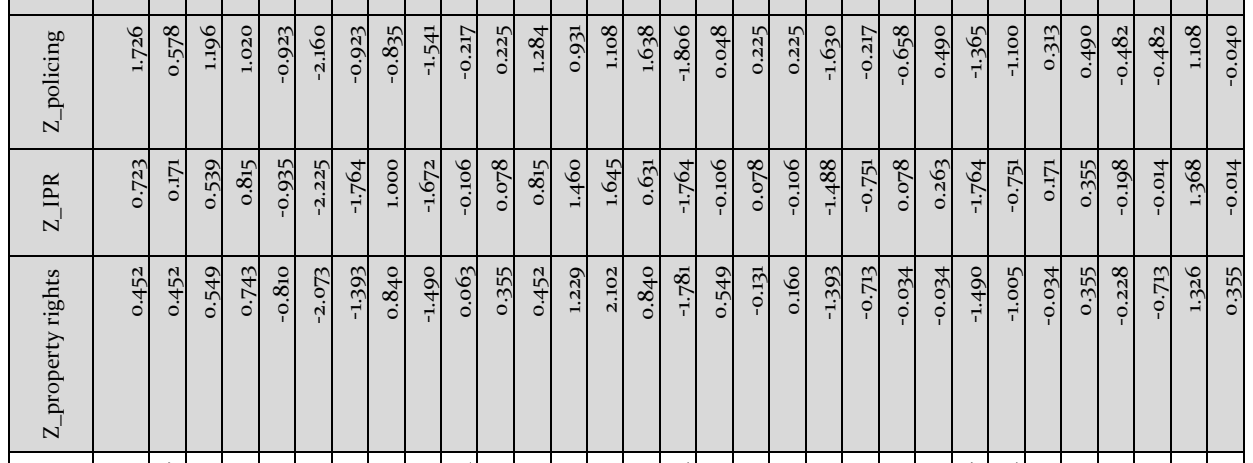

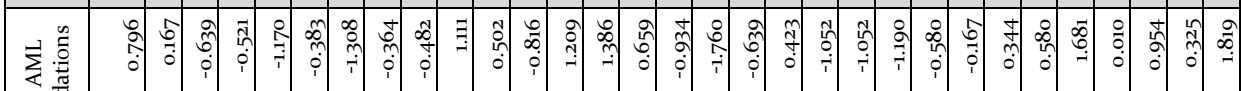

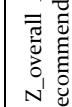

$N$.

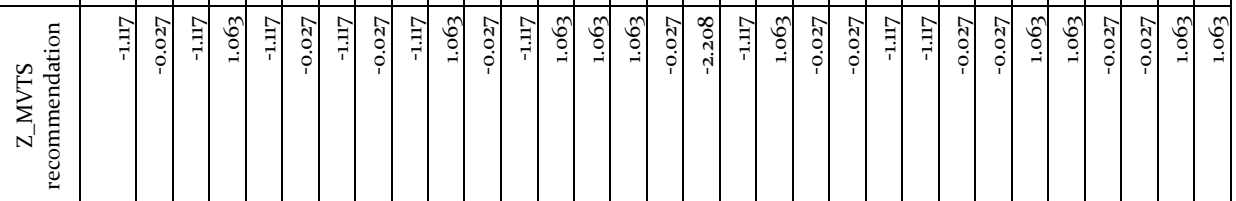

\begin{tabular}{|c|c|c|c|c|c|c|c|c|c|c|c|c|c|c|c|}
\hline$\sum_{i}^{n}$ & & : & $\begin{array}{ll}0 & 0 \\
0 & f \\
0 & f \\
0 & 0\end{array}$ & 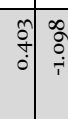 & 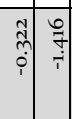 & 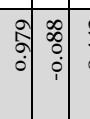 & $\stackrel{f}{f}: \stackrel{0}{=}$ & {$\left[\begin{array}{ccc}n & n \\
0 & 0 & 0 \\
0 & 0 & 0 \\
0\end{array}\right.$} & 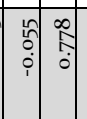 & 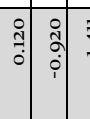 & $\begin{array}{lll}7 & 0 \\
i & 0\end{array}$ & 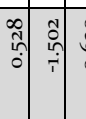 & 然: & 年 & \\
\hline 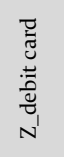 & | & : & 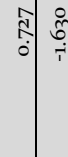 & 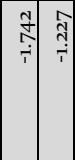 & 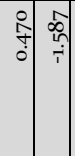 & $\begin{array}{l}0 \\
:\end{array}$ & 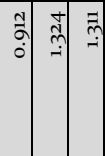 & 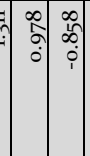 & 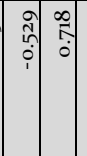 & 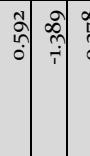 & 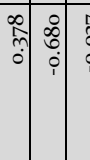 & & 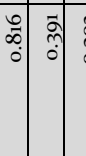 & \begin{tabular}{l}
0 \\
\hdashline
\end{tabular} & 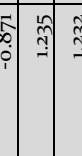 \\
\hline 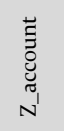 & ㅇํㅇ & $\stackrel{\infty}{\infty}$ & 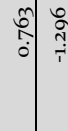 & 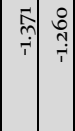 & 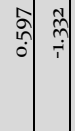 & 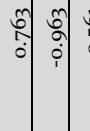 & : & $\left(\begin{array}{lll}n \\
0 \\
0\end{array}\right.$ & 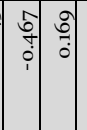 & 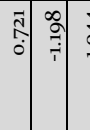 & & 帒 & : & 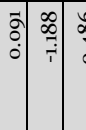 & \\
\hline 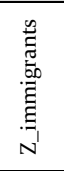 & $\mid$ & & 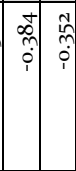 & 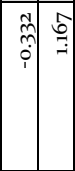 & $\begin{array}{ll}0 \\
0 \\
0\end{array}$ & 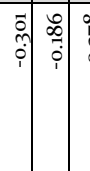 & 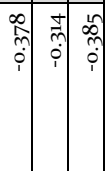 & $\begin{array}{ccc}6 & 0 & 0 \\
0 & 0 \\
0 & 0 \\
0 & 0\end{array}$ & 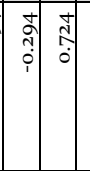 & 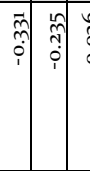 & 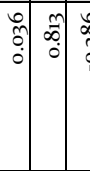 & 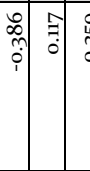 & 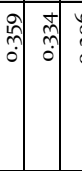 & 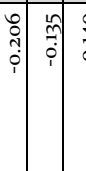 & \\
\hline 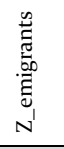 & . & & $\mid \begin{array}{cc}n & 0 \\
0 & 0 \\
\vdots & 0 \\
\vdots & 0\end{array}$ & 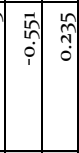 & \begin{tabular}{|c|c|c|c|} 
& 0 \\
0 & 0 & 0 \\
0 & 0 \\
$i$ & 0
\end{tabular} & 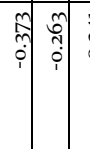 & 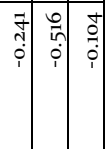 & 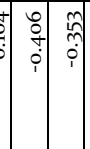 & 等 & 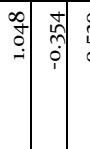 & 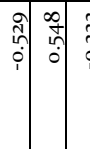 & 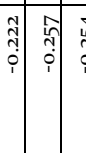 & 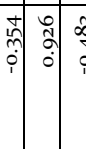 & 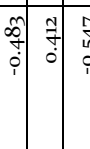 & \\
\hline & & & & & & & & & 푀 듸 & $\overrightarrow{\underline{s}}[\overline{\vec{s}}]$ & 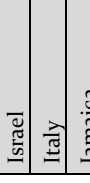 & & $\frac{\pi}{\frac{\pi}{\tilde{c}}}$ & 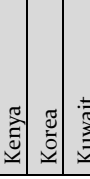 & 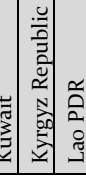 \\
\hline
\end{tabular}




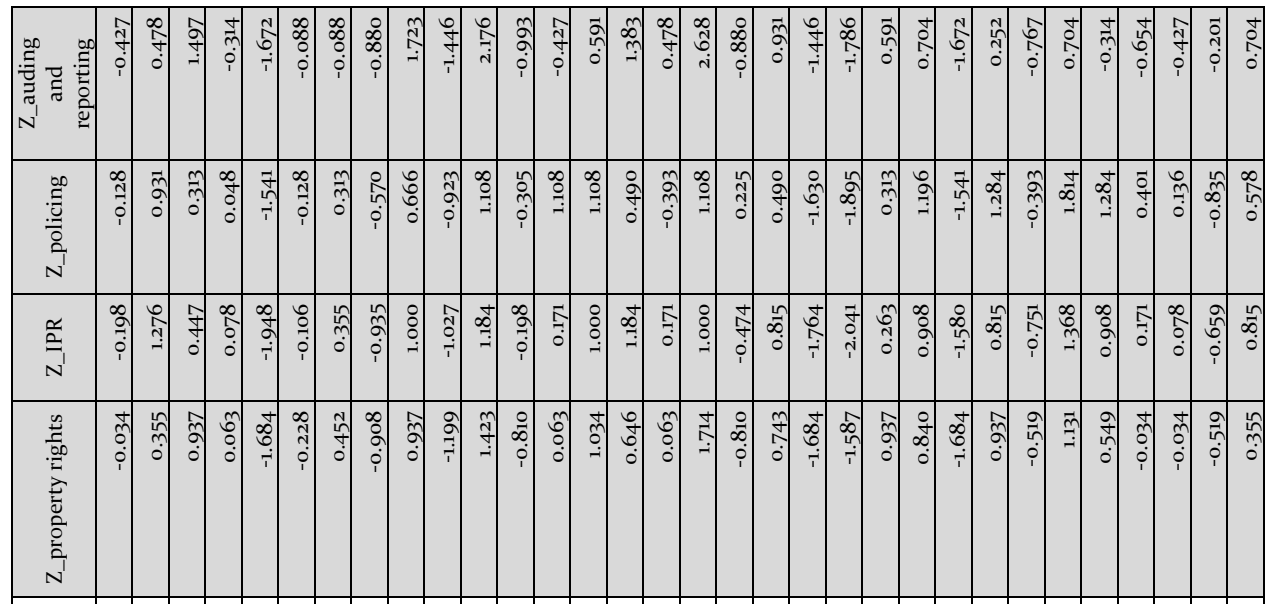

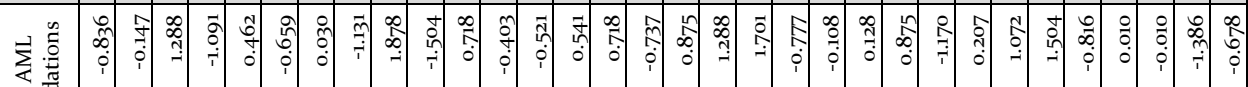
=

它

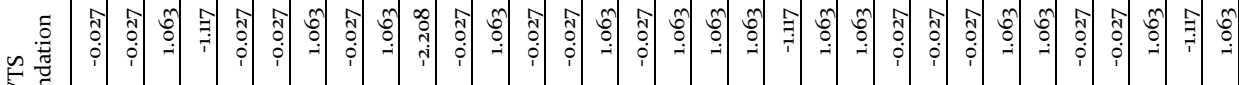
$\sum_{N}$ ह

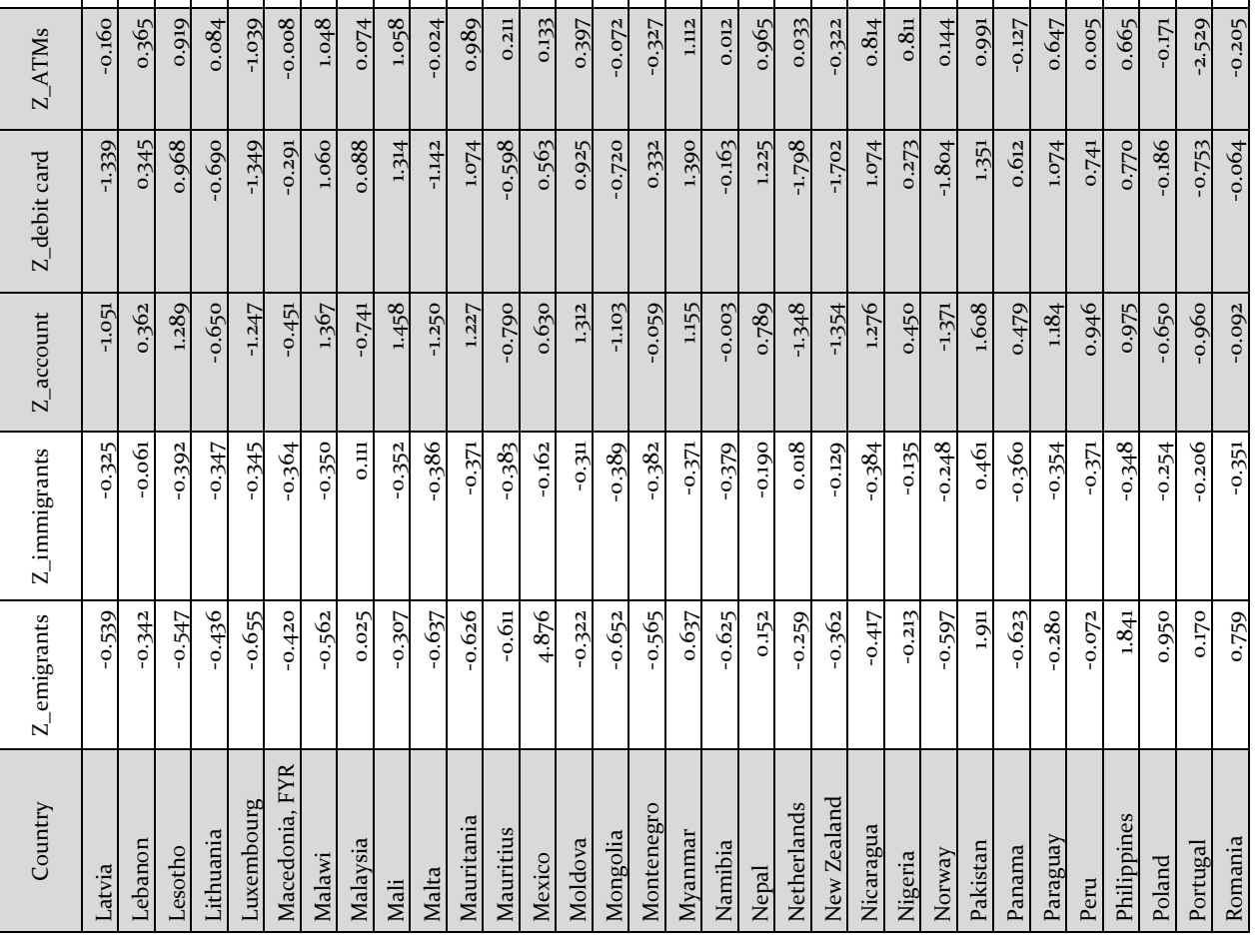




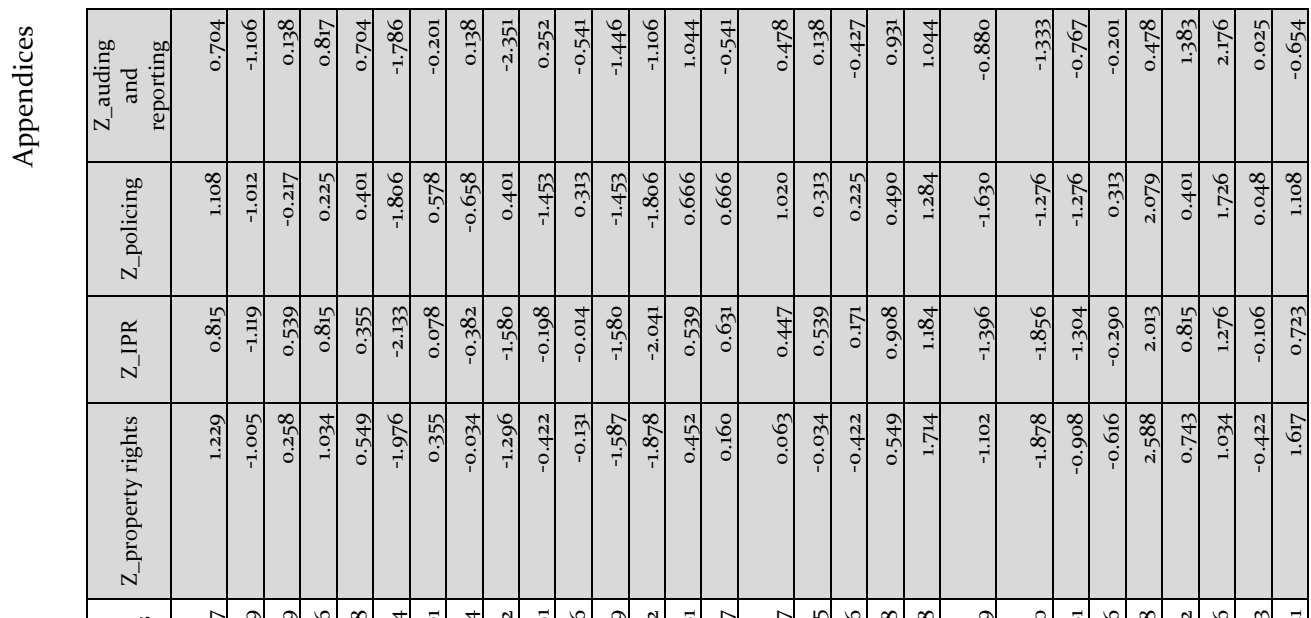

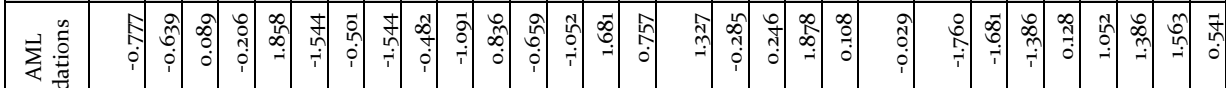

氞

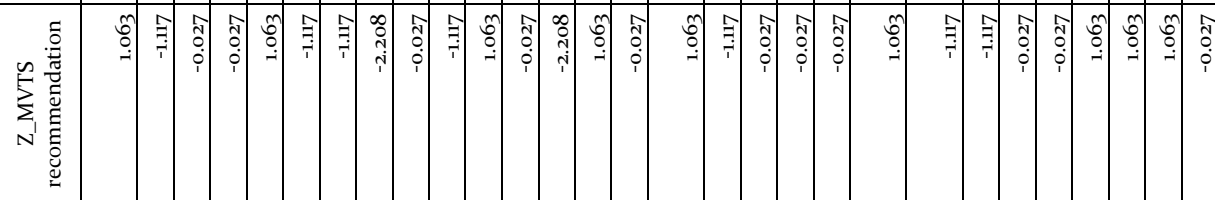

\begin{tabular}{|c|c|c|c|c|c|c|c|c|c|c|c|c|c|c|c|c|c|c|c|c|c|c|c|c|}
\hline$\sum_{\substack{1 \\
N}}^{\infty}$ & $\begin{array}{l}+ \\
0 \\
i \\
i\end{array}$ & $\begin{array}{l}\text { ồ } \\
\vdots \\
i\end{array}$ & |थ & : & $=\begin{array}{c}\infty \\
0 \\
0 \\
\vdots\end{array}$ & $\begin{array}{l}1 \\
0 \\
\vdots\end{array}$ & $\begin{array}{l}0 \\
0 \\
0\end{array}$ & | & जी & 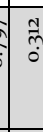 & $\mid \begin{array}{l}\infty \\
\infty \\
0 \\
i\end{array}$ & 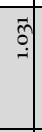 & $\underset{\vec{T}}{\vec{T}}$ & & & 4 & $\begin{array}{l}\text { D. } \\
\text { o. } \\
0\end{array}$ & $\begin{array}{c}\text { के } \\
\stackrel{0}{i}\end{array}$ & 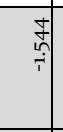 & 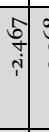 & |con & ○. & | & ڤ్ \\
\hline 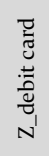 & 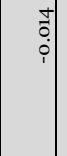 & $\begin{array}{l}\text { ڤ్ } \\
\vdots \\
i\end{array}$ & స્ح & $\begin{array}{ll}\text { tof } \\
\text { cha }\end{array}$ & $\begin{array}{ll}0 \\
0 \\
7 \\
7\end{array}$ & $\left|\begin{array}{c}\infty \\
0 \\
0 \\
0 \\
i\end{array}\right|$ & 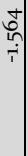 & 苞 & T) & 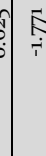 & 总 & $\begin{array}{l}\hat{\circ} \\
\stackrel{0}{-}\end{array}$ & 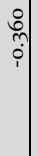 & $\begin{array}{l}10 \\
0 \\
0 \\
i\end{array}$ & & 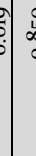 & 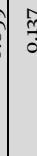 & $\begin{array}{r}0 \\
0 \\
i\end{array}$ & $\underset{i}{\tilde{i}}$ & $\begin{array}{l}\text { : } \\
\text { it } \\
\end{array}$ & & : & & $\begin{array}{c}0 \\
0 \\
0 \\
0\end{array}$ \\
\hline $\begin{array}{l}\text { 志 } \\
\underbrace{}_{0} \\
\tilde{\sigma}_{1}\end{array}$ & $\begin{array}{l}0 \\
0 \\
0 \\
i\end{array}$ & $\begin{array}{l}\hat{N} \\
\hat{i} \\
\hat{i}\end{array}$ & & & 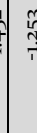 & $\mid \begin{array}{l}1 \\
0 \\
0 \\
i\end{array}$ & 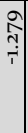 & مُ & ד̦ & 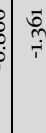 & 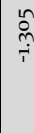 & $\underset{\substack{\mathbb{N} \\
-}}{\mathrm{N}}$ & $\begin{array}{l}0 \\
\stackrel{0}{0} \\
\vdots \\
i\end{array}$ & 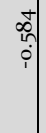 & & $\vec{b}^{\circ}$ & $\frac{5}{0}$ & $\begin{array}{l}n \\
0 \\
0 \\
0\end{array}$ & 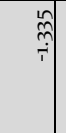 & لِّ & & $\mid \begin{array}{c}\infty \\
\infty \\
\infty \\
0\end{array}$ & $\begin{array}{l}\text { to } \\
\stackrel{+}{+}\end{array}$ & $\begin{array}{r}\mathbb{r} \\
\substack{0 \\
0}\end{array}$ \\
\hline 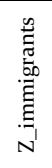 & 文 & $\begin{array}{l}\vec{b} \\
\dot{\mathrm{i}} \\
\text { (2) }\end{array}$ & :ै & 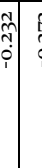 & 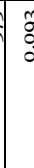 & $\left|\begin{array}{c}0 \\
0 \\
0 \\
i\end{array}\right|$ & ְֶ. & |. & : & 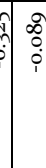 & ]ִ & 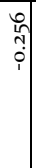 & $\begin{array}{l}\stackrel{\leftrightarrow}{0} \\
\stackrel{0}{0}\end{array}$ & $\begin{array}{c}0 \\
0 \\
0 \\
i \\
1\end{array}$ & & 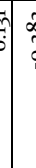 & 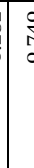 & 馬 & 勇 & 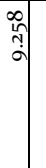 & & 离 & $\begin{array}{l}\hat{N} \\
\stackrel{i}{i}\end{array}$ & 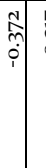 \\
\hline 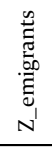 & $\begin{array}{l}n \\
\vdots \\
\dot{m}\end{array}$ & 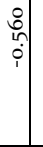 & 站 & & $=\begin{array}{l}5 \\
0 \\
1 \\
0 \\
0\end{array}$ & $\mid \begin{array}{l}0 \\
\text { fे } \\
i\end{array}$ & 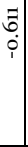 & 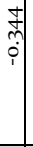 & : & 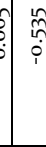 & $\begin{array}{l}0 \\
7 \\
i \\
i\end{array}$ & $\begin{array}{c}\infty \\
1 \\
1 \\
\vdots \\
1\end{array}$ & 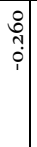 & $\begin{array}{l}0 \\
0 \\
0 \\
i \\
i\end{array}$ & 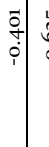 & : & & $\begin{array}{l}0 \\
0 \\
i \\
i\end{array}$ & $\stackrel{\infty}{=}$ & $\begin{array}{l}\text { fे } \\
\text { do } \\
0\end{array}$ & $\begin{array}{l}\text { o } \\
\vdots \\
\vdots \\
\vdots\end{array}$ & $\begin{array}{l}\circ \\
0 \\
0\end{array}$ & 足 & 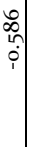 \\
\hline 壱 & 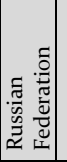 & 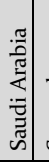 & 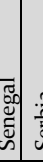 & : & 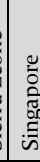 & 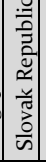 & & S & 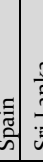 & 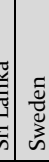 & 䔍 & 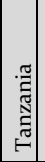 & & 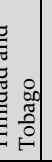 & 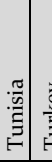 & & & 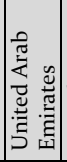 & : & 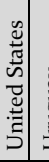 & : & 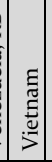 & 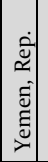 & ही \\
\hline
\end{tabular}


Appendices

Appendix 3: Ranks from IFT-risk element values

\begin{tabular}{|c|c|c|c|c|c|c|c|c|c|c|}
\hline \multirow[b]{2}{*}{ Country } & \multicolumn{5}{|c|}{ Rank from equal weighted IFT-risk element values } & \multicolumn{5}{|c|}{ Rank from PCA weighted IFT-risk element values } \\
\hline & $\begin{array}{l}\text { Market } \\
\text { size }\end{array}$ & \begin{tabular}{|l|} 
Financial \\
accessibilit \\
$\mathrm{y}$
\end{tabular} & $\begin{array}{l}\text { AML } \\
\text { Complianc } \\
\mathrm{e}\end{array}$ & Informality & Total & $\begin{array}{l}\text { Market } \\
\text { size }\end{array}$ & $\begin{array}{l}\text { Financial } \\
\text { accessibilit } \\
\text { y }\end{array}$ & $\begin{array}{l}\text { AML } \\
\text { Complianc } \\
\mathrm{e}\end{array}$ & Informality & Total \\
\hline Albania & 62 & 40 & 66 & 18 & 38 & 66 & 43 & 64 & 18 & 64 \\
\hline Algeria & 43 & 37 & 26 & 11 & 15 & 45 & 25 & 27 & 12 & 21 \\
\hline Angola & 97 & 32 & 47 & 4 & 13 & 99 & 28 & 41 & 4 & 46 \\
\hline Argentina & 37 & 59 & 18 & 8 & 21 & 38 & 63 & 19 & 7 & 19 \\
\hline Armenia & 78 & 33 & 94 & 62 & 64 & 80 & 50 & 88 & 63 & 90 \\
\hline Australia & 22 & 119 & 75 & 107 & 110 & 20 & 117 & 75 & 107 & 88 \\
\hline Austria & 67 & 112 & 101 & 110 & 117 & 61 & 111 & 99 & 110 & 109 \\
\hline Azerbaijan & 55 & 35 & 82 & 58 & 57 & 58 & 40 & 85 & 59 & 77 \\
\hline Bahrain & 102 & 80 & 112 & 97 & 100 & 101 & 57 & 103 & 97 & 110 \\
\hline Bangladesh & 9 & 18 & 29 & 13 & 4 & 11 & 15 & 29 & 13 & 1 \\
\hline Belgium & 61 & 111 & 121 & 100 & 119 & 53 & 102 & 121 & 102 & 121 \\
\hline Benin & 94 & 9 & 16 & 40 & 22 & 97 & 9 & 17 & 40 & 23 \\
\hline Bolivia & 79 & 42 & 24 & 21 & 29 & 81 & 45 & 25 & 21 & 30 \\
\hline $\begin{array}{l}\text { Bosnia and } \\
\text { Herzegovina }\end{array}$ & 46 & 56 & 57 & 46 & 54 & 52 & 54 & 53 & 47 & 61 \\
\hline Botswana & 119 & 50 & 20 & 84 & 61 & 119 & 44 & 21 & 84 & 37 \\
\hline Brazil & 39 & 91 & 89 & 81 & 86 & 41 & 106 & 80 & 79 & 97 \\
\hline Bulgaria & 54 & 83 & 116 & 39 & 81 & 60 & 98 & 115 & 38 & 114 \\
\hline Burkina Faso & 40 & 5 & 9 & 44 & 18 & 42 & 4 & 9 & 44 & 10 \\
\hline Cambodia & 69 & 11 & 1 & 32 & 9 & 71 & 16 & 1 & 34 & 5 \\
\hline Canada & 16 & 120 & 51 & 113 & 113 & 14 & 120 & 65 & 114 & 75 \\
\hline Chile & 84 & 67 & 75 & 93 & 87 & 83 & 68 & 75 & 93 & 85 \\
\hline China & 5 & 70 & 92 & 74 & 63 & 6 & 67 & 83 & 75 & 56 \\
\hline Colombia & 30 & 46 & 119 & 50 & 71 & 36 & 47 & 119 & 49 & 112 \\
\hline Costa Rica & 108 & 74 & 43 & 83 & 78 & 105 & 95 & 36 & 83 & 67 \\
\hline Cote d'Ivoire & 34 & 10 & 20 & 27 & 11 & 32 & 11 & 21 & 26 & 15 \\
\hline Croatia & 65 & 102 & 34 & 57 & 73 & 65 & 110 & 37 & 58 & 59 \\
\hline Cyprus & 113 & 78 & 111 & 88 & 96 & 113 & 73 & 113 & 88 & 113 \\
\hline $\begin{array}{l}\text { Czech } \\
\text { Republic }\end{array}$ & 81 & 82 & 79 & 61 & 75 & 79 & 70 & 79 & 60 & 79 \\
\hline Denmark & 99 & 101 & 93 & 101 & 104 & 98 & 91 & 87 & 103 & 105 \\
\hline $\begin{array}{l}\text { Dominican } \\
\text { Republic }\end{array}$ & 47 & 49 & 70 & 33 & 48 & 50 & 46 & 50 & 29 & 62 \\
\hline Ecuador & 63 & 52 & 60 & 45 & 53 & 64 & 55 & 56 & 45 & 65 \\
\hline Egypt & 23 & 13 & 98 & 24 & 37 & 24 & 19 & 95 & 27 & 73 \\
\hline El Salvador & 51 & 38 & 48 & 20 & 34 & 56 & 41 & 63 & 20 & 54 \\
\hline Estonia & 111 & 104 & 106 & 96 & 109 & 110 & 99 & 107 & 96 & 111 \\
\hline Finland & 101 & 96 & 72 & 121 & 118 & 102 & 72 & 72 & 121 & 96 \\
\hline France & 13 & 108 & 108 & 105 & 102 & 12 & 109 & 109 & 105 & 102 \\
\hline Georgia & 83 & 54 & 71 & 49 & 60 & 85 & 66 & 71 & 48 & 74 \\
\hline Germany & 6 & 116 & 94 & 109 & 98 & 5 & 113 & 88 & 109 & 71 \\
\hline Ghana & 77 & 26 & 18 & 68 & 41 & 77 & 21 & 19 & 72 & 29 \\
\hline Greece & 53 & 85 & 52 & 52 & 69 & 54 & 82 & 45 & 55 & 60 \\
\hline Guatemala & 72 & 39 & 103 & 36 & 56 & 74 & 42 & 102 & 36 & 91 \\
\hline Guinea & 95 & 1 & 16 & 7 & 5 & 96 & 1 & 17 & 9 & 17 \\
\hline Haiti & 58 & 8 & 11 & 2 & 3 & 63 & 3 & 12 & 2 & 7 \\
\hline Honduras & 89 & 30 & 31 & 26 & 28 & 93 & 30 & 31 & 23 & 35 \\
\hline Hong Kong & 36 & 88 & 84 & 118 & 105 & 31 & 78 & 90 & 118 & 95 \\
\hline Hungary & 85 & 75 & 119 & 71 & 92 & 84 & 75 & 119 & 67 & 118 \\
\hline India & 2 & 43 & 98 & 70 & 36 & 3 & 35 & 95 & 69 & 28 \\
\hline
\end{tabular}




\begin{tabular}{|c|c|c|c|c|c|c|c|c|c|c|}
\hline \multirow[b]{2}{*}{ Country } & \multicolumn{5}{|c|}{ Rank from equal weighted IFT-risk element values } & \multicolumn{5}{|c|}{ Rank from PCA weighted IFT-risk element values } \\
\hline & $\begin{array}{l}\text { Market } \\
\text { size }\end{array}$ & \begin{tabular}{|l|} 
Financial \\
accessibilit \\
$\mathrm{y}$
\end{tabular} & $\begin{array}{l}\text { AML } \\
\text { Complianc } \\
\mathrm{e}\end{array}$ & Informality & Total & $\begin{array}{l}\text { Market } \\
\text { size }\end{array}$ & \begin{tabular}{|l} 
Financial \\
accessibilit \\
$\mathrm{y}$
\end{tabular} & $\begin{array}{l}\text { AML } \\
\text { Complianc } \\
\text { e }\end{array}$ & Informality & Total \\
\hline Indonesia & 19 & 45 & 33 & 64 & 42 & 22 & 51 & 35 & 62 & 33 \\
\hline Ireland & 68 & 106 & 85 & 103 & 103 & 69 & 105 & 93 & 104 & 104 \\
\hline Israel & 60 & 90 & 85 & 92 & 93 & 51 & 108 & 93 & 92 & 100 \\
\hline Italy & 14 & 93 & 107 & 65 & 83 & 13 & 100 & 108 & 70 & 89 \\
\hline Jamaica & 71 & 63 & 97 & 66 & 79 & 72 & 49 & 92 & 65 & 94 \\
\hline Japan & 35 & 114 & 68 & 108 & 106 & 34 & 114 & 67 & 108 & 83 \\
\hline Jordan & 31 & 31 & 55 & 94 & 68 & 29 & 34 & 51 & 95 & 57 \\
\hline Kazakhstan & 15 & 58 & 32 & 60 & 46 & 16 & 77 & 32 & 61 & 26 \\
\hline Kenya & 80 & 47 & 6 & 47 & 39 & 76 & 31 & 6 & 46 & 16 \\
\hline Korea & 26 & 121 & 64 & 77 & 95 & 26 & 121 & 61 & 78 & 87 \\
\hline Kuwait & 49 & 84 & 41 & 85 & 76 & 43 & 76 & 33 & 85 & $5^{2}$ \\
\hline Kyrgyz, Rep. & 82 & 21 & 34 & 12 & 14 & 82 & 27 & 37 & 11 & 36 \\
\hline Lao PDR & 64 & 22 & 4 & 48 & 27 & 68 & 26 & 4 & $5^{2}$ & 12 \\
\hline Latvia & 100 & 95 & 82 & 79 & 89 & 100 & 94 & 85 & 80 & 92 \\
\hline Lebanon & 50 & 51 & 67 & 28 & 47 & 47 & 48 & 66 & 28 & 66 \\
\hline Lesotho & 109 & 19 & 14 & 25 & 19 & 109 & 22 & 15 & 30 & 22 \\
\hline Lithuania & 86 & 79 & 104 & 69 & 85 & 87 & 71 & 105 & 68 & 107 \\
\hline Luxembourg & 117 & 109 & 53 & 117 & 111 & 115 & 107 & 47 & 116 & 80 \\
\hline $\begin{array}{l}\text { Macedonia, } \\
\text { FYR }\end{array}$ & 87 & 69 & 77 & 78 & 80 & 88 & 69 & 77 & 77 & 82 \\
\hline Malawi & 104 & 14 & 37 & 51 & 40 & 103 & 12 & 46 & 51 & 48 \\
\hline Malaysia & 28 & 68 & 87 & 95 & 88 & 27 & 64 & 98 & 94 & 84 \\
\hline Mali & 76 & 6 & 2 & 14 & 6 & 78 & 7 & 2 & 14 & 4 \\
\hline Malta & 120 & 94 & 117 & 102 & 115 & 120 & 88 & 117 & 100 & 120 \\
\hline Mauritania & 116 & 17 & 45 & 6 & 10 & 116 & 17 & 40 & 6 & 43 \\
\hline Mauritius & 115 & 77 & 46 & 90 & 84 & 117 & 65 & 60 & 89 & 70 \\
\hline Mexico & 4 & 48 & 74 & 55 & 30 & 4 & $5^{2}$ & 74 & 53 & 25 \\
\hline Moldova & 74 & 29 & 49 & 16 & 31 & 73 & 38 & 43 & 16 & 51 \\
\hline Mongolia & 121 & 87 & 30 & 17 & 51 & 121 & 85 & 30 & 19 & 41 \\
\hline Montenegro & 110 & 61 & 80 & 63 & 72 & 111 & 80 & 82 & 64 & 86 \\
\hline Myanmar & 27 & 12 & 25 & 3 & 1 & 28 & 5 & 26 & 3 & 11 \\
\hline Namibia & 118 & 62 & 14 & 87 & 70 & 118 & 62 & 15 & 86 & 38 \\
\hline Nepal & 33 & 23 & 5 & 29 & 12 & 33 & 20 & 5 & 31 & 3 \\
\hline Netherlands & 41 & 103 & 102 & 115 & 116 & 39 & 92 & 101 & 115 & 108 \\
\hline New Zealand & 59 & 105 & 40 & 119 & 108 & 55 & 97 & 52 & 119 & 72 \\
\hline Nicaragua & 92 & 20 & 36 & 41 & 35 & 95 & 24 & 42 & 41 & 45 \\
\hline Nigeria & 45 & 44 & 42 & 19 & 33 & 46 & 36 & 34 & 17 & 39 \\
\hline Norway & 98 & 100 & 88 & 114 & 114 & 94 & 87 & 100 & 113 & 106 \\
\hline Pakistan & 10 & 3 & 59 & 23 & 8 & 10 & 10 & 55 & 22 & 20 \\
\hline Panama & 114 & 53 & 22 & 91 & 67 & 114 & 60 & 23 & 91 & 40 \\
\hline Paraguay & 75 & 24 & 9 & 10 & 7 & 75 & 29 & 9 & 10 & 13 \\
\hline Peru & 52 & 41 & 81 & 38 & 50 & 57 & 53 & 84 & 35 & 76 \\
\hline Philippines & 12 & 34 & 64 & 67 & 45 & 15 & 33 & 61 & 66 & 42 \\
\hline Poland & 20 & 73 & 38 & 72 & 62 & 21 & 81 & 48 & 71 & 44 \\
\hline Portugal & 32 & 115 & 109 & 89 & 99 & 35 & 118 & 110 & 90 & 115 \\
\hline Romania & 24 & 64 & 54 & 37 & 49 & 25 & 74 & 69 & 39 & $5^{8}$ \\
\hline $\begin{array}{l}\text { Russian } \\
\text { Federation }\end{array}$ & 3 & 99 & 56 & 15 & 24 & 2 & 116 & 70 & 15 & 6 \\
\hline Saudi Arabia & 11 & 81 & 98 & 98 & 90 & 8 & 89 & 95 & 98 & 69 \\
\hline Senegal & 93 & 7 & 63 & 59 & 44 & 92 & 8 & 59 & 57 & 63 \\
\hline Serbia & 48 & 76 & 69 & 30 & 59 & 49 & 61 & 68 & 32 & 68 \\
\hline
\end{tabular}


Appendices

\begin{tabular}{|c|c|c|c|c|c|c|c|c|c|c|}
\hline \multirow[b]{2}{*}{ Country } & \multicolumn{5}{|c|}{ Rank from equal weighted IFT-risk element values } & \multicolumn{5}{|c|}{ Rank from PCA weighted IFT-risk element values } \\
\hline & $\begin{array}{l}\text { Market } \\
\text { size }\end{array}$ & \begin{tabular}{|l|} 
Financial \\
accessibilit \\
y
\end{tabular} & \begin{tabular}{|l|} 
AML \\
Complianc \\
e
\end{tabular} & Informality & Total & $\begin{array}{l}\text { Market } \\
\text { size }\end{array}$ & \begin{tabular}{|l|} 
Financial \\
accessibilit \\
y
\end{tabular} & \begin{tabular}{|l|} 
AML \\
Complianc \\
e
\end{tabular} & Informality & Total \\
\hline Sierra Leone & 105 & 4 & 3 & 42 & 17 & 106 & 2 & 3 & 43 & 9 \\
\hline Singapore & 56 & 98 & 110 & 120 & 120 & 48 & 93 & 112 & 120 & 116 \\
\hline $\begin{array}{l}\text { Slovak } \\
\text { Republic }\end{array}$ & 90 & 86 & 96 & 56 & 82 & 89 & 83 & 91 & 56 & 98 \\
\hline Slovenia & 107 & 110 & 118 & 82 & 101 & 104 & 104 & 118 & 82 & 119 \\
\hline South Africa & 38 & 71 & 73 & 104 & 94 & 37 & 84 & 73 & 101 & 78 \\
\hline Spain & 17 & 113 & 104 & 86 & 97 & 17 & 112 & 105 & 87 & 101 \\
\hline Sri Lanka & 42 & 57 & 26 & 73 & 55 & 44 & 39 & 27 & 73 & 34 \\
\hline Sweden & 73 & 97 & 77 & 111 & 107 & 67 & 79 & 77 & 111 & 93 \\
\hline Switzerland & 44 & 107 & 115 & 116 & 121 & 40 & 103 & 111 & 117 & 117 \\
\hline Tanzania & 96 & 15 & 6 & 35 & 16 & 91 & 14 & 6 & 37 & 14 \\
\hline Thailand & 25 & 92 & 44 & 54 & 66 & 23 & 101 & 39 & 50 & 50 \\
\hline $\begin{array}{l}\text { Trinidad and } \\
\text { Tobago }\end{array}$ & 103 & 72 & 13 & 43 & 52 & 107 & 59 & 14 & 42 & 31 \\
\hline Tunisia & 88 & 27 & 90 & 53 & $5^{8}$ & 90 & 32 & 81 & 54 & 81 \\
\hline Turkey & 18 & 65 & 57 & 75 & 65 & 19 & 86 & 53 & 74 & 53 \\
\hline Uganda & 91 & 25 & 28 & 31 & 25 & 86 & 18 & 11 & 33 & 27 \\
\hline Ukraine & 8 & 66 & 62 & 9 & 23 & 9 & 96 & 58 & 8 & 32 \\
\hline $\begin{array}{l}\text { United Arab } \\
\text { Emirates }\end{array}$ & 21 & 89 & 39 & 106 & 91 & 18 & 90 & 49 & 106 & 49 \\
\hline $\begin{array}{l}\text { United } \\
\text { Kingdom }\end{array}$ & 7 & 117 & 114 & 112 & 112 & 7 & 115 & 116 & 112 & 103 \\
\hline United States & 1 & 118 & 113 & 99 & 74 & 1 & 119 & 114 & 99 & 2 \\
\hline Uruguay & 106 & 55 & 91 & 80 & 77 & 108 & 58 & 104 & 81 & 99 \\
\hline Venezuela & 66 & 60 & 61 & 1 & 26 & 62 & 56 & 57 & 1 & 55 \\
\hline Vietnam & 29 & 36 & 23 & 22 & 20 & 30 & 37 & 24 & 24 & 18 \\
\hline Yemen, Rep. & 57 & 2 & 11 & 5 & 2 & 59 & 6 & 12 & 5 & 8 \\
\hline Zambia & 112 & 28 & 8 & 76 & 43 & 112 & 23 & 8 & 76 & 24 \\
\hline Zimbabwe & 70 & 16 & 49 & 34 & 32 & 70 & 13 & 43 & 25 & 47 \\
\hline
\end{tabular}


Appendix 4: IFT-risk ranks of the 121 countries

\begin{tabular}{|c|c|c|c|c|c|}
\hline Country & $\begin{array}{c}\text { Rank based on equal } \\
\text { weighted values }\end{array}$ & $\begin{array}{l}\text { Rank based on } \\
\text { PCA weighted } \\
\text { values }\end{array}$ & Country & $\begin{array}{l}\text { Rank based on equal } \\
\text { weighted values }\end{array}$ & $\begin{array}{l}\text { Rank based on PCA } \\
\text { weighted values }\end{array}$ \\
\hline Albania & 38 & 64 & Lebanon & 47 & 66 \\
\hline Algeria & 15 & 21 & \begin{tabular}{|l|} 
Lesotho \\
\end{tabular} & 19 & 22 \\
\hline Angola & 13 & 46 & Lithuania & 85 & 107 \\
\hline Argentina & 21 & 19 & \begin{tabular}{|l|} 
Luxembourg \\
\end{tabular} & 111 & 80 \\
\hline Armenia & 64 & 88 & Macedonia, FYR & 80 & 82 \\
\hline Australia & 110 & 80 & Malawi & 40 & 48 \\
\hline Austria & 117 & 109 & Malaysia & 88 & 84 \\
\hline Azerbaijan & 57 & 77 & Mali & 6 & 4 \\
\hline Bahrain & 100 & 110 & Malta & 115 & 120 \\
\hline Bangladesh & 4 & 1 & Mauritania & 10 & 43 \\
\hline Belgium & 119 & 121 & Mauritius & 84 & 70 \\
\hline Benin & 22 & 23 & Mexico & 30 & 25 \\
\hline Bolivia & 29 & 30 & Moldova & 31 & 51 \\
\hline $\mathrm{BiH}$ & 54 & 61 & Mongolia & 51 & 41 \\
\hline Botswana & 61 & 37 & Montenegro & 72 & 86 \\
\hline Brazil & 86 & 97 & Myanmar & 1 & 11 \\
\hline Bulgaria & 81 & 114 & Namibia & 70 & 38 \\
\hline Burkina Faso & 18 & 10 & Nepal & 12 & 3 \\
\hline Cambodia & 9 & 5 & Netherlands & 116 & 108 \\
\hline Canada & 113 & 75 & New Zealand & 108 & 72 \\
\hline Chile & 87 & 85 & Nicaragua & 35 & 45 \\
\hline China & 63 & 56 & Nigeria & 33 & 39 \\
\hline Colombia & 71 & 112 & Norway & 114 & 106 \\
\hline Costa Rica & 78 & 67 & Pakistan & 8 & 20 \\
\hline Cote d'Ivoire & 11 & 15 & Panama & 67 & 40 \\
\hline Croatia & 73 & 59 & Paraguay & 7 & 13 \\
\hline Cyprus & 96 & 113 & Peru & 50 & 76 \\
\hline Czech Republic & 75 & 79 & Philippines & 45 & 42 \\
\hline Denmark & 104 & 105 & Poland & 62 & 44 \\
\hline $\begin{array}{l}\text { Dominican } \\
\text { Republic }\end{array}$ & 48 & 62 & Portugal & 99 & 115 \\
\hline Ecuador & 53 & 65 & Romania & 49 & 58 \\
\hline Egypt & 37 & 73 & Russian Federation & 24 & 6 \\
\hline El Salvador & 34 & 54 & Saudi Arabia & 90 & 69 \\
\hline Estonia & 109 & 111 & Senegal & 44 & 63 \\
\hline Finland & 118 & 96 & Serbia & 59 & 68 \\
\hline France & 102 & 102 & Sierra Leone & 17 & 9 \\
\hline Georgia & 60 & 74 & Singapore & 120 & 116 \\
\hline Germany & 98 & 71 & Slovak Republic & 82 & 98 \\
\hline Ghana & 41 & 29 & Slovenia & 101 & 119 \\
\hline Greece & 69 & 60 & South Africa & 94 & 78 \\
\hline Guatemala & 56 & 91 & Spain & 97 & 101 \\
\hline Guinea & 5 & 17 & Sri Lanka & 55 & 34 \\
\hline Haiti & 3 & 7 & Sweden & 107 & 93 \\
\hline Honduras & 28 & 35 & Switzerland & 121 & 117 \\
\hline Hong Kong & 105 & 95 & Tanzania & 16 & 14 \\
\hline Hungary & $9^{2}$ & 118 & Thailand & 66 & 50 \\
\hline India & 36 & 28 & Trinidad and Tobago & 52 & 31 \\
\hline Indonesia & 42 & 33 & Tunisia & 58 & 81 \\
\hline Ireland & 103 & 104 & Turkey & 65 & 53 \\
\hline Israel & 93 & 100 & Uganda & 25 & 27 \\
\hline Italy & 83 & 89 & Ukraine & 23 & 32 \\
\hline Jamaica & 79 & 94 & United Arab Emirates & 91 & 49 \\
\hline Japan & 106 & 83 & United Kingdom & 112 & 103 \\
\hline
\end{tabular}


Appendices

\begin{tabular}{|l|r|r|l|r|r|}
\hline \multicolumn{1}{|c|}{ Country } & $\begin{array}{l}\text { Rank based on equal } \\
\text { weighted values }\end{array}$ & $\begin{array}{l}\text { Rank based on } \\
\text { PCA weighted } \\
\text { values }\end{array}$ & Country & $\begin{array}{l}\text { Rank based on equal } \\
\text { weighted values }\end{array}$ & $\begin{array}{l}\text { Rank based on PCA } \\
\text { weighted values }\end{array}$ \\
\hline Jordan & 68 & 57 & United States & 74 & 27 \\
\hline Kazakhstan & 46 & 26 & Uruguay & 26 & 20 \\
\hline Kenya & 39 & 16 & Venezuela & 2 & 59 \\
\hline Korea, Rep. & 95 & 87 & Vietnam & 43 & 18 \\
\hline Kuwait & 76 & 52 & Yemen & 32 & 84 \\
\hline Kyrgyz Republic & 14 & 36 & Zambia & & 47 \\
\hline Lao PDR & 27 & 12 & Zimbabwe & & \\
\hline Latvia & 89 & 92 & &
\end{tabular}


Appendix 5: Consent form for interviews

Please consider this information carefully before deciding whether to participate in this research.

Purpose of the research: To understand the mechanism of informal fund transfer (IFT) systems.

What you will do in this research: If you decide to volunteer, you will be asked to participate in one interview. You will be asked several questions. You will not be asked to state your name while being interviewed.

Time required: The interview will take approximately 1 hour.

Risks: Some of the questions may cause discomfort or embarrassment.

Benefit: This is a chance for you to tell your experience and perception concerning IFTsystems and the fight against them.

Confidentiality: Your response to interview questions will be kept confidential. At no time will your actual identity be revealed. You will be assigned a random numerical code. No one but the researcher will know you by this code. The transcript without your name will be kept until the research is complete.

The key code linking your name with your number will be kept in a locked file cabinet, and no one else will have access to it. It will be destroyed when the research is complete. The data you give me will be used for a dissertation that I am currently writing and may be used as the basis for articles or presentation in the future. The researcher will not use your name or information that would identify you in any publications or presentations.

Participation and withdrawal: Your participation in this study is completely voluntary, and you may refuse to participate or withdraw from the study without penalty or loss of benefits to which you may otherwise be entitled. You may withdraw by informing the researcher that you no longer wish to participate (no questions will be asked). You may skip any question during the interview, but continue to participate in the rest of the study.

To Contact the Researcher: If you have questions or concerns about this research, please contact Chang-Ryung HAN of Maastricht University by e-mail (changhaan@gmail.com) or by phone (+82-10-4692-9986). You may also contact the faculty member supervising this work: Hans Nelen, Professor by e-mail (hans.nelen@ maastrichtuniversity.nl).

Agreement: The nature and purpose of this research have been sufficiently explained and I agree to participate in this study. I understand that I am free to withdraw at any time without incurring any penalty.

Name (print): $\quad$ Date:

Signature: 
Appendix 6: Semi-structured questionnaire for the KCS's customs investigators

Dear Colleagues,

My name is Chang-Ryung Han. I work as Director of Investigation Planning Division of Korea Customs Service (KCS) and conduct a study regarding Informal Fund Transfer Systems in Korea, being enrolled in a $\mathrm{PhD}$ program of Maastricht University in the Netherlands. This interview is designed to complement the analysis of IFT-case reports produced by the KCS between 2011 and 2013. It does not mean to evaluate your knowledge of IFT-systems but seek to obtain information that is not included in the IFT-case reports. There is thus no right or wrong answer to the questions asked for you.

\section{Section 1: General Information about the interviewee}

1. How long have you been working at the KCS?

(1) Longer than or equal to 20 years

(2) Shorter than 20 years but longer than or equal to 15 years

(3) Shorter than 15 years but longer than or equal to 10 years

(4) Shorter than 10 years but longer than or equal to 5 years

(5) Shorter than 5 years

2. What is your current rank at the KCS?

(1) Director

(2) Deputy Director

(3) Chief Investigator

(4) Investigator

(5) Other

3. How many IFT-cases have you investigated during the past 5 years?

(1) More than or equal to 10 cases

(2) Less than 10 cases but more than or equal to 5 cases

(3) Less than 5 cases but more than or equal to 2 cases

(4) Only 1 case

(5) None

\section{Section 2: Perception of harm incurred from IFT-systems}

4. Why do you think that IFT-systems are illegitimate?

5. What do you think of investigations of IFT-systems? Is it necessary?

6. Do you think that the current punishment level for IFT-systems is adequate?

7. Do you think that IFT-systems should be legalized? 


\section{Section 3: Investigation methods for IFT-systems}

8. What source is most frequently used in initiating investigations of IFT-systems?

9. What method is most useful in investigations of IFT-systems?

10. Why do investigations of IFT-systems concentrate on IFT-brokers rather than IFTusers?

11. Do you think that the number of IFT-cases investigated has a linear relationship with the number of IFT-systems operating in the market?

\section{Section 4: Relationship between IFT-brokers and IFT-users}

Few IFT-case reports include information about how to contact between IFT-brokers and IFT-users. Please answer the following questions on the basis of your knowledge obtained from investigations of IFT-systems.

12. Which side normally contact the other side first between IFT-brokers and IFT-users?

13. Which methods IFT-brokers (or IFT-users) make use of in order to contact the other party?

14. Do you think that either of IFT-brokers or IFT-users were aware that IFT-systems are illegal when they engaged in IFT-transactions?

15. Have you ever dealt with any case that either IFT-users or IFT-brokers informed on the other party to law enforcement authorities?

16. Among the IFT-cases that you investigated, was there a IFT broker that maintained an account book (ledger) including clients' names?

17. Why do you think IFT-systems are still used in Korea where the formal banking sector is well-developed?

18. Have you noticed any mechanism that IFT-users use to prevent themselves from being swindled by fraudulent IFT-brokers?

19. Have you noticed any pattern of IFT transaction charges or fees imposed by IFTbrokers?

20. What do you think of the phenomenon that IFT-systems regarding China are more than those regarding other neighboring countries? 
21. An IFT transaction is completed by coordination and agreement between two IFTbrokers in a sending country and a receiving country. How did you investigate IFTbrokers in another country?

22. How do IFT-brokers in Korea get to know their counterpart IFT-brokers in another country? Which method is most frequently used?

23. How are debt settlement transactions between IFT-brokers operating in different countries?

24. Among the remittances transferred via IFT-systems, have you identified the money associated with illicit drug dealing?

25. Among the remittances transferred via IFT-systems, have you identified the money associated with organized crime groups?

26. Have you track down on the source of money transferred via IFT-systems?

27. What do you think of the phenomenon that most IFT-brokers make use of bank accounts in taking remittances from remitters and giving money to recipients?

28. What do you think of some of the IFT-brokers using others' bank accounts?

29. According to the IFT-case reports, people who lent bank accounts to IFT-brokers were seemingly not investigated on charge with assistance of money laundering. Why do you think they were not investigated?

30. According to the IFT-case reports, some IFT-brokers appear to be an amateur in IFTbusinesses. How did IFT-brokers catch the IFT-business concept and engage in IFTbusinesses?

31. Why do the IFT-case reports not provide full information as to how IFT-brokers who operate in foreign countries, such as China, Thailand, and Japan, take remittances from remitters and give remittances to recipients designated by remitters? The case reports delineate how IFT-brokers in Korea usually make use of online banking systems in taking and giving remittances. 
Appendix 7: Semi-structured questionnaire for the KoFIU's officials

Dear Officials,

My name is Chang-Ryung Han. I work as Director of Investigation Planning Division of Korea Customs Service (KCS) and conduct a study regarding Informal Fund Transfer Systems in Korea, being enrolled in a PhD program of Maastricht University in the Netherlands. This interview is designed to complement the analysis of IFT-case reports produced by the KCS between 2011 and 2013. It does not mean to evaluate your knowledge of IFT-systems but seek to obtain information that is not included in the IFT-case reports. There is thus no right or wrong answer to the questions asked for you.

\section{Section 1: General Information about the interviewee}

1. How long have you been working at the KoFIU?

(1) Longer than 2 years

(2) Shorter than 2 years but longer than or equal to 1 years

(3) Shorter than 1 years but longer than or equal to 6 months

(4) Shorter than 6 months

2. Where did you work before joining the KoFIU?
(1) The Prosecution Service
(2) The National Tax Service
(3) The Korea Customs Service
(4) The National Police Agency
(5) Other

3. What is your current rank at the KoFIU?
(1) Director
(2) Deputy Director
(3) Chief Investigator
(4) Investigator
(5) Other

4. How many IFT-cases have you dealt with while working at the KoFIU?
(1) More than or equal to 10 cases
(2) Less than 10 cases but more than or equal to 5 cases
(3) Less than 5 cases but more than or equal to 2 cases
(4) Only 1 case
(5) None

Section 2: Experience with and Perception of IFT-systems

5. Did you deal with IFT-cases before joining the KoFIU? 
6. How prevalent do you think IFT-activities are in Korea?

7. How serious do you think the harm incurred from IFT-systems to the Korean society is?

8. The KoFIU closely works with formal financial institutions. Have you heard from them any concern about IFT-systems?

9. How much important the fight against IFT-systems is to the KoFIU? Please compare IFT-activities with other predicate offenses in terms of importance to the KoFIU.

10. Among law enforcement authorities working with the KoFIU, which agencies collaborate with the KoFIU in order to fight IFT-systems? Which agency is most active in the fight against IFT-systems?

11. How often do the STRs from financial institutions indicate the connection of the bank transactions that they suspected with IFT-activities?

12. Have you dealt with law enforcement authorities' requests for STRs or CTRs for the purpose of the fight against IFT-systems while working at the KoFIU?

13. Have you dealt with cases where organized crime groups made use of IFT-systems while working at the KoFIU?

14. Have you deal with cases where IFT-systems were used to transfer proceeds from drug trafficking or human smuggling?

15. What policy measures should be considered to reduce IFT-activities in Korea? 


\section{Curriculum Vitae}

Chang Ryung HAN (1973) graduated in public administration from Kyungpook National University in Republic of Korea in 1997. He was awarded a Master's degree in criminology and criminal justice at Rutgers University, Newark, in the United States in 2007. He started his doctoral research on informal fund transfer systems at Maastricht University in 2014. Mr. Han worked at Brookings Institution, Washington D.C. in 2010 as a visiting fellow for research on cross-border crime and at World Customs Organization in Belgium as a technical officer of its research unit from 2012 to 2016. Since 1999, he has worked at Korea Customs Service and is recently tasked with supervising customs investigations and anti-money laundering operations. He also worked as a director overseeing foreign exchange transactions at Korea Financial Intelligence Unit. His research interests are cross-border crime, informal economic activities, and financial flows in international trade. 